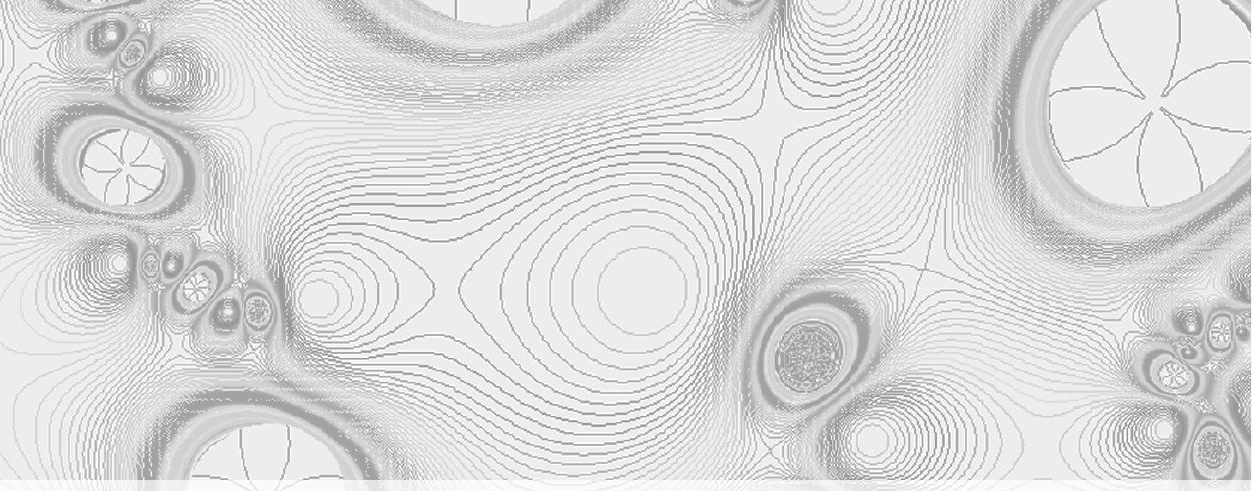

\title{
$\mathrm{UiO}$ : Institute of Basic Medical Sciences
} University of Oslo

\section{Timing is everything:}

Exploring the psychophysiology of affective touch through subjective reports, physiological responses and behaviour

By: Anbjørn Ree, 2021 
(C) Anbjørn Ree, 2021

Series of dissertations submitted to the Faculty of Medicine, University of Oslo

\section{ISBN 978-82-8377-933-2}

All rights reserved. No part of this publication may be reproduced or transmitted, in any form or by any means, without permission.

Cover: Hanne Baadsgaard Utigard.

Print production: Reprosentralen, University of Oslo. 


\section{Acknowledgements}

I consider myself fortunate and privileged to have been given the opportunity to complete a PhD at the University of Oslo. In that regard, I am grateful for the opportunity that was given to me by Uta Sailer, Siri Leknes and Reidar Tyssen and the fact that you were willing to take a chance on me. Although I am pretty sure that I have not met all of your expectations, I certainly hope that I have met most of them. During my four years at the University of Oslo, I have been given the opportunity to teach, travel abroad, learn new skills and meet some wonderful people. I will try to acknowledge them all, and will start with the most obvious:

My principal supervisor Uta Sailer. As my four years at the University of Oslo is approaching the end, I can reflect on many challenges, but countless more enjoyable and great moments. She has been considerate and thoughtful, encouraging and supportive, and the supervision I have received has been way beyond what I expected. She has ensured that I have been challenged when needed, and supervised as required and in that regard, she has given me the freedom to pursue ideas and interests whilst still being forthright and constructive in her criticisms. She has introduced me to her network of collaborators and this has enabled me to gain experience and knowledge in a broad range of topics: from collecting blood samples and investigating hunger hormones, to the mechanisms of touch satiety; presentations at international conferences and: writing a blog for the University webpages! It requires great intellectual capacity to be able to supervise somebody during their $\mathrm{PhD}$-degree, but it also requires perseverance, patience and a big heart. Together, we have published five papers, so our collaboration has been productive, but more than anything, I have enjoyed working with you and it's been a lot of fun learning!

My co-supervisor Siri Leknes: Thank you for giving me the opportunity as a novice researcher and allowing me to develop as a scientist. Under your supervision, I have been allowed to peer-review manuscripts, collect, synthesise and present topical reviews and engage in lively discussions during the LABLAB meetings. I am also grateful for all your specific contribution to the papers in the thesis and the very helpful feedback when drafting and writing this thesis.

All my colleagues at the department of behavioural medicine. I am indebted to Hanne Lie for showing such faith in my teaching abilities and for always being available to discuss science, or matters that revolve around life in academia or life in general. I am forever grateful for 
Trond Erstad, the senior engineer at the department, who has basically taken care of all technical affairs since we went into lockdown earlier this year. I am grateful for all the support I received from my first boss at the department Reidar Tyssen, (and also the only other person at the department with a genuine interest in sports!) and the current boss, Jarle Breivik, for trusting me to co-organise the conference that never happened due to Covid. Hilde Liudalen, for always being friendly and helping out with practical matters at the department. All the colleagues that I have seen often, yet not worked closely with, such as Harald, Anneli, Anette, Kristin, and Kristoffer; Thanks for sticking around and sharing the highs and lows of working in academia. And last, but not least, the wonderful Daniela Pfabigan: As much as I am grateful for being allowed to work with you on your (and Uta's) exciting ghrelin-project, it has been great getting to know you over the last couple of years!

All my Dresden colleagues, Johanna Bendas, Ilona Croy and Luise Pabel: You and the city of Dresden made my $\mathrm{PhD}$ worthwhile, every time. Ilona has also served as my de-facto cosupervisor for paper III in the thesis.

I am indebted to Leah Mayo for teaching me how to use facial EMG and for offering continuous support throughout the facial EMG analysis.

All the funding agencies which generously support and finance research. The "Dresden Study" (Study 2, paper III) was a collaboration between the University of Oslo and the Technische Universität Dresden, Germany. The study was supported by the Research Council of Norway, project number: 267446/F10, and the German Academic Exchange Service (DAAD), project number: 094_5159.

My principal supervisor during my MSc, Dagfinn Matre for encouraging me to get PhD'ed: Thanks!

Ralph Endemann for the incredible drawings of the experimental setups and the "Timeline" figure in the thesis.

Ragnhild Sørum Falk for statistical advice. Having complicated statistics explained in a simple and understandable manner surely is one of the hidden joys of science?

Ludvig Munthe for providing me with a copy of the "Ludvig's unofficial advice on writing the $\mathrm{PhD}$ thesis" booklet. It got me started and more importantly, provided me with a framework upon which to write my thesis. 
Morten Fahle at the IT-department who basically, through a single act of kindness rescued Study 2 (Dresden) by allowing me to bring a custom-built computer (built within a few days) to Dresden. Without you, who knows how my PhD might have turned out!

Reviewers, particularly the first paper! Wow, what an inspiration and learning curve that was! All the participants that devoted their time and efforts!

Friends and family for hanging out with me and supporting me. Joseph Greenshields and Sigurd Mikkelsen for actually caring about the scientific content of the $\mathrm{PhD}$ and Martin Jenssen and Henrik Øye for inviting me to the odd band sessions.

And of course, my lovely wife and kids. Without you, there really would be none of all this! Oslo, December 2020 

2 List of Abbreviations

A $\beta \quad$ A-Beta fibres

BPM Beats Per Minute

CT $\quad$ C-Tactile fibres

CLTMR C Low Threshold Mechanosensitive Receptors

EEG Electroencephalogram

ERP Event related potential

EDA Electrodermal activity

EMG Electromyography

fMRI Functional Magnetic Resonance Imaging

HR Heart Rate

HRV Heart rate variability

LTM Low Threshold Mechanoreceptors

RMSSD Root Mean Square Differences of Successive R-R intervals

S1 Primary somatosensory cortex

S2 Secondary somatosensory cortex

SDNN Standard deviation of normal-to-normal R-R intervals

SCL Skin conductance level

SCRs Skin Conductance Responses 



\section{Table of Contents}

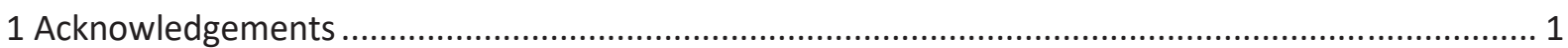

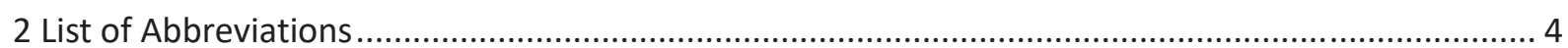

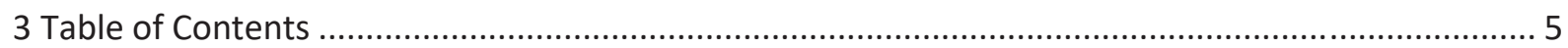

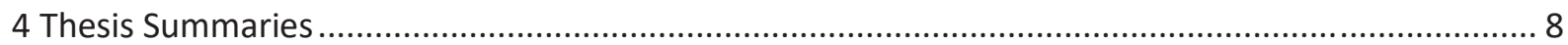

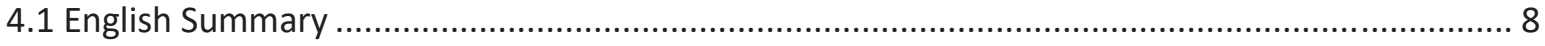

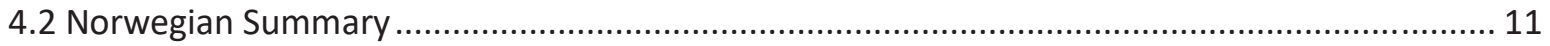

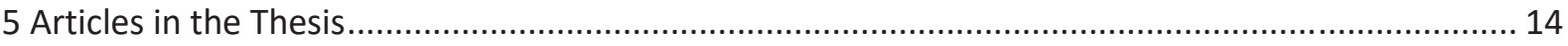

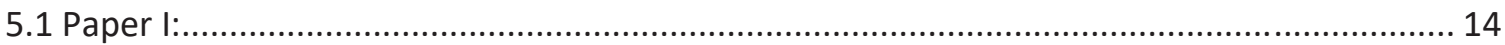

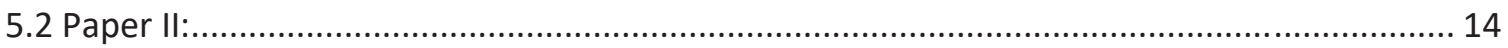

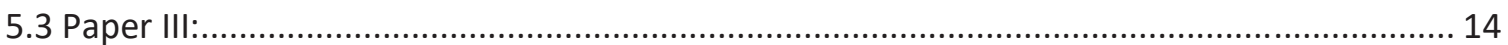

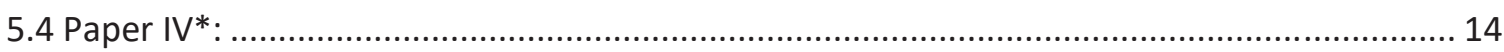

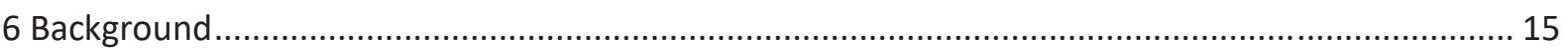

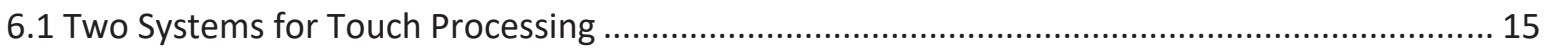

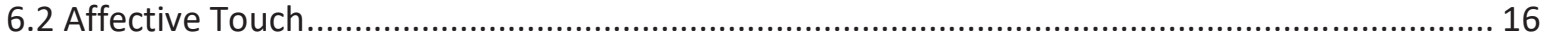

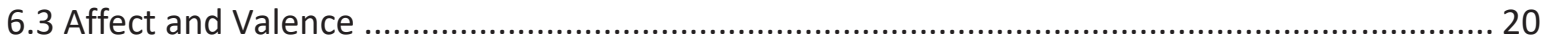

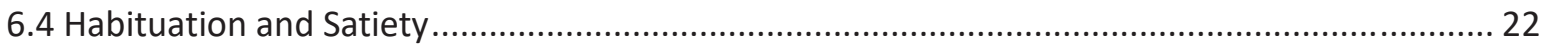

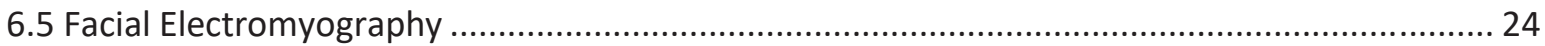

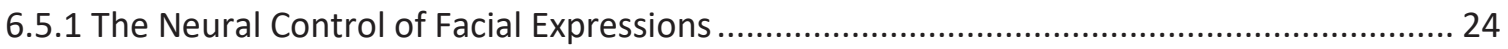

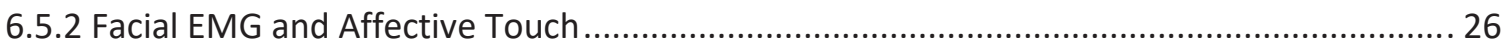

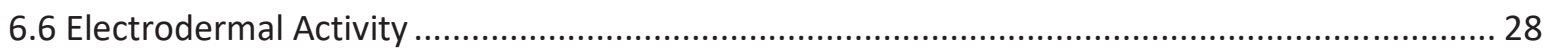

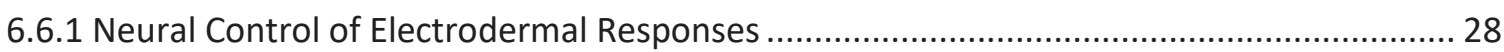

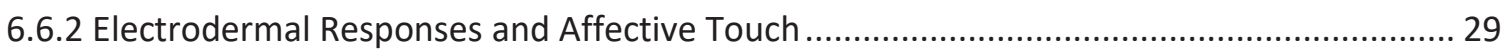

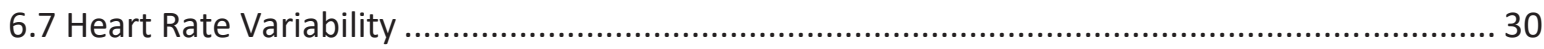

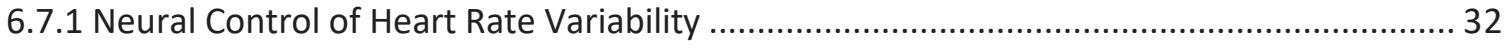

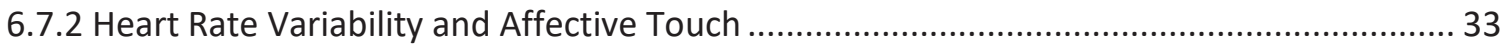

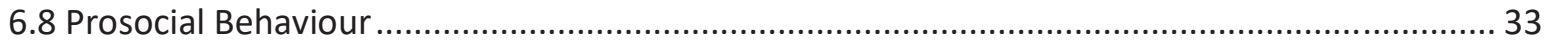

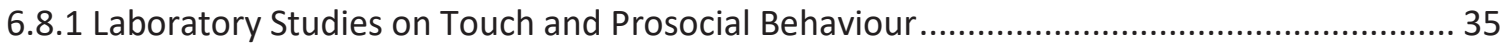

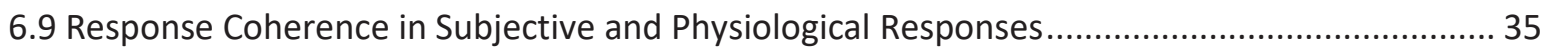

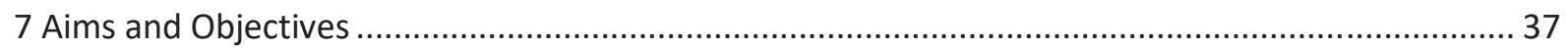

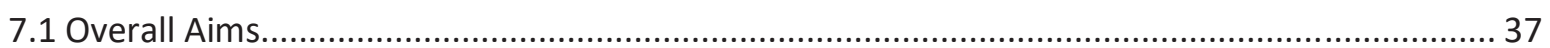

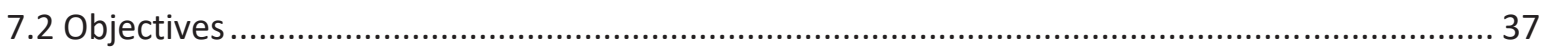




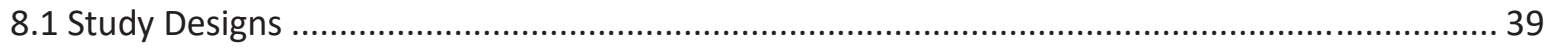

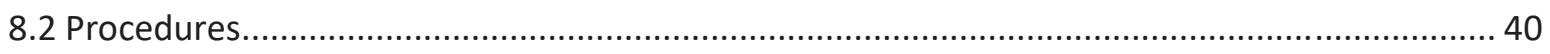

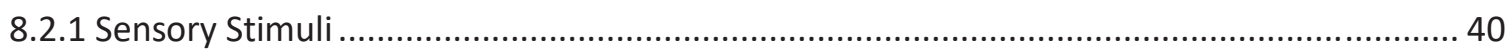

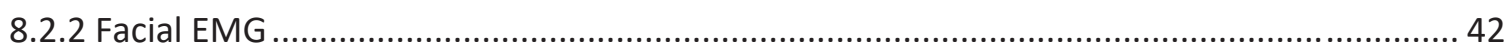

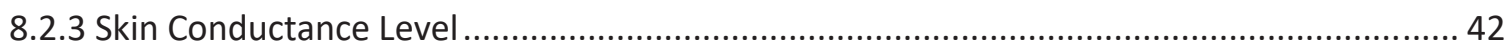

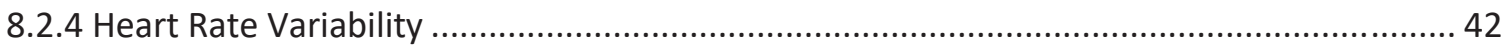

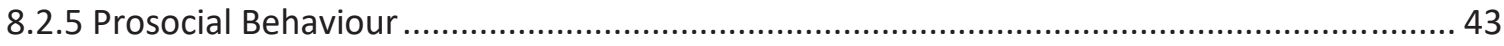

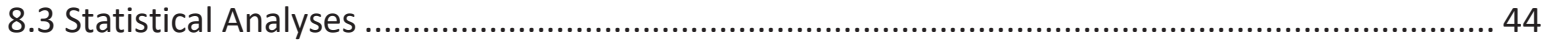

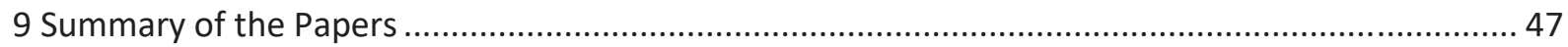

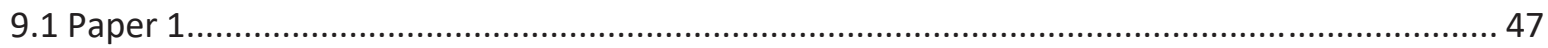

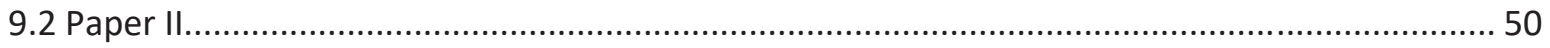

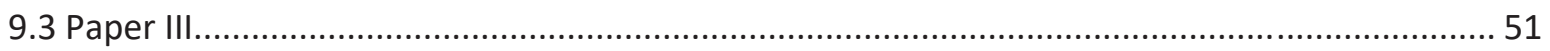

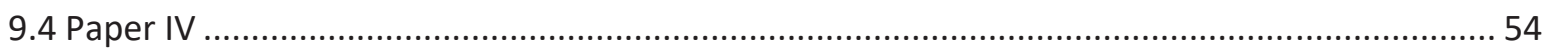

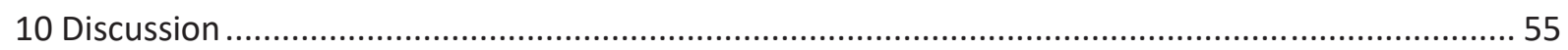

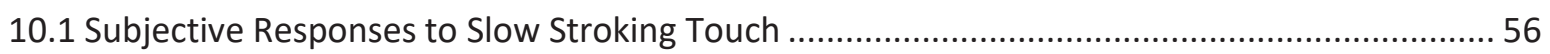

10.2 Physiological and Behavioural Responses to Slow Stroking Touch ......................................5 57

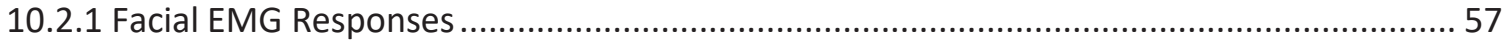

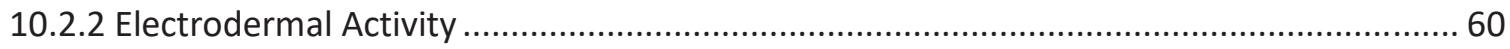

10.2.3 Heart Rate Variability Responses ................................................................ 61

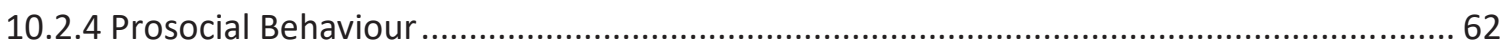

10.3 The Coherence between Subjective and Physiological Responses .................................... 64

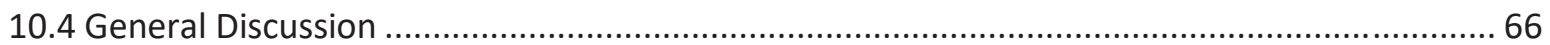

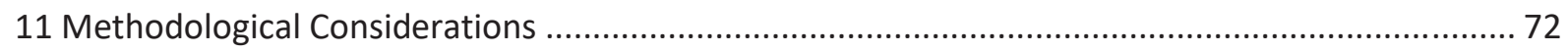

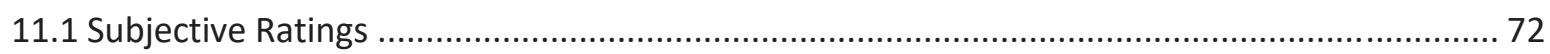

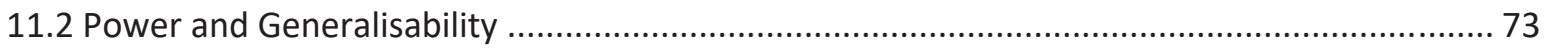

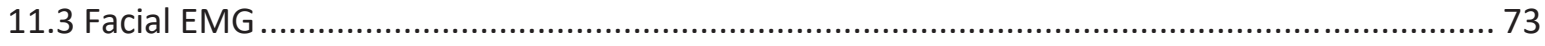

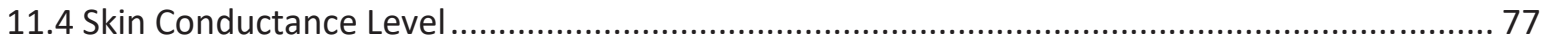

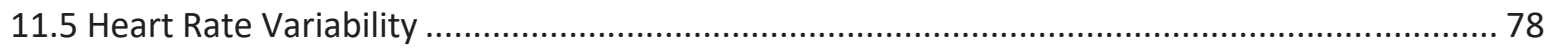

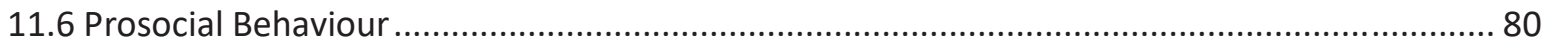

11.7 Stimulus Selection and Comparison ..................................................................... 81

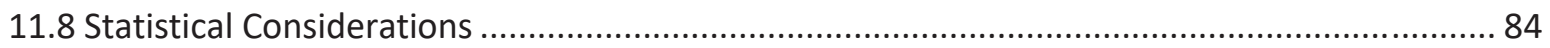

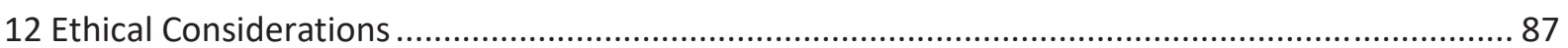

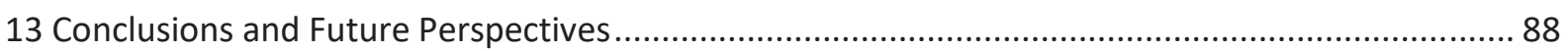





\section{Thesis Summaries}

\subsection{English Summary}

And there it is: The moment! Finally, someone is touching you. Not in a crude or abrupt way, but in a way that can be best described as, gentle. Or perhaps pleasant is more fitting, but pleasant certainly involves some kind of processing by the brain. As we all know, given the right circumstances, a touch can be perceived as anywhere between pleasant and unpleasant, or from all-consuming to barely noticeable. The touch that I have spent the last four years studying, is in itself, rather simple. A light, fleeting stroke across the arm. From the elbow towards the wrist. Not too fast and certainly not too slow. Just about right. Just how you would imagine someone stroking a child across the face when she's crying. Or how you would imagine two new lovers exploring each other's skin. Or even two friends rubbing each other's backs whilst saying their farewells. Key to these types of touch is that they involve touching people and not objects and it has been suggested that this form of affective touch activates a subgroup of unmyelinated nerve fibres, collectively referred to as C-tactile (CT) fibres. Most of us have observed, encountered and experienced these kinds of tactile interactions. However, although most of us find the touch pleasant, our understanding of what lies beneath this appreciation remains, largely, incomplete.

This thesis will try to answer some of these outstanding questions. Together with my colleagues, I have tried to investigate how we experience a slow stroking touch across the arm when the touch is repeated several times, continuously and at two different settings. I have asked my participants how pleasant and intense they perceived the touch. Moreover, I have investigated how their bodies responded to the touch and whether these bodily reactions cohered with their subjective ratings. To do so, I have analysed various physiological responses, such as skin conductance level, heart rate variability and facial electromyography. And lastly, I have tried to investigate whether people become more prosocial, or generous, after receiving CT targeted touch on the arm. In total, during my $\mathrm{PhD}$, I have conducted two separate experiments and a total of 93 participants kindly volunteered to participate. Some of our results were as expected; in paper I of the thesis, we replicated previous findings that have documented that the speed with which we stroke the skin is highly important in deciding its perceived pleasantness. A novel finding reported in paper I, was that the corrugator muscle of the face, involved in frowning and displaying negative affect, relaxed during CT targeted touch and this response may be recorded precisely using facial electromyography. Other results were unexpected; in paper II of the thesis, we were unable to demonstrate that people 
became more prosocial or generous after receiving CT targeted touch. In paper III of the thesis, we yet again demonstrated a close link between receiving slow stroking touch and the activation of the corrugator muscle and we tentatively proposed the potential for recording the corrugator activation in situations where speech is limited or alternatively that facial muscles activation may enhance and supplement verbal communication.

All of my analyses and conclusion are based on how people perceive and experience a slow, stroking touch on the skin of the arm. Therefore, for the novel reader to understand my interpretations and conclusions, you will need to understand how messages are conveyed from the skin, to the brain and ultimately, how these signals lead to some kind of action, or behaviour. In other words, I would like to take you on a journey through the skin of the beholder. Throughout the thesis, I will refer to a "Timeline" (see Fig 1), which guides the reader through the various aspects that have been investigated. I will start with the action or behaviour, if you like (passively receiving touch) and then go through the neuroscience that underpins this kind of behaviour. I will detail the immediate effects (milliseconds and seconds after the touch) and the effects that may last minutes and even hours within the human body. Lastly, I will explore some of the adaptations in the human body that have occurred over many generations to explore the basis for this "between kin" or "conspecific" behaviour. It really is astonishing, how touch can shape and form experiences between people and kin. So then: Are you ready to be touched? 


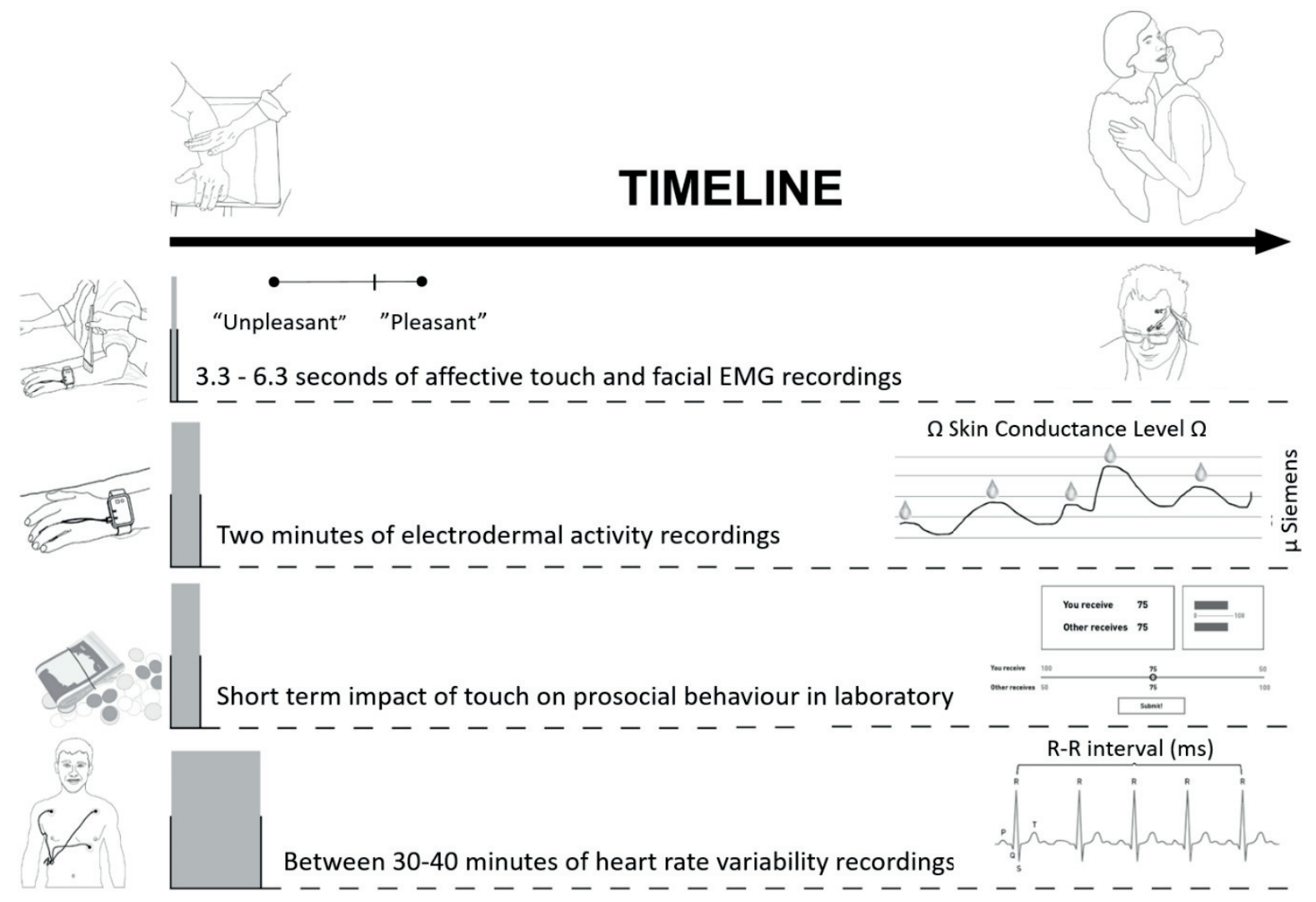

Fig. 1. Timeline: Graphical illustration depicting the timescales of the investigations and analyses that were carried out during the $\mathrm{PhD}$. Across two studies, we collected subjective ratings and physiological recordings. In study 1, we investigated the perceived pleasantness and intensity in response to touches of various velocities delivered by brush to the forearm, whereas in study 2 , the touch was delivered by a human hand. Specifically, in study 1 , touch targeting C-tactile (CT) fibres (touch with a velocity of $3 \mathrm{~cm} / \mathrm{sec}$ ) was compared to very slow, non-CT targeted touch (touch with a velocity of $0.3 \mathrm{~cm} / \mathrm{sec}$ ) delivered continuously for two minutes. In study 2 , we investigated 60 single trials of slow stroking touch $(3 \mathrm{~cm} / \mathrm{sec})$ during two sessions. Moreover, we collected physiological recordings, such as facial electromyography in both studies, skin conductance level was collected in study 1 and heart rate variability was collected in study 2 . In one of the papers, we also investigated whether CT targeted touch led to changes in prosocial behaviour, expressed by way of an online economic game where the participants had to allocate money between themselves and another participant $\left(3^{\text {rd }}\right.$ line). Please note: The shaded timescales are approximate indicators and used for illustrative purposes only. Figure demonstrating prosocial investigation $\left(3^{\text {rd }}\right.$ line) was originally published by Murphy et al. (2011) and modified under the Creative Commons Attribution 3.0 License. 


\subsection{Norwegian Summary}

Kroppens taktile sensoriske apparat består av et hurtig og et sakte ledende system som informerer hjernen vår om hva vi berører og når vi blir berørt. I motsetning til sensorisk berøring som ofte innebærer berøring med det formål å utforske eller håndtere objekter med håndflaten, er affektiv berøring ofte behagelige, taktile interaksjoner mellom mennesker og definert som berøring av hedonistisk og/eller emosjonell karakter. For eksempel, en varm omfavnelse ved et hyggelig gjensyn med en gammel venn, eller foreldre som skånsomt stryker kinnet til et barn som gråter. Det har blitt foreslått at affektiv berøring aktiverer en spesialisert gruppe nervefibrer i huden som blir referert til som C-taktile (CT) fibrer. CT fibrer er umyeliniserte afferente nerver som aktiveres maksimalt av lette, strykende berøringer med en hastighet mellom 1-10 cm/sek. Studier har også vist at det er positiv korrelasjon mellom hastigheter som maksimalt aktiverer CT fibrer og hvor behagelig berøringen oppleves. Veldig sakte eller rask berøring blir derfor ofte beskrevet som lite behagelig og aktiverer CT fibrene i liten grad, mens hastigheter i mellom 1-10 cm/sek blir ofte omtalt som behagelig og aktiverer CT fibrene maksimalt. Således har det blitt foreslått at CT fibrene har en unik plass i affektiv berøring og er en essensiell komponent i sosial berøring. I tillegg har flere felt-studier indikert at mennesker er mer prososiale og hjelpsomme etter berøring og at gjentatte ganger med affektiv berøring er resilient mot metthet. Med andre ord, selv etter gjentatte berøringer vil de fleste fortsatt beskrive berøringen som behagelig.

Laboratorie-studier som har undersøkt mekanismene som underbygger prososial atferd, berøringsmetthet og fysiologiske responser på berøring er begrenset og det er behov for studier som undersøker den potensielle prososiale effekten av berøring under kontrollerte laboratoriestudier. I tillegg er det behov for å undersøke de fysiologiske responsmekanismene for berøring ved hjelp av sofistikerte målemetoder og undersøke om de fysiologiske responsene er kontrollerbare, reproduserbare og om de verbale vurderingene samsvarer med de fysiologiske. Økt kunnskap om mekanismene som er involvert i affektiv berøring og prososial atferd kan øke vår forståelse av komplekse og dynamiske interaksjoner mellom mennesker og hvordan disse skapes og opprettholdes.

I denne doktorgradsavhandlingen ble det samlet inn data fra to studier. I studie 1 ble det samlet inn verbale rapporter på berøringsopplevelsen, som ble gradert på en skala fra -10 til +10 . Deltagere ble bedt om å vurdere behageligheten og intensiteten på to ulike berøringshastigheter på underarmen og en visuell kontrollbetingelse. Mens den ene berøringshastigheten $(3 \mathrm{~cm} / \mathrm{sek})$ stimulerte CT fibrene maksimalt var det forventet mindre 
aktivitet i CT fibrene under kontrollberøringen $(0.3 \mathrm{~cm} / \mathrm{sek})$. I tillegg ble det samlet inn overflate elektromyografimålinger (EMG) fra corrugator og zygomaticus musklene i ansiktet, som er forbundet med henholdsvis negativ og positiv affekt og uttrykkes via en rynke $\mathrm{i}$ pannen (corrugator) og et smil (zygomaticus). Ansikts EMG målingene ble spesifikt undersøkt i intervaller på 700 millisekund (ms), ettersom ledningshastigheten på CT fibrene tilsier at den første perioden etter iverksatt berøring (0-700ms) er fri fra CT fiber input og er utelukkende forbundet med input fra myeliniserte, hurtigledende $A \beta$ fibrer. I perioden etterpå (fra 700ms og utover) ble det forventet en gradvis økning i input fra CT fibrene.

I tillegg ble det samlet inn målinger på hudledningsevne (SCL), som et mål på graden av opphisselse og deltagerne spilte forskjellige økonomiske spill i etterkant av stimuleringene. I det ene spillet (Repeated Trust Game) ble det undersøkt hvor stor sum deltagerne var villige til å returnere til en motspiller, som et mål på tillit og gjensidighet. I det andre spillet (Social Value Orientation, SVO) ble graden av prososial atferd undersøkt via en simulert spillsituasjon, der deltagerne ble bedt om å fordele NOK 150 mellom seg selv og en annen deltager. Hver spiller spilte seks ganger per betingelse, og det ble deretter kalkulert hvorvidt deltageren utøvde prososial, individualistisk, altruistisk eller konkurransestyrt atferd. I studie 2 ble det samlet inn verbale rapporter fra berøring med en hastighet på $3 \mathrm{~cm} / \mathrm{sek}$. Samtidig samlet vi inn ansikts EMG og hjerterytmevariabilitet, som et mål på den kognitive kapasiteten på stresshåndtering. I studie 2 ble det samlet inn data fra to sesjoner med ca en ukes mellomrom. Dette ble gjennomført for å undersøke stabiliteten til de verbale og fysiologiske responsene.

Som forventet ble berøring som maksimalt aktiverer CT fibrene $(3 \mathrm{~cm} / \mathrm{sek})$ vurdert som mer behagelig og intenst enn kontrollberøring $(0.3 \mathrm{~cm} / \mathrm{sek})$. Derimot viste funnene våre at CT-rettet berøring ikke ble vurdert som mer behagelig og intens enn den visuelle kontrollbetingelsen og ikke mer engasjerende enn kontrollbetingelsen (målt med hudledningskonduktans). Samtidig demonstrerte vi at CT-rettet berøring førte til en gradvis reduksjon $\mathrm{i}$ corrugatoraktivitet og at denne reduksjonen kunne kobles mot ledningshastigheten til de umyeliniserte CT-fibrene. Påstanden underbygges av at det var ingen forskjell mellom CT-rettet og kontrollberøring i de første $700 \mathrm{~ms}$ av berøringen, som er fri for CT afferent input, mens etter $700 \mathrm{~ms}$ av berøringen hadde funnet sted ble det en gradvis reduksjon i corrugatoraktivitet under CT-rettet berøring og en gradvis økning under kontrollberøring. Derimot fant vi ikke støtte for hypotesen om at CT-rettet berøring øker graden av prososial 
atferd i en kontrollert laboratorium setting. Det var ingen målbar forskjell i deltagerne sin økonomiske generøsitet, målt ved hjelp av to ulike økonomiske spill.

I studie 2 ble det undersøkt om responsene på CT-rettet berøring var stabile når de ble eksaminert ved to anledninger og om det var samsvar mellom de verbale vurderingene av behagelighet og de fysiologiske responsene, målt ved ansikts EMG og hjerterytmevariabilitet. Som forventet ble den gradvise reduksjonen i behagelighetsvurdering akkompagnert av en gradvis økning i corrugator aktivitet. I tillegg var det en signifikant linear sammenheng mellom corrugatoraktivering og behagelighetsvurderingene. Det er sannsynlig at den økende graden av corrugatoraktivitet reflekterte den gradvis økende negative affekten mot berøringen, selv om berøringen sjeldent opplevdes ubehagelig. Det var derimot ingen samsvar mellom behagelighetsvurderingene og hjerterytmevariabiliteten.

Funnene fra doktorgradsavhandlingen må settes i en større sammenheng. Berøring er en naturlig del av vår atferd og har potensielt stor påvirkning på mellommenneskelige interaksjoner. Funnene fra denne doktorgradsavhandlingen er med på å bekrefte at CT-rettet berøring er behagelig, men det i seg selv er ikke nok til å endre vår prososiale atferd når den utforskes gjennom økonomiske spillsituasjoner i et laboratorium. Derimot dokumenterte vi at det er en grad av samsvar mellom hvordan vi sier vi opplever berøringen og hvordan vi kroppslig responderer på den. Berøring er med på å påvirke ansiktsmuskulatur som kan være kroppens måte å kommunisere affekt med eller indikere emosjonell ladning. I tillegg tyder funnene på at vi mennesker tolerer mye berøring uten at vi opplever den som ubehagelig. 


\section{Articles in the Thesis}

\subsection{Paper I:}

REE, A., MAYO, L. M., LEKNES, S. \& SAILER, U. 2019. Touch targeting C-tactile afferent fibers has a unique physiological pattern: A combined electrodermal and facial electromyography study. Biological Psychology, 140, 55-63.

\subsection{Paper II:}

ROSENBERGER, L. A., REE, A., EISENEGGER, C. \& SAILER, U. 2018. Slow touch targeting CT-fibres does not increase prosocial behaviour in economic laboratory tasks. Sci Rep, 8, 7700.

\subsection{Paper III:}

REE, A., BENDAS, J., PABEL, L., CROY, I. \& SAILER, U. 2020. Right between the eyes: Corrugator muscle activity tracks the changing pleasantness of repeated slow stroking touch. Physiol Behav, 222, 112903.

\subsection{Paper IV*:}

REE, A., MORRISON, I., OLAUSSON, H., SAILER, U., HEILIG, M. \& MAYO, L. M. 2019b. Using Facial Electromyography to Assess Facial Muscle Reactions to Experienced and Observed Affective Touch in Humans. JoVE, e59228.

\footnotetext{
* Paper IV is a methodological paper that demonstrates the use of facial EMG and utilises the subjective and facial EMG data from paper I.
} 


\section{Background}

\subsection{Two Systems for Touch Processing}

The sense of touch is the first to develop during foetal development (Bernhardt, 1987) and has traditionally been described as part of the cutaneous senses, such as temperature, itch, pain, pressure and vibration (McGlone et al., 2014). Any stimulation of the skin, whether that be through active manipulation of an object or passively receiving someone else's touch, activates low-threshold mechanoreceptors (LTMs) located in the skin. These mechanoreceptive afferents may be subdivided into two main groups: unmyelinated, slow conducting $\mathrm{C}$ afferents and myelinated, fast conducting $\mathrm{A} \beta$ afferents (Vallbo et al., 2016, Douglas and Ritchie, 1957). While $A \beta$ mechanoreceptive afferents are embedded in the human hairy skin, they reside in large quantities predominantly in the hands and feet (Johansson and Vallbo, 1979). Four specialised receptors; Meissner's corpuscles, Pacinian corpuscles, Merkel's discs and Ruffini endings, transform mechanical energy into afferent nerve impulses that are propagated along thickly myelinated $\mathrm{A} \beta$ fibres (Bolanowski et al., 1988, Johnson et al., 2000). Carefully constructed experiments on monkey and man provided evidence suggesting Meissner and Pacinian receptors were particularly important in the localisation of vibration (Verillo, 1963, Mountcastle et al., 1967) and Merkel receptors were involved in the sensation of pressure (Vallbo and Johansson, 1984, Mountcastle et al., 1972, Ochoa and Torebjörk, 1983). These four receptors may also be classified according to their response profile or receptive fields; Merkel and Ruffini receptors are slowly-adapting (SA) receptors that continue to fire in the presence of sustained pressure on the skin, whereas Meissner and Pacinian receptors are rapidly-adapting (RA) receptors that respond to temporally moving mechanical stimulation of the skin (Knibestöl and Vallbo, 1970, Knibestöl, 1975). Moreover, Meissner and Merkel receptors have small, well-defined receptive fields and Pacinian and Ruffini receptors have larger, less defined receptive fields (Johansson, 1978, Knibestöl and Vallbo, 1970, Vallbo and Johansson, 1984). The Ruffini receptors are less well understood, however, they are suggested to also aid in movement control and perception (Backlund Wasling et al., 2005, Edin, 2001). The combined activation of these receptors provides the foundation for the perception of slip, vibration, pressure and texture (Ochoa and Torebjörk, 1983, Vallbo and Johansson, 1984, Johnson et al., 2000, Abraira and Ginty, 2013).

This somatosensory information is conveyed to the brain in primary afferents (firstorder neurons) which ascend in the dorsal column of the spinal cord and synapse with second- 
order neurons at the level of the medulla. The second-order neurons decussate and continue in the contralateral medial lemniscus pathway to the thalamus. Here they synapse again with the third-order neurons before terminating in the somatosensory cortex of the brain (Gardner and Johnson, 2013). Due to the size and myelinated nature of their axons, their signalling is incredibly fast and provides the brain with continuous information regarding the size and shape of the object or person being touched [see for instance McGlone and Reilly (2010). The brain will then use this information to correct, if necessary, the calculated requirements to continue holding the object, drop it or manipulate it. Commonly, this part of the tactile system is referred to as "discriminatory" touch, see Fig 2 below (Gardner and Johnson, 2013, McGlone et al., 2014). Basically, if we lose this sense of touch, we start dropping objects, and our ability to explore our surroundings confidently and safely is greatly diminished (de Haan and Dijkerman, 2020). Until the late 1980s, most tactile research had focused on the fast conducting LTMs discriminatory aspect of touch, with less focus on the unmyelinated slow conducting $\mathrm{C}$ fibres (McGlone et al., 2014). Moreover, an increasing body of evidence suggested some of the $\mathrm{C}$ afferent fibres offered information that was involved in the affective side of touch, which will be elaborated upon in the following section.

\subsection{Affective Touch}

Affective touch has been defined as touch processing that encompasses emotional or hedonic components (Morrison, 2016a), and it has been suggested by several authors that $\mathrm{C}$ afferent tactile (CT) fibres form an integral part of the affective touch pathway [see for instance Vallbo et al., 1993, Vallbo et al., 1999, McGlone et al., 2014,)]. The discovery of CT fibres in mammals can be traced back to the late 1930s. Recording from the saphenous nerve of the cat, Yngve Zotterman demonstrated the presence of low-threshold mechanosensitive Cfibres [(CLTMRs), the abbreviation used when studying LTMs in furry animals] which exhibited a slow and erratic firing in response to needle prick, burning stimuli and, gently stroking of the skin (Zotterman, 1939). Through a series of studies on a variety of animals, it was then reported that some of the cutaneous C-fibres were highly sensitive to light mechanical stimuli such as pressure and touch, while others appeared to be more modulated by heating and cooling of the skin. These unmyelinated C-fibres were referred to as "warm" and "cold" C-fibres (Iggo, 1959, Iggo, 1960, Iriuchijima and Zotterman, 1960). It was initially postulated that these fibres were involved in mediating tickle and itch (Zotterman 1939) and later that they were also involved in the regulation of body temperature (Iriuchijima and Zotterman, 1960). An important distinction between CLTMRs and A $\beta$ afferents were made 
when Bessou et al. (1971) demonstrated a clear difference in the response properties of CLTMRs and $A \beta$ afferents: Whereas the CLTMRs responded by increasing and then decreasing their firing frequency in response to a glass rod that was stroked on the skin, the $\mathrm{A} \beta$ afferents, however, increased monotonously with the velocity of the glass rod stroking the skin.

Expanding on the animal research and through the careful exploration of the skin using the microneurography technique (carefully inserting small needles directly into peripheral nerves, [developed by Hagbarth and Vallbo (1967)], Johansson and colleagues reported the presence of low threshold, unmyelinated $\mathrm{C}$-afferent fibres in the infraorbital nerve in humans (Johansson et al., 1988). Their presence was subsequently confirmed in the supraorbital nerve (Nordin, 1990). The unmyelinated nature of these afferent fibres rendered them slow and inept at providing information that is essential for manipulating objects, with a reported conduction velocity between 0.6 and $1.3 \mathrm{~m} \mathrm{~s}^{-1}$ (Olausson et al., 2010, Watkins et al., 2017, Vallbo et al., 1999, Vallbo et al., 1993). Although the spinal projections of C afferent fibres remain an unresolved issue, animal studies suggest they ascend in the lamina I spinothalamic pathway to the posterior thalamus (Craig, 2002, Craig and Zhang, 2006) [but see also recent discussion by Marshall and McGlone (2020) for an alternative viewpoint].

Several studies have described these $\mathrm{C}$-afferent fibres and their characteristics in greater detail and are collectively referring to them as CT fibres. CTs are found abundantly in the hairy skin, but there appear to be some differences in their distribution density. As well as the presence of CT fibres in the orbital nerves (Johansson et al., 1988, Nordin, 1990), studies have reported that $\mathrm{CT}$ afferents constituted more than $70 \%$ of the total $\mathrm{C}$ afferents that responded to innocuous skin indentations in the forearm (Vallbo et al.,1999), and $40 \%$ of the total units in the forearm in another sample (Vallbo et al., 1993), whereas another study reported a numerous distribution in the lower leg (Edin, 2001). However, they have not been encountered in the glabrous skin of the palms and feet (Johansson and Vallbo, 1983, Abraira and Ginty, 2013), [although a very recent study suggests CT fibres may also be found in glabrous skin (Watkins et al., 2020)]. The early pioneering work using microneurography noticed that the CT fibres were responsive to light skin indentations ranging between 0.3-2.5 $\mathrm{mM}$ and even responded to sustained indentations (Vallbo et al., 1999). The most consistently reported feature of the CT fibres, however, was that they responded most vigorously to a light, slow stroking touch across the hairy skin (Vallbo et al., 1993, Vallbo et al., 1999). Subsequent investigations using several different velocities demonstrated that the pleasantness 
ratings exhibited a shape of an inverted "U" [see for instance Essick et al. (1999), Sehlstedt et al. (2016), Essick et al. (2010)]. Specifically, very slow and very fast speeds were rated less pleasant than medium speeds (see Fig 2 below). Additional work using the microneurography technique demonstrated that the inverted " $U$ " distribution of the subjective pleasantness ratings was accompanied by specific firing frequency of the CT fibres (Löken et al., 2009). Furthermore, in another microneurography investigation, the firing frequency of the CT fibres was higher when the touch was delivered at skin temperatures, than when the touch was delivered with cooler and warmer temperatures (Ackerley et al., 2014a). This study demonstrated a close correlation between CT fibres firing frequency and the perceived pleasantness of a slow stroking touch delivered at skin temperatures. Combined, these findings demonstrate an intimate relationship between the velocity of a stroke, the activity in the CT fibres and the perceived pleasantness of affective touch.

The close link between the perception of affective touch and CT fibre activity is further evidenced by studies examining the cortical responses to affective and discriminatory touch. The perceived intensity of a touch, which is considered part of the discriminatory aspect of touch, activates primarily the somatosensory cortices [see for instance Francis et al. (1999) or for a recent review; de Haan and Dijkerman (2020)]. CT fibres, however, project primarily to the orbitofrontal and insular cortices [see for instance McGlone et al. (2012), McCabe et al. (2008) or for a recent review; Morrison (2016a)], of which the latter region is given a putative role in the transformation and integration of affective and emotional stimuli (Craig, 2009). Thus, it has been suggested that the CT fibres form an integral part of a tactile system whose primary function is to mediate socially important, affiliative tactile stimuli between conspecifics, referred to as the "social touch hypothesis". Specifically, the social touch hypothesis postulates that $\mathrm{CT}$ fibres are responsive and active during close social interactions and that the activity of these fibres influences the experience of those involved in the tactile encounter (Morrison, 2016b, Olausson et al., 2010, Olausson et al., 2002). In summary, there is ample evidence to suggest that CT fibres are maximally activated when the touch is performed with velocities typical of a human caress, suggesting that the perceived pleasantness of the touch is intimately linked to its velocity [(see for instance Löken et al. (2009), Luong et al. (2017), Essick et al. (1999), Ackerley et al. (2014a), Sehlstedt et al. (2016), or Cruciani et al. (2021) for a recent review]. The perception of pleasantness, however, is also dependent on several other factors, such as the affective and emotional impact of the stimulus, which will be elaborated upon in the following section. 


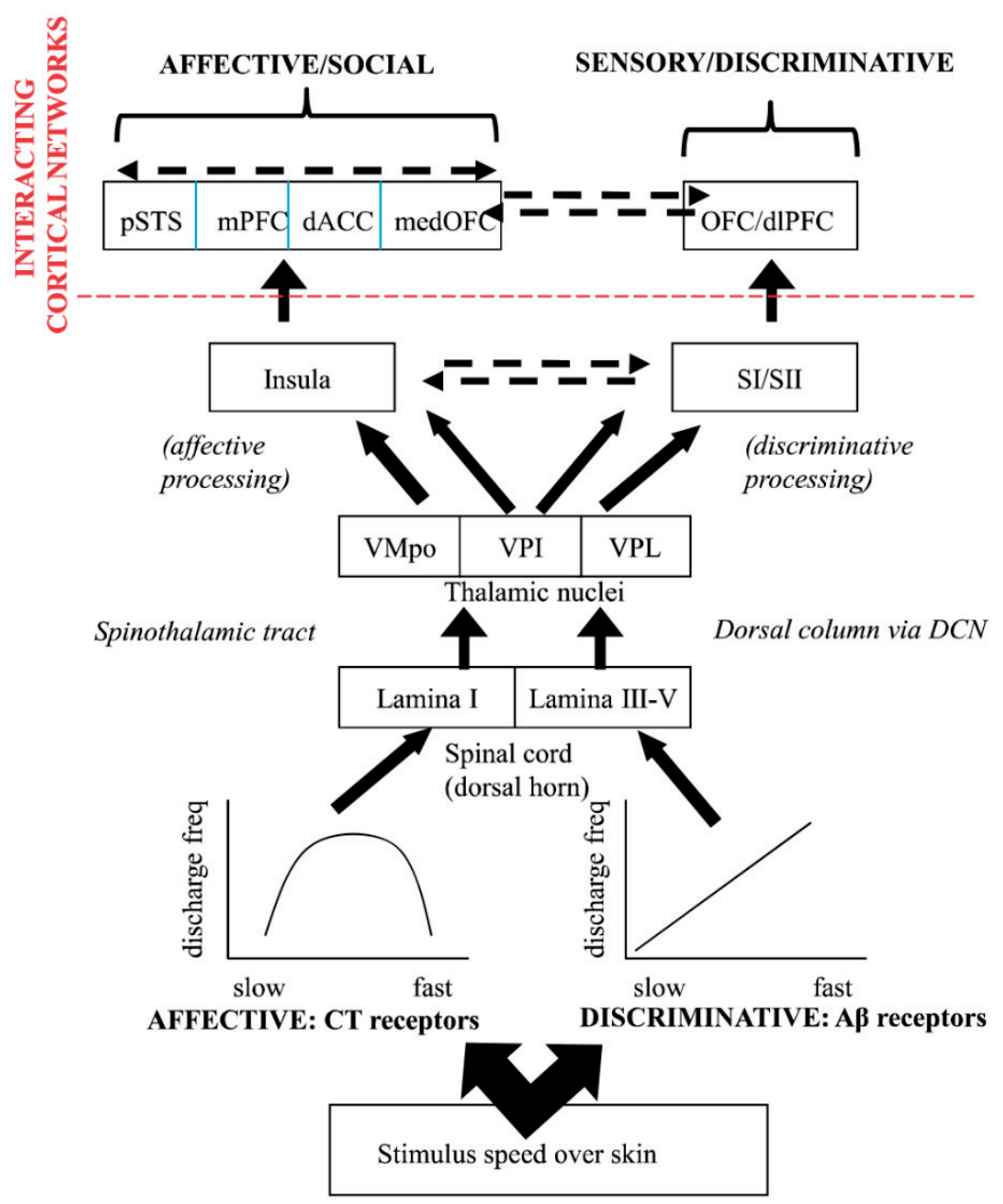

Fig. 2. Two systems for touch processing. Discriminative touch (right side of the graph) relies predominantly on $\mathrm{A} \beta$ fibres, which increase their firing frequency with faster stimulation speeds across the skin and progress to the somatosensory cortices. Affective touch (left side of the graph) relies predominantly on CT-fibres signalling, whose firing frequency resembles an inverted "U" with lower and faster stimulation speeds across the skin leading to less activity than medium stimulation speeds. Original figure published by McGlone et al. (2014) and reproduced by permission from the Copyright Clearance Center: Elsevier. 


\subsection{Affect and Valence}

Touch can affect us in many different ways, from the abrupt nudge on a crowded train leading to an irritated sigh of frustration, to the tickles between family members leading to giggles and laughter (Gallace and Spence, 2010). Thus, any study of touch needs to appreciate the multidimensional aspects that constitute our emotions and affective expressions. This thesis investigates the responses to affective touch using several different methods; verbal reports of pleasantness and intensity, which are closely linked to hedonic perception and valence, (Becker et al., 2019), electrodermal activity and heart rate variability measures, which are closely connected to the level of emotional arousal (Cacioppo et al., 2000, Boucsein, 2012), and electromyography recordings of facial muscle activity, which are closely connected to the manifestations of affect and emotional expressions (Cacioppo et al., 1986, Ekman et al., 1987). Thus, I will assume the view that the cognitive conceptualisation of emotion states are expressed through varying degrees of valence and affect, as described by Russel (1980). However, it is beyond the scope of this thesis to indulge in a comprehensive debate regarding emotion theory, [see for instance James (1884) or Lindquist et al., (2013); Schirmer and Adolphs (2017) for recent discussions]. Consequently, I will adopt the view maintained by Schirmer (2015) that emotions and affect may at the present state not be entirely distinguishable and both may be defined by behavioural responses to events, such as being touched.

Fundamentally, any hedonic experience, such as that experienced when receiving a slow stroking touch, may be divided into displeasurable and pleasurable feelings that serve as strong incentives to guide behaviour (Becker et al., 2019). Dimensional models (see Fig 3), suggest emotions are expressed on a single-dimensional axis (approach or avoid) or a twodimensional axis involving valence (negative-positive) and arousal (low-high) (Levenson et al., 2017). For example, we may express the pleasure of sensing the sun on our skin through a subdued sigh of delight and similarly, we may express the same level of pleasure from passing an exam through loud screams of joy. Whereas the subdued delight would involve positive valence and low arousal, the screams of joy would involve positive valence and high arousal, as suggested by a circumplex two-dimensional model (Russell, 1980). 


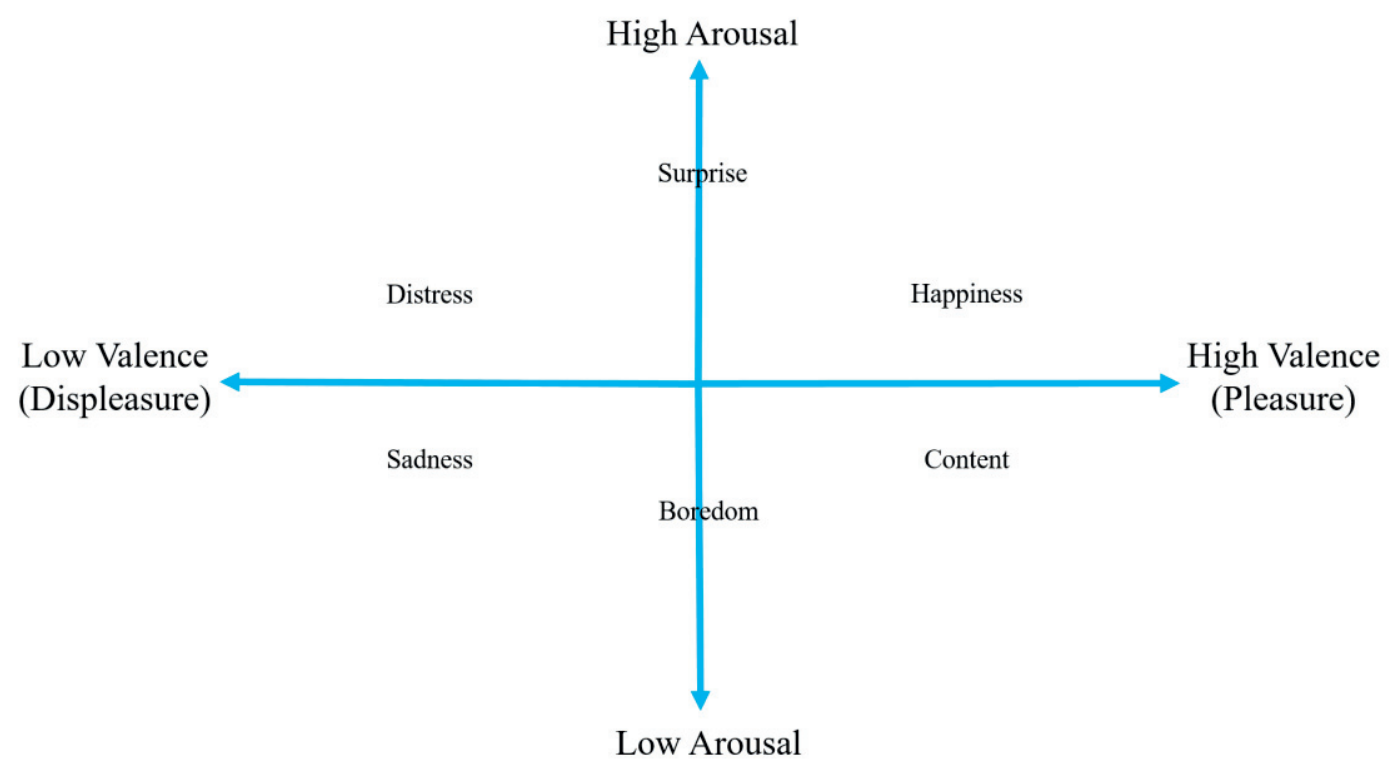

Fig. 3. Basic model adapted and modified with permission from Russell (1980). Emotional states may be expressed on a two-dimensional circumplex model indicating various degrees of arousal and valence. Please note: The model is not exhaustive and is used for illustrative purposes only.

In a recent review, Sander et al. (2018) maintained that most emotion theories share familiar and complementary understandings that can be deconstructed into five functionally connected cortical networks of the emotional brain. These subsystems of the emotional brain are referred to as the information/elicitation network, support/regulation network, executive/motivational network, the action/expressive network and finally the monitoring/feeling network. During different emotional events, the emotional construct is appraisal-driven, thus, the internal or external event that triggers the emotion may differently engage the various subsystems and therefore lead to different perceptions, actions and behaviour. Various emotional episodes that belong to the same family of emotion may thus vary within their multicomponential expression: For instance, being nudged by a stranger on a crowded train, as in the example above, may lead to overt anger (shouting, verbal abuse) or suppressed anger (clenching of the jaws). Overt anger may thus have greater motivational and expressive phases than suppressed anger, however, both emotions will demonstrate consistent activation across all subsystems of the emotional brain, with a unique activation pattern constructing their respective emotion (Sander et al., 2018). Nevertheless, despite over a century of studies, we still do not fully understand how the brain interprets stimuli to create 
and shape emotion and affect (Lindquist et al., 2012). What we do know, however, is that repeated exposure to a stimulus changes the way we perceive that stimulus.

\subsection{Habituation and Satiety}

Several studies from various sensory modalities suggest that the perceived pleasantness of a stimulus changes with repeated stimulation. A common response to repeated stimulation is habituation, which is defined as "a behavioral response decrement that results from repeated stimulation and that does not involve sensory adaptation/sensory fatigue or motor fatigue" (Rankin et al., 2009, p. 2). In its simplest form, habituation means that the perception of a stimulus is reduced or abolished altogether, although the stimulus intensity has not changed. Thus, stimuli originally considered pleasant are gradually considered less pleasant, and likewise, stimuli originally considered unpleasant are gradually considered less unpleasant. Affective habituation is considered a subform of habituation and is described as a process where the repeated presentation of emotionally valenced stimuli lead to reduced affective responses (Leventhal et al., 2007) and previous experiments have observed affective habituation in humans in the tactile (Triscoli et al., 2014a), visual (Mastria et al., 2017), olfactory (Triscoli et al., 2014b, Ferdenzi et al., 2014) and auditory senses (Mutschler et al., 2010).

Affective habituation is closely linked to satiety, which is the process whereby the repeated exposure to a stimulus leads to a reduction in reward valuation (Wilkinson and Brunstrom, 2016). Satiety has been extensively investigated in foods and flavours and refers to the process whereby someone is repeatedly exposed to a pleasant food and the pleasantness ratings of that particular food drop gradually as the person becomes satiated, or full (Rolls et al., 1981). Affective habituation and satiety predominantly involve top-down processes motivated by the drive to sustain the well-being of an organism (Rolls and Rolls, 1997, Rankin et al., 2009, Rolls, 2020). In the field of taste satiety, for instance, as someone becomes satiated to one type of food, the motivation and drive to eat other types of food is not affected. Importantly, there is considerable overlap and convergence between the sensory modalities of taste, olfaction and touch, particularly at the level of the insular and orbitofrontal cortices (Rolls, 2020).

The literature regarding satiety to affective touch is scarce, however, early microneurography studies indicated that CT fibres were prone to fatigue and adapted quickly to sustained skin indentations. For instance, it was reported that afferent $\mathrm{C}$ fibres in cats could 
fire persistently in response to mechanical stimulation, however, most frequently, they would cease to fire within a few seconds (Douglas and Ritchie, 1957, Iggo, 1960). Moreover, following suprathreshold stimulation, the fibres were less responsive to subsequent stimuli, an effect that could last between seconds to minutes (Douglas and Ritchie, 1957, Iggo, 1960), a finding also reported in early studies of $\mathrm{C}$ afferents in humans [see for instance Torebjörk and Hallin (1974)]. Vallbo et al. (1999) looked at the effects of repeated stimulation in human CT fibres and noted that fatigue occurred following repeated stimulation, however, the units continued firing, although with reduced impulse responses and duration of the response. Furthermore, using sustained indentations on the skin, the authors demonstrated that the CT fibres responded in a biphasic manner, with the nerve impulses reduced to zero within four seconds, however, after 10-30 seconds of sustained indentations, the CT fibres responded by a vigorous train of impulses. The authors referred to this as delayed acceleration (Vallbo et al., 1999). It is therefore unlikely that CT fibre fatigue or delayed acceleration affects touch satiety in humans, as these effects were less pronounced in humans compared to other mammals. Moreover, the participants were unable to relate to the delayed acceleration when verbally probed during the investigation (Vallbo et al., 1999). Thus, it is unlikely that delayed acceleration has a direct perceptual impact on touch satiety processes, which involves predominantly top-down processes (Rolls and Rolls, 1997, Rankin et al., 2009, Rolls, 2020).

To the best of my knowledge, only three previous studies have examined how the perceived pleasantness of CT targeted touch changes with repeated stimulation. In one of the studies, the perceived pleasantness of CT targeted touch $(3 \mathrm{~cm} / \mathrm{sec})$ dropped somewhat quicker than very slow $(0.3 \mathrm{~cm} / \mathrm{sec})$ and fast $(30 \mathrm{~cm} / \mathrm{sec})$ touch, however, the touch was never rated as unpleasant (Triscoli et al., 2014a). Similar demonstrations of touch satiety were reported in two other studies (Triscoli et al., 2017b, Sailer et al., 2016a). Importantly, although the perceived pleasantness of the CT targeted touch dropped significantly from the start of the sessions to the end of the sessions, the pleasantness ratings remained overall in the positive ranges, suggesting that people found the touch pleasant even after 50 minutes. In summary, findings on hedonics and the behaviour that stem from activation of the CT-fibres suggest that the perceptual impact of repeated CT targeted touch is rather resilient to satiety. Moreover, one affirmative conclusion regarding touch that activates CT fibres, is that most people, under most circumstances and for a prolonged period of time, find the touch, pleasant. The physiological and behavioural responses to affective touch, however, are not as well understood and will be explored below. 


\subsection{Facial Electromyography}

Surface electromyography (EMG) records the electromagnetic field generated by an ensemble of muscle action potentials as the electromagnetic signal propagates along the extracellular fluids of the muscle fibres towards the skin. Importantly, the EMG signal does not represent a direct measure of muscle tension or muscle activation, but rather a measure of the electrical activity associated with the muscular activation (Tassinary et al., 2017). The two major advantages of the EMG signals are the speed with which a muscular contraction can be detected and the ability to record muscular activity otherwise not visually detectable by others (Ravaja et al., 2004, Epstein, 1990). Investigations of muscular activity of the facial muscles are referred to as facial EMG, and facial expressions have long been considered a key manifestation of emotion and affect (Ekman et al., 1987). Two of the most commonly investigated muscles are the corrugator supercilii and zygomaticus major muscles, thought to be involved in expressing negative and positive affect. A contraction of the corrugator muscle leads to a furrowing of the brow ("frowning") while a contraction of the zygomaticus draws the corners of the mouth upwards and backwards ("smiling”) (Cacioppo et al., 1986, Dimberg, 1982). Several studies have demonstrated that stimuli that are perceived as negative increase and stimuli that are perceived as positive decrease responses of the corrugator muscle in a variety of stimuli, such as visual (Lang et al., 1993), olfactory (Joussain et al., 2017) and gustatory stimuli (Horio, 2003). Furthermore, increased activation of the zygomaticus muscle has been associated with watching and listening to pleasant pictures and sounds (Bradley and Lang, 2000, Lang et al., 1993, Larsen et al., 2003).

\subsubsection{The Neural Control of Facial Expressions}

The first scientific investigation describing the purpose and function of facial expressions dates back to Darwin and his seminal work on the expressive emotional behaviours in animals and humans (Darwin, 1872/1998). Darwin himself acknowledged the work of the French anatomist Duchenne de Boulogne (Duchenne, 1862/1990). Duchenne was the first to electrically stimulate the muscles of the face and was able to differentiate between a "fake" and "true" smile; the former involving voluntary contraction of the smiling muscles and the latter involving the autonomous, combined activity of the smiling muscles and eye muscles (commonly referred to as a "Duchenne smile") [Ekman et al., 1990]. Principally, Darwin argued that young and old, animals and humans expressed their state of mind using a set of core movements and facial expressions. Darwin's influence can be found in much subsequent work related to facial expressions and their meanings. Broadly speaking, 
researchers are often grouped according to whether they believe facial expressions are "hardwired" physical expressions of emotional status or "functional" expressions (Keltner et al., 2016). Advocates of the "hard-wired" category argue that there is a strong relationship between the emotional status of a person and his facial expression. Stated differently, if someone is feeling content and happy, he will express this through a smile on his face. And likewise, if someone is feeling angry, this will be expressed by the "anger face", typified by a furrowing of the brow, clenching of the jaws and a direct gaze [see for instance Ekman (1992)]. There are discussions as to how many different emotions may be communicated through facial expressions. Early work, by for instance Ekman and Friesen (1969) and Ekman et al. (1987) identified six basic emotions whose facial characteristics were universally understandable, irrespective of the cultural background of both sender and recipient. Moreover, although there is controversy regarding the development and purposes of expressing one's emotions through facial actions, several scholars maintain that facial expressions are emotive signals whose functions are to change the behaviour of the recipient to the benefit of the signaller [see for instance Maynard Smith and Harper (2003)]. And, importantly, through learning and contextual experiences, people learn when to display facial expression that conflict with their emotional status, if doing so benefits the sender. This phenomenon is commonly referred to as "display rules" [see for instance Ekman and Friesen (1969)].

However, the view that facial expressions are blueprint readout of someone's internal status has been challenged and critiqued by the "functionalists". Functionalists view emotions as relational, fleeting processes that change according to contextual, physical, emotional and social demands, with the overarching motivational aim of maintaining homeostasis (Levenson et al., 2017). Therefore, facial expressions are not accurate measures of how someone is feeling, but rather social and contextual signals whose presence may or may not indicate the emotional status of the person (Keltner et al., 2016). Stated differently, if someone is feeling angry, but has experienced previously that the current setting does not support anger expressions, rather than suppressing the "hard-wired" basic emotion circuitry associated with anger display, functionalists argue that a unique set of cortical networks would be activated using prior knowledge and experiences and current circumstances to initiate the best available action pattern (Barrett, 2017). The critique of the "hard-wired" view of facial expression has been further strengthened by reviews that have demonstrated poor correlations between facial expressions and emotions in laboratory studies (Reisenzein et al., 2013) and field studies 
(Fernández-Dols and Crivelli, 2013). Specifically, Reisenzein et al. (2013) investigated the correlation between self-reported emotional status and facial expressions in six core emotions (happiness, surprise, disgust, sadness, anger, fear) and found little to moderate levels of correlations for all emotions bar happiness. For happiness, the level of correlation was found to be moderate to high, depending on whether the emotion was induced by film clips or reading comic books. Regarding the evidence from field studies and observations from, for instance, people getting lost, complaining about lost airport luggage and observations of clinical interviews, the authors reported an overall very low correlation between the observed facial expression and the subsequent self-reported level of emotional status (Fernández-Dols and Crivelli, 2013).

\subsubsection{Facial EMG and Affective Touch}

The literature that relates to facial EMG responses and CT targeted touch is surprisingly scarce. To the best of my knowledge, at the start of this $\mathrm{PhD}$, no studies had looked primarily at CT targeted touch and facial EMG responses. That changed when Pawling and colleagues (2017a) in a novel study demonstrated for the first time that CT targeted touch was accompanied by a concomitant activation of the zygomaticus major muscle. The authors compared subjective and facial EMG responses to CT targeted touch $(3 \mathrm{~cm} / \mathrm{s})$ and fast nonCT targeted touch $(30 \mathrm{~cm} / \mathrm{s})$ when delivered to the glabrous skin of the palm to the responses when the touch was delivered to the CT-containing hairy skin of the forearm. An important finding was that although the slow stroking touch applied to the glabrous skin was rated as highly pleasant, only the slow stroking touch applied to the hairy skin yielded a contraction of the zygomaticus muscle. This, the authors maintain, was testimony to the implicit and innate nature of touch that activates the $\mathrm{CT}$ fibres. However, the authors did not find a consistent response pattern in the corrugator muscle (Pawling et al., 2017a). A recent study by Mayo et al. (2018), however, reported an increase in the corrugator muscle following fast non-CT targeted touch $(30 \mathrm{~cm} / \mathrm{s})$ and importantly, CT targeted touch $(3 \mathrm{~cm} / \mathrm{s})$ directed to the hairy skin of the forearm led to a relaxation of the corrugator muscle. The authors suggested that emotional responses to pleasant touch may occur even in the absence of facial expression cues, and that facial responses to valenced stimuli may be of importance when communicating affect to others, for instance during social interactions, such as consolation (Mayo et al., 2018). Recently, Korb et al. (2020) found that during anticipation and consumption of non-social reward (food) and social reward (touch), the corrugator muscle reflected a reduction in reported wanting of non-social reward, but not during social reward. 
The findings regarding the zygomaticus muscle were inconclusive, although the authors suggested following exploratory analyses that the zygomaticus muscle responded during certain phases of the delivery of social reward (touch), but not during non-social reward (Korb et al., 2020). Thus, there is uncertainty regarding the facial EMG responses to touch that aim to activate the $\mathrm{CT}$ fibres.

An important factor that cannot be underestimated when investigating CT targeted touch, however, is the different conduction velocity of the myelinated $\mathrm{A} \beta$ fibres compared to the unmyelinated CT fibres. Through the careful exploration of the skin using the microneurography technique, studies have reported that that the conduction velocity of CT afferents varies between 0.6 and $1.3 \mathrm{~m} \mathrm{~s}^{-1}$ (Olausson et al., 2010, Watkins et al., 2017). This is approximately 50 times slower than that reported for the fast conducting $A \beta$ fibres, reflecting the myelinated nature of the large diameter axons (Abraira and Ginty, 2013, Olausson et al., 2010). Thus, if the arm is touched, one may safely assume that it would require approximately $700 \mathrm{~ms}$ before any CT afferent input reaches the cortex and by extension, any detectable facial EMG response following CT fibre input could at the earliest manifest after $700 \mathrm{~ms}$ has passed. Importantly, any given touch to the hairy skin will involve tactile input signalling through $\mathrm{A} \beta$ and $\mathrm{CT}$ fibres, however, due to the physiological speed restrictions imposed on $\mathrm{CT}$ afferents by their unmyelinated nature, none of the $\mathrm{CT}$ mediated effects could occur during the initial phase of the touch.

A similar approach has already been implemented using electroencephalogram (EEG) recordings. More precisely, by detecting EEG responses to CT targeted touch directed to the forearm, Ackerley et al. (2013), noted the presence of an ultra-late event-related potential (ERP) that did not reach the cortex until at least $700 \mathrm{~ms}$ after the stroking had begun. By estimating the length of the neurons transmitting the signal from the forearm to the cortex and using the conduction velocity of the CT afferent fibres, the authors proposed that the ultra-late ERP reflected a volley of CT afferent input. Similarly, we utilised the high temporal resolution of the facial EMG signal to separate responses primarily derived by $A \beta$ fibre input to those derived by both $\mathrm{A} \beta$ and CT fibre input. Specifically, in paper I of this thesis, we analysed facial EMG responses that occurred during the initial $700 \mathrm{~ms}$ of touch separately from those that occurred during the remainder of the touch. This, we argue, offers a dynamic and precise analysis of tactile responses and how slow stroking touch influences facial muscles and behaviour involved in negative and positive affect (see Fig. 1, Timeline, for overview). 


\subsection{Electrodermal Activity}

The human skin is the largest organ of the body and provides the principal interface between the internal milieu of the body and the exterior surroundings (Dawson et al., 2007). It has complex functions and is densely innervated by neurons, blood vessels and immunological components, such as lymph. It remains one of the most widely investigated systems of human functioning, particularly the electrodermal activity (EDA). The EDA response system is an umbrella term that refers to alterations in the electrical properties of the skin, brought about by rapid and slow changes in the autonomic nervous system (ANS) (Braithwaite et al., 2013). Briefly, the traditional view of the ANS was that the sympathetic (SN) and the parasympathetic (PN) branches served as two opposing systems, the former responsible for "fight-flight" behaviours and the latter responsible for "rest-digest" behaviours. However, recent findings support a more functional view of these systems, where the dynamic and combined activity of both systems influence each other through reciprocal and coordinated actions, with the primary purpose of maintaining homeostasis (Mendes, 2016, Sequeira et al., 2009). The two primary components of the EDA system are the skin conductance level (SCL) and the skin conductance response (SCR), which reflect different aspects of the skin's electrical properties. The SCL refers to the gradual ebb and flow of the skin's tonic electrical potential whereas the SCR refers to rapid and phasic changes in electrical properties (Dawson et al., 2007). These changes are commonly investigated by placing two sensors on the skin of the palms or fingers, or the soles of the feet, as they have a high density of sweat glands. A weak electrical potential is then passed through the sensors and the electrical current flow is measured (Braithwaite et al., 2013). Thus, if someone is secreting more sweat due to a stimulus, the moisture of the sweat secretion reduces the resistance of the current running through two sensors, hence increasing the electrical conductance capacity of the skin. The increased electrical capacity of the skin can be measured quantitatively and is expressed in microsiemens $(\mu \mathrm{S})$ (Dawson et al., 2007). EDA has been considered a sensitive measure of arousal when the sensory stimulus is of lowintensity as opposed to cardiac measures, which are more commonly used to investigate highend arousal, such as running (Boucsein, 2012).

\subsubsection{Neural Control of Electrodermal Responses}

Importantly, the EDA response is controlled by the sympathetic portion of the ANS only and thus, is arguably the only psychophysiological variable that is not affected by parasympathetic activity (Sequeira et al., 2009). Therefore, as the EDA changes, we can be 
certain that the observations are due to changes in the activity of the sympathetic nervous system, which is controlled by a complex network involving the hypothalamus and the brain stem. These two regions of the brain are involved in autoregulation of the homeostatic demands placed on the body, to ensure that the bodily arousal level is adequate to meet the behavioural demand. This second-order level of modulation is typically expressed through discrete SCRs (Critchley, 2002). EDA responses are higher when viewing pleasant and unpleasant pictures than when viewing neutral pictures, which suggests EDA responses reflect the level of emotional arousal (Lang et al., 1993). Previous studies, using a variety of stimuli, such as discrete auditory (Bradley and Lang, 2000), visual (Bradley et al., 2001) and olfactory (Bensafi et al., 2002) stimuli have consistently reported EDA responses that are mediated by the sympathetic nervous system. Furthermore, higher-order modulation may also take place in response to cognitive, emotional and anticipatory demands. Several studies have demonstrated that the anticipation of a painful stimulus or cognitive efforts such as serial subtraction of the number seven involves activation of the amygdala, prefrontal cortex and the insula with concomitant specific EDA responses [see for instance review by Critchley (2002)].

\subsubsection{Electrodermal Responses and Affective Touch}

The EDA responses may be viewed as a measure of the arousal and/or motivational part of an emotion (Sequeira et al., 2009) and unravelling the EDA responses to affective touch may help us understand if the perceived pleasantness of different types of touch is substantiated by various levels of arousal. The EDA responses to touch, however, remain largely unexplored, and, at the commencement of this $\mathrm{PhD}$, only a handful of studies had investigated $\mathrm{CT}$ targeted touch and the accompanying EDA responses: In two patients suffering from a rare neuronopathy condition, CT targeted touch elicited distinct SCRs which were equal to those elicited in normal adults (Olausson et al., 2008). Importantly, this rare neuronopathy condition leads to the destruction of $A \beta$ afferents, negating the possibility of $A \beta$ afferents in mediating any observed effects. Therefore, the authors proposed that CT targeted touch was capable of influencing the ANS without concomitant A $\beta$ activity, suggestive of an important role of CT afferents in supporting homeostasis (Olausson et al., 2008). However, just how CT targeted touch influences the ANS remains unclear. Two studies have reported higher SCRs for fast non-CT targeted touch $(30 \mathrm{~cm} / \mathrm{s})$ than those elicited by CT targeted touch $(3 \mathrm{~cm} / \mathrm{s})$, indicating that faster types of touch are more arousing than slow stroking touch (Greco et al., 2016, Pawling et al., 2017b). Moreover, slow stroking touch performed with 
various fabrics leads to greater SCRs than the combined effects of watching and imagining being stroked by the same fabrics, suggesting that touch was indeed more physiologically arousing than visual input (Etzi and Gallace, 2016). In contrast to those studies, various forms of touch were reported to lead to a gradual reduction of tonic SCL, suggestive of a general relaxation effect (Greco et al., 2015). In a recent study, Etzi et al. (2018) investigated whether two types of stroking touch $(30 \mathrm{~cm} / \mathrm{s}$ and $3 \mathrm{~cm} / \mathrm{s}$ ) differed to non-stroking touch (tapping). Although fast touch was reported to yield greater SCRs than slow stroking touch, the overall arousal level did not differ between the two forms of stroking touch. Moreover, both stroking conditions (social) led to greater SCRs and SCL than those demonstrated by the tapping (nonsocial) conditions, and the participants considered slow stroking touch more social than fast touch and tapping (Etzi et al., 2018). However, the conclusions that can be drawn from the study by Etzi et al. (2018) are somewhat limited, as they did not control for differences in skin stimulation time between the various conditions. As EDA responses are controlled by the sympathetic nervous system and thus reflect different levels of arousal, it is of great interest to investigate the EDA responses to tactile (social) and other (non-social) input as they may indicate whether the presumable greater social nature of the touch yields a different EDA response than the non-social control condition. Moreover, comparing CT targeted to control touch may indicate whether the level of arousal is connected to the perceived pleasantness of the touch, or whether other features, such as saliency, are important in defining the arousing nature of touch. Thus, in paper I of this thesis, we compared the effects of CT targeted touch $(3 \mathrm{~cm} / \mathrm{s})$ on SCL to those observed in response to very slow non-CT targeted touch $(0.3 \mathrm{~cm} / \mathrm{s})$ and a non-tactile visual control stimulus. Furthermore, by exposing the participants to repeated stimulation over a fixed time period, we aimed to investigate the effects on the slower responding SCL, whilst still allowing for an equal amount of stimulation time for CT targeted touch, control touch and a visual control stimulus, (see also Fig. 1, Timeline).

\subsection{Heart Rate Variability}

Heart rate variability (HRV) refers to the variation of the heartbeats within a given period of time and is generally assumed to reflect an autonomous level of emotional arousal (Cacioppo et al., 2000). A great deal of the focus and likely reason for the popularity of HRV in psychophysiology research is that a low HRV is associated with illness and potentially a marker for disease and thus has important clinical implications (Nunan et al., 2010). Likewise, a high HRV has been suggested as a strong indicator for better top-down regulatory capacity 
(Holzman and Bridgett, 2017) and overall improved emotional stress regulation capacity (Appelhans and Luecken, 2006, Mather and Thayer, 2018).

Technically, HRV measurements are computations based on variations in the interbeat interval (IBI) of cardiac cycles which are recorded using an electrocardiogram (ECG), see Fig 4 below, (Nunan et al., 2010). The heart beats approximately 100000 times a day and under normal conditions, the sinoatrial node (SA) functions as a pacemaker and initiates each cardiac heartbeat together with the atrioventricular node (AV). Briefly, the action of these specialised cells ultimately leads to a contraction (systole) and relaxation (diastole) of the heart and each letter refers to a particular part of the cardiac cycle, which stretches from one heartbeat to the next. Thus, the "P" refers to the depolarization of the SA node, the "QRS" section refers to the ventricular contraction, of which the "Q" and "S" reflect downward waves and the "R" reflects the upward wave and peak of the contraction and the " $T$ " refers to the ventricular relaxation (Berntson et al., 2017). The heart rate (HR) refers to the number of heartbeats within a given time period, which is usually one minute. At rest, the HR of a healthy adult resides within 60-100 beats per minute (BPM) and acting through the vagal nerves, the parasympathetic nervous system can slow the HR, exerting their effects within less than $1 \mathrm{sec}$, as opposed to the sympathetic nerves, which require more than $5 \mathrm{sec}$ to initiate an increase in HR (Berntson et al., 2017). At rest, the HR is controlled largely by a relative activation of the parasympathetic and sympathetic branches of the autonomic nervous system. However, an important aspect of the HR is that contrary to what was common knowledge for years, even under "steady-state" conditions, the HR is highly irregular when observed on a beat-by-beat basis (Shaffer et al., 2014). This irregularity is commonly investigated by computing the millisecond (ms) variations in successive peaks of ventricular contractions (the R-R intervals, see Fig 4), and may be evident as changes in HRV (Nunan et al., 2010). Importantly, these variations probably reflect homeostatic adaptations of several interdependent physiological systems, such as autonomic nervous system dynamics and heartbrain interactions (Thayer and Lane, 2000, Mather and Thayer, 2018). Moreover, these fluctuations may ultimately be linked to someone's cognitive capacity to enhance or decrease the intensity of an emotional experience (Holzman and Bridgett, 2017), of which being stroked is one of many possible emotional experiences. However, contrary to other sensory experiences, touch requires close and reciprocal proximity between sender and receiver as opposed to, for instance, visual and auditory input, which may be passively perceived from a distance. Thus, by furthering our understanding of the HRV responses to touch, we may better 
understand the complexity behind highly emotional interactions, such as hugging. Importantly, this complexity may reflect a degree of reciprocal communication between the heart and emotion regulation areas of the brain (Mather and Thayer, 2018), which will be elaborated upon next.

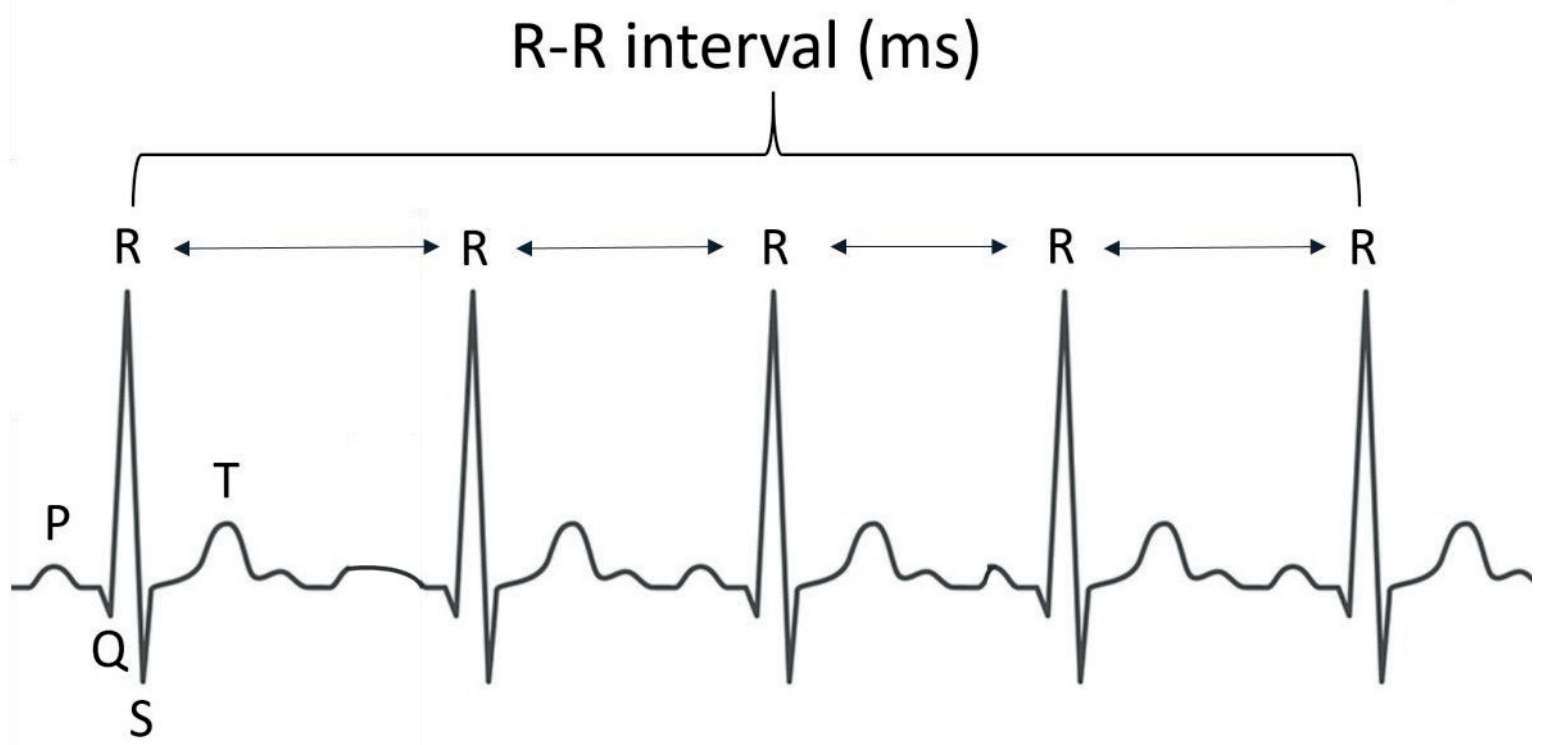

Fig. 4. Interbeat intervals (IBI) between successive intervals of repeated cardiac cycles expressed in milliseconds, here indicated using the peak of the ventricular contraction, the R$\mathrm{R}$ interval. Letters denote varies aspects of the cardiac cycle, from the depolarization of the SA node ("P”), ventricular contraction (“QRS") and ventricular relaxation (T"). Figure exported and adapted from a BioPac recording using the AcqKnowledge software (version 4.4, BioPac Systems Inc, Ca, USA).

\subsubsection{Neural Control of Heart Rate Variability}

The incessant beating by the heart is influenced and modulated by local regulatory mechanisms at the heart itself; at the dorsal root ganglion of the spinal nerves and in specialised areas of the brainstem (for instance, the brainstem regulation of the baroreceptor reflex) and cortical areas (Shaffer et al., 2014). This thesis will focus primarily on the cortical involvement in HRV measurements. One of the most prominent theories of HRV regulation is referred to as the "Neurovisceral Integration" model (Thayer and Lane, 2000). In their most recent model, the authors propose eight levels in a hierarchical model, from the basic intrinsic cardiac ganglia (level 1) to the executive control networks of the prefrontal cortices (level 8) (Smith et al., 2017). As is the case also for the Polyvagal Theory (Porges, 1995), the afferent 
and efferent effects and capabilities of the vagal nerves are fundamental to the models, allowing the nervous system to adapt to the ever-changing physical, emotional and cognitive loads placed upon the organism. As such, HRV may indicate the extent to which the physiological capability of the heart can meet the environmental and cognitive demands placed upon an individual (Appelhans and Luecken, 2006).

\subsubsection{Heart Rate Variability and Affective Touch}

There is, however, a great deal of uncertainty regarding the HRV responses to affective touch. In one study investigating pleasantness ratings and HRV responses to repeated slow CT targeted touch, participants demonstrated an increase in HRV at the later stages of the experiment. The authors suggested that CT targeted touch influenced the ANS activity, despite a reduction in the perceived pleasantness of the touch (Triscoli et al., 2017b). Evidence from a clinical study on therapeutic massage, however, did not report an increase in HRV in response to touch (Lindgren et al., 2013). In a very recent paper by Novembre et al. (2020), the HRV increased in response to slow stroking touch when the touch was paired to images of attractive faces. These findings suggest that touch may influence HRV, however, there is still a great deal of uncertainty. In paper III of this thesis, we investigated the HRV responses to slow stroking touch with the aim of demonstrating consistent responses across two separate sessions. A better understanding of how affective touch influences HRV responses may help shed light on some of the mechanisms behind the emotional and arousing aspects observed in normal tactile interactions, such as hugging, play and stroking.

\subsection{Prosocial Behaviour}

Activities and behaviours that are initiated and performed to the benefit of others are referred to as prosocial behaviours (Morrison, 2016b) and will quite commonly involve some kind of social interaction through touch. Touch, social play and grooming take place throughout the animal kingdom and these types of tactile behaviours are important for initiating and maintaining social affiliation and attachment in primates (Dunbar, 2010, Frank and Silk, 2009) and humans (Gulledge et al., 2003, Debrot et al., 2013). In humans, at least, it is likely that these forms of affective touch will activate CT fibres and CT activated neural pathways and contribute to prosocial behaviours such as allogrooming and consolation (Morrison, 2016b). For instance, mothers spontaneously stroke their children with speeds that have been reported to activate CT fibres maximally (Croy et al., 2016b).

Certainly, early field studies and observations of social behaviour in humans suggest that touch may significantly affect prosocial behaviour. A first study was provided by Fisher 
et al. (1976) who instructed library clerks to either touch the students' hand when returning the library card or avoid touching the students' hand as the library card was returned.

Afterwards, the students were approached by an experimenter, asking the students to rate the library services and personnel. The customers who had briefly been touched by the library clerk were more inclined to rate the personnel more favourably than those who were not touched, and indeed even reported feelings of a more positive affect than those who were not touched. In a similar study, it was reported that restaurant customer that received a brief touch on the hand or shoulder from the waiter gave larger tips than customers who had not been touched by the waiter (Crusco and Wetzel, 1984, Stephen and Zweigenhaft, 1986). Furthermore, other field studies reported that supermarket shoppers were more inclined to participate in interviews following touch (Hornik and Ellis, 1988) and strangers were more likely to assist in looking after a large and excited dog whilst the owner of the dog attended to a brief errand (Guéguen and Fischer-lokou, 2003). Thus, despite that these field studies have investigated a multitude of different forms of prosocial behaviour, they all seem to report that touch may lead to prosocial behaviour, often referred to as the "Midas touch" effect (Fisher et al., 1976, Gallace and Spence, 2010, Schirmer et al., 2016). Indeed, although some of the field studies suggested men responded less favourably to social touch than women [see for instance Fisher et al. (1976)], to the best of my knowledge, there appear to be no studies demonstrating a negative effect of touch on prosocial behaviour. The prosocial effects of being touched appear to be partially mediated by sub-conscious mechanisms, as the helping behaviour was maintained irrespective of whether the touched person was aware of the touch or not (Guéguen, 2002) and the inclination to rate library clerks more favourably after being touched occurred irrespective of whether the touch was consciously perceived or not (Fisher et al., 1976). However, as is the case with most field studies, it is difficult to conclude on the involved mechanisms, as the touch may only be effective when combined with the effects of other information, such as the voice of the toucher or eye contact between the toucher and touch-receiver (Gallace and Spence, 2010). Consequently, the mechanisms leading to prosocial behaviour as of today are still elusive. It has been suggested that oxytocin (Feldman, 2012) and opioids (Case et al., 2016) affect social touch perception and valuation, however, evidence from laboratory studies supporting opioids as mediators of prosocial behaviour in humans is still unconvincing (Løseth et al., 2019). 


\subsubsection{Laboratory Studies on Touch and Prosocial Behaviour}

A better understanding of the tactile-induced mechanisms that motivate and drive social communication and social behaviour is of great importance to understand the normal mechanisms that enable such behaviours. More importantly, it may help us understand the mechanisms when these tactile interactions are changed or maladaptive, such that occurs in people with Autism Spectre Disorder [see for instance Cascio et al. (2012)] or Post Traumatic Stress Disorder (Strauss et al., 2019). Experimental laboratory studies investigating the effects of touch on prosocial behaviours in humans, however, are scarce. Using a virtual reality paradigm, Harjunen et al. (2018) demonstrated that people were more inclined to accept an unfair offer if the offer was preceded by a virtual touch or a smile (by the aviator). Touch has also been found to modulate social impressions (Ellingsen et al., 2014). After the participants were given intranasal oxytocin, human touch had a greater effect on the social evaluation of others than touch provided by a machine. Specifically, smiling faces were perceived as more attractive and friendly and frowning expressions were perceived as less attractive (Ellingsen et al., 2014). Recently, it was demonstrated that the pleasantness of stroking touch was enhanced when the person receiving the touch imagined being stroked by someone attractive and the authors speculated as to whether the effects were driven by the social importance of touch (Novembre et al., 2020). However, Koppel et al. (2017) investigated the effects of CT targeted touch on economic decision-making and found no association between the reported pleasantness of the stroking and the amount of money donated to charities, risk-taking, altruism or aversion to betrayal. In fact, the authors did not report any difference in prosocial behaviour following the touch condition compared to the control condition, suggesting instead that the prosocial effects observed in field studies were driven primarily by contextual and social, rather than tactile mechanisms. Nevertheless, the combined evidence from field studies and the few available experimental studies suggest that touch has the potential to enhance various forms of prosocial behaviour, although the exact mechanisms are as of today, not firmly established. We aimed to investigate whether the prosocial effects of touch reported in field studies could be demonstrated in a laboratory setting, which served as the primary aim of paper II.

\subsection{Response Coherence in Subjective and Physiological Responses}

We know a great deal about affective touch, CT fibres and their functioning and we know a lot of how humans respond to touch, and how these responses can be measured to inform us of behaviours that stem directly, or indirectly, from the activation of touch 
pathways and tactile afferents. These findings nevertheless lead to an important question: To what extent do explicit subjective reports cohere with physiological responses in affective touch? Coherence refers to the extent to which we express affect and emotions similarly through subjective and physiological means (Mauss and Robinson, 2009). After all, subjective reports are constructed and consciously perceived concepts, normally provided after a stimulus has been processed and therefore, may not fully capture all aspects of an experience [see for instance Zajonc (2000), Winkielman and Berridge (2004), Öhman and Soares (1998)]. Physiological responses, however, offer continuous monitoring of small or large reactions that help shape an experience (Cowen and Keltner, 2017). Occasionally, these physiological reactions are obvious, like the pounding heart and sweaty palms during a panic attack. However, physiological reactions may occur irrespective of someone's consciousness. For instance, exposure to happy or sad faces influenced people's perception of their own mood and emotional status even if they were not consciously aware of the exposure (Winkielman and Berridge, 2004). Other times, the subjective and physiological reactions appear conflicting: The pounding heart and sweaty palms in the previous example could equally well happen whilst exercising, and therefore do not represent an emotional status or percept at all. Thus, there is considerable debate within the scientific field of emotions and affect regarding the extent to which subjective and physiological responses cohere in their expressive forms [see for instance Levenson et al. (2017), Mendes (2016), Cacioppo et al. (2000)]. Nevertheless, a combination of subjective and physiological responses may assist in furthering our understanding of affective responses (Strack and Deutsch, 2004), and a better understanding of the coherence between the subjective and physiological responses to affective touch appears particularly important in situations where speech is hampered or limited, such as in infants. In paper III, we aimed to investigate the coherence between the subjective and physiological responses in the field of affective touch and touch satiety at two separate sessions, which served as one of the overall aims of the current thesis. 


\section{Aims and Objectives}

\subsection{Overall Aims}

a. To explore and investigate the psychophysiological and behavioural responses to affective touch (Paper I-IV).

b. To investigate how people's perception of affective touch changes with repeated stimulation and investigate the stability and coherence of subjective and physiological responses to slow stroking touch (Paper I and III).

c. Propose novel and reliable means of investigating facial EMG responses to slow stroking touch (Paper I-IV).

\subsection{Objectives}

\section{Paper I:}

a. We aimed to replicate previous findings that relate to CT targeted touch and subjective ratings and extend these findings by comparing subjective reports of pleasantness and intensity to CT targeted touch $(3 \mathrm{~cm} / \mathrm{s})$ and very slow non-CT targeted touch $(0.3 \mathrm{~cm} / \mathrm{s})$ applied to hairy skin, to those obtained by a non-tactile visual control condition.

b. We hypothesised that subjective explicit ratings of pleasantness and intensity would cohere with implicit physiological measures of affect and arousal. Specifically related to facial electromyography responses, we expected the corrugator activity to decrease (indicating less negative affect towards the touch) and zygomaticus activity to increase (indicating positive affect towards the touch) during CT targeted touch, compared to the control touch and visual control condition.

c. Based on the reported difference in conduction velocity between $A \beta$-afferent and $\mathrm{CT}$ afferent fibres, we expected the facial EMG responses in the corrugator and zygomaticus muscle to be enhanced after $700 \mathrm{~ms}$ of touch, reflecting the arrival of the $\mathrm{CT}$ afferent input. 
d. Changes in skin conductance level reflect a change in arousal and thus, we expected a greater change in SCL to CT targeted touch, compared to the control touch and visual control condition.

\section{$\underline{\text { Paper II: }}$}

a. We hypothesised that CT-targeted touch would lead to greater prosocial behaviour than very slow non-CT targeted touch and visual stimulation when measured in a laboratory setting.

\section{Paper III:}

a. We hypothesised that subjective pleasantness ratings to slow stroking touch would drop with repeated stimulation and that the drop in subjective pleasantness ratings would be accompanied by specific physiological changes. Specifically, we expected the corrugator activity to gradually increase (suggestive of increased negative affect towards the touch) and the zygomaticus activity to gradually decrease (suggestive of decreased positive affect towards the touch).

b. We expected the heart rate variability to increase, reflecting a positive response to the slow stroking touch as examined during two sessions.

c. We expected the subjective and physiological responses to slow stroking touch to be consistent and coherent when examined during two sessions.

\section{Paper IV*:}

a. We aimed to describe a protocol for collecting and handling facial EMG data to touch responses and suggest appropriate means for assessing facial EMG data.

*Paper IV is a methodological video paper describing a protocol for collecting and analysing facial EMG data and is based on the data presented in full in paper I and in a publication by Mayo et al. (2018). The specific objectives for this paper are thus similar to those described for paper I. 


\section{Methods}

For a complete description of the methods that were used in the various papers, I encourage the interested reader to consult the original papers. The following section will provide an overview of the studies that are included in the thesis, whereas specific methodological considerations will be scrutinised in detail in the "Methodological Considerations" section.

\subsection{Study Designs}

All papers in the thesis had a within-subjects design. For the calculation of the sample size in paper I and paper III, the estimated a priori sample size was calculated with PANGEA [Power Analysis for General Anova Designs] (Westfall, 2016). To ensure a statistical power of 0.8 and a medium effect size of $d=0.45$, forty-five participants were considered sufficient in both papers. Whereas forty-five participants were recruited for study 1 , forty-eight participants were recruited in study 2 , to account for potential dropouts between session 1 and session 2. Paper I and II had 1 factor (sensory stimulus) and 3 levels (CT targeted touch, control touch and visual control condition). Paper III had 2 levels (session 1, session 2) and consisted of 60 single trials of slow stroking touch $(3 \mathrm{~cm} / \mathrm{s})$, see Fig 5 below for overview.

\begin{tabular}{|c|c|c|}
\hline \multicolumn{2}{|l|}{ Study 1} & $\begin{array}{l}\text { Paper I, II and IV: Total } N=44 \\
\text { Women: } \quad(N=27) \text { Age: } 24.3 \pm 6.3 \\
\text { Men: } \quad(N=17) \text { Age: } 25.9 \pm 4.9\end{array}$ \\
\hline $\begin{array}{l}\text { Paper I, II and IV* } \\
\text { Recruited, } \mathrm{N}=45 \\
\text { Data collected in } \\
\text { Oslo, Norway }\end{array}$ & $\begin{array}{l}1 \text { participant } \\
\text { excluded due to } \\
\text { acute bout of } \\
\text { Arthritis }\end{array}$ & $\begin{array}{l}\text { Data analyses ( } \mathrm{N} \text { following excluded participant due to } \\
\text { artifacts/techical issues etc indicated in [] ): } \\
\text { Subjective ratings (visual analogue scale): [ } \mathrm{N}=44 \text { ] } \\
\text { Facial Electromyography: } \\
\text { [Corrugator } \mathrm{N}=40 \text {, Zygomaticus } \mathrm{N}=42 \text { ] } \\
\text { Skin Conductance Level: [ } \mathrm{N}=41]\end{array}$ \\
\hline \multicolumn{2}{|l|}{ Study 2} & $\begin{array}{l}\text { Paper III: } \\
\text { Total } N=48 \\
\text { Women: } \quad(N=23) \text { Age: } 25.6 \pm 3.3 \\
\text { Men: } \quad(N=25) \text { Age: } 27.8 \pm 4.3\end{array}$ \\
\hline $\begin{array}{l}\text { Paper III } \\
\text { Recruited, } \mathrm{N}=48 \\
\text { Data collected in } \\
\text { Dresden, Germany }\end{array}$ & $\begin{array}{l}1 \text { participant } \\
\text { excluded from } \\
\text { session } 2 \text { due to } \\
\text { illness }\end{array}$ & $\begin{array}{l}\text { Data analyses ( } \mathrm{N} \text { following excluded participant due to } \\
\text { artifacts/techical issues etc indicated in [] ): } \\
\text { Subjective ratings (visual analogue scale): } \\
\text { [Session } 1: \mathrm{N}=48 \text {; Session } 2 \mathrm{~N}=47 \text { ] } \\
\text { Facial Electromyography: } \\
\text { [Session } 1 \mathrm{~N}=48 \text {; Session } 2: \mathrm{N}=42 \text { ] } \\
\text { Heart rate variability: [Session } 1: \mathrm{N}=43 \text {; Session } 2: \mathrm{N}=44 \text { ] }\end{array}$ \\
\hline
\end{tabular}

Fig. 5. Overview of the data collection and data analyses for study 1 (paper I and II) and study 2 (paper III). 


\subsection{Procedures}

All subjective reports were administered digitally using an electronic version of the visual analogue scale (VAS) and presented using E-Prime 2.0 (Psychology Software Tools, Pittsburgh, PA, USA). Physiological data were collected with the BioPac MP150 Nomadix wireless system (BioPac Systems Inc, Ca, USA) and recorded using the AcqKnowledge software (version 4.4, BioPac Systems Inc, Ca, USA).

\subsubsection{Sensory Stimuli}

In the papers of the thesis, we opted for a CT-targeted touch with a velocity of 3 $\mathrm{cm} / \mathrm{sec}$ that was delivered to $10 \mathrm{~cm}$ on the left forearm (see Fig 6, top). Thus, one touch took 3.3 seconds to complete (see "Timeline" for overview). In paper I and II, the participants were repeatedly touched for two minutes with a brush and then the participants rated the perceived pleasantness and intensity of the touch. This type of touch was then compared to very slow, almost static touch for two minutes $(0.3 \mathrm{~cm} / \mathrm{s})$. Additionally, the participants rated the pleasantness of watching moving objects of geometrically shaped figures on a computer screen for two minutes (see Fig 6, bottom). The screen displayed objects that were moving at a slow, comfortable speed and varied between a colourful veil moving from left-to-right, slowly drifting circles and eruption of colours that were gradually expanding from the centre of the screen. The visual condition consisted of commercially available videos (Shutterstock Inc; New York, USA) and was edited so that the different movies changed seamlessly. The colourful veil started and ended the two-minute trial as it was deemed to most closely resemble the velocity of a brushstroke. (For some example excerpts, please see: $\underline{\text { Spectrum }}$ Wave, Spectrum Curtain, Rainbow Explosion).

In paper III, the participants rated the pleasantness after every single touch trial, which was delivered using the experimenter's palm. In total, the participants rated 60 single trials of slow stroking touch and then attended a second session a few days later and rated another 60 single trials of slow stroking touch. In both studies, the participants were facing the computer and the left arm was concealed using a custom-made hat (study 1) or a curtain (study 2), see Fig 6 below. The left arm was resting on a pillow throughout the experiments. In both studies, ratings of pleasantness were given on a computerised visual analogue scale (VAS) with the question: "How did you experience the stimulus?" which the anchors on either side of the scale "unpleasant" (scored as -10$)$ and "pleasant" $(+10)$. In study 1 , the pleasantness ratings were followed by a question that related to the perceived intensity of the stimulus. Specifically, we asked the question: "How intensive did you experience the stimulus?" which 
was anchored by "weak" $(-10)$ and "strong" $(+10)$. Whereas the first study (paper I and II) was designed to investigate and compare different types of stimuli (touch and visual stimuli), the second study (paper III) was designed to investigate how people's perception of a slow touch changes with repetition and also the stability and coherence of subjective and physiological responses to slow stroking touch $(3 \mathrm{~cm} / \mathrm{sec})$.
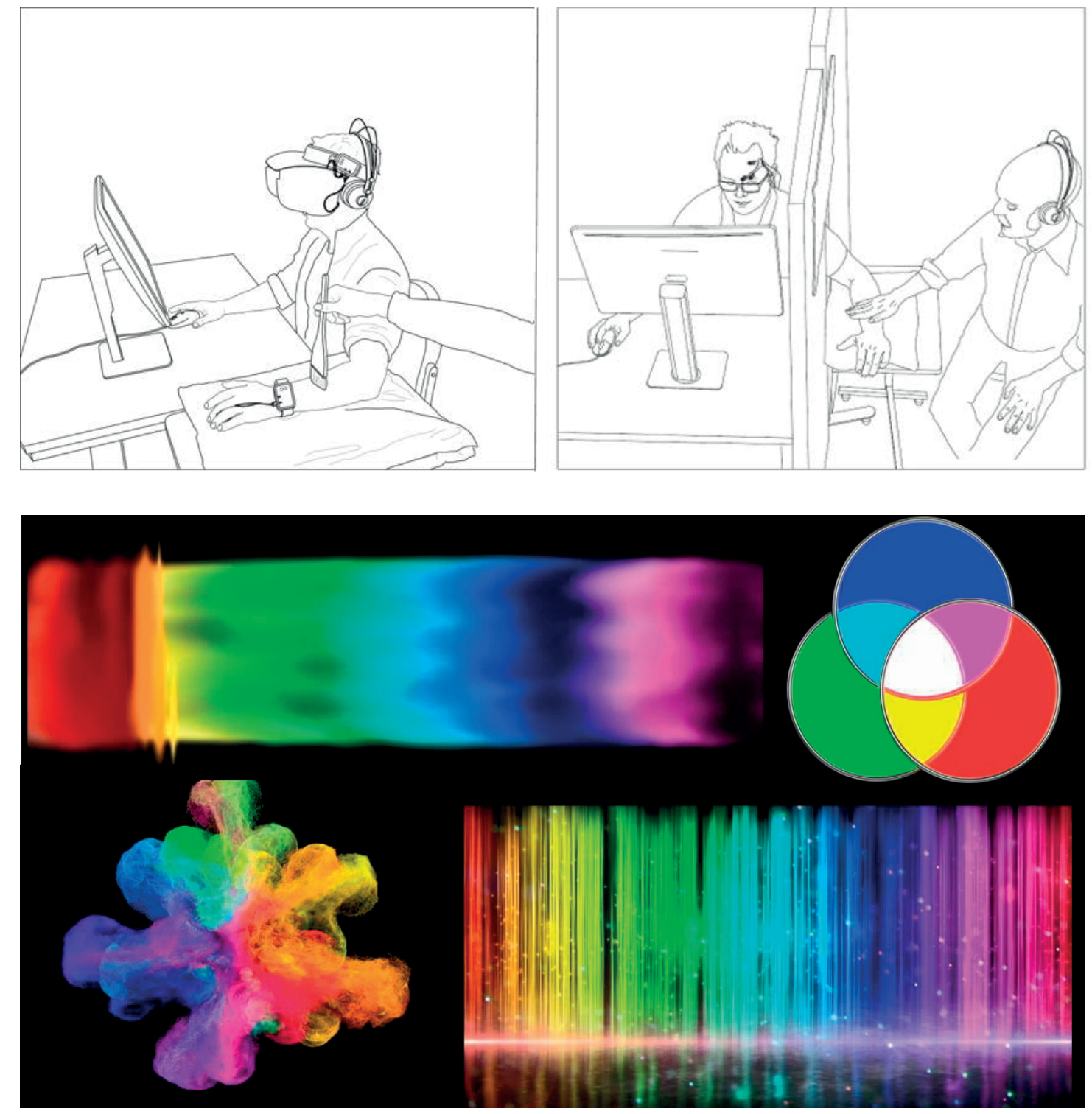

Fig. 6, top. Slow stroking touch delivered to the forearm using a brush (left) and skinto-skin touch (right). [Original figures published in Ree et al. (2019), left; and Ree et al. (2020), right, and reproduced under the Guidelines identified by STM (International Association of Scientific, Technical \& Medical Publishers]. Fig. 6, bottom. Screenshot of still images of excerpts from the visual condition (Shutterstock Inc; New York, USA). 


\subsubsection{Facial EMG}

In paper I and III, the procedures and data handling were similar and are reported in full in the papers. The placement of the electrodes was according to guidelines (Tassinary et al., 2017). The raw EMG data were filtered as recommended by Mayo et al. (2018). The facial EMG signals were amplified 5000x, before the data were filtered using a 10-500 $\mathrm{Hz}$ band pass filter, and digitized at $1000 \mathrm{~Hz}$. Then, in a subsequent step, a $50 \mathrm{~Hz}$ comb band stop filter was applied to the data to remove power line interference and finally, a $50 \mathrm{~Hz}$ FIR high pass filter was applied to remove potential electrocardiogram artefacts (Mayo et al., 2018, Zhou et al., 2007). Lastly, the processed EMG signals were rectified and integrated over $20 \mathrm{~ms}$ before they were used in the analyses. The actual activity was baseline corrected by subtracting the 1 sec preceding the start of every sensory stimulus. In paper I, we examined the initial $6300 \mathrm{~ms}$ of touch and also two-minutes of repeated touch. In paper III, we examined 60 single-trials of CT targeted touch, each lasting 3.3 seconds. Paper IV included the facial EMG from the initial $6300 \mathrm{~ms}$ of the touch conditions only.

\subsubsection{Skin Conductance Level}

The EDA data were handled according to guidelines by Braithwaite et al. (2013) and Dawson et al. (2007). First, we computed the SCL for each participant and each condition over the two-minute period. Then, using a threshold of $0.01 \mu \mathrm{S}$, we identified the SCRs from the initial $8 \mathrm{sec}$ of the start of each condition, to ensure that the SCL was not artificially elevated due to attending to salient stimuli (Bradley et al., 2001). Moreover, we identified the SCRs from five other specifically selected periods of eight seconds. These periods coincided with changes in the visual control condition, i.e. when the moving geometrical objects changed from one pattern or shape to another. The mean SCRs value from these six periods were subtracted from the SCL. Moreover, the mean SCL was baseline corrected by subtracting the mean SCL during baseline (two minutes of pink noise), also as recommended by Braithwaite et al. (2013).

\subsubsection{Heart Rate Variability}

In paper III, we collected the ECG data according to guidelines described by BioPac (AcqKnowledge, 4.4). Specifically, Ag/AgCl surface click electrodes (BioPac Inc, EL 503) were placed inferior to the right and left clavicle and left eighth rib. After checking the quality of the signal, the participant was instructed to look at the computer screen and breathe normally. Then, a 3-minute baseline was collected before the start of the actual experiment. After the data collection, we identified the peak-to-peak R-R intervals using the BioPac event- 
related analysis routine. On a participant-by-participant basis, we inspected every data file visually, to correct for missing heartbeats or multiple peak identifications. The raw ECG file served as a cross-reference and, in the case of artefacts, multiple peaks or missing beats, the R-peak was manually inserted into the correct position, as recommended by the Task Force Guidelines of the European Society of Cardiology and the North American Society of Pacing and Electrophysiology (1996) [from now abbreviated as the Task Force Guidelines]. Afterwards, the R-R intervals were converted to a tachogram and exported to Kubios Standard 3.1.0 [Kubios Oy, Kuopio, Finland; Tarvainen et al. (2014)]. According to recommendations by the Task Force Guidelines (1996), we investigated the root mean square of successive R-R interval differences (RMSSD), which is a HRV measurement in the timedomain recommended for short time periods (Task Force Guidelines, 1996).

\subsubsection{Prosocial Behaviour}

Specifically for paper II, the participants played a computerised version of the "Social Value Orientation" task [SVO-slider, (Murphy et al., 2011)]. The SVO-slider measures the degree of prosocial behaviour, specifically, by encouraging the participants to share a set of money between themselves and another (denoted "self" and "other" in the game, see Fig 7 below, or "Timeline"). In paper II, every participant played three games in total and each game consisted of six monetary allocations. Subsequently, the participant's score is transformed into an angle and the behaviour is categorised into either "altruistic" ( $>57.15$ deg), "individualistic" (between -12.04 - 22.45 deg), "prosocial” (between 22.45-57.15 deg) or "competitive (<-12.04 deg)". The SVO-angle corresponds "to the quantity of how much a decision maker is willing to sacrifice in order to make another decision maker better off (or perhaps worse off)" [Murphy et al. (2011); p.772]. It was important that the participants perceived the economic game to have real consequences to ensure full commitment to the distribution of money between themselves and the other. We therefore instructed the participants that how they chose to allocate the money would influence both their own and a future participant's compensation for participating in the study. During the debriefing however, the participants were informed of this deception and they received a gift voucher with a value of $200 \mathrm{NOK}$ ( 20 EUR). 

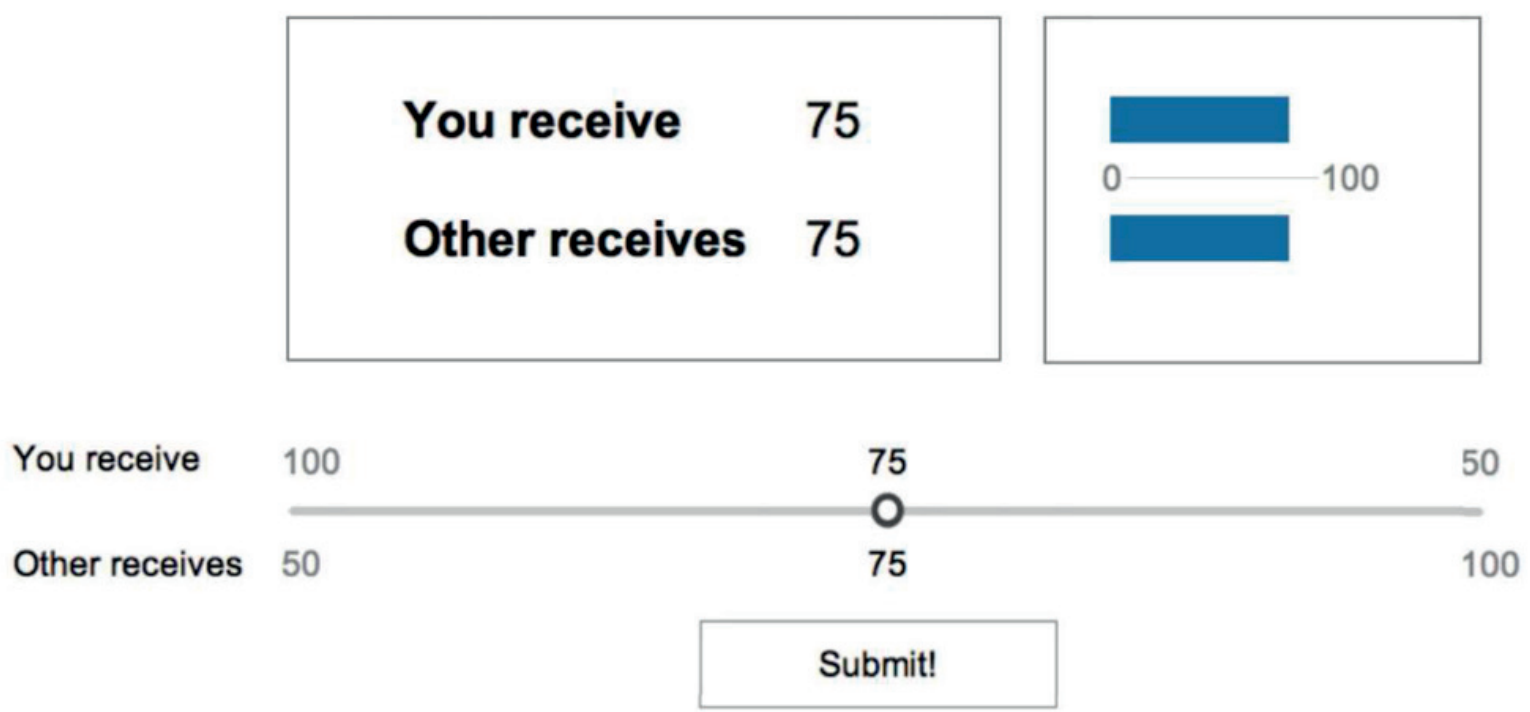

Fig. 7. The online version of the SVO-slider provides a visual demonstration (blue bars) and a numerical overview (numbers) of the amount of money allocated between self and other and the changes as the participants slide the button left or right. Figure is reproduced from Murphy et al. (2011) under the Creative Commons Attribution 3.0 License.

\subsection{Statistical Analyses}

In paper I the statistical analyses were implemented using the Linear Mixed Model (LMM) function of the Generalised Linear Mixed Model Module in SPSS version 24.0 (IBM Corp., NY, USA). In paper III the statistical analyses were implemented using the LMM function in the Mixed Model Module in SPSS version 25.0 (IBM Corp., NY, USA). LMM offers several advantages to traditional repeated measures ANOVA that were considered important in the papers in the thesis: First, LMM is more flexible when modelling time effects (Gueorguieva and Krystal, 2004, Barr et al., 2013), which was considered particularly important, as we were interested in how the participants rated various types of touch over time. LMM offers the ability to test various types of covariance structures and select the one covariance structure that is most appropriate to the a priori hypotheses. Furthermore, LMMs that incorporate random intercept and random slopes in the statistical model, demonstrate greater statistical accuracy than traditional ANOVA as random intercept and random slope models estimate individual rating behaviour more accurately (Gueorguieva and Krystal, 2004, Barr et al., 2013, West et al., 2014). These aspects were considered highly relevant in our papers, given the repeated nature of the stimuli in our studies. Lastly, LMMs deal with missing data better than traditional ANOVA (Gueorguieva and Krystal, 2004). This was considered particularly important in paper III, as we considered the possibility that some of 
the participants would not attend both sessions. Additionally, EMG is an inherently noisy signal and therefore, we considered it likely that some of the data would be missing due to artefacts.

In general, we aimed for a parsimonious model, as suggested by Bolker et al. (2009). Specifically, in paper I, "sensory stimulus" served as fixed factor (CT targeted, control touch, visual) and pleasantness and intensity ratings, SCL and facial EMG served as dependant variables. "Sensory stimulus" was treated as a nominal category variable and the dependent variables were treated as continuous category variables. In addition, a separate analysis of facial EMG was carried out that investigated the initial $6300 \mathrm{~ms}$ of activity, with the "sensory stimulus" (CT targeted and control touch) and "intervals" (1-9) as fixed factors. In this analysis, sensory stimulus and intervals were treated as nominal category variables, and interactions were followed up with Bonferroni-corrected pairwise contrasts. In all analyses, three covariance structure types were tested: autoregressive (assumes higher correlation between observations close in time than those further apart), scaled identity (assumes equal variance between the observations) and unstructured (assumes no correlations between observations), (West et al., 2014). Once the final model of fixed and random effects had been determined, the covariance structures were tested for an improvement in Bayesian Information Criteria (BIC). The information criteria provide a means for comparing various models fitted to the same set of observations and selecting the most appropriate model based on "less is more", i.e., a reduction in BIC value suggests a better fit (West et al., 2014). Thus, scaled identify was used as the covariance structure type and an intercept was modelled for subjects and used for all analyses. In paper III, pleasantness ratings, corrugator and zygomaticus activity and RMSSD served as dependant variables and were treated as continuous category variables. In the analyses of pleasantness ratings, corrugator and zygomaticus, "session" (session 1 and session 2) served as fixed factors and "trial" was added as a fixed factor as a continuous covariate. For the RMSSD analysis, "session" and "bins" were included as fixed factors (11 levels: baseline +10 three minutes bins) and the interaction was included to test for differences in session over bins. "Session" was treated as a nominal category variable in all analyses and bins as a nominal category variable in the RMSSD analysis. The covariance structure was tested as in paper I and an unstructured covariance type was selected on the basis of a better BIC in all analyses except for the RMSSD analysis. In that particular analysis, scaled identity was selected to ensure convergence of the model. Random slope (bins) and intercept (subjects) were included for all analyses and were 
modelled for subjects, as in paper I. In Paper II, the statistical analyses were carried out by the first author and will not be discussed further in this thesis. Please refer to the published paper for details. In paper I and III we reported effect sizes as described by Page-Gould (2016). 


\section{Summary of the Papers}

In this section, I will summarise the main findings from papers I, II and III in order to provide answers to the key research questions identified in the aims of the thesis, see p. 37-38. Interested readers are encouraged to consult the original publications for a complete description of the results with accompanying statistical results.

\subsection{Paper 1}

In paper I, we aimed to reproduce previous findings that relate to the pleasantness and intensity of CT targeted touch and compare these to a control touch condition and a nontactile visual control condition. Indeed, we found that CT targeted touch was rated as significantly more pleasant and intense than control touch, however, we extend previous findings by demonstrating that $\mathrm{CT}$ targeted touch was not significantly more pleasant than the visual control condition (see Fig 8 below). Furthermore, CT targeted touch appeared no more intense or arousing than the visual control condition, as neither subjective intensity ratings nor skin conductance level were significantly different (see Fig 9).
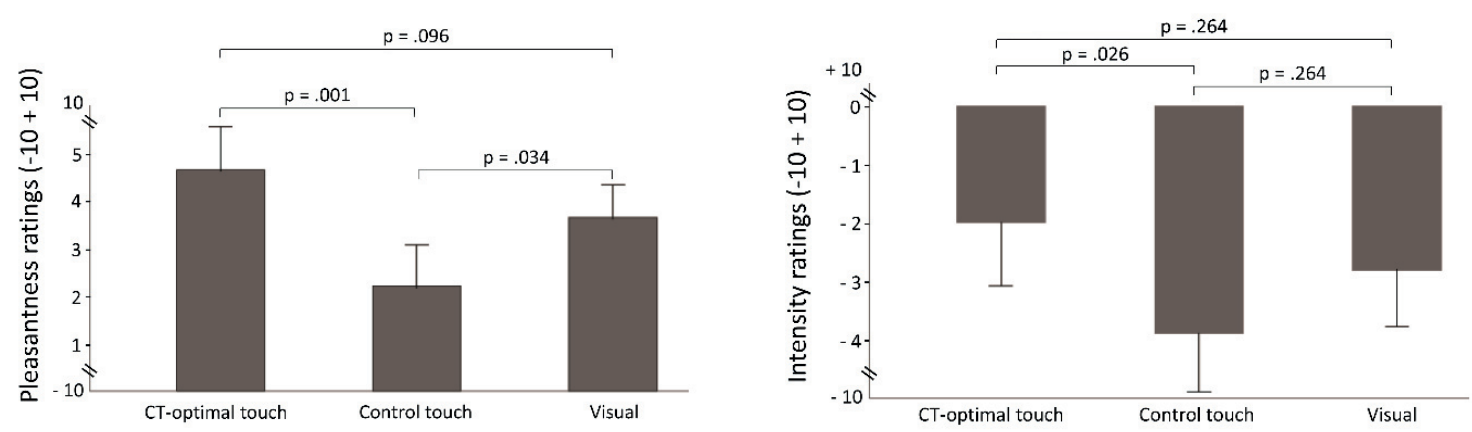

Fig. 8. Mean ratings of pleasantness (left) and intensity (right) with SEM after the participants received continuous touch for two minutes at CT targeted velocity $(3 \mathrm{~cm} / \mathrm{s})$, non-CT targeted control touch $(0.3 \mathrm{~cm} / \mathrm{s})$ and a two-minute visual control condition. Original figures published in Ree et al. (2019) and reproduced under the STM Guidelines.

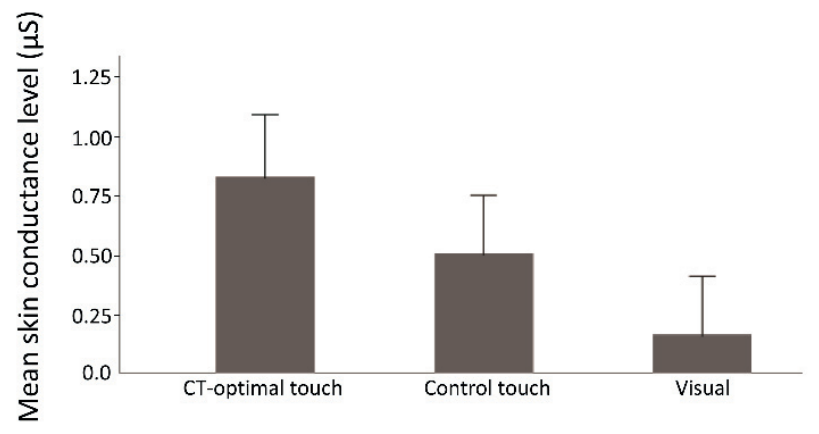


Fig. 9. Skin conductance level during two minutes of CT targeted touch, non-CT targeted control touch and a two minutes visual control condition. There were no significant differences in arousal level, as expressed by the SCL between the three conditions. Original figure published in Ree et al. (2019) and reproduced under the STM Guidelines.

In addition, we hypothesised that the physiological responses of the corrugator and zygomaticus muscles would mirror the explicit subjective reports and we aimed to propose a novel way of analysing facial EMG responses by utilising the rapid temporal resolution of the EMG signal. As CT fibres are unmyelinated, their conduction velocity is slower than the myelinated A $\beta$ fibres. Thus, we proposed to analyse facial EMG data in intervals of $700 \mathrm{~ms}$ (see Fig 10 below). In doing so, we were able to demonstrate that after the touch had been initiated, during the initial $700 \mathrm{~ms}$ of facial EMG activity, there was no difference between CT targeted touch and control touch. However, following the initial $700 \mathrm{~ms}$ of activity (and importantly, the earliest possible arrival of CT afferent input), CT targeted touch led to a gradual reduction of corrugator activity, as opposed to control touch, which was accompanied by a gradual increase in corrugator activity. In paper I, we therefore tentatively proposed that the observed reduction in corrugator activity after the initial $700 \mathrm{~ms}$ of touch reflected the arrival of a volley of CT afferent input. We were, however, unable to demonstrate a similar pattern in the zygomaticus muscle (see Fig 10, right).
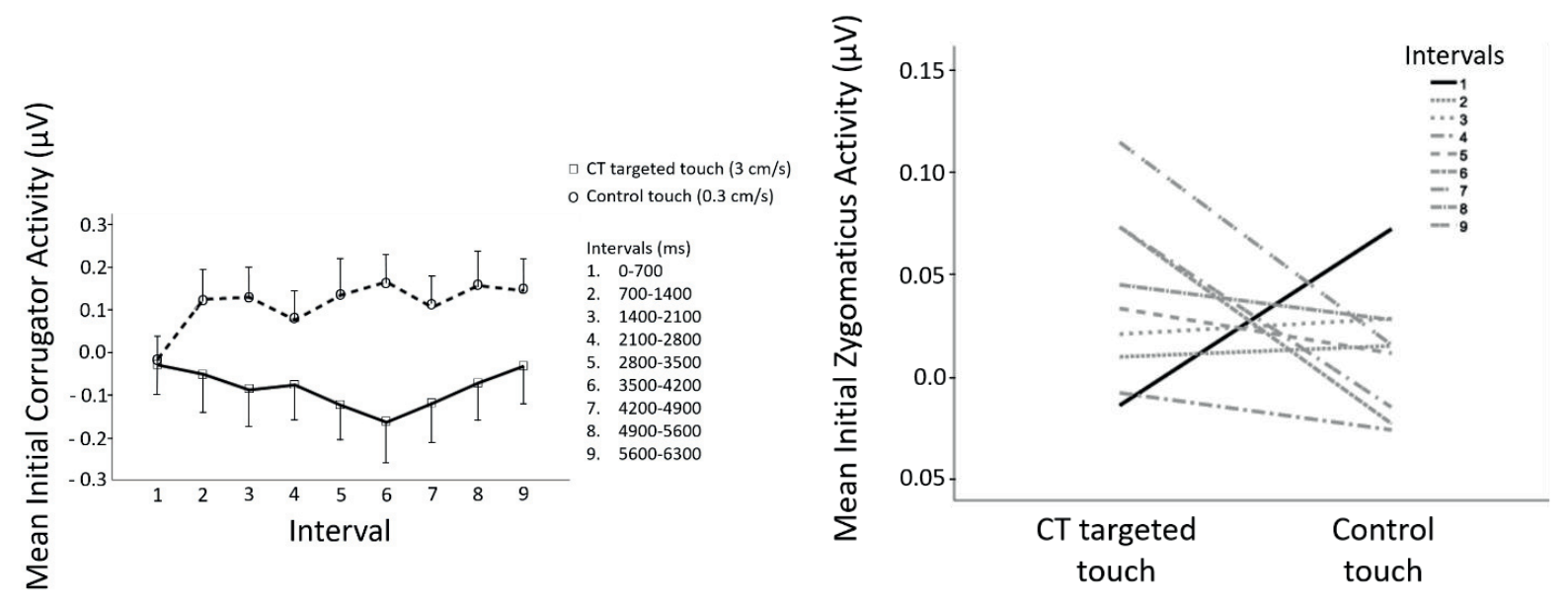

Fig. 10. The temporal response pattern of the corrugator muscle (left) and the zygomaticus muscle (right) in response to CT targeted touch (left; full line) and control touch (left; dotted line). During the initial $700 \mathrm{~ms}$ of touch, there was no difference in corrugator activity. After the initial $700 \mathrm{~ms}$ of activity, however, there was a gradual increase in activity of the corrugator muscle in response to control touch and gradually reduced activity in response to 
CT targeted touch. There appeared to be no consistent response pattern in the zygomaticus muscle (right). Original figures published in Ree et al. (2019), and modified under the STM Guidelines.

The aim of the reanalysis was to investigate whether the significant change in corrugator activation following the tactile stimulations was driven by an increased corrugator activation in response to control touch, or driven by a reduction in corrugator activation in response to $\mathrm{CT}$ targeted touch. This had not been investigated in the original publication. The reanalysis followed the same procedure as that reported in paper I. To reduce the number of levels in the statistical model, intervals 2-9 (between 700-6300 ms) were recoded as one interval and compared to interval 1 (between 0-700 ms). This allowed us to estimate the effects of absent CT fibre input (interval 1) versus the combined $\mathrm{A} \beta$ and $\mathrm{CT}$ fibre input (interval 2) following CT targeted touch and control touch. Specifically, corrugator activation served as the dependent variable, sensory stimulus served as fixed factor, and interval and pleasantness ratings were added as continuous covariates. Scaled identity served as the covariance type, a random slope was modelled over trials and intercept was modelled over subjects. The significant main effect of sensory stimulus was still present as in the original analysis $(\mathrm{F}(1,1310)=5.873, \mathrm{p}=0.02)$, as was the absent main effect of interval $(\mathrm{F}(1,1298)$ $=0.197, \mathrm{p}=0.66)$. Interestingly, in contrast to the original publication which reported a nonsignificant interaction effect when investigating all nine intervals individually $(p=0.23)$, here there was now a significant interaction effect between sensory stimulus and interval (F (1, $1296)=4.794, \mathrm{p}=0.03)$. There was no effect of mean pleasantness ratings $(\mathrm{F}(1,1169)=$ $0.008, p=0.93$ ), suggesting that the interaction effects between sensory stimulus and interval were not driven by the perceived pleasantness of the touch. Resolving the interaction effect by interpreting the change in corrugator activation (slope) from the first and second interval, there was no difference between CT targeted touch and control touch during interval $1(b=-$ $0.02, \mathrm{t}(1300)=-0.16, \mathrm{p}=0.87)$. However, from interval 1 to interval 2 , the corrugator activation in response to CT targeted touch dropped by $0.09 \mu \mathrm{V}(\mathrm{b}=-0.09, \mathrm{t}(1296)=-2.19$, $\mathrm{p}=0.03)$ and the corrugator activation in response to control touch increased by $0.14 \mu \mathrm{V}(\mathrm{b}=$ $0.14, \mathrm{t}(1296)=1.88, \mathrm{p}=0.06)$. Thus, the interaction between the interval and sensory stimulus was driven partly by an increased corrugator activation in response to control touch, and mainly by a reduced corrugator activation in response to CT. 


\subsection{Paper II}

In paper two, we aimed to investigate the extent to which CT targeted touch could influence prosocial behaviour in a laboratory setting. Importantly, these results are drawn from the same experiment as paper I and the pleasantness and intensity ratings are presented in paper I. In addition to the subjective responses, the participants were encouraged to allocate a given amount of money between themselves and a future participant using an online economic game after experiencing two-minutes of $\mathrm{CT}$ targeted touch, control touch and a non-tactile visual control condition. Although CT targeted touch was rated as more pleasant than control touch, we were unable to demonstrate that the experience of CT targeted touch led to a more prosocial or generous behaviour than following the control conditions (see Fig 11). Thus, contrary to our hypothesis, we did not find that CT targeted touch led to an increase in prosocial behaviour when examined in a laboratory setting.

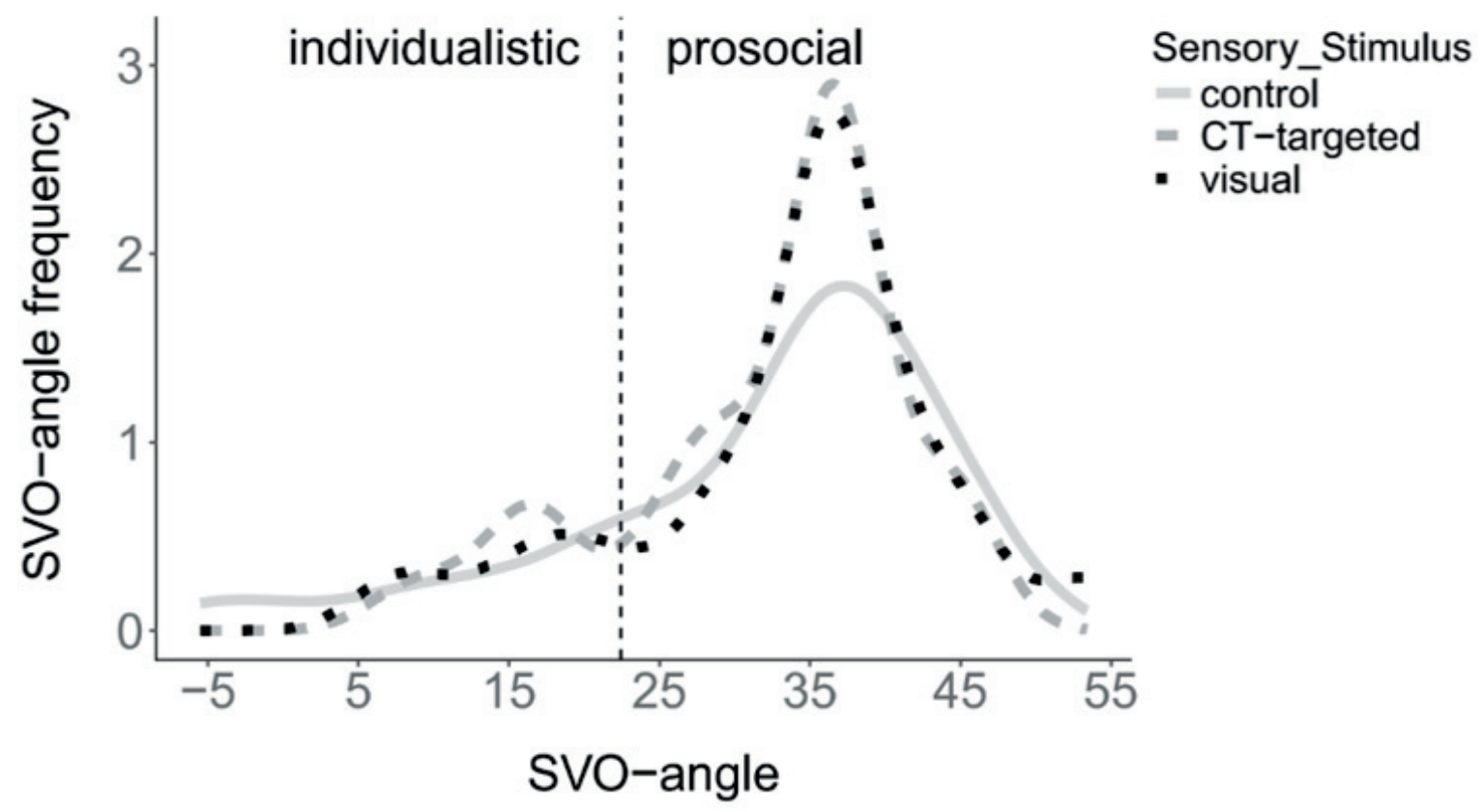

Fig. 11. SVO-angles following two minutes of CT targeted touch (dotted line, light grey), control touch (full line) and visual (dotted line dark grey) stimulation. The behavioural categories are based on the following ranges: "altruistic" (>57.15 deg), "individualistic" (between -12.04-22.45 deg), "prosocial" (between 22.45-57.15 deg), or "competitive" $(<-12.04 \mathrm{deg})$. Figure is adapted from Rosenberger et al. (2018) under the Creative Commons Attribution 3.0 License. 


\subsection{Paper III}

Drawing on the findings in paper I, in paper III, we aimed to investigate more specifically the coherence between subjective and physiological responses to repeated slow stroking touch at two separate sessions using subjective reports, facial EMG responses and changes in heart rate variability (HRV). In this study, we examined CT targeted touch using the same participants at two separate sessions and compared these responses to those obtained when smelling a pleasant odorant. However, while the odour responses are discussed at length in the original paper, I will limit the discussion in the thesis to those responses that are derived from touch. In line with our hypothesis, we found that slow stroking touch repeatedly delivered to the arm was rated as pleasant, but dropped gradually with every trial. This pattern was reproducible at session 2 and suggests that slow stroking touch administered several times leads to slow touch satiety. In session 1, the perceived drop in pleasantness occurred with a concomitant gradual increase in corrugator activity. We believe this indicated a gradual reduction in positive affect towards the slow stroking touch. Importantly, we were not able to demonstrate the same coherent response pattern during session 2, and we were unable to identify coherent response patterns in the zygomaticus muscle and the HRV response in either session (see Fig 12). Thus, while we believe there is support for our hypothesis that relates to the expected drop in pleasantness ratings and slow touch satiety, we believe there is only partial support for our hypothesis that relates to the coherence between subjective and physiological responses to slow stroking touch. Nevertheless, corrugator muscle activation appears to be a promising measure of physiological responses to touch responses and touch satiety.
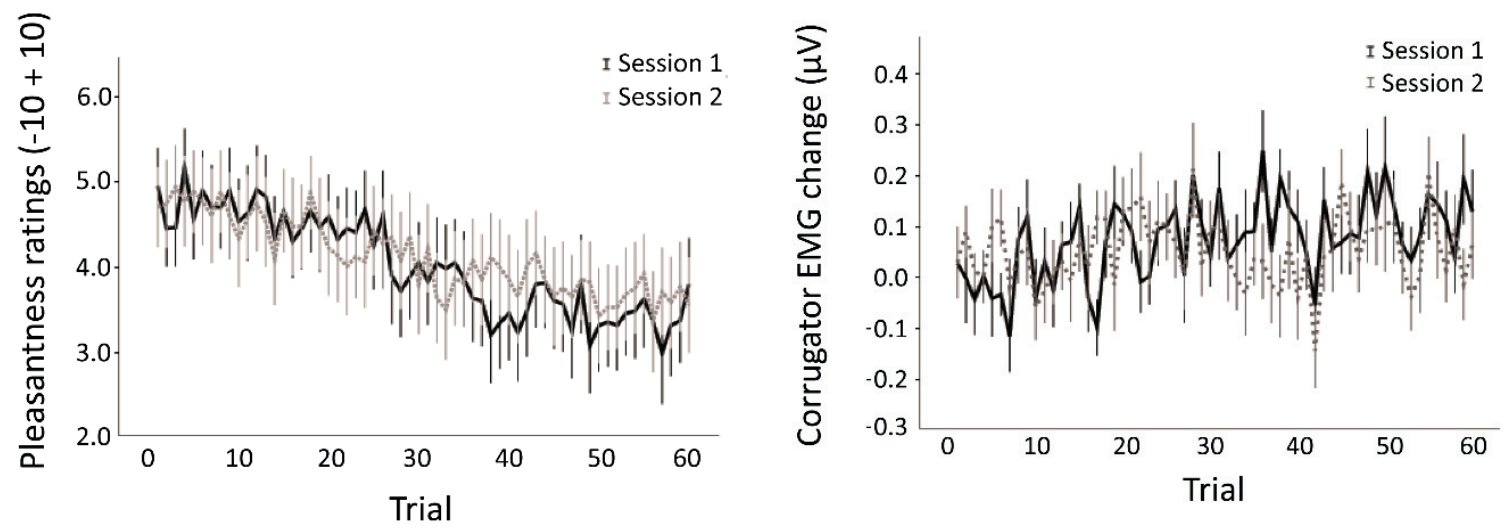

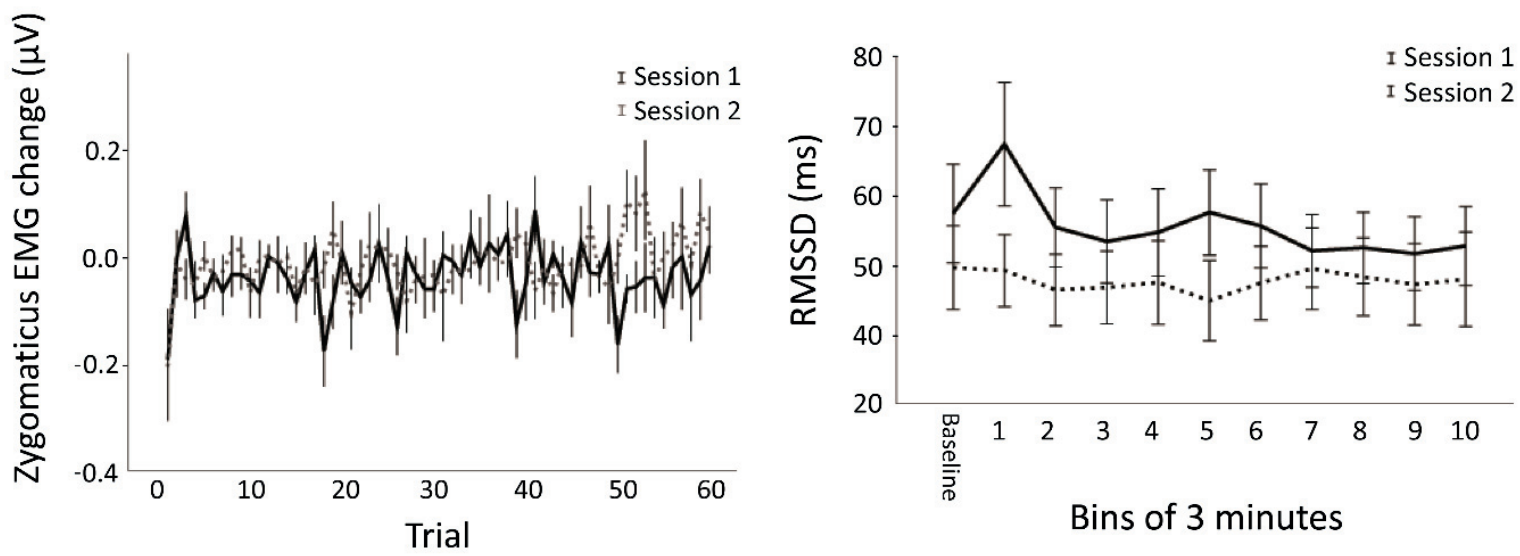

Fig. 12. Subjective and physiological responses to 60 trials of slow stroking touch administered at two separate sessions. Top left: Pleasantness ratings. Top right: Corrugator activity. Bottom left: Zygomaticus activity. Bottom right: The Root Mean Square of the Successive Differences (RMSSD). All responses are expressed as means with SEM. Original figures published in Ree et al. (2020) and reproduced under the STM Guidelines.

Table 1. Linear mixed model with statistical effects. Pleasantness ratings, corrugator and zygomaticus activity served as dependent variables. Legends: VAS; visual analogue scale ($10+10$ ), SE, standard error of the mean, dfd; degrees of freedom denominator, X; interaction between "Session" and "Trial". "Trials Session 1": effect of trials in session 1, "Trials Session 2": effect of trials in session 2. Original table published in Ree et al. (2020) and reproduced under the STM Guidelines. 


\begin{tabular}{|c|c|c|c|c|c|c|}
\hline & & Coefficient & 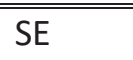 & Dfd & $\mathrm{t}$ & $p$ \\
\hline a & Session X Trial & 0.009 & 0.003 & 5598 & -2.66 & 0.008 \\
\hline Pleasantness & Trials Session 1 & -0.031 & 0.01 & 51 & -3.86 & 0.001 \\
\hline ratings (VAS) & Trials Session 2 & -0.022 & 0.008 & 51 & -2.79 & 0.007 \\
\hline $\mathrm{b}$ & Session X Trial & -0.0023 & 0.001 & 5601 & 3.21 & 0.001 \\
\hline \multirow{2}{*}{$\begin{array}{l}\text { Corrugator } \\
\text { activity }(\mu \mathrm{V})\end{array}$} & Trials Session 1 & 0.0024 & 0.001 & 107 & 3.99 & 0.001 \\
\hline & Trials Session 2 & 0.0001 & 0.001 & 107 & 0.23 & 0.817 \\
\hline c & Session X Trial & 0.0009 & 0.0005 & 5546 & 1.759 & 0.079 \\
\hline Zygomaticus & Trials Session 1 & 0.0004 & 0.0001 & 71 & 0.734 & 0.466 \\
\hline \multicolumn{7}{|l|}{ activity $(\mu \mathrm{V})$} \\
\hline & Trials Session 2 & 0.0013 & 0.0005 & 72 & 2.309 & 0.024 \\
\hline
\end{tabular}

The aim of the reanalysis was to investigate the coherence between subjective ratings (pleasantness ratings) and physiological responses (corrugator activation) at the single-subject level. Coherence in this context refers to the extent to which affect and emotions are expressed similarly through subjective and physiological means. The analysis followed the same procedure as that reported in the thesis and in paper III. Specifically, corrugator activity served as the dependent variable, ratings and trial were treated as continuous variables, and sessions as a nominal variable. Random slope (trial) and intercept (subject) were included for all analyses and an unstructured covariance type was favoured over scaled identity, based on an improvement in BIC value. To examine the effects of subjective ratings on the responses in corrugator activity, corrugator served as the dependent variable, session was added as fixed 
factor and trial and ratings were added to the model as fixed factors as continuous covariates. In these analyses, I assumed that the effects of session, trials and ratings on corrugator activity were independent, thus only main effects were explored. The results demonstrated a linear relationship between ratings and corrugator activity with a significant main effect of ratings (F $(1,1454)=20.308, p=0.001)$. Specifically, for every unit increase in pleasantness ratings, the corrugator activity dropped by $0.012 \mu \mathrm{V}(\mathrm{b}=-0.0117, \mathrm{t}(1454)=-4.506, \mathrm{p}=0.001)$. As was the case in the main analysis, here there was still a significant effect of trial $(\mathrm{F}(1,49)=$ $4.153, \mathrm{p}=0.047)$ and a borderline non-significant effect of $\operatorname{session}(\mathrm{F}(1,5581)=3.753, \mathrm{p}=$ 0.053). Thus, the corrugator activity increased significantly as the pleasantness ratings decreased, suggesting a coherent response pattern between the physiological and subjective responses to slow stroking touch.

\subsection{Paper IV}

The aim of this paper was to develop and demonstrate a protocol as a means for investigating affective responses to touch using facial EMG. A demonstration of the video may be accessed here: [https://www.jove.com/v/59228/using-facial-electromyography-toassess-facial-muscle-reactions-to] 


\section{Discussion}

In study 1 of this thesis (papers I and II), my colleagues and I set out to investigate the subjective, physiological and behavioural responses to CT targeted touch and compare these to those obtained during non-CT targeted touch and a non-tactile visual control condition. We specifically investigated subjective pleasantness and intensity ratings, facial electromyography (EMG) of the corrugator and zygomaticus muscles, electrodermal activity (EDA) responses and prosocial behaviour in a laboratory setting. In study 2 of the thesis (paper III), we aimed to investigate the coherence between the subjective pleasantness ratings and the physiological responses, such as facial EMG and heart rate variability, in response to a slow stroking touch. Overall, for both studies, we aimed to propose novel ways of analysing facial EMG responses to affective touch and a novel way of investigating the extent to which CT targeted touch affects prosocial behaviour in a laboratory setting. Lastly, we aimed to demonstrate consistent subjective and physiological responses to touch when a group of participants' responses were measured at two separate sessions.

In paper I, we successfully replicated previous findings that relate to the pleasantness and intensity of CT targeted touch, in that touch aimed at targeting CT fibres $(3 \mathrm{~cm} / \mathrm{s})$ was more pleasant and intense than control touch $(0.3 \mathrm{~cm} / \mathrm{s})$. However, CT targeted touch was no more pleasant or intense than watching a visual control condition for two minutes, evident by similar pleasantness and intensity ratings and similar skin conductance level throughout the two-minute trial. In paper II, we aimed to investigate the extent to which people's prosocial behaviour towards others changed in response to touch and visual stimulation using a novel online measure of prosocial behaviour. However, we were unable to demonstrate that people became more prosocial following two minutes of CT targeted touch compared to two minutes of control touch and a visual control condition. In paper III, we successfully demonstrated that people's subjective pleasantness ratings in response to 60 trials of slow stroking touch decreased steadily and was reciprocated by increasing corrugator muscle activation during the first of two sessions. However, these findings were not evident during session 2, and there was no coherence at either session for the heart rate variability and zygomaticus responses. In the following section, I will discuss the main findings in light of existing knowledge and theories and expand the discussion to topics that were not covered in detail in the original publications. 


\subsection{Subjective Responses to Slow Stroking Touch}

In general, our main findings that relate to the perceived pleasantness of the types of touch that were implemented in the thesis, were in line with previous findings from the literature [see for instance Ackerley et al. (2014b), Sehlstedt et al. (2016), Essick et al. (2010), Wijaya et al. (2020)]. The findings from paper I further corroborate the apparent velocity specificity in affective touch, first described by Löken et al. (2009). Moreover, the pleasantness ratings in response to repeated slow stroking touch in paper III were similar, albeit less prone to satiety effects than that reported previously (Triscoli et al., 2014a). Importantly, the consistency of these findings demonstrates that we were successful in administering touch that the participants found pleasant and thus, comparable to other studies.

This leads us to an important finding that was only briefly discussed in paper I and relates specifically to the level of perceived pleasantness of the touch. While the CT targeted touch was indeed more pleasant and intense than control touch, the CT targeted touch was no more intense and only fractionally more pleasant than watching colourful objects moving at various speeds on a computer screen. These findings need to be discussed for two particular reasons. First, it may be relevant for readers looking for a non-tactile control condition that matches the CT targeted touch in pleasantness. There is an increasing body of evidence describing the multimodal nature of several perceptual processes [see for instance Stein et al. (1996)] and considerable overlap in the cortical areas that are engaged by a variety of sensory stimuli (Rolls, 2020, Schirmer and Adolphs, 2017). Thus, tactile responses should be compared and contrasted to those obtained from other sensory modalities, as it may help us better understand the mechanisms behind the perceptual processes that take place.

Second, there is a need to compare the level of perceived pleasantness of CT targeted touch to other sensory modalities. By all means, the subjective pleasantness of CT targeted touch is among the most consistent and characteristic finding in affective touch, however, in paper I, it was hardly more pleasant than watching geometrically shaped moving objects on a computer screen. Obviously, the findings in paper I could be arbitrary, but they could also reflect a tendency for certain velocities of any stimulus to be appreciated more than others. For instance, a previous paper reported activity in the human middle temporal V5 complex in response to tactile input (Hagen et al., 2002). Importantly, the human middle temporal V5 complex is generally considered a unimodal visual processing area, therefore, the findings reported by Hagen et al. (2002) suggest the area could be a general area for motion processing. In this regard, findings that pertain to velocity specific responses to vicarious 
touch [see for instance Walker et al. (2017) and Morrison et al. (2011)] are interesting, as it is difficult to ascertain the mechanisms that drive this form of behaviour. It could well be that people perceive slow stroking touch performed to others as more pleasant and social than very fast or very slow touch performed to others. Equally, the actual visual motion of the speed of the vicarious touch at $3 \mathrm{~cm} / \mathrm{s}$ could be more visually pleasing on the eye than other velocities and therefore rated higher by the participants. Although I cannot provide a definite answer to these particular questions, it is important to discuss the implications from paper I and the comparable similarity between the pleasantness ratings of CT targeted touch and visual stimulation. It is certainly possible that the previously reported pleasantness of CT targeted touch has been warranted too much recognition, thus failing to acknowledge the relative unpleasantness of very slow touch $(0.3 \mathrm{~cm} / \mathrm{s})$ or the brisk, unsocial nature of very fast touch $(30 \mathrm{~cm} / \mathrm{s})$.

\subsection{Physiological and Behavioural Responses to Slow Stroking Touch \\ 10.2.1 Facial EMG Responses}

In paper I, we demonstrated that slow stroking touch delivered at $3 \mathrm{~cm} / \mathrm{sec}$ led to a reduction in corrugator activity. Importantly, a reduction of activity in the corrugator muscle suggests that $\mathrm{CT}$ targeted touch led to a reduction in negative affect. Furthermore, we provide tentative support for the hypothesis that any detectable change in the facial EMG signal from a slow stroking touch is driven primarily by A $\beta$ fibres in the first $700 \mathrm{~ms}$, and that the subsequent reduction in corrugator activity observed after this time interval reflects a gradually increasing afferent volley of CT fibre input. Due to the inherently slow nature of the unmyelinated CT fibres, we argue that the volley of CT afferent input would not reach the cortex until at least $700 \mathrm{~ms}$ has passed, in line with the known conduction velocity of CT fibres (Olausson et al., 2010, Watkins et al., 2017). As can be seen by Figure 10 (Results section, p. 48), after the initial $700 \mathrm{~ms}$ of activity, CT targeted touch led to a gradual reduction of corrugator activity. Further support of this statement can be seen by the reanalysis of the data from paper I: This analysis confirmed that indeed, whilst the corrugator activation in response to control touch increased significantly, there was also a significant reduction in corrugator activation in response to CT targeted touch. Moreover, the reduction in corrugator activation in response to $\mathrm{CT}$ targeted touch coincided temporally with the known conduction velocity of CT afferents (Watkins et al., 2017, Vallbo et al., 1999). While it is impossible to separate the afferent input derived solely from $A \beta$ fibres from the afferent input derived exclusively from $\mathrm{CT}$ fibres, the conduction velocity of the slow unmyelinated CT fibres 
suggests the afferent input cannot reach the cortex until $700 \mathrm{~ms}$ of activity has passed. This finding is also consistent with a previous finding that reported an ultra-late EEG potential in response to CT targeted touch (Ackerley et al., 2013). Thus, there is tentative evidence that this effect is driven, at least partly, by the afferent volley of CT fibre input, arriving after the initial $700 \mathrm{~ms}$ of touch has passed.

These findings have been discussed in depths in the original paper, but at the most basic level, the activity in the corrugator muscle could simply reflect the level of perceived pleasantness of the touch. As such, the higher pleasantness of the CT targeted touch led to a reduction in negative affect as opposed to the increased corrugator activity (and increased negative affect) observed in response to control touch. In this regard, the facial responses in paper I could be interpreted as a basic emotional expression described in basic emotion theory [see for instance Tracy and Randles (2011) for a review of four basic emotion theories]. Specifically to paper I, because the CT targeted touch is making the participant feel better than when he is receiving the control touch, this leads to the activation of "hard-wired" response patterns, evident by a reduction of frowning. However, the responses to slow stroking touch in paper III only partially support this statement. In this paper, while we argued that the increasing corrugator activity reflected the gradually decreasing pleasantness rating of the repeated touch trials, the ratings remained in the positive ranges throughout the study and the touch was not perceived as unpleasant. Nevertheless, the corrugator muscle is an interesting investigation of the physiological responses to tactile stimuli, offering small "snapshots" of physiological processing and expressions of affect, that appear partially unrelated to the conscious appreciation of the stimulus.

Touch may also serve a primary role in sharpening the receiver's attention, as maintained by, for instance, Schirmer et al. (2011) and Spapé et al. (2017). Accordingly, in the findings from paper I, the initial $700 \mathrm{~ms}$ of touch would serve to notify the touch-recipient of a tactile stimulus on the skin, which would involve predominantly the fast conducting $A \beta$ fibres. Then, the remaining part of the stroke, delivered with a velocity that maximally stimulates an increasing number of CT fibres would serve as an affective signal of warmth, comfort and safety that ultimately leads to a greater reduction of corrugator activation than that obtained by the presumably, less social control touch. Although these are speculations, we have some tentative support from unpublished observations from the data collection in study 2. As can be seen below (Fig 13, right), there is a significant increase in the zygomaticus activity late during the touch trial. In fact, the zygomaticus activity peaked after 
the slow stroking touch had finished, and increased during the post-touch period of the trial. This could indicate the participants' appreciation of the pleasantness of the stimulus, possibly reflecting a hedonic reminiscence triggered by the pleasantness of the tactile stimulus. Thus, it may be suggested that the initial part of a touch relies on the fast $A \beta$ fibre signalling and the latter part of a touch relies more on the afferent volley of CT fibre input.

However, we did not see a reduction of the corrugator during the post-touch period, but rather a gradual increased activation through the touch period and throughout the posttouch period. One potential explanation could simply be that the increased activity of both muscles reflected the cognitive load of processing the stimulus [see for instance van Boxtel et al. (1996) and Lishner et al. (2008)]. Further studies should investigate this more precisely, using the temporal dynamics of facial EMG to unravel the minute, yet seemingly important difference in physiological responses, potentially reflecting the conduction velocity of these fibres. Compared to other studies which have analysed larger sections of facial EMG activity, this thesis proposes an alternative way to analyse facial EMG responses that utilises the high temporal resolution of the EMG signal, thereby offering a more dynamic, and ultimately, more precise analysis of how slow stroking touch affects the facial muscles involved in signalling positive and negative affect.
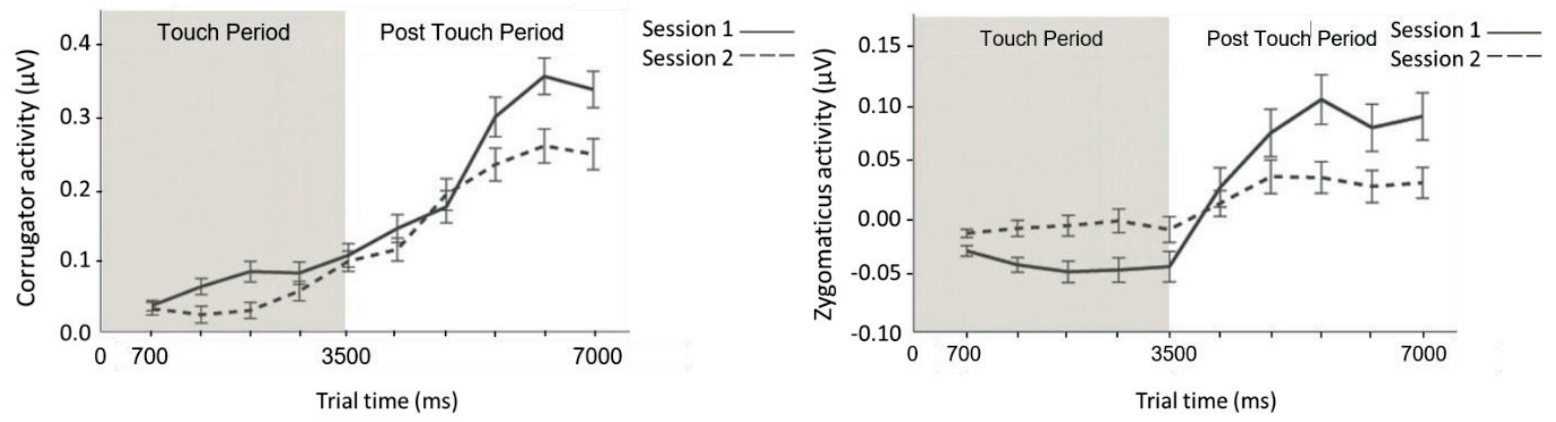

Fig. 13. Unpublished data collected in study 2. By analysing the facial EMG data in intervals of $700 \mathrm{~ms}$, we demonstrate that the corrugator muscle activity (left) increases gradually through the touch phase and throughout the post-touch phase. The zygomaticus muscle activity (right), however, increases during the post-touch phase only and particularly during the first session. 


\subsubsection{Electrodermal Activity}

The findings that relate to the arousal aspect of touch, evident by a change in SCL, were inconclusive. There was a slightly higher SCL following two minutes of CT targeted touch than following two minutes of control touch and visual stimulation, but these findings were non-significant. In fairness, we were uncertain as to how the SCL would respond to CT targeted touch, as there were conflicting findings from the existing literature. One study reported a larger SCL response to fast and slow touch compared to tapping, suggesting the larger SCL reflected the social nature of touch over vibration (Etzi et al., 2018). Others had reported a reduction in SCL in response to several types of touch, though to reflect the relaxing nature of touch in general (Greco et al., 2015, Greco et al., 2016).

Thus, based on the existing studies, we expected either a larger SCL following CT targeted touch, reflecting the presumably greater social nature of touch, or a diminished SCL, reflecting the presumably more relaxing nature of CT targeted touch. The fact that CT targeted touch was no different to control touch or visual stimulation was unexpected, however, both top-down and bottom-up factors may provide explanations: As an example of a top-down modulator, the participant's attention to the presented stimuli is likely to change with time and is particularly relevant when it comes to the physiological responses, as they are, largely, unedited by the conscious mind [see for instance Mendes (2016) for a summary of emotions and the ANS]. In fact, findings from the literature that pertains to visual perception indicate that even highly salient visual events go unnoticed by participants, particularly if the participants are in highly cognitively demanding situations (Yates et al., 2010). This is referred to as "inattentional blindness", indicating that conscious perceptions require attention [see Simons and Chabris (1999) for a discussion on the topic]. Moreover, painful stimuli show diminished physiological responses, such as event-related potentials (ERPs), when the stimulus is presented repeatedly (Legrain et al., 2011). The extent to which attention may have influenced the effects of touch on the SCL investigated in this thesis, however, is less clear. For instance, in a series of experiments, Schirmer et al. (2011) found that touch influenced the ERP responses in the absence of conscious appreciation, irrespective of whether the touch was applied by a mechanical device or a friend. Importantly, the ERP responses were not modulated by auditory stimulus, which led the authors to suggest that touch, in contrast to sound, has the ability to influence the participants' physiological responses in the absence of conscious awareness. From this study, one may conclude that attention is not required for touch to produce an effect on the physiological responses. Thus, 
given the results of Schirmer et al. (2011) and the low overall attention level required in our task, it is unlikely that fluctuations in attention would largely affect the SCL observed in paper I of this thesis.

However, our findings that relate to the overall arousal level and SCL in paper I may also be explained by bottom-up mechanisms, and particularly one that refers to the sustained conduction capacity of the $\mathrm{CT}$ and $\mathrm{A} \beta$ fibres; fatigue. On the one hand, since the first investigations of the CT fibres in humans, the uncertainty regarding the development of fatigue in these fibres has been present (Nordin, 1990, Vallbo et al., 1993), whereas A $\beta$ fibres, on the other hand, are reportedly resilient to fatigue (Abraira and Ginty, 2013). Thus, using repeated tactile stimulation aimed at maximally activating CT fibres, as we did in paper I of this thesis, there may have been a risk of the CT fibres fatiguing. This may subsequently have affected the overall impact on arousal over the two minutes of stimulation, as the CT targeted touch may have been more prone to fatigue than the control touch, which presumably relied more on the fatigue-resilient A $\beta$ fibre input. In a paper by Vallbo et al. (1999), the issue of fatigue was dealt with in detail using the microneurography technique. The authors reported that during 20 repeated touch applications (with a gap of $\sim 2 \mathrm{~s}$ between) the responses of the CT-fibres became shorter, but the initial peak firing frequency was maintained. The authors concluded that $\mathrm{CT}$ fibres fatigued a little, but they kept on responding throughout the experiment. Nevertheless, to counter the possibility of fatigue in paper I and II, we alternated between two stimulation sites, so that every stimulation was about $5 \mathrm{~cm}$ apart from each other. It is likely that this reduced the risk CT fibre fatigue and of not activating CT fibres optimally and by extension, it is unlikely that CT fibre fatigue explains the lack of differences in SCL following CT targeted touch, control touch and visual stimulation.

\subsubsection{Heart Rate Variability Responses}

In paper III, we investigated changes in heart rate variability to slow stroking touch, expressed as changes in the time-domain measure, the root mean square differences of successive R-R intervals (RMSSD). Overall, we were unable to document any change in the RMSSD compared to baseline in either session, despite that the majority of the participants found the touch pleasant. Specifically, we expected the perceived pleasantness of the slow stroking touch to lead to a higher RMSSD during the active part of the experiment than during baseline. This was based on suggestions that touch could function as a stress-buffer (Morrison, 2016b) and that a high HRV, in general, is considered a proxy for emotional wellbeing, emotion regulation and improved resilience to stress responses [see for instance Mather 
and Thayer (2018), Holzman and Bridgett (2017) for reviews on the topic]. However, despite one previous study reporting higher HRV in response to CT targeted touch (Triscoli et al., 2017b), no such effects were observed in our study. This suggests that slow stroking touch, although perceived and rated as pleasant by the participants, does not invariably lead to a higher HRV and our hypothesis that pertain to slow stroking touch and HRV has to be refuted. Other than methodological explanations for this null effect, which will be discussed separately under the methodological considerations section, a potential explanation may be found in a recent paper by Novembre et al. (2020).

In that paper, the authors investigated slow CT targeted touch to fast non-CT targeted touch paired to images of attractive and less-attractive people. The touches were applied to the glabrous skin of the palm and the hairy skin of the forearm, to further differentiate between CT containing touch (hairy skin) and non-CT containing touch (glabrous skin). Importantly, when the participants imagined being stroked by the person that the touch was paired to, slow touch paired to attractive faces led to a greater RMSSD than when the touch was unpaired or paired to unattractive faces. Moreover, this effect occurred irrespective of whether the touch was applied to the hairy or glabrous skin (Novembre et al., 2020). These findings are interesting as they point to an important mechanism that was not present in paper III of this thesis. The slow stroking touch was pleasant, however, in itself, not sufficiently pleasant to lead to a distinct change in HRV. Given the right contextual or social circumstances, such as that described in Novembre et al. (2020), however, the overall higher pleasantness ratings of the slow stroking touch compared to the fast touch were sufficient to instigate a physiological adaptation when combined with an additional factor, such as an attractive face. Thus, the combined findings from other papers investigating touch responses and their effects on heart rate deceleration (Triscoli et al., 2017a, Pawling et al., 2017a, Fairhurst et al., 2014) and HRV (Triscoli et al., 2017b, Novembre et al., 2020) suggest slow affective touch affects physiological responses, however, the means through which these effects are exerted, remain largely unknown.

\subsubsection{Prosocial Behaviour}

In paper II, we aimed to investigate in a laboratory setting previous claims and observations from field studies that relate to the prosocial behaviour in humans following exposure to touch. In those contexts, prosocial behaviour refers to the willingness to act out behaviour and actions to the benefit of somebody else, without expecting immediate gratifications themselves in return (Morrison, 2016b). By extension, in experiment 1 and 2 of 
paper II, we investigated the willingness of the participants to return money they received from the person who had been touching them, as they played the Repeated Trust Game (Berg et al., 1995) following fast non-CT targeted and slow CT targeted touch. Throughout the Repeated Trust Game, the players are able to see how much money they have themselves and how much the other participant receives. In experiment 3 of paper II, we investigated whether participants' monetary allocations between themselves and a future participant changed when playing the SVO-slider (Murphy et al., 2011) in response to repeated CT targeted, non-CT targeted control touch and a visual control condition. We were, however, unable to document any prosocial effects in response to touch when carefully administered in a laboratory setting. Moreover, although the participants found the CT targeted touch more pleasant than the control touch in all three experiments in paper II, this perceptual difference did not lead to a difference in prosocial behaviour. These findings speak highly against the pleasantness as the motivating incentive behind the prosocial behaviour that has been observed in field studies following touch. Furthermore, in experiment 3 of paper II, although CT targeted touch was rated slightly more intense than control touch, the SCL (reported in paper I) between CT targeted touch and control was not different. Thus, it is unlikely that the arousal level is the mediating factor behind the prosocial findings reported in field studies.

What could then be potential explanations for the lack of a prosocial effect observed in our laboratory studies when this effect has been observed so consistently in field studies? Certainly, Koppel et al. (2017) faced the same challenges as we did, in that they were unable to demonstrate any prosocial effect attributable to touch in a laboratory setting, arguing that the contextual and social aspects in the field studies override what is possible to recreate in a laboratory setting. Moreover, the authors also raise the possibility that touch, CT targeted or not, does not mediate any prosocial effects (Koppel et al., 2017). According to Schirmer et al. (2016), however, there are several mechanisms through which touch can exert its prosocial effect: Touch may lead to changes in affect and consequently, as we feel better, we are more likely to be generous, or prosocial. These responses could be acquired through activating "hard-wired" cortical connections between somatosensory and emotional areas of the brain or through classical conditioning of touch and positive social interactions. Alternatively, touch may act on more abstract concepts, such as embodiment, whereby the tactile interaction serves to inform us of the other person's mental status and perhaps level of approachability. Until now, laboratory studies investigating the prosocial aspects of touch have primarily focused on changing the affective status of the receiver of touch. Before firm conclusions can 
be made regarding the prosocial nature of touch, studies should focus on influencing the other potential avenues outlined by Schirmer et al. (2016).

\subsection{The Coherence between Subjective and Physiological Responses}

The findings from the papers in the thesis that relate to the coherence between subjective and physiological responses to touch are somewhat conflicting. In paper I, CT targeted touch was rated as more pleasant than control touch and these ratings were accompanied by decreased and increased activity of the corrugator muscle, respectively. In paper III, the corrugator activity increased as the subjective pleasantness of the slow stroking touch started to decrease, particularly during the first session. This supports the notion that affective and emotional responses to touch may be expressed through explicit and implicit means in a coherent manner (Mauss and Robinson, 2009). This is further supported by the reanalysis of the data from paper III, which demonstrated a significant linear relationship between the subjective pleasantness ratings and the corrugator activation. It has previously been reported that the corrugator muscle responds to the presentation of affective pictures, sounds and words in a linear manner, whereby positive affective stimuli led to a reduction in corrugator activation and negative stimuli led to an increased corrugator activation (Larsen et al., 2003). Thus, the findings reported in the thesis that relate to the coherence between subjective pleasantness ratings to slow stroking touch and the corrugator activation, offer tentative evidence that activity in the corrugator muscle responds in a linear manner to affective touch stimuli applied at CT targeted velocity and that this response is coherent with the subjective pleasantness ratings.

The zygomaticus muscle, however did not cohere with the subjective ratings in either paper, and we were unable to document that the level of arousal expressed by way of skin conductance level (SCL) in paper I cohered with the pleasantness ratings, and neither did the heart rate variability (HRV) in paper III. These differences suggest that the physiological and subjective measures in affective touch reflect different aspects of the experience. For instance, in paper III, the same experimental set up was repeated at two separate sessions, and the coherence between the subjective ratings and corrugator activation at group level was present during session 1 only. Subjective ratings require that the participants consciously reflect, or, at the very least, acknowledge that touch has taken place. This process likely involves appraisal of the contextual setting as well. It has been previously reported that participants try to achieve consistency in their ratings [see for instance Wallace et al. (1992)], however, it is unlikely that the participants were voluntarily and actively influencing the activity of the 
facial muscles, SCL or HRV to a great extent. Thus, the physiological responses in paper III are more likely to change from one session to the other than the subjective appraisal of the stimulus.

The lack of coherence may be due to the "mere-exposure effect", originally described by Zajonc (1968). The "mere-exposure effect" suggests that through two opposing processes, habituation and boredom, the repeated presentation of the same stimulus leads to the stimulus being initially rated as more pleasant before the ratings drop with the increasing number of stimulus presentation (Montoya et al., 2017, Bornstein and D'Agostino, 1992, Leventhal et al., 2007). This could partly explain the different level of coherence observed in paper I and III. Specifically, subjective ratings and the various physiological responses develop differently over time and thus represent different aspects of the "mere-exposure effect". For instance, as the participants habituated to the presentation of the touch in paper III, the cognitive processes likely became more fluent and this subsequently led to higher subjective ratings and less corrugator activity. As the level of boredom increased, however, the subjective ratings decreased and the level of negative affect increased, evident by increased corrugator activation. The HRV, however, may to a greater extent than facial EMG reflect long-term processes, such as emotion regulation (Thayer et al., 2012, Holzman and Bridgett, 2017). Thus, it seems that the physiological responses to affective touch are far from blueprint readouts of the subjective responses and that subjective responses in particular are affected by cognitive and contextual factor. 


\subsection{General Discussion}

This leads us to an important part of affective touch: What is the primary purpose of affective touch, and do CT fibres have a unique role in the perception of affective touch? Certainly, the evidence from paper I suggests that touch targeting CT fibres is favoured over non-CT targeted touch and this is partly supported by physiological findings, most notably a reduction in corrugator activation. Nevertheless, I would argue that one of the most striking findings from this thesis relates to the resilience to touch satiety reported in paper III. Stated differently, it is not surprising that the participants found the touch pleasant, but rather that the touch appeared to be pleasant even towards the end of a 60-minute long session. This indicates that slow stroking touch is remarkably resilient to affective habituation, or a process that has been described as "touch satiety" (Triscoli et al., 2014a). In that study, it was reported that touch targeting CT fibres satiated somewhat quicker than slow $(0.3 \mathrm{~cm} / \mathrm{s})$ and fast touch $(30 \mathrm{~cm} / \mathrm{s})$, however, CT targeted touch was rated as pleasant throughout the session (Triscoli et al., 2014a). In paper III, when we compared the initial 30 touch trials to 30 odour trials, we found that the odour ratings dropped significantly and more rapidly than the touch trials. Thus, it may be speculated that satiety develops differently for touch and odour response.

While it is difficult to discuss the mechanisms of satiety across sensory modalities, it is nevertheless interesting to discuss the implications of the resiliency to touch satiety in light of what we know from other modalities. For instance, in the field of odour and taste, a process called sensory specific satiety occurs and refers to the process where people rate eaten foods gradually lower, but this reduced pleasantness does not apply to other types of unconsumed foods (Rolls et al., 1981, Rolls, 2020, Rolls and Rolls, 1997). The primary evolutionary purpose of sensory specific satiety is to ensure that we eat a varied diet of foods and nutrients to allow the organism to prosper and develop optimally (Rolls, 2020, Wilkinson and Brunstrom, 2016). By extension, the resiliency to touch satiety demonstrated in paper III and elsewhere (Sailer et al., 2016a, Triscoli et al., 2014a, Triscoli et al., 2017b), point to an important evolutionary drive to seek and sustain tactile affiliative interactions between conspecifics. Certainly, observations from primates demonstrate that social touch expressed through social grooming surpasses the time needed for hygienic requirements (Dunbar, 2010). Moreover, the seminal experiments by Harlow (1958) and Harlow and Suomi (1970) demonstrated that baby-monkeys sought the comforts of a fluffy surrogate mother over an iron surrogate mother, despite that the fluffy surrogate mother was incapable of meeting the nutritional demands of the baby-monkeys. Indeed, in a recent review, it was suggested that the 
social and affective touch that occurs in close relationships provides the toucher with a means of regulating the physiological needs of the touch-receiver and as a means to form and sustain relationships (Morrison, 2016b). Thus, in light of the increasing data suggesting humans have a need and desire to be touched, the resilience to touch satiety may not be all that surprising after all. Consequently, at the end of the sessions in study 2 (paper III), which required approximately one hour every session; despite the repetitiveness of the slow stroking touch and the lack of other novel stimuli, and despite the (presumably) gradually increasing boredom experienced by the participants, the overall majority of participants still rated the touch as pleasant. It is difficult to conclude as to whether the resilience to touch satiety observed in paper III and other studies (Triscoli et al., 2014a, Sailer et al., 2016a, Triscoli et al., 2017b) reflects the affiliative nature of affective touch. However, people appear to crave tactile interactions as they crave a variety of foods, expressed as sensory specific satiety in foods and, perhaps, by way of resilience to touch satiety in tactile interactions. Thus, I do believe the resilience to touch satiety speaks volumes regarding the importance of tactile interactions in general, irrespective of the type of touch and perhaps, irrespective of the degree of perceived pleasantness of the touch.

Indeed, recent findings argue that affective touch may serve to facilitate socioemotive salient signals across modalities (Schirmer and Gunter, 2017). As the seminal research by Harlow (1958) demonstrated, primates have an innate need of touch that transcends the nutritional requirements and this applies to humans as well. In fact, touch between infant and mother has been reported to improve immediate outcomes, such as the length of hospital stay and weight gain and long term outcomes, such as the ability to form social bonds in adolescence [for a recent review on touch and social development, see Cascio et al. (2019)]. In humans, the verbal communicative means of infants are obviously limited, but their desire to be held, loved, and cuddled is fundamental to their well-being and development (Field et al., 2006, Vickers et al., 2004). What better way to signal this to the caregiver than by smiles of affect or by changes in parasympathetic breathing pattern that can be perceived and interpreted by the caregiver as positive emotive signals, signalling the desire to continue doing whatever is leading to this response? Thus, the significance of facial muscle responses and other physiological states of affect and emotion becomes more pertinent in cases where verbal communication is hampered or hindered altogether. In fact, studies on the development of facial expressions in infants and children suggest both maturation of cortical processes and socialisation norms are important in this regard (Camras et al., 2016). Previous findings have 
also indicated that $\mathrm{CT}$ targeted touch reduces the heart rate in infants compared to other velocities (Fairhurst et al., 2014), but that maternal touch, irrespective of velocity, is important in assisting the child in forming and maintaining social bonds (Reece et al., 2016).

Thus, infancy is one example where an infant learns to respond to the caregiver's touches and through learning, associates the touches with something pleasant. Certainly, the observations and studies by Ekman and colleagues [see for instance Ekman (1992), Ekman et al. (1987)] or Dimberg (1982) would support this notion, painting a picture where someone's emotional state mirrors, for instance, their facial expressions. However, as noted previously, these "hard-wired" connections have been critiqued, most recently by Lindquist et al. (2013), Barrett (2017) and Crivelli and Fridlund (2018). Using the example of the infant above, in Barrett's view on emotion described in detail as the "Theory of Constructed Emotion" (Barrett, 2017), the brain does not respond to stimuli per se, but rather creates "concepts" that are explanations to the brain regarding the input and the significance of that input.

Furthermore, Barrett proposes that no neurons or brain regions are singularly responsible for any emotional status, but rather different neurons and brain regions have several receptive fields and function as multimodal neurons in networks driving the constructions of the current emotion (Barrett, 2017). By this extension, no tactile fibre, be that CT or A $\beta$ fibres, are singularly driving the affective component from touch, and the insula, proposed as the affective "hotspot" in the brain (de Haan and Dijkerman, 2020, Craig, 2009, Morrison, 2016a) is just one of many multimodal brain networks that create affective touch responses and behaviours. As these cortical networks of different people will have developed somewhat differently during the formative phases of early life, each individual is likely to construct slight variation in expressed affect and emotion when these cortical areas are engaged, as, in the case of this thesis, by a slow stroking touch. In that regard, it is unlikely that CT fibres have a privileged, or "hard-wired" right to initiate or shape affective tactile responses, but rather remain one vital component of tactile afferent input that is shaped and modulated by several interactive cortical networks. Indeed, very recent findings by Watkins et al. (2020) using the microneurography technique demonstrated the presence of CT fibres in the glabrous skin in two out of 42 participants in one data set that investigated the palmar innervation of the median nerve. Furthermore, they were able to document the presence of CT fibres in one participant from another data set that investigated the palmar innervation of the radial nerve. These findings are important contributions to the ongoing debate regarding the importance of $\mathrm{CT}$ fibres in shaping and modulating affect and pleasantness and social interactions. 
According to Watkins et al. (2020), the scarcely distributed presence of CT fibres in the glabrous skin of the palm may support the notion that CT fibres in glabrous skin are less influential in shaping tactile perceptions than CT fibres in hairy skin. Alternatively, the presence of CT fibres in glabrous skin may support the notion that central processes, such as previous experiences, and expectations of touch, are equally important in deciding the pleasantness and significance of human touch (Watkins et al., 2020).

The findings and theories discussed above may also help explain why we were unable to demonstrate a response in the zygomaticus muscle, as opposed to that demonstrated by Pawling et al. (2017a). Potential reasons for this difference, including methodological differences, have been discussed at length in the original publications (paper I and III). However, in light of the recent discussion of different emotion theories, I would like to elaborate on one issue that seems particularly relevant: Facial expressions whilst being observed versus facial expressions provided in solitude. One of the most prominent differences between the experimental set-up used by Pawling et al. (2017a) and those implemented in paper I and III, is that Pawling et al. (2017a) had the participants facing an additional assistant experimenter. This, one would have to assume, allowed for facial communication to occur between the experimenter and participant. In striking contrast to that set-up, the participants in our experiments were visually shielded from the experimenter, thereby prohibiting any kind of facial communication between experimenter and participant.

The issue of facial communication between experimenter and participants goes straight to the core of emotional facial expressions and their significance: Do we smile because the pleasant touch is making us feel good, and we therefore express this by smiling, or do we smile because we want to communicate to the stroker that this is a pleasant activity and I would like you to continue with that activity? Certainly, the evidence from observing facial expressions and facial muscle activation suggest we smile when confronted with a happy face and similarly, we frown when confronted with angry faces [see for instance Dimberg (1982)]. Unfortunately, regarding the facial responses to pleasant touch, I do not believe firm conclusions can be drawn, however, allowing myself to speculate on the matter, a few tentative opinions may be put forward: First, there is certainly evidence that facial muscles, most prominently the corrugator and the zygomaticus, do respond to affective touch. As of today, three papers have reported a reduction in corrugator activity following affective touch (Ree et al., 2019, Ree et al., 2020, Mayo et al., 2018) and one paper has reported an increase in zygomaticus activity following affective touch (Pawling et al., 2017a). In addition, 
we have unpublished data (see Fig 13 above) reporting a significant response in the zygomaticus muscle and Korb et al. (2020) recently reported increased activity in the zygomaticus muscle during post-hoc exploratory analyses of the latter part of the trials.

Furthermore, it is possible the zygomaticus response would have been more prominent in our studies if the experimental set-up had allowed facial communication between the experimenter and participants. After all, many of us have experienced how a good story becomes a great story, all depending on the contagious smiles of the audience. By extension, a pleasant touch may become a pleasant touch worthy of a smile in the presence of others. Certainly, there is some evidence to suggest that facial expressions in response to a stimulus are magnified with an audience present and suppressed once the stimulus is appreciated in solitude (Jäncke and Kaufmann, 1994). Second, although speculative, perhaps a contraction of the zygomaticus (a smile) has more communicative repercussions than a reduction of corrugator activity (less frowning), just as much as a contraction of the corrugator is easier to interpret and notice than a reduction of corrugator activation. Stated differently, if the sole purpose of facial expressions were communicative, both smiles and frowning communicate clearly the stated intent of the signals, as opposed to the more ambiguous signal of a reduction in corrugator activation. The former activities may be observed to the naked eye, but the latter may only be detectable with sophisticated laboratory equipment and therefore has less value in the real world. Third, if we interpret facial expressions in light of the theory posited by Barrett (2017), ultimately, both genuine smiles and frowning are closer to the subcortical expressions of basic emotions also acknowledged by Barrett (2017), and therefore more likely to demonstrate a unified constructed concept of emotion across a variety of study populations. The more subtle differences in facial muscle activity, however, may depend on too many individually constructed concepts of emotions, reflecting greater interindividual differences in development, experience and ultimately, expressive behaviour of the facial muscles.

Although we were able to demonstrate physiological responses that appear closely related to the CT fibres, we were unable to demonstrate changes in overt behaviour that were related to CT fibres or indeed, affective touch at all. Using the repeated trust game (Berg et al., 1995) and the Social Value Orientation Slider (SVO-slider) (Murphy et al., 2011) to investigate prosocial behaviour, such as generosity, we found no difference in the participants' behaviour following CT targeted touch, control touch and a visual control condition. Several potential reasons may account for this. Studies on hedonic responses often investigate the subjective experience (e.g. self-reports in response to a pleasurable stimulus), 
physiological responses (e.g. reduction in heart rate) and the actual behaviour to the stimulus (e.g. approaching the person providing the stimulus) (Becker et al., 2019). Therefore, changing somebody's prosocial behaviour appears a higher mountain to climb than merely asking him or her to receive and rate a stimulus applied to the skin of the arm. This is in accordance by the view on emotion maintained by Lang and Bradley (2010) who state "...motivational arousal is the foundation of emotion" (Lang and Bradley, 2010, p. 438) and that appetitive stimuli engage the primary limbic circuits of the brain before engaging the expressive behavioural output. In the current thesis, increasing the motivational status of the participants, I believe, would require several events to coincide in time and would involve a higher level of cortical processing by the participant. For instance, if the CT targeted touch was sufficient to instigate a prosocial change in the participants, the participants would still have to remain in an "elevated" prosocial state of mind throughout the monetary allocation period. By increasing the level of emotional closeness between the monetary allocator and receiver, however, it is possible that the prosocial behaviour would have been greater. This could be achieved by for instance investigating donations to people perceived as "in-group" or "out-group", or by having couples or close friends donate to each other, rather than monetary allocation between themselves and a future randomised participant, as was the case in paper II. Future studies investigating the prosocial aspects of affective touch could include these parameters to delineate the social and affective nature of touch further. 


\section{Methodological Considerations}

The following section will primarily discuss the results from the papers in light of the advantages and disadvantages of the applied methods.

\subsection{Subjective Ratings}

In the papers of this thesis, we used visual analogue scales (VAS) to collect data from self-reports. There are several reported benefits of using a VAS compared to for instance Likert-type scales and commonly VASs are considered to offer more fine-grained responses (Wewers and Lowe, 1990) and detect more normal variation in the participants' responses (Cook et al., 2001). Although I am not aware of a specific paper that has investigated the reliability and validity of VASs in affective touch, studies from the pain field, in particular, have verified the reliable and valid use of VASs in experimental studies (Price et al., 2008b, Hawker et al., 2011). However, although self-reports may offer considerable introspective insight, they are also potentially confounded by several contextual, cognitive and social biases (Lindquist et al., 2012).

For all the benefits of using VASs, in the papers of this thesis, they offer only onedimensional investigations of the touch experience ("unpleasant-pleasant, not intense-veryintense" and are thus likely to capture only a limited aspect of the multidimensional features that constitute affective touch (Ackerley et al., 2014b). Moreover, it is maintained that a variety of methods are required to capture the multidimensional aspects that constitute any emotional experience (Mauss and Robinson, 2009). In that regard, paper I and particularly paper III of this thesis would have benefitted from a richer description of the tactile experience. In paper I, the participants were able to make comparisons between several types of stimuli whereas in paper III, they received the same stimulus throughout the experiment. Thus, although the ratings dropped and we demonstrated this consistently at two separate sessions, it would have been interesting to investigate if the emotional and arousing aspect of the touch changed differently to the pleasantness ratings. For instance, the "Touch Perception Task" (TPT) [(Guest et al., 2011)] is a questionnaire that investigates 26 sensory and 14 emotional aspects of touch processing. In one study using the TPT it was reported that three emotional factors; positive affect, arousal and negative arousal, were particularly important in influencing how the participants perceived the touch (Ackerley et al., 2014b). In that regard, using such a questionnaire in paper III at the start and at the end of the sessions would have complemented our findings in that they would have potentially offered a richer description of 
how the slow stroking touch changed with repeated stimulation and if the reduction in pleasantness ratings were driven primarily by sensory or emotional mechanisms.

One of the strengths of paper III, however, was that the participants provided subjective reports immediately after the touch had been experienced, which has been reported as more valid than retrospective subjective reports that are provided some distance in time from the experience (Robinson and Clore, 2002). Moreover, the main strength of paper III was the inclusion of a second session. Previous studies have shown that people try to achieve consistency in their ratings, [see for instance Wallace et al. 1992)], however, considering we were able to demonstrate a consistent response pattern to slow stroking touch at a second time of testing, suggests the subjective reports were indeed genuine representations of how people perceived the touch.

\subsection{Power and Generalisability}

In paper I and III of this thesis, we calculated the a priori power analysis using PANGEA (Westfall, 2016, Westfall et al., 2014) as described in the Methods section. Moreover, the sample sizes in the papers are comparable to similar papers in the field of affective touch [see for instance Pawling et al. (2017b), Keizer et al. (2019), Essick et al. (2010), Schirmer et al. (2011)]. However, the reported effects sizes for the subjective and physiological responses were moderate-to-low, as described by Page-Gould (2016). As the effect size may be considered a proxy for the experimental effect and the strength between two variables (Kelley and Preacher, 2012), a low effect-size obviously has implications for the strength of the findings and the overall generalisability of the findings. For instance, in paper III, even the largest effect size describing the relationship between the pleasantness ratings and "Trial" was reported at 0.2. This may suggest that the experimental effect that we observed was not greater than the overall effect of time. A larger sample could have substantiated our findings and thus increased the confidence in our findings.

\subsection{Facial EMG}

Hess and colleagues have previously demonstrated that facial EMG is a reliable method for quantifying muscular activation to visual stimuli (Hess et al., 2017), although issues that relate to the meaning of emotional expressions persist. However, during the revision of paper I, we were criticised for the filtering procedures. Specifically, in paper I and III, we opted for a somewhat different filtering procedure, which does not follow the standard filtering pipeline [see for instance van Boxtel (2001) for suggested filtering standards]. 
Specifically, in our studies, we used a $50 \mathrm{~Hz}$ FIR high pass filter as opposed to the conventional $20 \mathrm{~Hz}$ high pass filter. To be entirely precise regarding the filtering steps that were used in the paper I and III: The 10-500 Hz bandpass filtering happens on the amplifiers in real-time and determines what data is relayed into the BioPac system. In the next step, the comb band stop filter and the FIR filter were applied to the raw data and outputted to the "processed" channels. This procedure allowed us to keep the raw EMG data separated from the processed EMG data, offering flexibility in processing the data and the ability to retrace without the loss of data if mistakes were made. The FIR filter was used to filter out contaminating ECG activity, as previous data sets have been found to be affected by ECG artefacts (Zhou et al., 2007). Previously, and in close collaboration with BioPac, the second author of paper I (Leah M. Mayo) tested this procedure by processing 30 data files with and without the filter. In doing so, she found that the $50 \mathrm{~Hz}$ high pass filter did not change the overall results per se, but led to 'cleaner' data, i.e. the average EMG responses to all types of stimuli (positive, neutral, and negative IAPS stimuli) were lower, resulting in a clearer distinction between stimuli types. Thus, the reasons for applying the $50 \mathrm{~Hz}$ high pass filter were twofold: 1; The $50 \mathrm{~Hz}$ FIR high pass filter was used to eliminate line noise and 2; to allow for comparisons with previous publications by the second author of paper I [see for instance Mayo and de Wit (2015), Mayo et al. (2018)]. However, in paper I and III this filtering procedure was applied as one of the later filtering steps (and not to the incoming raw EMG data) in case it was determined to be unnecessary or harmful.

Nevertheless, to verify the results from the current data collection, we re-analysed the corrugator responses from ten randomly selected participants from paper I. In this reanalysis, the data were filtered using a standard $10-500 \mathrm{~Hz}$ band pass filter, a $50 \mathrm{~Hz}$ comb band stop filter, and a $20 \mathrm{~Hz}$ high pass filter. We then compared the results from the same ten participants using a $50 \mathrm{~Hz}$ high pass filter. As can be seen from the mean values and Fig. 14 below, the amplitudes were similar and the reanalysed data also demonstrated that $\mathrm{CT}$ targeted touch led to a reduction in corrugator activation and control touch led to a slight increase in corrugator activation. 

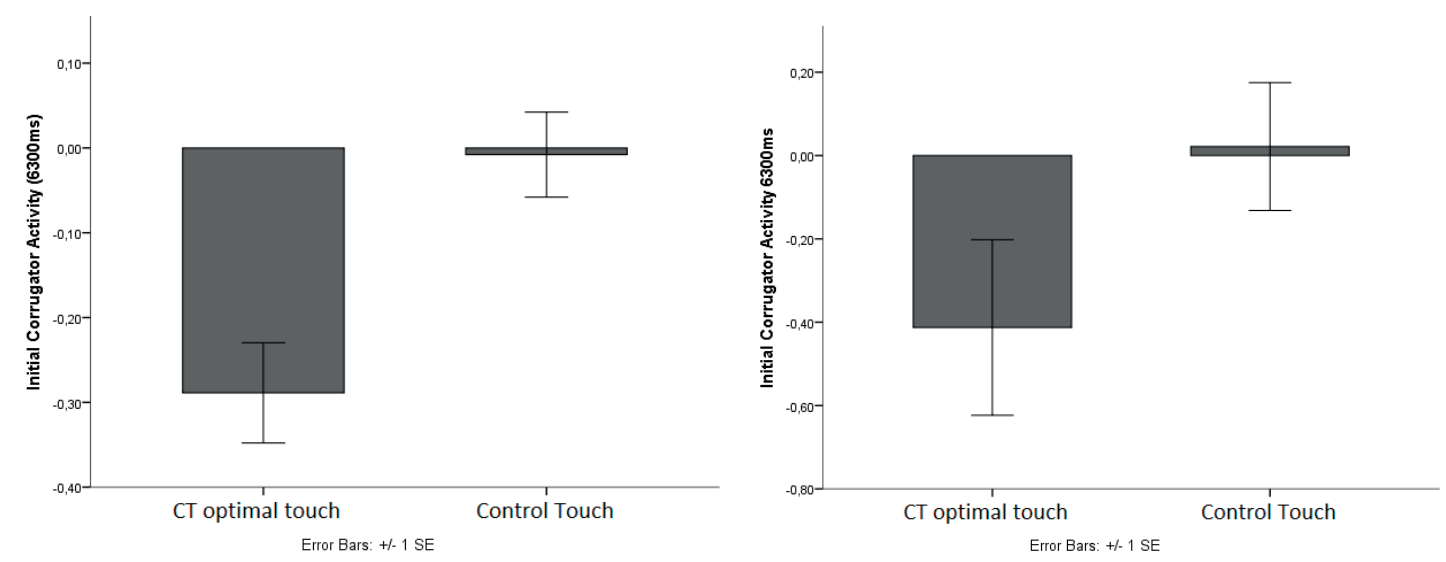

Fig. 14. Both samples were subjected to a $10-500 \mathrm{~Hz}$ band pass filter and a $50 \mathrm{~Hz}$ comb band stop filter. Left: Corrugator activity in ten random participants using a $50 \mathrm{~Hz}$ high pass filter. Right: Results from the same ten random participants using a $20 \mathrm{~Hz}$ high pass filter. Note that the mean applies to the initial $6300 \mathrm{~ms}$ of activity. 
Table 2. Mean corrugator values with SD in response to CT targeted touch and control touch.

\begin{tabular}{rllcrcc} 
Participant & Condition & \multicolumn{2}{c}{ 20 Hz highpass } & \multicolumn{2}{c}{ Hz highpass } \\
& & Mean & SD & Mean & SD \\
1 & CT & $-0,57$ & 0,48 & $-0,41$ & 0,52 \\
9 & Control & 0,02 & 0,13 & 0,04 & 0,29 \\
9 & Control & 0,08 & 1,75 & 0,36 & 0,87 \\
14 & CT & $-0,23$ & 0,42 & $-0,38$ & 0,35 \\
14 & Control & $-0,27$ & 0,34 & $-0,29$ & 0,34 \\
18 & CT & $-0,08$ & 0,17 & $-0,05$ & 0,16 \\
18 & Control & $-0,05$ & 0,19 & $-0,06$ & 0,24 \\
20 & CT & 0,35 & 0,29 & 0,24 & 0,52 \\
20 & Control & $-0,25$ & 0,27 & $-0,07$ & 0,35 \\
31 & CT & $-0,67$ & 0,39 & $-0,57$ & 0,28 \\
31 & Control & 0,11 & 1,65 & 0,04 & 1,41 \\
32 & CT & 0,05 & 0,07 & 0,12 & 0,19 \\
32 & Control & 0,29 & 0,70 & $-0,02$ & 0,48 \\
40 & CT & $-2,16$ & 1,40 & $-1,16$ & 1,07 \\
40 & Control & 0,00 & 0,04 & $-0,21$ & 0,30 \\
42 & CT & $-0,40$ & 1,12 & $-0,36$ & 1,10 \\
42 & Control & 0,28 & 0,27 & 0,14 & 0,35 \\
\hline & & & & &
\end{tabular}

As Table 2 demonstrates, there was slightly more variance in the single-subject data that had been filtered using a $20 \mathrm{~Hz}$ high pass filter. A paired samples t-test demonstrated that the "old" (50 Hz filter) and "new" (20 Hz filter) measures of corrugator activity during CT targeted touch were not significantly different $(p=0.31)$ and control touch "old" vs "new" values were not significantly different $(p=0.64)$. Thus, the additional analysis suggests that the lower corrugator activity observed during CT-targeted touch in paper I was not due to the filtering procedures of the facial EMG data, but rather due to reasons that have been discussed in depth previously in the papers and the thesis. However, from a personal point of view, in retrospect, I should have checked the filtering procedures more thoroughly and adhered to published, consensual procedures. It was a hard-earned lesson that led to much subsequent 
work and one that is likely to sit with me for a while; As of today, I have published three papers that deal with facial EMG responses and for the next one I will ultimately have to decide on whether I continue with the $50 \mathrm{~Hz}$ high pass filter, which will allow me to make strict comparisons with my previous publications or whether I use the $20 \mathrm{~Hz}$ high pass filter to allow for direct comparisons with a larger publication database of facial EMG findings.

\subsection{Skin Conductance Level}

Several methodological challenges need to be addressed when it comes to the use of skin conductance level (SCL). First, a change in SCL is in itself not a very reliable measure, due to the normally fluctuating levels within subjects and the ebb and flow of naturally occurring skin conductance responses (SCRs) (Boucsein, 2012, Dawson et al., 2007). However, based on the recommendations by Braithwaite et al. (2013) and Dawson et al. (2007), we subtracted the SCRs from the SCL (see "Methods" section for specific details). Therefore, I am confident that the change in SCL that we observed in paper I represents a reliable indicator of arousal. However, a more pertinent question is whether I should have favoured SCRs as the designated methodology over SCL or not. This is particularly true considering that SCRs are a component of the orienting response to stimuli and therefore associated with attention to a stimulus (Dawson, Schell et al. 2007). In Paper I, we specifically subtracted the mean SCRs value from the mean SCL value derived from the initial eight seconds of the two minutes period, as recommended by Braithwaite et al. (2013). Effectively, this procedure reduces the effects of the SCRs on the actual SCL, as major changes in attention during this rather short interval of eight seconds are not very likely. However, in retrospect, the experimental set-up should have allowed for separate periods of investigations, where we should have specifically investigated the SCRs to the initial touches, whilst still investigating the overall change in SCL across the two-minute period. This would have provided us with richer and more accurate data and allowed us to compare the SCRs to previous studies that have investigated SCRs to affective touch (Pawling et al., 2017b, Greco et al., 2015, Olausson et al., 2008)]. However, at the time of planning the study, no other studies had reported the SCL in response to CT targeted touch and it therefore appeared more novel than investigating the SCRs.

Another issue with the reported SCL in paper I, however, is that our findings suffer from having used incorrect application of electrode gel, which may ultimately interfere with sweat glands activity (Dawson et al., 2007). Unfortunately, as a novice researcher in the field of EDA, I relied too heavily on the practical aspect of the beginner's guide, which does not 
specify in the same detailed manner the importance of selecting appropriate gel. The extent to which this affected our results, I can only speculate. However, a study reported the effects of leakage of sweat into high NaCL content gel, to be slow, and to quote the authors: "only significant in long time monitoring" (Tronstad et al., 2010, p, 1406). Moreover, the authors reported that the effects of the different types of gel were most significant at abdominal measurements, as the thicker skin corneum of the palms provided a "protection" against the depletion of gel into the sweat ducts. Nevertheless, I entirely acknowledge that it may affect the validity of the results, and the results were therefore discussed cautiously in paper I.

\subsection{Heart Rate Variability}

During the planning of study 2, we were aware of one study that had documented an effect in HRV following prolonged exposure to CT targeted touch (Triscoli et al., 2017b). In that study, the participants HRV, as expressed by the standard deviation of N-N intervals (SDNN) increased in response to $\mathrm{CT}$ targeted touch compared to vibration. The authors suggested that CT targeted touch had a positive modulatory effect on the ANS, in line with prominent theories of HRV, [see for instance Thayer and Lane (2000) and Smith et al. (2017)]. Moreover, several studies had documented changes in other heart-related outcome measures, such as heart rate deceleration (Fairhurst et al., 2014, Pawling et al., 2017b, Triscoli et al., 2017a). Thus, in paper III, we expected the slow stroking touch to lead to an increase in HRV and were somewhat surprised by the null effect. However, in retrospect, this part of my $\mathrm{PhD}$ research appears the most exploratory and would have benefitted from more planning and work on my behalf prior to the start of the study.

At the time of the data collection, however, I was more focused on the technical aspects of the study, such as setting up the experimental laboratory in a different country and collecting data of good quality, rather than asking myself how this methodology could provide potential answers to my scientific questions. Reflecting on that period in hindsight, I remember discussing with my co-authors during the planning of the study whether RMSSD was a better outcome measure than SDNN, due to the relatively short time period that we investigated. This was based on reading the recommendations by the Task Force Guidelines (1996), which explicitly stated that RMSSD was the preferred measure to SDNN when investigating short time intervals. Perhaps it was the genuine naivety of being a novice researcher that made me believe that demonstrating a response in the RMSSD as opposed to the SDNN reported in Triscoli et al. (2017b) would actually bring the scientific community forward. In all fairness, even if we had documented an increase in RMSSD following the slow 
stroking touch applied in paper III, it would be difficult to distinguish the effects of the slow stroking touch from those obtained by, for example, simply relaxing in a chair during the approximately 60 minutes it took to complete the experimental sessions.

The obvious reason for this is the lack of a control question in our study. We discussed this issue during the planning phase of the experiment, however, as we were interested in documenting consistent subjective and physiological responses to slow stroking touch, we opted to examine these responses in detail at two sessions and therefore deemed it unnecessary to have a control condition. Moreover, we collected odour ratings after the touch trials, which served as a control and was reported in the original publication (Ree et al., 2020). Importantly, in paper III, we demonstrated consistent subjective responses and partially consistent facial EMG responses to slow stroking touch and these findings suggest that we partly implemented the appropriate methodology to answer our scientific questions. The selected cardiac measure, however, appears suboptimal, as we collected an outcome measure that is more reliable the longer the period of data collection, when in fact, the tactile input in our study was only transient and brief (3.3 sec per trial). One striking difference between the tactile stimulation in our study and that used by Triscoli et al. (2017b), is that Triscoli and colleagues investigated repeated stimulation for 35 minutes intersected by ratings every two minutes, whereas our study investigated single trials of slow stroking touch with an interstimulus interval of approximately $30 \mathrm{sec}$. Thus, the tactile impact in Triscoli et al. (2017b) largely exceeded that used in our paper and consequently, our study was less likely to yield a response in the HRV measure.

A final point should be made as to whether a cardiac outcome measure was the appropriate measure of arousal, given the experimental setup. In fact, it is maintained by Boucsein (2012) that heart measures should be used for high-intensity levels of arousal, such as exercise, whereas skin conductance level should be used in cases of lower intensity arousal, such as those induced by various cognitive loads. Thus, in retrospect, perhaps a combination of subjective response, facial EMG responses and skin conductance level would have offered even richer data and more satisfactory answers to the original scientific questions outlined in paper III. Furthermore, investigating electrodermal responses in a second study would also have reinforced my skills of conducting and analysing data that relate to electrodermal responses and thus, served as a natural extension from study 1 . 


\subsection{Prosocial Behaviour}

An important issue with the thesis' investigation of prosocial behaviour relates to the null findings published in paper II. Put bluntly, we did not manage to recreate the prosocial nature of touch, consistently reported in field and observational studies (Fisher et al., 1976, Crusco and Wetzel, 1984, Guéguen, 2002, Guéguen and Fischer-lokou, 2003, Stephen and Zweigenhaft, 1986). Our participants in experiment 3 of paper II were predominantly prosocial, with the remainder classified as individualistic, meaning that most of the participants decided to share the allocated money evenly between themselves and the "other" participant. This is similar to the original publication, where $59 \%$ were categorised as prosocial, 35\% as individualistic and the remainder as competitive (Murphy et al., 2011). Thus, it is unlikely that the null finding in our study was due to the participants and their level of generosity or prosocial status before the start of the experiment.

One potential explanation for the null findings has to do with the intention, or meaning of the touch, as perceived by the participants. As someone is receiving touch, he or she is likely to bestow, consciously or subconsciously, a meaning to the touch (Jakubiak and Feeney, 2017). Thus, receiving touch by a waiter in a restaurant may be interpreted as a sign of physical and emotional closeness, or even as a sign of affection (Floyd, 2006) or need (Rose, 1990). This may initiate physiological and psychological changes in the receiver of the touch, ultimately leading to a prosocial behaviour towards the waiter. Moreover, CT targeted touch is also known to be modulated by top-down cognitive processes, such as the gender of the toucher, [see recent review by Russo et al. (2019)], and the concomitant presence of an odorant (Croy et al., 2016a) or visual stimulus (Ellingsen et al., 2015), all of which may have been present in one form or shape in the field studies. Thus, prosocial touch in field studies appears to have several contextual and social additives that we were unable to re-create in a laboratory setting and therefore we were unable to document the same level of prosocial behaviour following touch.

However, rather than considering which specific contextual or social factor lacked in our laboratory setting, perhaps a slight change of perspective is needed? After all, studies from the pain field have consistently demonstrated that placebos can have profound painrelieving effects [see for instance Price et al. (2008a) and Geers and Miller (2014)], despite the pills themselves carrying no active ingredients. This has led some researcher to adopt the term "meaning-response" to the traditional placebo-response [see for instance Moerman and Jonas (2002)], to reinforce that the pain-relieving mechanisms of placebos reside not in the 
pill itself, but in the meaning bestowed upon the pill by its recipients. Thus, the greater the meaning bestowed upon the pill, the greater the response. By extension, if we had been able to increase the meaning the participants perceived of the touch when it was applied in the laboratory, there is a chance we would have seen a greater response. A relatively simple (yet expensive) way to do so would be to allow people to allocate real and large sums of money between themselves and a friend and investigate if touch, applied openly or discretely to one of the participants, changed the level of prosocial behaviour. Future studies could hopefully use the information from our study and those reported by Koppel et al. (2017) to design experiments that mimic the events taking place in real life more closely, yet still controlling the variables with the same precision as that described in highly controlled laboratory experiments.

\subsection{Stimulus Selection and Comparison}

A critical aspect of the various stimuli that have been used in this thesis is whether comparing touch applied at $3 \mathrm{~cm} / \mathrm{s}$ to $0.3 \mathrm{~cm} / \mathrm{s}$ is contrasting enough to offer meaningful insights into $\mathrm{CT}$ processes. This is particularly important, considering that $\mathrm{CT}$ fibres have been reported to respond to slow and even static touch (Vallbo et al., 1999, Iggo, 1960, Iriuchijima and Zotterman, 1960). One way to increase the contrast between the tactile conditions would be to compare hairy skin to glabrous skin, which, up until the recent discovery of CT fibres in glabrous skin (Watkins et al., 2020), was considered free from CT fibres. However, this poses several problems. First, touch at approximately $3 \mathrm{~cm} / \mathrm{s}$ applied to the glabrous skin is frequently rated as equally pleasant as when applied to the hairy skin [see for instance Luong et al. (2017), Pawling et al. (2017a), Schirmer and Gunther (2017), Mayo et al. (2018)]. Moreover, at the time of the planning of the study, studies had shown the different pleasantness ratings of the various velocities to be one of the most defining aspects of the touch and linked to the firing frequency of the CT fibres (Löken et al., 2009, Ackerley et al., 2009). Thus, we expected that touch applied to the hairy skin at $0.3 \mathrm{~cm} / \mathrm{s}$ would offer greater contrasts in pleasantness ratings than comparing $3 \mathrm{~cm} / \mathrm{s}$ applied to hairy and glabrous skin. More importantly, however, is the fact that changing body sites changes the dynamics of the "sensory cocktail", both at peripheral and central levels. For instance, it is well known that the density of CT fibres and A $\beta$ fibres vary according to body site [see for instance Johansson and Vallbo, (1979), Vallbo et al. (1995), Edin, (2001)]. Moreover, the cortical representations of the hand versus the arm, are known to be different (Penfield and Boldrey, 1937). Thus, the 
sensory input and representation would have been very different had we investigated the responses to glabrous and the hairy skin.

In paper I, we also considered comparing CT targeted touch to a faster type of touch, such as $30 \mathrm{~cm} / \mathrm{s}$ instead of the very slow $0.3 \mathrm{~cm} / \mathrm{s}$. However, $0.3 \mathrm{~cm} / \mathrm{s}$ was favoured over 30 $\mathrm{cm} / \mathrm{s}$ for several reasons: First, as we used constant stimulation for two minutes, it was considered easier to control for variation in sensory stimulation over time, as $0.3 \mathrm{~cm} / \mathrm{s}$ would lead to approximately four strokes delivered during the two-minute trials, compared to the 30 $\mathrm{cm} / \mathrm{s}$, which would lead to approximately 363 strokes delivered during the two-minute trials. Second, (although not always the primary investigations of the studies) several studies suggested slow touch $(0.1-0.3 \mathrm{~cm} / \mathrm{s})$ was rated as less pleasant than fast touch $(30-50 \mathrm{~cm} / \mathrm{s})$ [see for instance Sehlstedt et al. (2016), Triscoli et al. (2014a), Essick et al. (1999), Löken et al. (2009)]. Consequently, we expected that $0.3 \mathrm{~cm} / \mathrm{s}$ would offer a greater contrast in pleasantness to CT targeted touch than $30 \mathrm{~cm} / \mathrm{s}$. A third and final point was based mostly on empirical experience: At the commencement of my PhD degree, I had worked sixteen years as a physiotherapist and osteopath with a special interest in therapeutic touch. In these years, I had yet to encounter people who actually found very fast, "brisk" movements, similar to 30 $\mathrm{cm} / \mathrm{s}$, comforting or pleasant. However, slow, almost static touch had frequently been described as relaxing and pleasant by patients and used in many situations to offer consolation and comfort. Consequently, during the planning of the study, when weighing the pros and cons of $0.3 \mathrm{~cm} / \mathrm{s}$ versus $30 \mathrm{~cm} / \mathrm{s}$, I was more inclined to use $0.3 \mathrm{~cm} / \mathrm{s}$, as I considered the slower form of touch as inherently more clinical. Thus, while I acknowledge that CT fibres certainly respond to static and very slow touch (Vallbo et al., 1999, Iggo, 1960, Iriuchijima and Zotterman, 1960), the overwhelming data suggest that the inverted U applies to the hedonic ratings of pleasantness and that touch applied at $0.3 \mathrm{~cm} / \mathrm{s}$ offered a suitable contrast to the more pleasant $3 \mathrm{~cm} / \mathrm{s}$ (Löken et al., 2009, Luong et al., 2017, Essick et al., 1999, Ackerley et al., 2014a, Sehlstedt et al., 2016).

One of the novel aspects of this thesis is the comparison of tactile responses to those obtained when watching a visual control condition (paper I and II) and smelling an odorant (paper III). In paper I and II, the visual control condition was included for several reasons. At the time of planning the study, we were uncertain as to the mechanisms that were driving the prosocial effects of touch that had been reported in field studies, as some studies had indeed reported that the participants had not consciously perceived being touched (Guéguen, 2002, Fisher et al., 1976). This suggested that subconscious mechanisms were involved and we 
speculated as to whether some of the prosocial mechanisms were due to the relaxing effects of touch. Therapeutic touch had been reported to reduce anxiety and promoted well-being [see for instance Lindgren et al. (2010)]. Other studies pointed to the attentional effects of the touch (Schirmer et al., 2011, Spapé et al., 2017). However, in the study by Lindgren et al. (2010), the participants in the control group were left waiting passively without any kind of stimulation. Contrary to this, we were looking for a control condition that was mildly pleasing and engaging, rather than passively watching a black screen for two minutes. Thus, the visual control condition was considered appropriate, as we considered it relaxing and engaging.

Another motivation for including the visual control condition was based on a paper by Löken et al. (2011). In that paper, it was suggested that CT-targeted touch could modify the perceived pleasantness of non-CT targeted touch. The authors reported that touch aimed to stimulate CT fibres of hairy skin subsequently led to enhanced pleasantness ratings of touch directed to the glabrous skin, potentially leading to activation of "emotional memory circuits", (Löken et al., (2011), p. 13). The order effect described in Löken et al. (2011), however, could equally take place at other levels, particularly at the dorsal horn of the spinal cord, which hosts a complicated network of interconnected interneurons receiving input from both myelinated A fibres and unmyelinated C fibres (Craig, 2002, Abraira and Ginty, 2013). It is known from studies in the pain field that input from A fibres may modulate C-nociceptive input at the dorsal horn of the spinal cord (Melzack and Wall, 1965, Mendell, 2014), however, the CT fibre pathway is still not fully understood and it remains debatable as to whether CT fibres ascend in the spinothalamic pathway or not (Marshall and McGlone, 2020). At the time of planning the study, I was motivated to investigate the potential for CT targeted touch to influence a visual control stimulus and by extension, effectively support the notion that the mechanisms would be supramodal. Unfortunately, as a novice researcher, I was unable to communicate my intentions effectively to my supervisors and unable to design the study appropriately myself, and sadly, the experimental set-up did not allow me to investigate this further.

One of the main objectives of paper III was to investigate whether the responses to slow stroking touch were consistent when tested under similar conditions during a second session. Moreover, we wanted to investigate if the affective habituation response patterns were specific to touch responses or if the affective habituation responses were similar across modalities. Consequently, we included odour as a control condition, as the affective habituation responses to odour had already been investigated in a previous study (Sailer et al., 
2016b). During the planning of Study 2, we discussed different possible means of grouping the participants' tactile responses and their affective habituation patterns. Based on the publication of Sailer et al. (2016b) we at first tried to group participants based on statistically determined models, such as stepwise decrease, linear decrease, exponential decrease, linear increase and so forth. However, this resulted in a very low number of participants per category which hampered statistical analysis and consequently, this method was discarded. We also considered discarding the odour condition and reducing the number of touch trials, to include a comparable touch condition. However, reducing the number of touch trials at $3 \mathrm{~cm} / \mathrm{s}$ would have reduced the power of the findings and as we wanted to investigate the stability of touch satiety responses, we deemed it more important to include more touch trials at $3 \mathrm{~cm} / \mathrm{s}$ than including a tactile control condition.

A limitation of paper III was that we did not check how the participants' mood or feeling of boredom affected the rating behaviour. Self-reported measures of mood are simple to administer and offer a reliable means of assessing someone's conscious appreciation of their current mood status [see for instance Barrett, (1996)]. Boredom may be considered an emotion that is closely linked to the degree to which we perceive our present attention as meaningful and engaging, and thus, likely to affect behaviour (Westgate and Steidle, 2020). The feeling of boredom may be triggered by predictability, confinement and monotony (Toohey, 2011) and consequently, the monotonous experimental set-up of Study 2 could have triggered boredom, as experienced by the participants. During the planning of the study, we discussed the possibility of asking for boredom ratings during the sessions, however, as we did not want to prime the participants' responses, we decided against asking how they felt during the session. This could have been solved, potentially, by asking the participants how they felt after the sessions, however, this was forgotten during the planning of the study. This was unfortunate and should have been planned better. Moreover, we could have collected a baseline reference for boredom and pleasantness ratings at the start of the session. This would have enabled us to compare the effects of time on boredom and pleasantness ratings.

Nevertheless, the pleasantness ratings were similar between session 1 and session. If the effects of boredom had been profound, we would have expected to see a larger drop in ratings in session 1 than in session 2.

\subsection{Statistical Considerations}

The reasons for preferring LMMs over traditional ANOVA are based on the growing body of literature that favours LMMs over ANOVA. The influential paper by Gueorguieva 
and Krystal (2004) lists several advantages of mixed models, including the ability to deal with missing data from participants with greater accuracy, and allow greater flexibility to model time effects. Moreover, even the simplest models incorporating random intercept and slope allow for greater accuracy of the statistical analysis than traditional ANOVA (Gueorguieva and Krystal, 2004). These aspects were considered particularly relevant for the data in the thesis, given the repeated nature of the stimuli in our studies. Thus, a tailored LMM will allow for estimation of varying individual differences in rating behaviour and starting points, such that individuals whose ratings drop faster than others will individually be fitted to the model, rather than a group-average estimation. This, it is argued, allows for greater precision and ultimately greater statistical power than the traditional ANOVA (West et al., 2014, Gueorguieva and Krystal, 2004). Naturally, the greater flexibility also puts additional responsibility on the researcher, as it is paramount that the model has to be tailored to the individual study. In my research, I have tried to conduct statistical analysis to the best of my ability and by adhering to principles laid out by several scholars (West et al., 2014, Bolker et al., 2009, Magezi, 2015, Barr et al., 2013, Gueorguieva and Krystal, 2004). Consequently, the LMMs have been parsimonious and constructed with the aims of testing our specific hypothesis rather than being data driven. This is referred to as a "top-down" model by West et al. (2014), where one typically starts by including all the relevant fixed factors and their interactions, then the random effects before selecting the covariance structure of the residuals. Finally, the model is reduced through appropriate statistical usage of the Bayesian Information Criteria (BIC). If a model is changed by adding or removing one of the factors or by changing covariance structure and the BIC values is reduced by more than two units, the models precedes with the added change, as described by Bolker et al. (2009).

An important aspect of any $\mathrm{PhD}$ degree is that statistical skills should evolve and improve - and so have mine during my PhD studies and particularly following discussions and tutorials with statisticians and other colleagues. Prior to the data analysis in paper III, I consulted a statistician at the department and this led to a different form of analysis than in paper I. This was partially due to the fact that I found it rather arbitrary to compare several pairwise contrasts which had been the case in paper I. In paper III, this issue would have been magnified, as we had a total of 120 trials across two sessions. Thus, rather than computing several pair-wise post-hoc tests (which would have increased the risk of making type I errors), we investigated whether the slope of the regression line ("Trial") differed between session 1 and session 2. To resolve the interactions, the slopes (for example for the corrugator 
activation across trials) and their $p$-values were reported separately for session $1(b=0.0024$, $\mathrm{t}(107)=3.99, \mathrm{p}=0.001)$ and session $2(\mathrm{~b}=0.0001, \mathrm{t}(107)=0.23, \mathrm{p}=0.817)$ [see Table 1 in paper III or Table 1, p. 53 in the thesis for a complete overview]. A significant slope in session 1, but not in session 2 would then explain the interaction, in this case that the corrugator activity increased during session one, but not during session 2 . We favoured this approach instead of multiple pairwise comparisons of 60 trials. One reason for this is practical (SPSS does not allow more than 50 pairwise comparisons). Moreover, correcting the alphalevel for 60 comparisons would be overly conservative and would not reflect the exploratory nature of the study and, importantly, we would not be any wiser about how to interpret the interaction. One could select only particular comparisons from those 60 trials (like every tenth trial) but we believe this would have appeared somewhat arbitrary. In contrast, finding out that the slope of the regression line fitted to a variable increases over 60 trials is more informative than, say, that trial 12 differs from trial 53. Additionally, it resolves the issue of having to account for multiple comparisons and the potential for making Type I errors. 


\section{Ethical Considerations}

All the papers have been approved by the appropriate institutions and this has been specified in the respective papers. Copies are attached as appendices 1-5.

Paper II of this thesis presented us with an additional issue that needed special considerations: Since we wanted to investigate if touch made people more generous towards other people, we needed a cover story. Therefore, we told the participants that the amount of money that they shared with a random another participant, could affect both the money they were allocated themselves and the amount of money the randomised other participant received. At the end of the study, however, they were informed that they would receive a gift voucher of NOK 200 irrespective of how they had allocated the money. This kind of mild deception was deemed necessary to reduce the likelihood that the participants' expectations of having to behave in a certain manner influenced the way the participants allocated the money. Moreover, we deemed it necessary to ensure that the participants were thorough and meticulous when deciding how to allocate the money, and not just allocating the money at random. In contrast to this approach, however, Koppel et al. (2017) did not deceive the participants and did not report that it affected the participants' behaviour.

In study 1 and 2, interested participants were provided with written and verbal information regarding the design and purpose of the study and the possibility to withdraw from the study at any time. In study 2, a specific point of potential ethical concern pertains to the private nature of being touched on the arm by a hand, as opposed to by a robot or brush. This was particularly relevant in the data collection for study 2 as the \#metoo movement was gaining international recognition. Although people volunteer to participate in scientific research, at the time we felt it was especially important to ensure that the participants' personal boundaries were not intimidated by any means. Therefore, before the start of each experimental session in study 2 , the participants, all consensual adults, were explicitly told that the study involved skin-to-skin touch on the participant's left arm and that they could terminate the session at any time. Additionally, due to the lengthy nature of study 2 , we had a "touch-aversion" cut-off criterion which ensured that the study was terminated if a participant found the touch unpleasant. Specifically, if a participant rated the touch as unpleasant for five consecutive trials (between -10 and -8 ), the session was terminated. This, thankfully, occurred only once for one participant in session 1 after the $49^{\text {th }}$ trial, suggesting that the experiment was indeed tolerable. 


\section{Conclusions and Future Perspectives}

At the start of my $\mathrm{PhD}$, my colleagues and I set out to investigate several aspects that relate to the psychophysiology of affective touch and the subjective, physiological and behavioural responses that can be attributable to touch that aims to activate CT fibres of the human hairy skin. Overall, we were able to demonstrate consistent findings that relate to the perceived pleasantness of CT targeted touch which were in line with previous publications. Moreover, we extended previous findings by demonstrating that the subjective reports in response to slow stroking touch were consistent and similar when the same group of participants were tested at a second session.

We also aimed to demonstrate coherent and novel responses to affective touch using physiological and behavioural measures, of which we were only partially successful. Specifically, we did not find a coherent response pattern in the skin conductance level and heart rate variability measures that could be attributable to the impact of the CT fibres, or indeed, affective touch in general. Despite that several field studies have consistently shown that people are more prosocial after receiving touch, we were unable to document any such effects in a laboratory setting, using investigations of generosity, expressed through various economic games. However, we were partly successful in demonstrating that the corrugator muscle of the face, involved in frowning and expressions of affect, appeared to mirror the subjective responses. Specifically, in paper I, the corrugator activity was lower during CT targeted touch and higher during non-CT targeted control touch and the reduced corrugator activation during CT targeted touch probably reflected an increasing volley of CT afferent input. This type of activity, we propose, is more precisely explored by investigating facial muscle activation in smaller time intervals, to reflect the conduction velocity of the CT afferent fibres.

The impact of being touched should not be trivialised or taken for granted. As I write the concluding remarks to the work that has spanned four years, we are suffering the effects of being in the middle of a global pandemic, avoiding close physical contact at all costs and using facial masks to prevent the further spread of the Covid-19 virus. How I miss being able to embrace friends and smile purposefully to the shop assistant as I collect my weekly shopping. Touch and facial expressions, which have been explored in detail throughout this thesis, are vital everyday interactive activities that are used to signal affect and intent between people. Moreover, touch affects us on so many levels, both emotionally, physiologically and socially and appears vital to our overall well-being and health. In that regard the findings from 
this thesis offer new and important information that further our understanding of how affective touch is processed and the mechanisms that mediate touch-related behaviour. 


\section{References}

ABRAIRA, V. E. \& GINTY, D. D. 2013. The sensory neurons of touch. Neuron, 79, 618-39 DOI: 10.1016/j.neuron.2013.07.051.

ACKERLEY, R., BACKLUND WASLING, H., LILJENCRANTZ, J., OLAUSSON, H., JOHNSON, R. D. \& WESSBERG, J. 2014a. Human C-tactile afferents are tuned to the temperature of a skin-stroking caress. The Journal of Neuroscience, 34, 2879-83 DOI: 10.1523/jneurosci.2847-13.2014.

ACKERLEY, R., ERIKSSON, E. \& WESSBERG, J. 2013. Ultra-late EEG potential evoked by preferential activation of unmyelinated tactile afferents in human hairy skin. Neurosci Lett, 535, 62-6 DOI:

10.1016/j.neulet.2013.01.004.

ACKERLEY, R., SAAR, K., MCGLONE, F. \& BACKLUND WASLING, H. 2014b. Quantifying the sensory and emotional perception of touch: differences between glabrous and hairy skin. Front Behav Neurosci, 8, 34 DOI: 10.3389/fnbeh.2014.00034.

ACQKNOWLEDGE SOFTWARE GUIDE. 2018. BioPac Inc. https://www.biopac.com/wp-content/uploads/AcqKnowledge-5Software-Guide.pdf

APPELHANS, B. M. \& LUECKEN, L. J. 2006. Heart rate variability as an index of regulated emotional responding. Review of General Psychology, 10, 229-240 DOI: $10.1037 / 1089-2680.10 .3 .229$.

BACKLUND WASLING, H., NORRSELL, U., GÖTHNER, K. \& OLAUSSON, H. 2005.

Tactile directional sensitivity and postural control. Exp Brain Res, 166, 14756 DOI: $10.1007 / \mathrm{s} 00221-005-2343-5$.

BARR, D. J., LEVY, R., SCHEEPERS, C. \& TILY, H. J. 2013. Random effects structure for confirmatory hypothesis testing: Keep it maximal. J Mem Lang, 68, 255278 DOI: $10.1016 /$ j.jml.2012.11.001.

BARRETT, L. F. 2017. The theory of constructed emotion: an active inference account of interoception and categorization. Soc Cogn Affect Neurosci, 12, 1-23 DOI: $10.1093 /$ scan/nsw154.

BARRETT, L. F. 1996. Hedonic Tone, Perceived Arousal, and Item Desirability: Three Components of Self-reported Mood. Cognition and emotion, 10, 4768 DOI: 10.1080/026999396380385.

BECKER, S., BRÄSCHER, A. K., BANNISTER, S., BENSAFI, M., CALMA-BIRLING, D., CHAN, R. C. K., EEROLA, T., ELLINGSEN, D. M., FERDENZI, C., HANSON, J. L., JOFFILY, M., LIDHAR, N. K., LOWE, L. J., MARTIN, L. J., MUSSER, E. D., NOLLHUSSONG, M., OLINO, T. M., PINTOS LOBO, R. \& WANG, Y. 2019. The role of hedonics in the Human Affectome. Neurosci Biobehav Rev, 102, 221-241 DOI: 10.1016/j.neubiorev.2019.05.003.

BENSAFI, M., ROUBY, C., FARGET, V., BERTRAND, B., VIGOUROUX, M. \& HOLLEY, A. 2002. Psychophysiological correlates of affects in human olfaction. Neurophysiol Clin, 32, 326-32 DOI: 10.1016/s0987-7053(02)00339-8.

BERG, J., DICKHAUT, J. \& MCCABE, K. 1995. Trust, Reciprocity, and Social History. Games and economic behavior, 10, 122-142 DOI: 10.1006/game.1995.1027. 
BERNHARDT, J. 1987. Sensory capabilities of the fetus. MCN Am J Matern Child Nurs, 12, 44-6

BERNTSON, G. G., QUIGLEY, K. S., NORMAN, G. J. \& LOZANO, D. L. 2017. Cardiovascular Psychophysiology. In: CACIOPPO, J. T., TASSINARY, L. G. \& BERNTSON, G. G. (eds.) Handbook of psychophysiology. 4th ed. Cambridge: Cambridge University Press.

BESSOU, P., BURGESS, P. R., PERL, E. R. \& TAYLOR, C. B. 1971. Dynamic properties of mechanoreceptors with unmyelinated (C) fibers. J Neurophysiol, 34, 11631 DOI: 10.1152/jn.1971.34.1.116.

BOLANOWSKI, S. J. J., GESCHEIDER, G. A., VERRILLO, R. T. \& CHECKOSKY, C. M. 1988. Four channels mediate the mechanical aspects of touch. J Acoust Soc $A m, 84,1680-1694$ DOI: $10.1121 / 1.397184$.

BOLKER, B. M., BROOKS, M. E., CLARK, C. J., GEANGE, S. W., POULSEN, J. R., STEVENS, M. H. \& WHITE, J. S. 2009. Generalized linear mixed models: a practical guide for ecology and evolution. Trends Ecol Evol, 24, 127-35 DOI: 10.1016/j.tree.2008.10.008.

BORNSTEIN, R. F. \& D'AGOSTINO, P. R. 1992. Stimulus recognition and the mere exposure effect. Journal of Personality and Social Psychology, 63, 545-52 DOI: $10.1037 / / 0022-3514.63 .4 .545$.

BOUCSEIN, W. 2012. Generalized Psychophysiological States. In: Electrodermal activity. Springer Science \& Business Media.

BRADLEY, M. M., CODISPOTI, M., CUTHBERT, B. N. \& LANG, P. J. 2001. Emotion and motivation I: defensive and appetitive reactions in picture processing. Emotion, 1, 276-98 DOI: 10.1037/1528-3542.1.3.276.

BRADLEY, M. M. \& LANG, P. J. 2000. Affective reactions to acoustic stimuli. Psychophysiology, 37, 204-15 DOI: 10.1111/1469-8986.3720204.

BRAITHWAITE, J. J., WATSON, D. G., JONES, R. \& ROWE, M. 2013. A guide for analysing electrodermal activity (EDA) \& skin conductance responses (SCRs) for psychological experiments. Psychophysiology, 49, 1017-1034

CACIOPPO, J. T., BERNTSON, G. G., LARSEN, J. T., POEHLMANN, K. M. \& ITO, T. A. 2000. The Psychophysiology of Emotions. In: HAVILAND-JONES, J. M. \& LEWIS, M. (eds.) Handbook of Emotions. 2nd ed. ed. New York: Guilford Press.

CACIOPPO, J. T., PETTY, R. E., LOSCH, M. E. \& KIM, H. S. 1986. Electromyographic activity over facial muscle regions can differentiate the valence and intensity of affective reactions. Journal of Personality and Social Psychology, 50, 260-268 DOI: 10.1037/0022-3514.50.2.260.

CAMRAS, L. A., FATANI, S. S., FRAUMENI, B. R. \& SHUSTER, M. M. 2016. The Development of Facial Expressions. In: BARRETT, L. F., LEWIS, M. \& HAVILAND-JONES, J. M. (eds.) Handbook of Emotions. Fourth edition. ed. New York, New York,London, England: The Guilford Press.

CASCIO, C. J., MOANA-FILHO, E. J., GUEST, S., NEBEL, M. B., WEISNER, J., BARANEK, G. T. \& ESSICK, G. K. 2012. Perceptual and neural response to affective tactile texture stimulation in adults with autism spectrum disorders. Autism Res, 5, 231-44 DOI: 10.1002/aur.1224. 
CASCIO, C. J., MOORE, D. \& MCGLONE, F. 2019. Social touch and human development. Dev Cogn Neurosci, 35, 5-11 DOI: 10.1016/j.dcn.2018.04.009.

CASE, L. K., ČEKO, M., GRACELY, J. L., RICHARDS, E. A., OLAUSSON, H. \& BUSHNELL, M. C. 2016. Touch Perception Altered by Chronic Pain and by Opioid Blockade. eNeuro, 3 DOI: 10.1523/eneuro.0138-15.2016.

COOK, C., HEATH, F., THOMPSON, R. L. \& THOMPSON, B. 2001. Score Reliability in Webor Internet-Based Surveys: Unnumbered Graphic Rating Scales versus Likert-Type Scales. 61, 697-706 DOI: 10.1177/00131640121971356.

COWEN, A. S. \& KELTNER, D. 2017. Self-report captures 27 distinct categories of emotion bridged by continuous gradients. Proc Natl Acad Sci U S A, 114, E7900-e7909 DOI: 10.1073/pnas.1702247114.

CRAIG, A. D. 2002. How do you feel? Interoception: the sense of the physiological condition of the body. Nat Rev Neurosci, 3, 655-66 DOI: 10.1038/nrn894.

CRAIG, A. D. 2009. How do you feel--now? The anterior insula and human awareness. Nat Rev Neurosci, 10, 59-70 DOI: 10.1038/nrn2555.

CRAIG, A. D. \& ZHANG, E. T. 2006. Retrograde analyses of spinothalamic projections in the macaque monkey: input to posterolateral thalamus. $J$ Comp Neurol, 499, 953-64 DOI: 10.1002/cne.21155.

CRITCHLEY, H. D. 2002. Electrodermal responses: what happens in the brain. Neuroscientist, 8, 132-42 DOI: 10.1177/107385840200800209.

CRIVELLI, C. \& FRIDLUND, A. J. 2018. Facial Displays Are Tools for Social Influence. Trends Cogn Sci, 22, 388-399 DOI: 10.1016/j.tics.2018.02.006.

CROY, I., DRECHSLER, E., HAMILTON, P., HUMMEL, T. \& OLAUSSON, H. 2016 a. Olfactory modulation of affective touch processing - A neurophysiological investigation. Neuroimage, 135, 135-41 DOI:

10.1016/j.neuroimage.2016.04.046.

CROY, I., LUONG, A., TRISCOLI, C., HOFMANN, E., OLAUSSON, H. \& SAILER, U. 2016b. Interpersonal stroking touch is targeted to $C$ tactile afferent activation. Behav Brain Res, 297, 37-40 DOI: 10.1016/j.bbr.2015.09.038.

CRUCIANI, G., ZANINI, L., RUSSO, V., MIRABELLA, M., PALAMOUTSI, E. M. \& SPITONI, G. F. 2021. Strengths and weaknesses of affective touch studies over the lifetime: A systematic review. Neurosci Biobehav Rev, 127, 1-24 DOI: 10.1016/j.neubiorev.2021.04.012.

CRUSCO, A. H. \& WETZEL, C. G. 1984. The Midas Touch: The Effects of Interpersonal Touch on Restaurant Tipping. Personality \& social psychology bulletin, 10, 512-517 DOI: 10.1177/0146167284104003.

DARWIN, C. 1872/1998. The expression of the emotions in man and animals, London, John Murray/New York:Oxford University Press.

DAWSON, M. E., SCHELL, A. M. \& FILION, D. L. 2007. The electrodermal system. In: CACIOPPO, J. T., TASSINARY, L. G., BERNTSON, G. G. \& (eds.) Handbook of Psychophysiology. 3rd ed. Cambridge. Cambridge University Press.

DE HAAN, E. H. F. \& DIJKERMAN, H. C. 2020. Somatosensation in the Brain: A Theoretical Re-evaluation and a New Model. Trends Cogn Sci, 24, 529-541 DOI: 10.1016/j.tics.2020.04.003. 
DEBROT, A., SCHOEBI, D., PERREZ, M. \& HORN, A. B. 2013. Touch as an Interpersonal Emotion Regulation Process in Couples' Daily Lives: The Mediating Role of Psychological Intimacy. Pers Soc Psychol Bull, 39, 13731385 DOI: 10.1177/0146167213497592.

DIMBERG, U. 1982. Facial reactions to facial expressions. Psychophysiology, 19, 643-7 DOI: 10.1111/j.1469-8986.1982.tb02516.x.

DOUGLAS, W. W. \& RITCHIE, J. M. 1957. Discharges in non-medullated afferent fibres in the cat's saphenous nerve in response to touch and to drugs. $J$ Physiol, 139, 9-10p

DUCHENNE, G. B. 1862. Mécanisme de la physionomie humaine, ou Analyse électrophysiologique de l'expression des passions / par le Dr. G.B. Duchenne (de Boulogne), Vve J. Renouard (Paris).

DUCHENNE, G. B. \& CUTHBERTSON, R. A. 1990. The mechanism of human facial expression. Cambridge England ;,New York :,Paris: Cambridge University Press ; Editions de la Maison des Sciences de l'Homme.

DUNBAR, R. I. 2010. The social role of touch in humans and primates: behavioural function and neurobiological mechanisms. Neurosci Biobehav Rev, 34, 260 8 DOI: 10.1016/j.neubiorev.2008.07.001.

EDIN, B. B. 2001. Cutaneous afferents provide information about knee joint movements in humans. J Physiol, 531, 289-297 DOI: 10.1111/j.14697793.2001.0289j.x.

EKMAN, P. 1992. Are there basic emotions? Psychol Rev, 99, 550-3 DOI: 10.1037/0033-295x.99.3.550.

EKMAN, P., DAVIDSON, R. J. \& FRIESEN, W. V. 1990. The Duchenne Smile: Emotional Expression and Brain Physiology II. Journal of personality and social psychology, 58, 342-353 DOI: 10.1037/0022-3514.58.2.342.

EKMAN, P. \& FRIESEN, W. V. 1969. The repertoire of nonverbal behavior: Categories, origins, usage, and coding. J Nonverbal communication, interaction and gesture, 57-106

EKMAN, P., FRIESEN, W. V., O'SULLIVAN, M., CHAN, A., DIACOYANNI-TARLATZIS, I., HEIDER, K., KRAUSE, R., LECOMPTE, W. A., PITCAIRN, T., RICCI-BITTI, P. E. \& ET AL. 1987. Universals and cultural differences in the judgments of facial expressions of emotion. J Pers Soc Psychol, 53, 712-7 DOI: 10.1037//0022-3514.53.4.712.

ELLINGSEN, D. M., LEKNES, S., LOSETH, G., WESSBERG, J. \& OLAUSSON, H. 2015. The Neurobiology Shaping Affective Touch: Expectation, Motivation, and Meaning in the Multisensory Context. Front Psychol, 6, 1986 DOI: 10.3389/fpsyg.2015.01986.

ELLINGSEN, D. M., WESSBERG, J., CHELNOKOVA, O., OLAUSSON, H., LAENG, B. \& LEKNES, S. 2014. In touch with your emotions: oxytocin and touch change social impressions while others' facial expressions can alter touch.

Psychoneuroendocrinology, 39, 11-20 DOI:

10.1016/j.psyneuen.2013.09.017. 
EPSTEIN, L. H. 1990. Perception of activity in the Zygomaticus major and Corrugator supercilii muscle regions. Psychophysiology, 27, 68-72 DOI: 10.1111/j.1469-8986.1990.tb02181.x.

ESSICK, G. K., JAMES, A. \& MCGLONE, F. P. 1999. Psychophysical assessment of the affective components of non-painful touch. Neuroreport, 10, 2083-7 DOI: 10.1097/00001756-199907130-00017.

ESSICK, G. K., MCGLONE, F., DANCER, C., FABRICANT, D., RAGIN, Y., PHILLIPS, N., JONES, T. \& GUEST, S. 2010. Quantitative assessment of pleasant touch. Neurosci Biobehav Rev, 34, 192-203 DOI: 10.1016/j.neubiorev.2009.02.003.

ETZI, R., CARTA, C. \& GALLACE, A. 2018. Stroking and tapping the skin: behavioral and electrodermal effects. Exp Brain Res, 236, 453-461 DOI: 10.1007/s00221-017-5143-9.

ETZI, R. \& GALLACE, A. 2016. The arousing power of everyday materials: an analysis of the physiological and behavioral responses to visually and tactually presented textures. Exp Brain Res, 234, 1659-66 DOI: 10.1007/s00221-016-4574-z.

FAIRHURST, M. T., LÖKEN, L. \& GROSSMANN, T. 2014. Physiological and behavioral responses reveal 9-month-old infants' sensitivity to pleasant touch. Psychol Sci, 25, 1124-31 DOI: 10.1177/0956797614527114.

FELDMAN, R. 2012. Oxytocin and social affiliation in humans. Horm Behav, 61, 380-91 DOI: 10.1016/j.yhbeh.2012.01.008.

FERDENZI, C., PONCELET, J., ROUBY, C. \& BENSAFI, M. 2014. Repeated exposure to odors induces affective habituation of perception and sniffing. Front Behav Neurosci, 8, 119 DOI: 10.3389/fnbeh.2014.00119.

FERNÁNDEZ-DOLS, J.-M. \& CRIVELLI, C. 2013. Emotion and Expression: Naturalistic Studies. Emotion Review, 5, 24-29 DOI: 10.1177/1754073912457229.

FIELD, T., DIEGO, M. A., HERNANDEZ-REIF, M., DEEDS, O. \& FIGUEREIDO, B. 2006. Moderate versus light pressure massage therapy leads to greater weight gain in preterm infants. Infant Behav Dev, 29, 574-8 DOI: 10.1016/j.infbeh.2006.07.011.

FISHER, J. D., RYTTING, M. \& HESLIN, R. 1976. Hands touching hands: affective and evaluative effects of an interpersonal touch. Sociometry, 39, 416-21 DOI https://doi.org/10.2307/3033506

FLOYD, K. 2006. Communicating Affection: Interpersonal behavior and social context, Cambridge, Cambridge University Press.

FRANCIS, S., ROLLS, E. T., BOWTELL, R., MCGLONE, F., O'DOHERTY, J., BROWNING, A., CLARE, S. \& SMITH, E. 1999. The representation of pleasant touch in the brain and its relationship with taste and olfactory areas. Neuroreport, 10, 453-9

FRANK, R. \& SILK, J. 2009. Impatient traders or contingent reciprocators? Evidence for the extended time-course of grooming exchanges in baboons. Behaviour, 146, 1123-1135 DOI: 10.1163/156853909X406455. 
GARDNER, E. P. \& JOHNSON, K. O. 2013. Touch. In: KANDEL, E. R., SCHWARTZ, J. H., JESSEL, T. M., SIEGELBAUM, S. A. \& HUDSPIETH, A. J. (eds.) Principles of neural science. 5th ed. New York: McGraw-Hill Medical.

GEERS, A. L. \& MILLER, F. G. 2014. Understanding and translating the knowledge about placebo effects: the contribution of psychology. Curr Opin Psychiatry, 27, 326-31 DOI: 10.1097/yco.0000000000000082.

GRECO, A., VALENZA, G., NARDELLI, M., BIANCHI, M., LANATA, A. \& SCILINGO, E. P. 2015. Electrodermal activity analysis during affective haptic elicitation. Annu Int Conf IEEE Eng Med Biol Soc, 2015, 5777-80 DOI: 10.1109/embc.2015.7319705.

GRECO, A., VALENZA, G. \& SCILINGO, E. P. 2016. Investigating mechanical properties of a fabric-based affective haptic display through electrodermal activity analysis. Annu Int Conf IEEE Eng Med Biol Soc, 2016, 407-410 DOI: 10.1109/embc.2016.7590726.

GUÉGUEN, N. 2002. Touch, Awareness of Touch, and Compliance with a Request. Perceptual and motor skills, 95, 355-360 DOI: 10.2466/pms.2002.95.2.355.

GUÉGUEN, N. \& FISCHER-LOKOU, J. 2003. Tactile Contact and Spontaneous Help: An Evaluation in a Natural Setting. J Soc Psychol, 143, 785-787 DOI: 10.1080/00224540309600431.

GUEORGUIEVA, R. \& KRYSTAL, J. H. 2004. Move over ANOVA: Progress in analyzing repeated-measures data and its reflection in papers published in the Archives of General Psychiatry. Arch Gen Psychiatry, 61, 310-317 DOI 10.1001/archpsyc.61.3.310

GUEST, S., DESSIRIER, J. M., MEHRABYAN, A., MCGLONE, F., ESSICK, G., GESCHEIDER, G., FONTANA, A., XIONG, R., ACKERLEY, R. \& BLOT, K. 2011. The development and validation of sensory and emotional scales of touch perception. Atten Percept Psychophys, 73, 531-50 DOI: 10.3758/s13414010-0037-y.

GULLEDGE, A. K., GULLEDGE, M. H. \& STAHMANNN, R. F. 2003. Romantic Physical Affection Types and Relationship Satisfaction. The American journal of family therapy, 31, 233-242 DOI: 10.1080/01926180390201936.

HAGBARTH, K. E. \& VALLBO, Å. B. 1967. Mechanoreceptor Activity Recorded Percutaneously with Semi-Microelectrodes in Human Peripheral Nerves. Acta Physiol Scand, 69, 121-122 DOI: 10.1111/j.17481716.1967.tb03498.x.

HAGEN, M. C., FRANZÉN, O., MCGLONE, F., ESSICK, G., DANCER, C. \& PARDO, J. V. 2002. Tactile motion activates the human middle temporal/V5 (MT/V5) complex. Eur J Neurosci, 16, 957-64 DOI: 10.1046/j.14609568.2002.02139.x.

HARJUNEN, V. J., SPAPÉ, M., AHMED, I., JACUCCI, G. \& RAVAJA, N. 2018. Persuaded by the machine: The effect of virtual nonverbal cues and individual differences on compliance in economic bargaining. Computers in Human Behavior, 87, 384-394 DOI: 10.1016/j.chb.2018.06.012.

HARLOW, H. F. 1958. The nature of love. American Psychologist, 13, 673-685 DOI: $10.1037 / \mathrm{h} 0047884$. 
HARLOW, H. F. \& SUOMI, S. J. 1970. Nature of love--simplified. Am Psychol, 25, 161-8 DOI: $10.1037 / \mathrm{h} 0029383$.

HAWKER, G. A., MIAN, S., KENDZERSKA, T. \& FRENCH, M. 2011. Measures of adult pain: Visual Analog Scale for Pain (VAS Pain), Numeric Rating Scale for Pain (NRS Pain), McGill Pain Questionnaire (MPQ), Short-Form McGill Pain Questionnaire (SF-MPQ), Chronic Pain Grade Scale (CPGS), Short Form-36 Bodily Pain Scale (SF-36 BPS), and Measure of Intermittent and Constant Osteoarthritis Pain (ICOAP). 63, S240-S252 DOI: https://doi.org/10.1002/acr.20543.

HESS, U., ARSLAN, R., MAUERSBERGER, H., BLAISON, C., DUFNER, M., DENISSEN, J. J. \& ZIEGLER, M. 2017. Reliability of surface facial electromyography. Psychophysiology, 54, 12-23 DOI: 10.1111/psyp.12676.

HOLZMAN, J. B. \& BRIDGETT, D. J. 2017. Heart rate variability indices as biomarkers of top-down self-regulatory mechanisms: A meta-analytic review. Neuroscience and Biobehavioral Reviews, 74, 233-255 DOI: 10.1016/j.neubiorev.2016.12.032.

HORIO, T. 2003. EMG activities of facial and chewing muscles of human adults in response to taste stimuli. Percept Mot Skills, 97, 289-98 DOI: 10.2466/pms.2003.97.1.289.

HORNIK, J. \& ELLIS, S. 1988. Strategies to Secure Compliance for a Mall Intercept Interview. Public opinion quarterly, 52, 539-551 DOI: 10.1086/269129.

IGGO, A. 1959. Cutaneous heat and cold receptors with slowly conducting (C) afferent fibres. QJ Exp Physiol Cogn Med Sci, 44, 362-70 DOI: 10.1113/expphysiol.1959.sp001417.

IGGO, A. 1960. Cutaneous mechanoreceptors with afferent C fibres. J Physiol, 152, 337-53 DOI: 10.1113/jphysiol.1960.sp006491.

IRIUCHIJIMA, J. \& ZOTTERMAN, Y. 1960. The specificity of afferent cutaneous C fibres in mammals. Acta Physiol Scand, 49, 267-78 DOI: 10.1111/j.17481716.1960.tb01952.x.

JAKUBIAK, B. K. \& FEENEY, B. C. 2017. Affectionate Touch to Promote Relational, Psychological, and Physical Well-Being in Adulthood: A Theoretical Model and Review of the Research. Pers Soc Psychol Rev, 21, 228-252 DOI: $10.1177 / 1088868316650307$.

JOHANSSON, R. S. 1978. Tactile sensibility in the human hand: receptive field characteristics of mechanoreceptive units in the glabrous skin area. $J$ Physiol, 281, 101-125 DOI: 10.1113/jphysiol.1978.sp012411.

JOHANSSON, R. S., TRULSSON, M., OLSSON, K. A. \& WESTBERG, K. G. 1988. Mechanoreceptor activity from the human face and oral mucosa. Exp Brain Res, 72, 204-8 DOI: 10.1007/bf00248518.

JOHANSSON, R. S. \& VALLBO, A. B. 1979. Tactile sensibility in the human hand: relative and absolute densities of four types of mechanoreceptive units in glabrous skin. J Physiol, 286, 283-300 DOI: 10.1113/jphysiol.1979.sp012619. 
JOHANSSON, R. S. \& VALLBO, Å. B. 1983. Tactile sensory coding in the glabrous skin of the human hand. Journal of Neurophysiology, 6, 27-32 DOI: 10.1016/0166-2236(83)90011-5.

JOHNSON, K. O., YOSHIOKA, T. \& VEGA-BERMUDEZ, F. 2000. Tactile Functions of Mechanoreceptive Afferents Innervating the Hand. J Clin Neurophysiol, 17, 539-558 DOI: 10.1097/00004691-200011000-00002.

JOUSSAIN, P., FERDENZI, C., DJORDJEVIC, J. \& BENSAFI, M. 2017. Relationship Between Psychophysiological Responses to Aversive Odors and Nutritional Status During Normal Aging. Chem Senses, 42, 465-472 DOI: 10.1093/chemse/bjx027.

JÄNCKE, L. \& KAUFMANN, N. 1994. Facial EMG responses to odors in solitude and with an audience. Chem Senses, 19, 99-111 DOI: 10.1093/chemse/19.2.99.

KEIZER, A., DE JONG, J. R., BARTLEMA, L. \& DIJKERMAN, C. 2019. Visual perception of the arm manipulates the experienced pleasantness of touch. Developmental Cognitive Neuroscience, 35, 104-108 DOI: 10.1016/j.dcn.2017.09.004.

KELLEY, K. \& PREACHER, K. J. 2012. On effect size. Psychol Methods, 17, 137-52 DOI: $10.1037 / \mathrm{a} 0028086$.

KELTNER, D., TRACY, J., SAUTER, D. A., CORDACO, D. C. \& MCNEIL, G. 2016. Expression of Emotion. In: BARRETT, L. F., LEWIS, M. \& HAVILAND-JONES, J. M. (eds.) Handbook of Emotions. Fourth ed. New York, New York,London, England: The Guilford Press.

KNIBESTÖL, M. 1975. Stimulus-response functions of slowly adapting mechanoreceptors in the human glabrous skin area. J Physiol, 245, 63-80 DOI: 10.1113/jphysiol.1975.sp010835.

KNIBESTÖL, M. \& VALLBO, A. B. 1970. Single Unit Analysis of Mechanoreceptor Activity from the Human Glabrous Skin. Acta Physiol Scand, 80, 178-195 DOI: $10.1111 /$ j.1748-1716.1970.tb04783.x.

KOPPEL, L., ANDERSSON, D., MORRISON, I., VÄSTFJÄLL, D. \& TINGHÖG, G. 2017. The (Null) Effect of Affective Touch on Betrayal Aversion, Altruism, and Risk Taking. Front Behav Neurosci, 11, 251 D0I: 10.3389/fnbeh.2017.00251.

KORB, S., MASSACCESI, C., GARTUS, A., LUNDSTRÖM, J. N., RUMIATI, R., EISENEGGER, C. \& SILANI, G. 2020. Facial responses of adult humans during the anticipation and consumption of touch and food rewards. Cognition, 194, 104044 DOI: 10.1016/j.cognition.2019.104044.

LANG, P. J. \& BRADLEY, M. M. 2010. Emotion and the motivational brain. Biol Psychol, 84, 437-50 DOI: 10.1016/j.biopsycho.2009.10.007.

LANG, P. J., GREENWALD, M. K., BRADLEY, M. M. \& HAMM, A. 0. 1993. Looking at pictures: affective, facial, visceral, and behavioral reactions.

Psychophysiology, 30, 261-73 DOI: 10.1111/j.1469-8986.1993.tb03352.x.

LARSEN, J. T., NORRIS, C. J. \& CACIOPPO, J. T. 2003. Effects of positive and negative affect on electromyographic activity over zygomaticus major and corrugator supercilii. Psychophysiology, 40, 776-85 DOI: 10.1111/14698986.00078. 
LEGRAIN, V., IANNETTI, G. D., PLAGHKI, L. \& MOURAUX, A. 2011. The pain matrix reloaded: a salience detection system for the body. Prog Neurobiol, 93, 11124 DOI: $10.1016 /$ j.pneurobio.2010.10.005.

LEVENSON, R. W., LWI, S. J., BROWN, C. L., FORD, B. Q., OTERO, M. C. \& VERSTAEN, A. 2017. Emotion. In: CACIOPPO, J. T., TASSINARY, L. G., \& BERNTSON, G.G. (ed.) Handbook of psychophysiology, 4th ed. New York, NY, US: Cambridge University Press.

LEVENTHAL, A. M., MARTIN, R. L., SEALS, R. W., TAPIA, E. \& REHM, L. P. 2007. Investigating the dynamics of affect: Psychological mechanisms of affective habituation to pleasurable stimuli. Motivation and Emotion, 31, 145-157 DOI: $10.1007 / s 11031-007-9059-8$.

LINDGREN, L., LEHTIPALO, S., WINSO, O., KARLSSON, M., WIKLUND, U. \& BRULIN, C. 2013. Touch massage: a pilot study of a complex intervention. Nursing in Critical Care, 18, 269-77 DOI: 10.1111/nicc.12017.

LINDGREN, L., RUNDGREN, S., WINSÖ, O., LEHTIPALO, S., WIKLUND, U., KARLSSON, M., STENLUND, H., JACOBSSON, C. \& BRULIN, C. 2010. Physiological responses to touch massage in healthy volunteers. Auton Neurosci, 158, 105-10 DOI: 10.1016/j.autneu.2010.06.011.

LINDQUIST, K. A., SIEGEL, E. H., QUIGLEY, K. S. \& BARRETT, L. F. 2013. The hundred-year emotion war: are emotions natural kinds or psychological constructions? Comment on Lench, Flores, and Bench (2011). Psychological Bulletin, 139, 255-63 DOI: 10.1037/a0029038.

LINDQUIST, K. A., WAGER, T. D., KOBER, H., BLISS-MOREAU, E. \& BARRETT, L. F. 2012. The brain basis of emotion: a meta-analytic review. Behav Brain Sci, 35, 121-43 DOI: $10.1017 / \mathrm{s} 0140525 \times 11000446$.

LISHNER, D. A., COOTER, A. B. \& ZALD, D. H. 2008. Rapid Emotional Contagion and Expressive Congruence Under Strong Test Conditions. Journal of Nonverbal Behavior, 32, 225-239 DOI: 10.1007/s10919-008-0053-y.

LUONG, A., BENDAS, J., ETZI, R., OLAUSSON, H. \& CROY, I. 2017. The individual preferred velocity of stroking touch as a stable measurement. Physiology \& Behavior, 177, 129-134 DOI: 10.1016/j.physbeh.2017.04.022.

LÖKEN, L. S., EVERT, M. \& WESSBERG, J. 2011. Pleasantness of touch in human glabrous and hairy skin: order effects on affective ratings. Brain Res, 1417, 9-15 DOI: 10.1016/j.brainres.2011.08.011.

LÖKEN, L. S., WESSBERG, J., MORRISON, I., MCGLONE, F. \& OLAUSSON, H. 2009. Coding of pleasant touch by unmyelinated afferents in humans. Nature Neuroscience, 12, 547-8 DOI: 10.1038/nn.2312.

LØSETH, G. E., EIKEMO, M. \& LEKNES, S. 2019. Effects of opioid receptor stimulation and blockade on touch pleasantness: a double-blind randomised trial. Soc Cogn Affect Neurosci, 14, 411-422 DOI: $10.1093 /$ scan/nsz022.

MAGEZI, D. A. 2015. Linear mixed-effects models for within-participant psychology experiments: an introductory tutorial and free, graphical user interface (LMMgui). Front Psychol, 6, 2-2 DOI: 10.3389/fpsyg.2015.00002. 
MARSHALL, A. G. \& MCGLONE, F. P. 2020. Affective Touch: The Enigmatic Spinal Pathway of the C-Tactile Afferent. Neurosci Insights, 15, 2633105520925072 DOI: $10.1177 / 2633105520925072$.

MASTRIA, S., FERRARI, V. \& CODISPOTI, M. 2017. Emotional Picture Perception: Repetition Effects in Free-Viewing and during an Explicit Categorization Task. Front Psychol, 8, 1001 DOI: 10.3389/fpsyg.2017.01001.

MATHER, M. \& THAYER, J. 2018. How heart rate variability affects emotion regulation brain networks. Current Opinion in Behavioral Sciences, 19, 98104 DOI: $10.1016 /$ j.cobeha.2017.12.017.

MAUSS, I. B. \& ROBINSON, M. D. 2009. Measures of emotion: A review. Cognition and Emotion, 23, 209-237 DOI: 10.1080/02699930802204677.

MAYNARD SMITH, J. \& HARPER, D. 2003. Animal signals, Oxford, Oxford University Press.

MAYO, L. M. \& DE WIT, H. 2015. Acquisition of responses to a methamphetamineassociated cue in healthy humans: self-report, behavioral, and psychophysiological measures. Neuropsychopharmacology, 40, 1734-41 DOI: $10.1038 /$ npp.2015.21.

MAYO, L. M., LINDE, J., OLAUSSON, H., HEILIG, M. \& MORRISON, I. 2018. Putting a good face on touch: Facial expression reflects the affective valence of caress-like touch across modalities. Biol Psychol, 137, 83-90 DOI: 10.1016/j.biopsycho.2018.07.001.

MCCABE, C., ROLLS, E. T., BILDERBECK, A. \& MCGLONE, F. 2008. Cognitive influences on the affective representation of touch and the sight of touch in the human brain. Soc Cogn Affect Neurosci, 3, 97-108 DOI: $10.1093 /$ scan/nsn005.

MCGLONE, F., OLAUSSON, H., BOYLE, J. A., JONES-GOTMAN, M., DANCER, C., GUEST, S. \& ESSICK, G. 2012. Touching and feeling: differences in pleasant touch processing between glabrous and hairy skin in humans. The European Journal of Neuroscience, 35, 1782-8 DOI: 10.1111/j.14609568.2012.08092.x.

MCGLONE, F. \& REILLY, D. 2010. The cutaneous sensory system. Neurosci Biobehav Rev, 34, 148-59 DOI: 10.1016/j.neubiorev.2009.08.004.

MCGLONE, F., WESSBERG, J. \& OLAUSSON, H. 2014. Discriminative and affective touch: sensing and feeling. Neuron, 82, 737-755 DOI: 10.1016/j.neuron.2014.05.001.

MELZACK, R. \& WALL, P. D. 1965. Pain mechanisms: a new theory. Science, 150, 971-9 DOI: $10.1126 /$ science.150.3699.971.

MENDELL, L. M. 2014. Constructing and deconstructing the gate theory of pain. Pain, 155, 210-216 DOI: 10.1016/j.pain.2013.12.010.

MENDES, W. B. 2016. Emotion and the Autonomic Nervous System. In: BARRETT, L. F., LEWIS, M. \& HAVILAND-JONES, J. M. (eds.) Handbook of Emotions. Fourth ed. New York, New York,London, England: The Guilford Press.

MOERMAN, D. E. \& JONAS, W. B. 2002. Deconstructing the placebo effect and finding the meaning response. Ann Intern Med, 136, 471-6 DOI: 10.7326/0003-4819-136-6-200203190-00011. 
MONTOYA, R. M., HORTON, R. S., VEVEA, J. L., CITKOWICZ, M. \& LAUBER, E. A. 2017. A re-examination of the mere exposure effect: The influence of repeated exposure on recognition, familiarity, and liking. Psychol Bull, 143, 459-498 DOI: 10.1037/bul0000085.

MORRISON, I. 2016a. ALE meta-analysis reveals dissociable networks for affective and discriminative aspects of touch. Hum Brain Mapp, 37, 1308-20 DOI: $10.1002 / \mathrm{hbm} .23103$.

MORRISON, I. 2016b. Keep Calm and Cuddle on: Social Touch as a Stress Buffer. Adaptive Human Behavior and Physiology, 2, 344-362 DOI: 10.1007/s40750-016-0052-x.

MORRISON, I., BJÖRNSDOTTER, M. \& OLAUSSON, H. 2011. Vicarious responses to social touch in posterior insular cortex are tuned to pleasant caressing speeds. J Neurosci, 31, 9554-62 DOI: 10.1523/jneurosci.0397-11.2011.

MOUNTCASTLE, V. B., LAMOTTE, R. H. \& CARLI, G. 1972. Detection thresholds for stimuli in humans and monkeys: comparison with threshold events in mechanoreceptive afferent nerve fibers innervating the monkey hand. $J$ Neurophysiol, 35, 122-36 DOI: 10.1152/jn.1972.35.1.122.

MOUNTCASTLE, V. B., TALBOT, W. H., DARIAN-SMITH, I. \& KORNHUBER, H. H. 1967. Neural Basis of the Sense of Flutter-Vibration. Science, 155, 597-600 DOI: $10.1126 /$ science.155.3762.597.

MURPHY, R. O., ACKERMANN, K. A. \& HANDGRAAF, M. 2011. Measuring social value orientation. Judgement and Decision Making, 6, 771-781 DOI: 10.2139/ssrn.1804189.

MUTSCHLER, I., WIECKHORST, B., SPECK, O., SCHULZE-BONHAGE, A., HENNIG, J., SEIFRITZ, E. \& BALL, T. 2010. Time scales of auditory habituation in the amygdala and cerebral cortex. Cereb Cortex, 20, 2531-9 DOI: 10.1093/cercor/bhq001.

NORDIN, M. 1990. Low-threshold mechanoreceptive and nociceptive units with unmyelinated (C) fibres in the human supraorbital nerve. The Journal of Physiology, 426, 229-40 DOI: 10.1113/jphysiol.1990.sp018135.

NOVEMBRE, G., ETZI, R. \& MORRISON, I. 2020. Hedonic responses to touch are modulated by the perceived attractiveness of the caresser. Neuroscience, DOI: $10.1016 /$ j.neuroscience.2020.10.007.

NUNAN, D., SANDERCOCK, G. R. \& BRODIE, D. A. 2010. A quantitative systematic review of normal values for short-term heart rate variability in healthy adults. Pacing Clin Electrophysiol, 33, 1407-17 DOI: 10.1111/j.15408159.2010.02841.x.

OCHOA, J. \& TOREBJÖRK, E. 1983. Sensations evoked by intraneural microstimulation of single mechanoreceptor units innervating the human hand. J Physiol, 342, 633-54 DOI: 10.1113/jphysiol.1983.sp014873.

OLAUSSON, H., COLE, J., RYLANDER, K., MCGLONE, F., LAMARRE, Y., WALLIN, B. G., KRÄMER, H., WESSBERG, J., ELAM, M., BUSHNELL, M. C. \& VALLBO, A. 2008. Functional role of unmyelinated tactile afferents in human hairy skin: sympathetic response and perceptual localization. Exp Brain Res, 184, 135-40 DOI: 10.1007/s00221-007-1175-x. 
OLAUSSON, H., LAMARRE, Y., BACKLUND, H., MORIN, C., WALLIN, B. G., STARCK, G., EKHOLM, S., STRIGO, I., WORSLEY, K., VALLBO, A. B. \& BUSHNELL, M. C. 2002. Unmyelinated tactile afferents signal touch and project to insular cortex. Nat Neurosci, 5, 900-4 DOI: 10.1038/nn896.

OLAUSSON, H., WESSBERG, J., MORRISON, I., MCGLONE, F. \& VALLBO, A. 2010. The neurophysiology of unmyelinated tactile afferents. Neuroscience and Biobehavioral Reviews, 34, 185-91 DOI: 10.1016/j.neubiorev.2008.09.011.

PAGE-GOULD, E. 2016. Multilevel modeling. In: J.T, C., TASSINARY, L. G. \& G.G, B. (eds.) The handbook of psychophysiology. 4th ed. Cambridge: Cambridge University Press.

PAWLING, R., CANNON, P. R., MCGLONE, F. P. \& WALKER, S. C. 2017a. C-tactile afferent stimulating touch carries a positive affective value. PLoS One, 12, e0173457 DOI: 10.1371/journal.pone.0173457.

PAWLING, R., TROTTER, P. D., MCGLONE, F. P. \& WALKER, S. C. 2017b. A positive touch: C-tactile afferent targeted skin stimulation carries an appetitive motivational value. Biol Psychol, 129, 186-194 DOI:

10.1016/j.biopsycho.2017.08.057.

PENFIELD, W. \& BOLDREY, E. 1937. Somatic motor and sensory representation in the cerebral cortex of man as studied by electrical stimulation. Brain: $A$ Journal of Neurology, 60, 389-443 DOI: 10.1093/brain/60.4.389.

PORGES, S. W. 1995. Orienting in a defensive world: mammalian modifications of our evolutionary heritage. A Polyvagal Theory. Psychophysiology, 32, 30118 DOI: 10.1111/j.1469-8986.1995.tb01213.x.

PRICE, D. D., FINNISS, D. G. \& BENEDETTI, F. 2008a. A comprehensive review of the placebo effect: recent advances and current thought. Annu Rev Psychol, 59, 565-90 DOI: 10.1146/annurev.psych.59.113006.095941.

PRICE, D. D., PATEL, R., ROBINSON, M. E. \& STAUD, R. 2008b. Characteristics of electronic visual analogue and numerical scales for ratings of experimental pain in healthy subjects and fibromyalgia patients. Pain, 140, 158-66 DOI: 10.1016/j.pain.2008.07.028.

RANKIN, C. H., ABRAMS, T., BARRY, R. J., BHATNAGAR, S., CLAYTON, D. F., COLOMBO, J., COPPOLA, G., GEYER, M. A., GLANZMAN, D. L., MARSLAND, S., MCSWEENEY, F. K., WILSON, D. A., WU, C. F. \& THOMPSON, R. F. 2009. Habituation revisited: an updated and revised description of the behavioral characteristics of habituation. Neurobiol Learn Mem, 92, 135-8 DOI: 10.1016/j.nlm.2008.09.012.

RAVAJA, N., KALLINEN, K., SAARI, T. \& KELTIKANGAS-JARVINEN, L. 2004. Suboptimal exposure to facial expressions when viewing video messages from a small screen: Effects on emotion, attention, and memory. Journal of Experimental Psychology: Applied, 10, 120-131 DOI: 10.1037/1076898X.10.2.120.

REE, A., BENDAS, J., PABEL, L., CROY, I. \& SAILER, U. 2020. Right between the eyes: Corrugator muscle activity tracks the changing pleasantness of 
repeated slow stroking touch. Physiol Behav, 222, 112903 DOI: 10.1016/j.physbeh.2020.112903.

REE, A., MAYO, L. M., LEKNES, S. \& SAILER, U. 2019. Touch targeting C-tactile afferent fibers has a unique physiological pattern: A combined electrodermal and facial electromyography study. Biological Psychology, 140, 55-63 DOI: 10.1016/j.biopsycho.2018.11.006.

REECE, C., EBSTEIN, R., CHENG, X., NG, T. \& SCHIRMER, A. 2016. Data set demonstrating an absence of touch effects on social orienting in adults. Data Brief, 8, 904-9 DOI: 10.1016/j.dib.2016.07.013.

REISENZEIN, R., STUDTMANN, M. \& HORSTMANN, G. 2013. Coherence between Emotion and Facial Expression: Evidence from Laboratory Experiments. Emotion Review, 5, 16-23 DOI: 10.1177/1754073912457228.

ROBINSON, M. D. \& CLORE, G. L. 2002. Episodic and semantic knowledge in emotional self-report: evidence for two judgment processes. J Pers Soc Psychol, 83, 198-215 DOI: 10.1037//0022-3514.83.1.198.

ROLLS, B. J., ROLLS, E. T., ROWE, E. A. \& SWEENEY, K. 1981. Sensory specific satiety in man. Physiol Behav, 27, 137-42 DOI: 10.1016/00319384(81)90310-3.

ROLLS, E. T. 2020. The texture and taste of food in the brain. J Texture Stud, 51, 23-44 DOI: $10.1111 /$ jtxs.12488.

ROLLS, E. T. \& ROLLS, J. H. 1997. Olfactory sensory-specific satiety in humans. Physiol Behav, 61, 461-73 DOI: 10.1016/s0031-9384(96)00464-7.

ROSE, S. A. 1990. The sense of touch. In: Touch: The Foundation of Experience. International Universities Press, Madison, WI, 299-324.

ROSENBERGER, L. A., REE, A., EISENEGGER, C. \& SAILER, U. 2018. Slow touch targeting CT-fibres does not increase prosocial behaviour in economic laboratory tasks. Sci Rep, 8, 7700 DOI: 10.1038/s41598-018-25601-7.

RUSSELL, J. A. 1980. A circumplex model of affect. Journal of Personality and Social Psychology, 39, 1161-1178 DOI: 10.1037/h0077714.

RUSSO, V., OTTAVIANI, C. \& SPITONI, G. F. 2019. Affective touch: A meta-analysis on sex differences. Neurosci Biobehav Rev, 108, 445-452 DOI: 10.1016/j.neubiorev.2019.09.037.

SAILER, U., TRISCOLI, C. \& CROY, I. 2016b. Still Eating Despite Decreased Olfactory Pleasure-The Influence of Odor Liking and Wanting on Food Intake. Chem Senses, 41, 497-504 DOI: 10.1093/chemse/bjw052.

SAILER, U., TRISCOLI, C., HÄGGBLAD, G., HAMILTON, P., OLAUSSON, H. \& CROY, I. 2016a. Temporal dynamics of brain activation during 40 minutes of pleasant touch. Neuroimage, 139, 360-367 DOI:

10.1016/j.neuroimage.2016.06.031.

SANDER, D., GRANDJEAN, D. \& SCHERER, K. R. 2018. An Appraisal-Driven Componential Approach to the Emotional Brain. 10, 219-231 DOI: $10.1177 / 1754073918765653$.

SCHIRMER, A. 2015. What Is an Emotion? Modern Thoughts and Concepts. Emotion. Thousand Oaks: Thousand Oaks: SAGE Publications, Inc. 
SCHIRMER, A. \& ADOLPHS, R. 2017. Emotion Perception from Face, Voice, and Touch: Comparisons and Convergence. Trends Cogn Sci, 21, 216-228 DOI: 10.1016/j.tics.2017.01.001.

SCHIRMER, A. \& GUNTER, T. C. 2017. The right touch: Stroking of CT-innervated skin promotes vocal emotion processing. Cogn Affect Behav Neurosci, 17, 1129-1140 DOI: 10.3758/s13415-017-0537-5.

SCHIRMER, A., TEH, K. S., WANG, S., VIJAYAKUMAR, R., CHING, A., NITHIANANTHAM, D., ESCOFFIER, N. \& CHEOK, A. D. 2011. Squeeze me, but don't tease me: human and mechanical touch enhance visual attention and emotion discrimination. Soc Neurosci, 6, 219-30 DOI: 10.1080/17470919.2010.507958.

SCHIRMER, A., WIJAYA, M. T. \& LIU, S. 2016. The Midas Effect: How Somatosensory Impressions Shape Affect and Other-Concern. In: OLAUSSON, H., WESSBERG, J., MORRISON, I. \& MCGLONE, F. (eds.) Affective Touch and the Neurophysiology of CT Afferents. New York, NY, Springer New York.

SEHLSTEDT, I., IGNELL, H., BACKLUND WASLING, H., ACKERLEY, R., OLAUSSON, H. \& CROY, I. 2016. Gentle touch perception across the lifespan. Psychology and Aging, 31, 176-84 DOI: 10.1037/pag0000074.

SEQUEIRA, H., HOT, P., SILVERT, L. \& DELPLANQUE, S. 2009. Electrical autonomic correlates of emotion. Int J Psychophysiol, 71, 50-6 DOI: 10.1016/j.ijpsycho.2008.07.009.

SHAFFER, F., MCCRATY, R. \& ZERR, C. L. 2014. A healthy heart is not a metronome: an integrative review of the heart's anatomy and heart rate variability. Frontiers in Psychology, 5, 1040 DOI: 10.3389/fpsyg.2014.01040.

SHUTTERSTOCK VIDEOS:

Rainbow Explosion: https://www.shutterstock.com/nb/video/clip1031555522-color-burst-iridescent-multicolored-colorful-rainbow-smoke; Spectrum Curtain: https://www.shutterstock.com/nb/video/clip1339612-spectrum-curtain;

Spectrum Wave: https://www.shutterstock.com/nb/video/clip-1319365spectrum-wave; Accessed September, 2021.

SIMONS, D. J. \& CHABRIS, C. F. 1999. Gorillas in our midst: sustained inattentional blindness for dynamic events. Perception, 28, 1059-74 DOI: 10.1068/p281059.

SMITH, R., THAYER, J. F., KHALSA, S. S. \& LANE, R. D. 2017. The hierarchical basis of neurovisceral integration. Neurosci Biobehav Rev, 75, 274-296 DOI: 10.1016/j.neubiorev.2017.02.003.

SPAPÉ, M. M., HARJUNEN, V. \& RAVAJA, N. 2017. Effects of touch on emotional face processing: A study of event-related potentials, facial EMG and cardiac activity. Biol Psychol, 124, 1-10 DOI: 10.1016/j.biopsycho.2017.01.002.

STEIN, B. E., LONDON, N., WILKINSON, L. K. \& PRICE, D. D. 1996. Enhancement of perceived visual intensity by auditory stimuli: a psychophysical analysis. $J$ Cogn Neurosci, 8, 497-506 DOI: 10.1162/jocn.1996.8.6.497. 
STEPHEN, R. \& ZWEIGENHAFT, R. L. 1986. The Effect on Tipping of a Waitress Touching Male and Female Customers. The Journal of social psychology, 126, 141-142 DOI: 10.1080/00224545.1986.9713586.

STRACK, F. \& DEUTSCH, R. 2004. Reflective and impulsive determinants of social behavior. Pers Soc Psychol Rev, 8, 220-47 DOI: 10.1207/s15327957pspr0803_1.

STRAUSS, T., ROTTSTÄDT, F., SAILER, U., SCHELLONG, J., HAMILTON, J. P., RAUE, C., WEIDNER, K. \& CROY, I. 2019. Touch aversion in patients with interpersonal traumatization. Depress Anxiety, 36, 635-646 DOI: 10.1002/da.22914.

TARVAINEN, M. P., NISKANEN, J. P., LIPPONEN, J. A., RANTA-AHO, P. O. \& KARJALAINEN, P. A. 2014. Kubios HRV--heart rate variability analysis software. Computer Methods and Programs in Biomedicine, 113, 210-20 DOI: 10.1016/j.cmpb.2013.07.024.

TASK FORCE OF THE EUROPEAN SOCIETY OF CARDIOLOGY AND THE NORTH AMERICAN SOCIETY OF PACING AND ELECTROPHYSIOLOGY 1996. Heart rate variability: Standards of measurement, physiological interpretation, and clinical use. Task Force of the European Society of Cardiology and the North American Society of Pacing and Electrophysiology. Circulation, 93, 1043-1065

TASSINARY, L. G., CACIOPPO, J. T. \& VANMAN, E. J. 2017. The Somatic System. In: CACIOPPO, J. T., TASSINARY, L. G. \& BERNTSON, G. G. (eds.) Handbook of psychophysiology. 4th ed. Cambridge: Cambridge University Press.

THAYER, J. F., AHS, F., FREDRIKSON, M., SOLLERS, J. J., 3RD \& WAGER, T. D. 2012. A meta-analysis of heart rate variability and neuroimaging studies: implications for heart rate variability as a marker of stress and health. Neurosci Biobehav Rev, 36, 747-56 DOI: 10.1016/j.neubiorev.2011.11.009.

THAYER, J. F. \& LANE, R. D. 2000. A model of neurovisceral integration in emotion regulation and dysregulation. J Affect Disord, 61, 201-16 DOI: 10.1016/s0165-0327(00)00338-4.

TOOHEY, P. 2011. Boredom : a lively history, New Haven, Conn, Yale University Press.

TOREBJÖRK, H. E. \& HALLIN, R. G. 1974. Identification of afferent C units in intact human skin nerves. Brain Res, 67, 387-403 DOI: 10.1016/00068993(74)90489-2.

TRACY, J. L. \& RANDLES, D. 2011. Four Models of Basic Emotions: A Review of Ekman and Cordaro, Izard, Levenson, and Panksepp and Watt. Emotion Review, 3, 397-405 DOI: 10.1177/1754073911410747.

TRISCOLI, C., ACKERLEY, R. \& SAILER, U. 2014a. Touch satiety: differential effects of stroking velocity on liking and wanting touch over repetitions. PLoS One, 9, e113425 D0I: 10.1371/journal.pone.0113425.

TRISCOLI, C., CROY, I., OLAUSSON, H. \& SAILER, U. 2014b. Liking and wanting pleasant odors: different effects of repetitive exposure in men and women. Front Psychol, 5, 526 DOI: 10.3389/fpsyg.2014.00526. 
TRISCOLI, C., CROY, I., OLAUSSON, H. \& SAILER, U. 2017a. Touch between romantic partners: Being stroked is more pleasant than stroking and decelerates heart rate. Physiology \& Behavior, 177, 169-175 DOI: 10.1016/j.physbeh.2017.05.006.

TRISCOLI, C., CROY, I., STEUDTE-SCHMIEDGEN, S., OLAUSSON, H. \& SAILER, U. $2017 \mathrm{~b}$. Heart rate variability is enhanced by long-lasting pleasant touch at CT-optimized velocity. Biological Psychology, 128, 71-81 DOI: 10.1016/j.biopsycho.2017.07.007.

TRONSTAD, C., JOHNSEN, G. K., GRIMNES, S. \& MARTINSEN Ø, G. 2010. A study on electrode gels for skin conductance measurements. Physiol Meas, 31, 1395410 DOI: $10.1088 / 0967-3334 / 31 / 10 / 008$.

VALLBO, A. B. \& JOHANSSON, R. S. 1984. Properties of cutaneous mechanoreceptors in the human hand related to touch sensation. Hum Neurobiol, 3, 3-14

VALLBO, A., LÖKEN, L. \& WESSBERG, J. 2016. Sensual Touch: A Slow Touch System Revealed with Microneurography. In: OLAUSSON, H., WESSBERG, J., MORRISON, I. \& MCGLONE, F. (eds.) Affective Touch and the Neurophysiology of CT Afferents. 1st ed. 2016. ed. New York, NY: Springer New York : Imprint: Springer.

VALLBO, A., OLAUSSON, H. \& WESSBERG, J. 1999. Unmyelinated afferents constitute a second system coding tactile stimuli of the human hairy skin. Journal of Neurophysiology, 81, 2753-63 DOI: 10.1152/jn.1999.81.6.2753.

VALLBO, A. B., OLAUSSON, H., WESSBERG, J. \& KAKUDA, N. 1995. Receptive field characteristics of tactile units with myelinated afferents in hairy skin of human subjects. J Physiol, 483 ( Pt 3), 783-95 DOI: 10.1113/jphysiol.1995.sp020622.

VALLBO, A., OLAUSSON, H., WESSBERG, J. \& NORRSELL, U. 1993. A system of unmyelinated afferents for innocuous mechanoreception in the human skin. Brain Research, 628, 301-4 DOI: 10.1016/0006-8993(93)90968-S.

VAN BOXTEL, A. 2001. Optimal signal bandwidth for the recording of surface EMG activity of facial, jaw, oral, and neck muscles. Psychophysiology, 38, 22-34

VAN BOXTEL, A., DAMEN, E. J. \& BRUNIA, C. H. 1996. Anticipatory EMG responses of pericranial muscles in relation to heart rate during a warned simple reaction time task. Psychophysiology, 33, 576-83 DOI: 10.1111/j.14698986.1996.tb02434.x.

VERRILLO, R. T. 1963. Effect of Contactor Area on the Vibrotactile Threshold. The Journal of the Acoustical Society of America, 35, 1962-1966 DOI: 10.1121/1.1918868.

VICKERS, A., OHLSSON, A., LACY, J. B. \& HORSLEY, A. 2004. Massage for promoting growth and development of preterm and/or low birth-weight infants. Cochrane Database Syst Rev, 2004, Cd000390 DOI:

10.1002/14651858.CD000390.pub2.

WALKER, S. C., TROTTER, P. D., WOODS, A. \& MCGLONE, F. 2017. Vicarious ratings of social touch reflect the anatomical distribution \& velocity tuning of C- 
tactile afferents: A hedonic homunculus? Behav Brain Res, 320, 91-96 DOI: 10.1016/j.bbr.2016.11.046.

WALLACE, R. B., KOHOUT, F. J. \& COLSHER, P. L. 1992. Observations on interviews surveys of the oldest old, In: SUZMAN, R. M., WILLIS, D. P. \& MANTON, K. G. (eds). The Oldest Old, Oxford, New York, pp. 123-135.

WATKINS, R. H., DIONE, M., ACKERLEY, R., BACKLUND WASLING, H., WESSBERG, J. \& LOKEN, L. S. 2020. Evidence for sparse C-tactile afferent innervation of glabrous human hand skin. J Neurophysiol, DOI: 10.1152/jn.00587.2020.

WATKINS, R. H., WESSBERG, J., BACKLUND WASLING, H., DUNHAM, J. P., OLAUSSON, H., JOHNSON, R. D. \& ACKERLEY, R. 2017. Optimal delineation of single C-tactile and C-nociceptive afferents in humans by latency slowing. J Neurophysiol, 117, 1608-1614 D0I: 10.1152/jn.00939.2016.

WEST, B. T., WELCH, K. B. \& GALECKI, A. T. 2014. Linear mixed models: a practical guide using statistical software, Crc Press.

WESTFALL, J. 2016. PANGEA: Power analysis for general anova designs. https://jakewestfall.shinyapps.io/pangea/.

WESTFALL, J., KENNY, D. A. \& JUDD, C. M. 2014. Statistical power and optimal design in experiments in which samples of participants respond to samples of stimuli. J Exp Psychol Gen, 143, 2020-45 DOI: 10.1037/xge0000014.

WESTGATE, E. C. \& STEIDLE, B. 2020. Lost by definition: Why boredom matters for psychology and society. Social and personality psychology compass, 14, n/a DOI: $10.1111 /$ spc3.12562.

WEWERS, M. E. \& LOWE, N. K. 1990. A critical review of visual analogue scales in the measurement of clinical phenomena. Res Nurs Health, 13, 227-36 DOI: 10.1002/nur.4770130405.

WIJAYA, M., LAU, D., HORROCKS, S., MCGLONE, F., LING, H. \& SCHIRMER, A. 2020. The human "feel" of touch contributes to its perceived pleasantness. J Exp Psychol Hum Percept Perform, 46, 155-171 DOI: 10.1037/xhp0000705.

WILKINSON, L. L. \& BRUNSTROM, J. M. 2016. Sensory specific satiety: More than 'just' habituation? Appetite, 103, 221-228 DOI:

10.1016/j.appet.2016.04.019.

WINKIELMAN, P. \& BERRIDGE, K. C. 2004. Unconscious Emotion. Current Directions in Psychological Science, 13, 120-123 DOI: 10.1111/j.09637214.2004.00288.x.

YATES, A., ASHWIN, C. \& FOX, E. 2010. Does emotion processing require attention? The effects of fear conditioning and perceptual load. Emotion, 10, 822-30 DOI: $10.1037 / \mathrm{a} 0020325$.

ZAJONC, R. B. 1968. Attitudinal effects of mere exposure. Journal of Personality and Social Psychology, 9, 1-27 DOI: 10.1037/h0025848.

ZAJONC, R. B. 2000. Feeling and thinking: Closing the debate over the independence of affect. Feeling and thinking: The role of affect in social cognition. New York, NY, US: Cambridge University Press.

ZHOU, P., LOCK, B. \& KUIKEN, T. A. 2007. Real time ECG artifact removal for myoelectric prosthesis control. Physiol Meas, 28, 397-413 DOI: 10.1088/0967-3334/28/4/006. 
ZOTTERMAN, Y. 1939. Touch, pain and tickling: an electro-physiological investigation on cutaneous sensory nerves. J Physiol, 95, 1-28 DOI: 10.1113/jphysiol.1939.sp003707.

ÖHMAN, A. \& SOARES, J. J. 1998. Emotional conditioning to masked stimuli: expectancies for aversive outcomes following nonrecognized fear-relevant stimuli. J Exp Psychol Gen, 127, 69-82 DOI: 10.1037//0096-3445.127.1.69.

Figure 2: Original figure published by McGlone et al. (2014). Reproduced by permission from the Copyright Clearance Center: Elsevier. Neuron; Discriminative and Affective Touch: Sensing and Feeling, Francis McGlone et al. (2014). License Number: 4965451451664.

Figure 3: Original figure published by Russell (1980). A circumplex model of affect. Journal of Personality and Social Psychology, 39, 1161-1178. "Adapted with permission, APA". 
Appendices 


\section{Appendix 1}

\begin{tabular}{|c|c|c|c|c|}
\hline Region: & Saksbehandler: & Telefon: & Vår dato: & Vår referanse: \\
\hline \multirow[t]{3}{*}{ REK sør-øst } & Silje U. Lauvrak & 22845520 & 05.10 .2016 & $\begin{array}{l}2011 / 1337 \\
\text { REK sør-øst D }\end{array}$ \\
\hline & & & Deres dato: & Deres referanse: \\
\hline & & & 02.09 .2016 & \\
\hline
\end{tabular}

Vår referanse må oppgis ved alle henvendelser

Siri Leknes

Universitetet i Oslo

\section{1/1337 Hjernemekanismer for opplevelse av og motivasjon for belønning}

Forskningsansvarlig: Universitetet i Oslo

Prosjektleder: Siri Leknes

Vi viser til søknad om prosjektendring datert 02.09.2016 for ovennevnte forskningsprosjekt. Søknaden er behandlet av leder for REK sør-øst D på fullmakt, med hjemmel i helseforskningsloven § 11 .

\section{Endringene innebærer:}

- Tre nye prosjektmedarbeidere er knyttet til prosjektet.

- Utsettelse av prosjektslutt til 01.01.2020.

- Økning i antall forskningsdeltakere med 260 personer. Totalt antall deltakere i prosjektet økes dermed fra 250 til 510.

- Det skal gjøres ytterligere to understudier: en for å undersøke effekt av berøring på prososial atferd og en om forventningseffekter på behagelig berøring og smerte. For å bestemme de best egnede oppgavene for det førstnevnte delprosjektet vil det gjennomføres en pilot med 60 friske forsøkspersoner uten farmakologisk administrasjon og uten fMRI-måling.

- De nye understudiene er beskrevet i revidert protokoll.

- Det er utarbeidet egne informasjonsskriv for hver av understudiene.

\section{Vurdering}

REK har vurdert de omsøkte endringene, og har ingen forskningsetiske innvendinger til endringene slik de er beskrevet i søknad om prosjektendring.

\section{Vedtak}

REK godkjenner prosjektet slik det nå foreligger, jfr. helseforskningsloven § 11, annet ledd.

Godkjenningen er gitt under forutsetning av at prosjektet gjennomføres slik det er beskrevet i søknad, endringssøknad, oppdatert protokoll og de bestemmelser som følger av helseforskningsloven med forskrifter.

\section{Klageadgang}

REKs vedtak kan påklages, jf. forvaltningslovens $\S 28$ flg. Eventuell klage sendes til REK sør-øst D. Klagefristen er tre uker fra du mottar dette brevet. Dersom vedtaket opprettholdes av REK sør-øst D, sendes klagen videre til Den nasjonale forskningsetiske komité for medisin og helsefag for endelig vurdering.

Vi ber om at alle henvendelser sendes inn på korrekt skjema via vår saksportal:

http://helseforskning.etikkom.no. Dersom det ikke finnes passende skjema kan henvendelsen rettes på e-post til: post@helseforskning.etikkom.no. 
Vennligst oppgi vårt referansenummer i korrespondansen.

Med vennlig hilsen

Finn Wisløff

Professor em. dr. med.

Leder

Silje U. Lauvrak

Rådgiver

Kopi til: birgitte.bogh-olsen@psykologi.uio.no

Universitetet i Oslovedøverste administrative ledelse: universitetsdirektor@uio.no 


\title{
$\mathrm{UiO}:$ University of Oslo
}

Faculty of Social Sciences - Departement of Psychology

Appendix 2

\author{
Anbjørn Ree \\ CC: Siri Leknes
}

Ref.number: 2566552

Date: 1 March 2018

\section{Ethical evaluation of research project}

Your project, "Does CT-targeted touch have a unique physiological pattern and mediate pro-social behaviour? a combined electrodermal and facial electromyography study " has been ethically evaluated by the Department of Psychology's internal research ethics committee based on received information.

Your project, "Does CT-targeted touch have a unique physiological pattern and mediate pro-social behaviour? a combined electrodermal and facial electromyography study" has been exempt from full review and thus approved by the Department of Psychology's Research Ethics Committee. Remember to register the project in Helseforsk: http://www.uio.no/for-ansatte/arbeidsstotte/fa/regelverk-ogforskningsetikk/kvalitetssystem-helse/prosjekter/sv/psi/

Sincerely yours, on behalf of the Committee,

Anne-Kristin Solbakk and Nils Inge Landrø

Members of the Department of Psychology's Research Ethics Committee

https://www.uio.no/for-ansatte/enhetssider/sv/psi/psi-eng/internal-ethics-committee/index.html 
Projektansvarig:

Dnr:

Exp. 2015-04-27

Uta Sailer 288-15

Göteborgs universitet

Psykologiska institutionen

Box 500

40530 Göteborg

Forskningshuvudman: Västra Götalandsregionen

\section{Närvarande beslutande:}

Bo Rolfson, ordförande

Bibbi Ringsby Jansson, bitr. vetenskaplig sekreterare (deltog ej $i$ ärende 257-15, p g a jäv)

Ledamöter med vetenskaplig kompetens:

Johan Berlin

Bengt Brülde

Elisabeth Björk Brämberg (deltog ej i ärende 289-15, p g a jäv)

Sally Boyd

Kerstin Grundén (deltog ej i 283-15, 288-15, 298-15)

Jonas Hinnfors, auskulterande

Karin Klinga Levan

Peter Korp

Jesper Lundgren (vetenskaplig sekr Dnr 257-15, deltog ej i ärende 263-15, 288-15 p g a jäv)

Helle Wijk (deltog ej i ärende 247-15 p g a jäv)

Ledamöter som företräder allmänna intressen:

Robert Engström, (deltog ej i ärende 149-15, 276-15, 289-15, 294-15, 295-15, 305-15)

Bengt Fernström

Curt Hedlund

Lars Muregård

Beatrice Toll

Projekttitel: Effekter av långvarig behaglig beröring

\section{Beslutsprotokoll från sammanträde med Regionala etikprövningsnämnden i Göteborg, Avdelningen för övrig forskning, den 20 april 2015}

Föredragande: Helle Wijk

\section{Godkännes med villkor}

Etikprövningsnämnden godkänner studien med följande villkor:

att informationsbrevet kompletteras med uppgift om att data ska förvaras i minst 10 år för att möjliggöra granskning, och att provmaterial samlas i biobank i Sverige och anmäls enligt biobankslagen, och 
att sökanden noterar att kodlistor ska förvaras i låst brandsäkert utrymme och skiljt från data, samt att detta framgår av informationsbrevet.

Beslutet kan överklagas till Centrala etikprövningsnämnden. Skrivelsen ska vara ställd till Centrala etikprövningsnämnden men skickas eller lämnas till Regionala etikprövningsnämnden i Göteborg. Överklagandet ska vara underskrivet av behörig företrädare för forskningshuvudmannen. Denne kan lämna fullmakt till forskaren att skriva under. Bifoga i så fall fullmakten. I skrivelsen ska anges vilket beslut som överklagas och den ändring som $\mathrm{Ni}$ begär. Överklagandet ska ha kommit in till Regionala etikprövningsnämnden senast tre veckor från det att klaganden fick del av beslutet.

Att denna avskrift i transumt överensstämmer med originalet intygar: [signature removed]

$\checkmark$ Barbro Morsíng, adminıstrativ sekreterare 
Ethikkommission an der TU Dresden

Fetscherstraße 74, 01307 Dresden

Frau

Dr. Ilona Croy

Klinik und Poliklinik für Psychotherapie und

Psychosomatik

Universitätsklinikum Dresden

- Hauspost -
Prof. Dr. med

Uwe Platzbecker

Vorsitzender der Ethikkommission

Telefon: $\quad 0351458-2992$

Telefax: $\quad 0351458-4369$

E-Mail: ethikkommission@mailbox.tu-dresden.de

Dresden, 23.08.2017

Studie:

Modelle der Habituation affektiver Berührungswahrnehmung

Bearbeitungs-Nr.:

EK 221062017 (bitte stets angeben)

Antragsteller:

Klinik und Poliklinik für Psychotherapie und Psychosomatik des

Dresden, Fetscherstr. 74, 01307 Dresden

\section{Eingangsbestätigung}

- $\quad$ Anschreiben an unsere Ethikkommission vom 15.08.2017

- $\quad$ Antragsformular mit markierten Änderungen, datiert 15.08.2017

- $\quad$ Literatur mit markierten Änderungen

- Versuchsplan mit markierten Änderungen

- $\quad$ Probandeninformation mit markierten Änderungen

- $\quad$ Einwilligungserklärung mit markierten Änderungen

- Dokumentationsbogen

Sehr geehrte Frau Dr. Crov,

hiermit bestätigen wir Ihnen Erhalt und Kenntnisnahme der aufgeführten Unterlagen zu o. g. Studie und bedanken uns für Ihr Schreiben vom 15.08.2017.

Nach Durchsicht der Unterlagen teilen wir Ihnen mit, dass seitens der Ethik-Kommission an der Technischen Universität Dresden gegen die nachträglichen Änderungen vom 15.08.2017 keine ethischen Bedenken bestehen.

Das Votum der Ethik-Kommission der Sitzung vom 20.06.2017 bleibt unberührt.

Mit fkeundlichen Grüßen

[signature removed]

Dr. phil. nat. Joachim Siegert

FA für Klinische Pharmakologie

geschäftsf. Mitglied der Ethikkommission

Geschäftsstelle der Ethikkommission http://tu-dresden, de/ die_tu_dresden/ an der TU Dresden

Fiedlerstr. 33

01307 Dresden
Internet gremien_und_beauftragte/kommissionen/ ethikkommission/ 
India Morrison

Neurofysiologiska kliniken

Universitetssjukhuset

58185 LINKÖPING

Ansökan: Neurala mekanismer för affektiv beröring: gener, hjärna och beteende.

Sökande forskningshuvudman: Landstinget i Östergötland

Dnr 2014/341-31

Nämnden har den 20 oktober, med förtydliganden den 3 november, 2014 erhållit komplettering i ärendet.

Ansökan godkänns med villkor att uppgift om och samtycke avseende biobank i patientinformationen revideras enligt bifogad underbilaga 2

På nämndens vägnar

[signature removed]

Charlotta Dabrosin, professor

Vetenskaplig sekreterare 
I 



\title{
Touch targeting C-tactile afferent fibers has a unique physiological pattern: A combined electrodermal and facial electromyography study
}

\author{
Anbjørn Ree ${ }^{\mathrm{a}, *}$, Leah M. Mayo ${ }^{\mathrm{b}}$, Siri Leknes ${ }^{\mathrm{c}, \mathrm{d}}$, Uta Sailer ${ }^{\mathrm{a}}$ \\ ${ }^{a}$ Department of Behavioral Sciences in Medicine, Institute of Basic Medical Sciences, Faculty of Medicine, University of Oslo, Oslo, Norway \\ ${ }^{\mathrm{b}}$ Center for Social and Affective Neuroscience, Department of Clinical and Experimental Medicine, Linköping University, Sweden \\ ${ }^{\mathrm{c}}$ Department of Psychology, University of Oslo, Oslo, Norway \\ ${ }^{\mathrm{d}}$ The Intervention Centre, Oslo University Hospital, Oslo, Norway
}

\section{A R T I C L E I N F O}

\section{Keywords:}

C fibers

C-tactile fibers

Affective touch

Social touch

Pleasantness

Intensity

Facial EMG

Corrugator

Zygomaticus

\begin{abstract}
A B S T R A C T
Caress-like touch is thought to rely on C-tactile (CT) fiber signaling. Here, the arousing and emotional effects of CT-optimal touch were assessed via participants' skin conductance level (SCL), facial electromyography (EMG) responses and subjective ratings of pleasantness and intensity. Temporal facial EMG analysis was based on the conduction velocity of CT-fibers.

45 healthy participants received CT-optimal touch, control touch and visual control input during 2-minute trials.

CT optimal touch was significantly more pleasant and intense than control touch. In the initial $700 \mathrm{~ms}$ of stimulation there was no difference in facial EMG responses to touch. Between 700 and $6300 \mathrm{~ms}$ there was a significant reduction of corrugator activity in response to CT optimal touch only, possibly reflecting the affective value of CT optimal touch. Based on the temporal dynamics of the reduced corrugator activity, we suggest that CT fibers are involved in mediating a reduction in corrugator activity.
\end{abstract}

\section{Introduction}

Touch is one of several senses that we use to orient and interact with the social and physical environment. Whereas the visual and auditory systems allow us to observe and communicate at great distances, the tactile components of our explorative and communicative system are concerned with the immediate, close proximity of our surroundings (Gallace \& Spence, 2010). Tactile research has predominantly focused on the sensory-discriminatory aspects of touch (McGlone, Wessberg, \& Olausson, 2014), mediated by fast-conducting, large diameter A $\beta$ fibers (Abraira \& Ginty, 2013). However, Olausson et al. (2008); Olausson, Wessberg, McGlone, \& Vallbo, 2010) argue that humans have a tactile system working in parallel with the sensory-discriminatory system. This system appears to be related to the social and affective aspects of touch, subserving aspects of human interoception and well-being. Parts of this signaling is thought to be mediated by a group of C-afferent fibers (McGlone et al., 2014).

C-tactile (CT) fibers are afferent, unmyelinated skin receptors that typically respond to stimuli similar to a light, stroking touch (Ackerley, Wasling et al., 2014), and were first described in humans by Johansson, Trulsson, Olsson, and Westberg (1988). CT afferents exhibit an apparent velocity dependent firing frequency which also coincides with subjective pleasantness ratings in healthy humans (Ackerley, Wasling et al., 2014; Löken, Wessberg, McGlone, \& Olausson, 2009). The preferred velocity seems to reside between 1 and $10 \mathrm{~cm} / \mathrm{sec}$, giving rise to an inverted "U", with lower CT-afferent firing and lower pleasantness ratings at slower and faster stroking velocities (Ackerley, Wasling et al., 2014; Löken et al., 2009). However, recent evidence suggests that different subjective evaluations of touch responses, such as intensity ratings, are not in the same way velocity specific (Jonsson et al., 2015; Luong, Bendas, Etzi, Olausson, \& Croy, 2017), and were more resilient to change in the presence of disgusting odor than pleasantness ratings (Croy, Angelo, \& Olausson, 2014). Moreover, whereas subjective pleasantness decreases with repeated stimulation, intensity does not (Triscoli, Croy, Steudte-Schmiedgen et al., 2017). Thus, pleasantness and intensity ratings of tactile stimulation appear to account for different parts of the subjective experience.

Explicit subjective reports however, require a conscious evaluation of the stimulus (Cohen, Moyal, Lichtenstein-Vidne, \& Henik, 2016), which may not capture all aspects of the response (Nisbett \& Wilson, 1977). Moreover, subjective reports are constructed appraisals based on several processes, such as recollection, and thus, represent selected

\footnotetext{
* Corresponding author.

E-mail address: anbjorn.ree@medisin.uio.no (A. Ree).
} 
fragments in a series of processes that ultimately form an experience (Cowen \& Keltner, 2017). Therefore, collecting involuntary ('implicit'), physiological measures may complement our current understanding of affective responses (Strack \& Deutsch, 2004). It has been previously shown that changes in peripheral physiology and/or behavior can capture affective reactions that do not manifest as changes in conscious emotional experiences e.g.,(Öhman \& Soares, 1998; Quirin, Kazen, Rohrmann, \& Kuhl, 2009; Winkielman \& Berridge, 2004; Zajonc, 2000). Thus, self-reports might not capture responses that do not make it to consciousness. Alternative measures are also important in situations where speech is limited (such as in infants), and an increased understanding of physiological responses signaling positive or negative affect in this population may have important clinical implications (Hartley et al., 2015).

As a measure of implicit responses, facial electromyography (EMG) has been used reliably in the field of psychology to distinguish between negative and positive emotional responses (Dimberg, 1982). Studies of facial EMG responses to visual (Lang, Greenwald, Bradley, \& Hamm, 1993), olfactory (Joussain, Ferdenzi, Djordjevic, \& Bensafi, 2017) and gustatory (Horio, 2003) stimuli have all reported that negative stimuli increase, whereas positive stimuli can decrease, responses of the corrugator supercilii ("frown") muscle. Furthermore, studies also report an increased zygomaticus major response ("smile") to positive stimuli (Bradley \& Lang, 2000; Lang et al., 1993; Larsen, Norris, \& Cacioppo, 2003). Recently, Pawling, Cannon et al. (2017) investigated CT targeted touch responses using facial EMG and reported an increase in the zygomaticus major muscle during CT targeted touch to the hairy skin, but not the glabrous skin of the palms. Importantly, the difference in facial EMG activity was not mirrored by a difference in pleasantness ratings. The authors propose that the facial EMG response is indicative of an implicit emotional response to CT targeted touch and that facial EMG may be a more sensitive measure of affective responses induced by CT targeted touch than subjective reports (Pawling, Cannon et al., 2017).

Affective stimuli are also often accompanied by responses of the autonomic nervous system (ANS), which are assumed to reflect the arousal dimension of emotions (Braithwaite, Watson, Jones, \& Rowe, 2013). Electrodermal activity (EDA) is commonly used as a measure of ANS activity. Typically, EDA is higher when viewing pleasant and unpleasant pictures in contrast to neutral pictures, which is interpreted as evidence that ANS responses correspond to emotional arousal (Lang et al., 1993). EDA may be broadly defined into phasic skin conductance responses (SCRs) and tonic skin conductance level (SCL), thought to reflect rapid and slower changes in autonomic arousal, respectively (Boucsein et al., 2012). Previous EDA studies have consistently demonstrated sympathetically mediated responses to discrete auditory (Bradley \& Lang, 2000), visual (Bradley, Codispoti, Cuthbert, \& Lang, 2001) and olfactory (Bensafi et al., 2002) stimuli. Moreover, it is maintained by Boucsein (2012) that EDA measures are preferred over cardiac measures when investigating responses that are primarily of lower arousal, although tactile stimuli have been reported to affect other autonomic measures previously [see for instance Fairhurst, Löken, and Grossmann, (2014); Pawling, Trotter et al. (2017); Triscoli, Croy, Olausson et al., 2017; Triscoli, Croy, Steudte-Schmiedgen et al., 2017].

The few studies which have investigated EDA responses to CT-targeted touch report greater SCRs for fast touch $(30 \mathrm{~cm} / \mathrm{s})$ compared to CT targeted touch ( $3 \mathrm{~cm} / \mathrm{s}$ ) (Greco et al., 2015; Pawling, Cannon et al., 2017). Olausson et al. (2008) reported a distinct SCR to CT targeted touch, in both normal adults and in two rare neuronopathy patients without normal functioning $\mathrm{A} \beta$-afferents. According to the authors, this suggests an important role of CT mediated touch in influencing the ANS (Olausson et al., 2008). Although higher SCL in response to touch compared to non-CT targeted tapping has been reported (Etzi, Carta, and Gallace, (2017), the authors were unable to conclude as to whether the higher arousal was due to the type of touch or the different stimulation time. To our knowledge, previous studies investigating CT targeted touch and EDA responses have not compared very slow touch to CT targeted touch over a fixed interval, thereby controlling for stimulation time. The present study aimed to investigate the effects of stroking on the slower responding SCL, allowing for equal amount of stimulation time between CT targeted touch and control touch.

In the present study, subjective ratings of pleasantness and intensity, as well as both facial EMG and SCL data were collected with an aim to obtain a more complete picture of the physiological and affective impact of CT-targeted touch. In addition, we took advantage of the high temporal resolution of facial EMG to investigate the temporal dynamics of A $\beta$ - and CT afferent input. More precisely, Ackerley, Eriksson, and Wessberg, (2013) reported an ultra-late ERP in response to CT targeted touch to the forearm that did not reach the cortex until approximately $700 \mathrm{~ms}$ after stroking began. Microneurography studies indicate that the conduction velocity of CT afferents varies between 0.6 and $1.3 \mathrm{~m}$ s-1 (Olausson et al., 2010; Watkins et al., 2017), which is distinctly slower than the large diameter, fast conducting $\mathrm{A} \beta$ fibers (Abraira \& Ginty, 2013; Olausson et al., 2010). Therefore, one would expect a time-lag of approximately $700 \mathrm{~ms}$ before the facial EMG responses following CT afferent input from the arm become evident. In the present study, facial EMG responses during the first $700 \mathrm{~ms}$ of CT-targeted stimulation were analyzed separately from the following intervals, to differentiate between responses due to mainly $A \beta$-activation, and responses due to both CT- and A $\beta$-activation. Moreover, we assessed the relationship between facial EMG and EDA responses to CT optimal touch, control touch and visual input and subjective ratings of pleasantness and intensity. By exposing the participants to several twominute trials of sensory stimulation, we aimed to investigate not only the initial responses to touch and visual input but also how the participants responded over prolonged stimulation.

Thus, our aims were threefold. Firstly, we expected to reproduce previous findings related to touch and subjective ratings, in which CT targeted touch $(3 \mathrm{~cm} / \mathrm{sec})$ to the hairy skin of the forearm is rated as more pleasant and intense than control touch $(0.3 \mathrm{~cm} / \mathrm{sec})$. Moreover, we wanted to extend these findings by using a non-tactile visual control condition. Secondly, we wanted to examine to what extent explicit subjective ratings of pleasantness and intensity correspond to implicit physiological measures of affect and arousal. To this end, we hypothesized that CT targeted touch would lead to an overall reduction in corrugator activity and increase in zygomaticus activity, compared to control touch and visual control condition. Based on the reported different conduction velocities of A $\beta$-afferent input and CT afferent input (Abraira \& Ginty, 2013; Ackerley et al., 2013; Watkins et al., 2017), we expected these differences to be evident only after $700 \mathrm{~ms}$ of touch. Thirdly, the SCL to repeated tactile and non-tactile stimuli was explored.

\section{Methods}

\subsection{General procedure}

The study had a within-subjects design with 1 factor (sensory stimulus) and 3 levels (CT optimal touch, control touch and visual control condition). The a priori sample size estimation was calculated using the program PANGEA [Power Analysis for General Anova Designs] (Westfall, 2016). 45 participants were deemed necessary for a statistical power of 0.8 and a medium effect size of $d=0.45$. 45 healthy people were recruited by announcements in various academic institutions in Oslo. One participant was removed from the study due to an acute bout of rheumatoid arthritis affecting the left wrist in particular. One participant showed signs of clinical depression [Beck Depression Inventory-II; score 36 (Beck, Steer, \& Brown, 1996)], however, her mean pleasantness ratings and facial EMG activity levels were within the group mean \pm 1 standard deviation and the participant was therefore included in the study. Thus, data from a total of 27 women and 17 men were included in the study (see Table 1 ). The study was approved by the 
Table 1

Demographic overview of age and BDI-II scores with standard deviation.

\begin{tabular}{llll}
\hline Measure & Women $(\mathrm{N}=27)$ & Men $(\mathrm{N}=17)$ & Total $(\mathrm{N}=44)$ \\
\hline Age & $24.3 \pm 6.3$ & $25.9 \pm 4.9$ & $24.9 \pm 5.7$ \\
BDI-II & $9.37 \pm 7.8$ & $9.35 \pm 6.5$ & $9.36 \pm 7.2$ \\
\hline
\end{tabular}

local ethical committee at the Department of Psychology, University of Oslo and the participants gave written consent.

The participants were instructed that the main purpose of the study was to investigate if and how various forms of sensory input could affect decision making and perceptions of various sensations. They were asked to rate the experience of different sensory stimuli and film clips using both computerized questionnaires and visual analogue scales (VAS).

Participants were equipped with facial EMG and EDA electrodes (see below for details). The participants were told that the electrodes would record muscle and sweat activity, to prevent the conscious and unconscious desire to frown and smile during the experiment. The participants were seated in front of a computer screen with the left arm placed on an inflatable cushion that was adjusted to their comfort. The participants were restricted from watching the researcher and their own arm during the experiment by wearing a custom-made cap which limited lateral view (see Fig. 1). This was to ensure that the tactile stimuli were not facilitated by visual input (Tipper et al., 1998), and to reduce the influence of other contextual factors that may influence hedonic responses, such as the (expectation of) facial feedback from the experimenter (Jäncke \& Kaufmann, 1994). After completing the practice trials, they were equipped with a set of headphones which were worn throughout the experiment (AKG, K 271 MkII). As recommended by Boucsein et al. (2012), we ensured the electrodes were placed on the skin at least 5-10 minutes before the actual data collection started.

Three different types of sensory stimulation were investigated: CToptimal touch, control touch, and visual stimulation. The trials lasted two minutes and each stimulus type was presented twice, thus totaling 6 trials per participant. The order of conditions and repetitions was pseudorandomized across participants.

CT-optimal touch was delivered during two minutes in a proximaldistal direction to the left forearm at a speed of $3 \mathrm{~cm} / \mathrm{s}$ and an approximate force of $0.4 \mathrm{~N}$ using a cosmetic brush made from goats' hair. To reduce the possibility of CT-fiber fatigue (Vallbo, Olausson, \& Wessberg, 1999; Wessberg, Olausson, Fernstrom, \& Vallbo, 2003), the experimenter alternated the stroking between two equally large parts of the forearm which were in a distance of approximately $5 \mathrm{~cm}$ from each

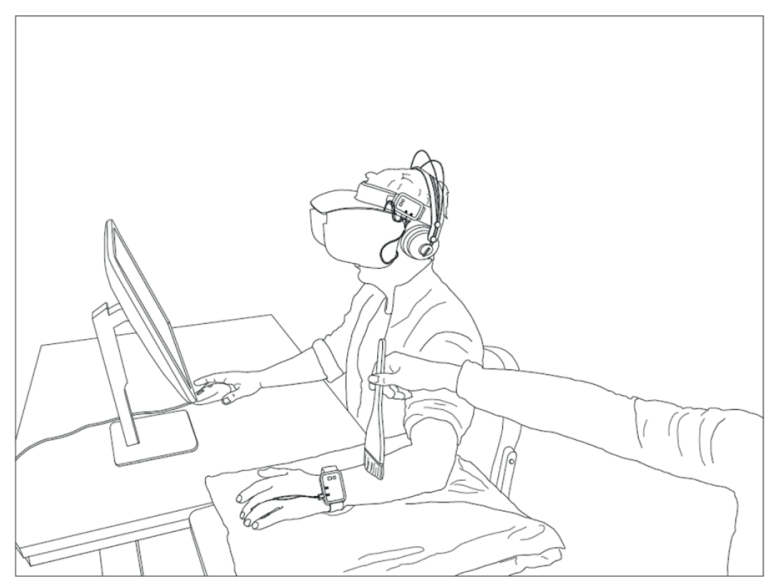

Fig. 1. Overview of experimental set-up. Tactile stimulation was delivered for 2 min using a paint brush. The visual control was presented on a computer screen in front of the participant. A custom-made hat limited lateral view and contact between the experimenter and participants. other. Control touch was delivered at $0.3 \mathrm{~cm} / \mathrm{s}$ in a similar manner. The experimenter was trained to deliver the stimulation with appropriate force and velocity and was guided by a visual meter displayed to the experimenter only. The visual stimulation consisted of $2 \mathrm{~min}$ of colorful patterns moving at various speeds on the computer screen and was edited from 6 movies purchased from Shutterstock (Shutterstock Inc; New York, USA). Following each type of sensory stimulation, the participants rated the pleasantness and intensity of the stimulation on two visual analogue scales (VAS) anchored by "Very pleasant/very unpleasant" and Very intense/not intense". The minimum and maximum scores of the scale were coded as "-10" and "+10" (see Fig. 2).

Additionally, the participants were exposed once to $2 \mathrm{~min}$ of pink noise and a custom made questionnaire that contained random questions pertaining to dietary preferences, facial attractiveness and how one would spend an imaginary lottery win. This served to further consolidate the impression that the aim of the study was to investigate the response to various types of sensory stimuli. The auditory data served as baseline for the skin conductance level investigations.

Following CT optimal touch, control touch and visual stimulation (but after VAS ratings), the participants performed an economic task [reported in Rosenberger, Ree, Eisenegger, and Sailer, (2018)] and rated different videos (data not reported here). At the end of the experiment, the participants were debriefed about the main purpose of the study, completed a set of questionnaires and were offered a selection of different gift vouchers as reimbursement for participating in the study (approximate value $200 \mathrm{NOK}$ ).

\subsection{Psychophysiology}

The BioPac MP150 Nomadix wireless system (BioPac Systems Inc, Ca, USA) was used to collect facial EMG and EDA responses. Data were sampled at $1000 \mathrm{kHz}$ and recorded using AcqKnowledge software (version 4.4, BioPac Systems Inc, Ca, USA). Stimulus presentation and timing were controlled using E-Prime 2.0 (Psychology Software Tools, Pittsburgh, PA).

\subsection{Electromyography}

Facial EMG was recorded using $4 \mathrm{~mm} \mathrm{Ag} / \mathrm{AgCl}$ surface click electrodes with disposable adhesive caps (BioPac Inc, Add204), which were filled with electrode gel (BioPac SignaGel 100). The participants were seated in a chair and electrodes were positioned over the Mm corrugator supercilii and zygomaticus major of the left side of the face, as described by Fridlund and Cacioppo (1986) and Tassinary, Cacioppo, and Vanman (2007). Prior to the start of the study, the participants were instructed to actively frown, lift the eyebrows, blink, smile and clench their teeth whilst the signal was checked. The reference electrode was placed centrally on the participant's forehead. Impedance was kept below $10 \mathrm{k} \Omega$ and checked using the EL-CHECK (BioPac Inc, Ca USA). If the impedance exceeded $10 \mathrm{k} \Omega$, the area under the electrodes was cleaned again and the electrodes readjusted.

\subsection{Electrodermal activity}

EDA activity was recorded using the BioPac wireless direct current set-up, including 2x BioPac Lead $110 \mathrm{~A}$ and 2x EL-507 disposable selfadhesive click electrodes, which were lubricated with gel (BioPac SignaGel 100) and taped to the palmar surface of the middle phalanges of the $3^{\text {rd }}$ and $4^{\text {th }}$ fingers of the left hand. The skin was cleaned using water or alcohol if required. If alcohol was used, the fingers were cleansed with water afterwards. The equipment was then calibrated according to procedures described by BioPac (AcqKnowledge (4.4), 2018). 


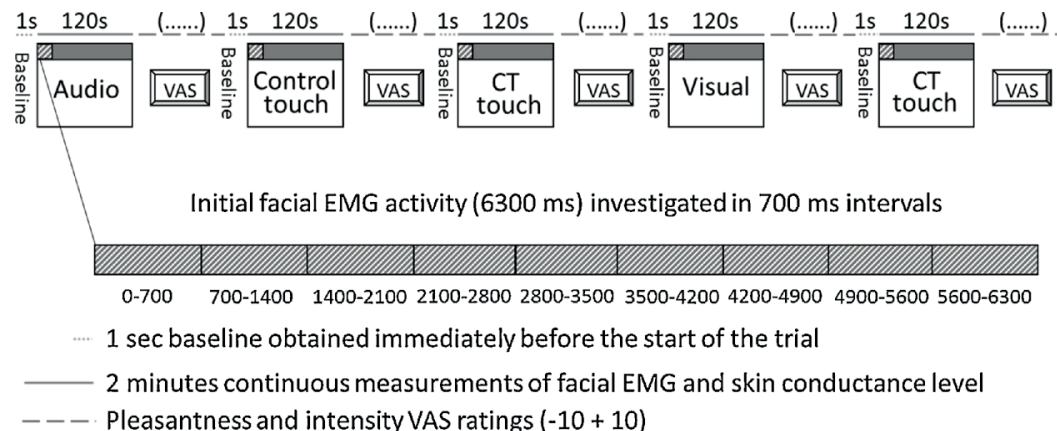

Fig. 2. Overview of experimental set-up. The order of trials was pseudo-randomized across participants. Facial EMG and skin conductance level were analyzed continuously during the $2 \mathrm{~min}$ trial. Specific investigation into the facial EMG pattern of the initial $6300 \mathrm{~ms}$ was analyzed to separate responses containing primarily $\mathrm{A} \beta$ fiber input from responses containing both $\mathrm{C}$ tactile fiber and $\mathrm{A} \beta$ fiber input. The participants rated the pleasantness and intensity following each trial on a visual analogue scale $(-10+10)$.

\subsection{Data processing}

\subsubsection{Facial EMG}

The facial EMG signals were amplified 5000x, submitted to a $10-500 \mathrm{~Hz}$ band pass filtering, and digitized at $1000 \mathrm{~Hz}$. Offline, AcqKnowledge software was used to apply a $50 \mathrm{~Hz}$ comb band stop filter to remove power line interference and a $50 \mathrm{~Hz}$ FIR high pass filter to remove electrocardiogram artifacts (Mayo, Linde, Olausson, Heilig, \& Morrison, 2018; Zhou, Lock, \& Kuiken, 2007). Filtered signals were then rectified and integrated over $20 \mathrm{~ms}$, and the resulting data were used in the analysis. The baseline was designated as the $1 \mathrm{~s}$ immediately preceding the onset of each type of sensory stimulation (see Fig. 2). If the baseline was found to be contaminated by artifacts by visual inspection, the contaminated baseline was replaced by the baseline from the next trial. An average of $8.9 \%$ of baselines were contaminated. The facial EMG activity was then analyzed in three separate analyses. First, the mean muscle activity across the two minutes of stimulation was computed for the corrugator and zygomaticus muscles before subtracting the respective baseline. Thus, the variables "Mean Corrugator Activity" and "Mean Zygomaticus Activity" represent mean change in muscle activity from baseline across the two minute period.

Second, the first $6300 \mathrm{~ms}$ (corresponding to $\sim 2$ strokes) of these two minutes were also analyzed by subtracting the baseline designated as the $1 \mathrm{~s}$ preceding the start of each trial from the $6300 \mathrm{~ms}$ section. The variables "Initial Corrugator Activity" and "Initial Zygomaticus Activity" represent mean activity during these initial $6300 \mathrm{~ms}$ of activity.

Third, the first $6300 \mathrm{~ms}$ of the two-minute period were further divided into 9 consecutive intervals of $700 \mathrm{~ms}$ activity (see Fig. 2). Here, the same baseline ( $1 \mathrm{~s})$ immediately preceding the start of the trial was subtracted from the activity of each of the 9 intervals. Using an interval of $700 \mathrm{~ms}$ is based on the findings of Ackerley et al. (2013) who investigated CT mediated activity in EEG potentials and reported a $700 \mathrm{~ms}$ lag from stroke onset until the proposed CT mediated input reached the cortex. This interval is also supported by nerve conduction studies using microneurography recordings (Olausson et al., 2010; Watkins et al., 2017). The first intervals (1-5) were used to include the time-window of $3.1 \mathrm{~s}$ applied by Ackerley et al. (2013). The latter intervals (6-9) include the completion of a full second brush stroke and were used to explore the possibility of CT-fiber fatigue, as described by Vallbo et al. (1999). Thus, a $700 \mathrm{~ms}$ time-window was chosen to investigate tactile sensory input predominantly reflecting $A \beta$ input (initial $700 \mathrm{~ms}$ ) and activity containing $\mathrm{A} \beta$ and CT-fiber input (post $700 \mathrm{~ms}$ ). "Interval 1" represents the period between 0-700 ms, "interval 2", represents the period between $700-1400 \mathrm{~ms}$ and so forth until "interval 9", which refers to the period between 5600-6300 ms.

\subsubsection{EDA dato}

The data were filtered offline using a high pass filter $(0.05 \mathrm{~Hz})$. Next, mean skin conductance level (SCL) during the two-minute period was computed for each participant and condition. Then, phasic skin conductance responses (SCRs) were identified from the initial $8 \mathrm{~s}$ and 5 other specifically selected $8 \mathrm{~s}$ periods from the same condition, using a threshold of $0.01 \mu \mathrm{S}$. These time periods coincided with the onset of the tactile and visual input and to changes in the visual background and were removed to account for the orienting response (Bradley et al., 2001). To this end, we used the BioPac event-related analysis routine. To obtain a measure of mean SCL, the phasic mean SCR was subtracted from the tonic SCL of the same condition. The two minutes of pink noise served as baseline. Thus, mean SCL equals ((tonic SCL-phasic SCR) baseline)), as recommended by Braithwaite et al. (2013). One participant had a major artifact during one of the visual trials and this was replaced by activity from the other visual trial.

\subsection{Data analysis}

Following visual inspection of the facial EMG and EDA data, values exceeding the upper quartile plus the threefold interquartile range (IQR) and values less than the lower quartile minus the threefold IQR were defined as outliers and deleted from the dataset. The total amount of data removal was $2-13 \%$, with least removal for SCL data and most for zygomaticus data. The raw facial EMG and EDA files from two participants were corrupted due to technical issues and could not be included in the analysis. One participant showed no noticeable phasic or tonic changes in EDA levels and was removed from further analysis. This is slightly less than the typical reported $10 \%$ of the population (Braithwaite et al., 2013). Two subjects accidentally detached the corrugator electrodes whilst scratching the foreheads and the signal was subsequently too noisy. Consequently, data from 41 participants were used for EDA analysis and the facial EMG analysis was based on responses from 42 and 40 participants for zygomaticus and corrugator activity, respectively.

The data were analyzed using linear mixed models in the generalized linear mixed model option in SPSS version 24.0 (IBM Corp., NY, USA). Residuals were plotted and inspected for normality. Bayesian Information Criteria (BIC) was used to determine the optimal model, as described by Bolker et al. (2009). A parsimonious model using random intercept and random slope was used in all analyses, using the Satterthwaite approximation of the degrees of freedom. The random covariance type refers to the covariance structure of the residuals in the statistical model (West, Welch, \& Galecki, 2014). In the present study, we assumed that the tactile and visual conditions would demonstrate equal variance. Based on these assumptions and an improvement in BIC value (Bolker et al., 2009), scaled identity was used as the random covariance type. 
Dependent variables were the trial-wise subjective ratings of pleasantness and intensity, mean skin conductance level during the 2-min trial, and mean corrugator and zygomaticus activity. Separate analyses were run for each dependent variable. Additionally, three different analyses of mean facial EMG activity were run: 1) during the entire 2mintrial, 2) during the initial $6300 \mathrm{~ms}$ of this 2-min trial, and 3) during nine consecutive $700 \mathrm{~ms}$-intervals within those $6300 \mathrm{~ms}$. The latter analysis of $700 \mathrm{~ms}$ intervals was performed in order to disentangle facial EMG activity due to mainly $A \beta$-activation from that due to $A \beta$ and CT-activation. Here, sensory stimulus (levels: CT-optimal and control) and interval (levels: 1-9) served as fixed factors. Interactions were followed up with Bonferroni-corrected pairwise contrasts.

For all other analyses, sensory stimulus (levels: CT-optimal, control, visual) served as fixed factor. In all analyses, subject served as random intercept and random slope was modelled around sensory stimulus (levels: CT-optimal, control, visual).

Significant main effects were followed up with pair-wise contrasts. Effect sizes were calculated as described by Edwards, Muller, Wolfinger, Qaqish, and Schabenberger, (2008), which may be interpreted as follows: $0.02=$ "small semi-partial $\mathrm{r}^{2}$ "; $0.13=$ "medium semi-partial r ${ }^{2}$ "; 0.26 = "large semi-partial $\mathrm{r}^{2}$ "(Page-Gould, 2016).

\section{Results}

\subsection{Pleasantness and intensity ratings}

There was a significant main effect of stimulus type on pleasantness ratings $(\mathrm{F}(2,162)=8.418, \mathrm{p}=0.001)$, [semi-partial $\mathrm{r}^{2}=0.09$ ]. CT optimal touch was rated as significantly more pleasant (Mean $\pm \mathrm{SD}=4.6 \pm 4.2$ ) than control touch (Mean $\pm \mathrm{SD}=2.2 \pm 4.1$, pairwise contrast $p=0.001$ ), but not significantly more pleasant than visual stimulation (Mean $\pm \mathrm{SD}=3.6 \pm 3.2$, pairwise contrast $\mathrm{p}=0.096$, see Fig. 3). The intensity of all types of stimuli was generally rated as low, as negative values indicate ratings close to the anchor "not intense". There was a significant main effect of stimulus type on intensity ratings ( $F$ (2, $165)=3.536, p=0.031$ ), [semi-partial $r^{2}=0.04$ ]. CT optimal touch was rated as significantly more intense (Mean $\pm \mathrm{SD}=-2.0 \pm 5.0$ ) than control touch (Mean \pm SD $-3.9 \pm 4.6$, pairwise contrast $\mathrm{p}=0.026$ ), but not significantly more intense than visual stimulation (Mean $\pm \mathrm{SD}=$ $-2.8 \pm 4.5$, pairwise contrast $\mathrm{p}=0.264$ ).

\subsection{Facial EMG}

\subsubsection{Corrugator}

There was no significant difference in mean corrugator activity in response to CT optimal touch, control touch, and visual stimulation (F $(2,200)=1.462, \mathrm{p}=0.234)$ over the two-minute blocks [semi-partial $\left.\mathrm{r}^{2}=0.01\right]$. However, during the initial $6300 \mathrm{~ms}$ of sensory stimulation, there was a significant main effect of stimulus type on mean corrugator activity, $(\mathrm{F}(2,122)=4.242, \mathrm{p}=0.017$, see Fig. 4, left) such that CT optimal touch was associated with significantly less corrugator activity $(-0.085 \pm 0.723 \mathrm{mV})$ than control touch $(0.111 \pm 0.625 \mu \mathrm{V}$, pairwise contrast $\mathrm{p}=0.020$ ) and marginally non-significantly less activity compared to visual stimulation, $(0.057 \pm 0.747 \mu \mathrm{V}$, pairwise contrast $\mathrm{p}=0.062)$ [semi-partial $\mathrm{r}^{2}=0.07$.

A specific analysis pertaining to tactile responses and the conduction velocity of $A \beta$ and CT fibers were conducted for CT optimal touch and control touch only. There was a significant main effect of stimulus type on mean corrugator activity $(F(1,83)=9.723, p=0.002)$, such that CT optimal touch was associated with significantly less corrugator activity than control touch [semi-partial $\mathrm{r}^{2}=0.11$ ]. There was, however, no main effect of interval $(F(8,1239)=0.254$, $p=0.980)$ [semipartial $\left.\mathrm{r}^{2}=0.01\right]$, nor any stimulus type*interval interaction ( $\mathrm{F}(8$, $1239)=1.328, \quad p=0.225) \quad$ [semi-partial $\left.r^{2}=0.01\right]$. When investigating the temporal dynamics in $700 \mathrm{~ms}$ intervals of activity, the corrugator activity in the initial $700 \mathrm{~ms}$ in response to CT optimal touch and control touch was similar $(-0.031 \pm 0.60 \mu \mathrm{V}$ and $-0.017 \pm 0.49 \mu \mathrm{V}, \mathrm{p}_{\text {bonf }}=0.982$ ). Over the next 5 intervals, corrugator activity in response to CT optimal touch decreased gradually, whereas it gradually increased in response to control touch [See Fig. 4, right]: during interval 2 , the corrugator activity was marginally lower for CT optimal touch than control touch $\left(\mathrm{p}_{\mathrm{bon}}=0.071\right.$ ). During intervals $3,5,6,7$ and 8, the corrugator activity was significantly lower during CT optimal touch than during control touch ( $\mathrm{p}_{\text {bon }}<0.034$ ).

\subsubsection{Zygomaticus}

There was no significant main effect of stimulus type zygomaticus activity across the full two-minute period $(\mathrm{F}(2,203)=1.464$, $\mathrm{p}=0.233$ ) [semi-partial $\mathrm{r}^{2}=0.01$ ]. When investigating the initial $6300 \mathrm{~ms}$ of sensory stimulation, there was no significant main effect of sensory stimulus $(\mathrm{F} \quad(2,110)=2.137, \mathrm{p}=0.123) \quad$ [semi-partial $\left.r^{2}=0.04\right]$. A specific analysis pertaining to tactile responses and the conduction velocity of $A \beta$ and CT fibers were conducted for CT optimal touch and control touch only. There was no significant main effect of stimulus type on mean zygomaticus activity $(F(1,82)=0.897$, $\mathrm{p}=0.346$ ) [semi-partial $\mathrm{r}^{2}=0.01$ ], nor a significant main effect of interval $(\mathrm{F}(8,1245)=0.536, \mathrm{p}=0.830) \quad$ [semi-partial $\mathrm{r}^{2}=0.01$ ] There was no stimulus type *interval interaction $(F(8,1244)=1.212$, $\mathrm{p}=0.288$ ) [semi-partial $\mathrm{r}^{2}=0.01$ ], see Fig. 5, right.

\subsection{Skin conductance level}

The skin conductance level was somewhat higher for CT optimal touch compared to control touch and visual input, however, the differences did not reach statistical significance $(F(2,191)=1.896$, $\mathrm{p}=0.153$, see Fig. 6), [semi-partial $\mathrm{r}^{2}=0.02$ ].

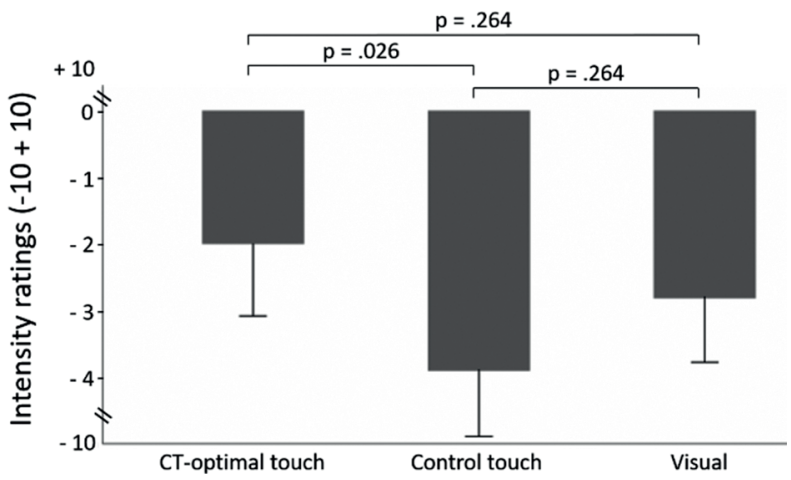

Fig. 3. Mean pleasantness (left) and intensity (right) ratings with SEM after receiving two minutes of CT optimal touch $(3 \mathrm{~cm} / \mathrm{sec})$, $\mathrm{control}$ touch $(0.3 \mathrm{~cm} / \mathrm{sec})$ and visual sensory stimulation. As expected, CT optimal touch was rated significantly more pleasant and intense than control touch, however, CT optimal touch was not rated significantly more pleasant or intense than watching two minutes of geometrical objects moving at various speeds (visual condition). 

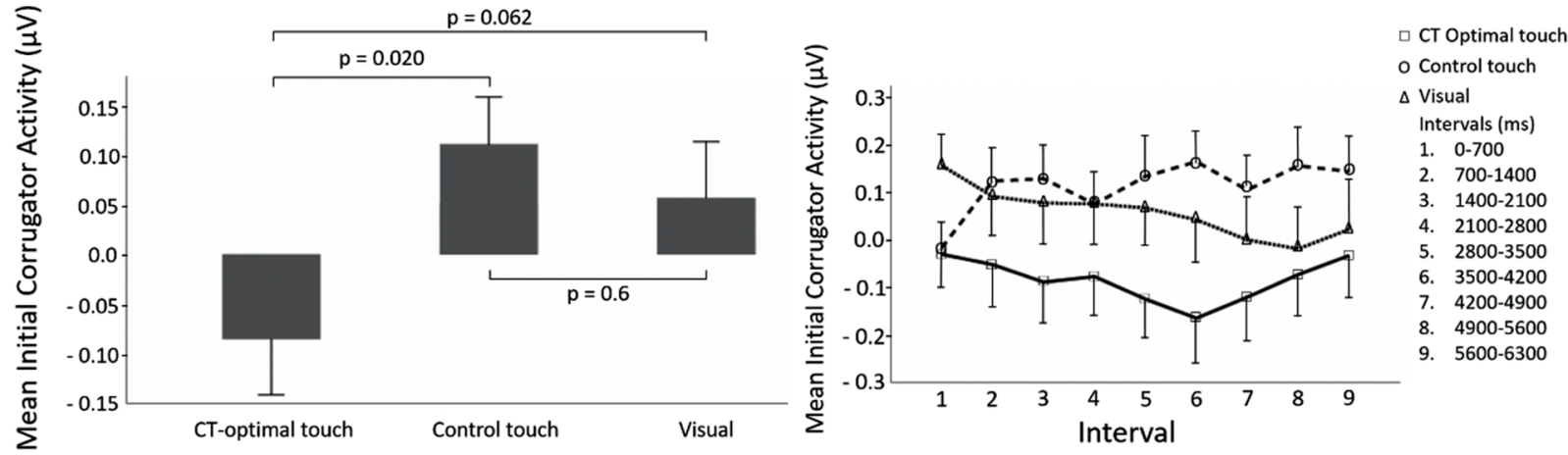

Fig. 4. Mean corrugator activity with SEM (left) measured during the initial $6300 \mathrm{~ms}$ of stimulation onset. CT optimal touch led to significantly less corrugator activity compared to control touch. Right: Mean corrugator activity with SEM during the initial 6300 ms of activity split into intervals of 700 ms.

\section{Discussion}

This study investigated physiological responses and their temporal dynamics during CT optimal touch, control touch and visual stimulation using facial electromyography (EMG) and skin conductance level (SCL). We demonstrate that CT optimal touch ( $3 \mathrm{~cm} / \mathrm{second}$ ) administered over two minutes is more pleasant and intense than slow, control touch $(0.3 \mathrm{~cm} / \mathrm{second})$, as measured by self-report. While we found no differences between pleasant and control touch-related facial EMG and SCL responses over the 2-minute stimulation periods, there was a significant reduction in corrugator (frowning) activity during the first CT optimal strokes.

The findings from the present study are in line with previous findings (Ackerley, Carlsson et al., 2014; Crucianelli, Metcalf, Fotopoulou, \& Jenkinson, 2013; Essick et al., 2010; Triscoli, Olausson, Sailer, Ignell, \& Croy, 2013) in which CT optimal touch $(3 \mathrm{~cm} / \mathrm{sec}$ ) delivered by brush to the hairy skin of the forearm was rated significantly more pleasant than slow control touch $(0.3 \mathrm{~cm} / \mathrm{sec})$. As such, the results provide further support of a velocity specificity in pleasantness ratings of tactile stimuli, first described by Löken et al. (2009). Additionally, the intensity ratings were significantly higher for CT optimal touch than control touch, which has previously been reported by Triscoli et al. (2013). However, there appears to be less agreement as to how velocity affects the perceived intensity of the stimulus. Etzi et al. (2017) recently reported higher intensity ratings in response to fast touch $(30 \mathrm{~cm} / \mathrm{s})$ than CT-targeted touch $(3 \mathrm{~cm} / \mathrm{s})$, whereas Luong et al. (2017) found no effect of velocity on intensity ratings. McGlone et al. (2012) reported higher intensity ratings in response to active touch than static pressure applied to the palm, however, there were no differences in intensity

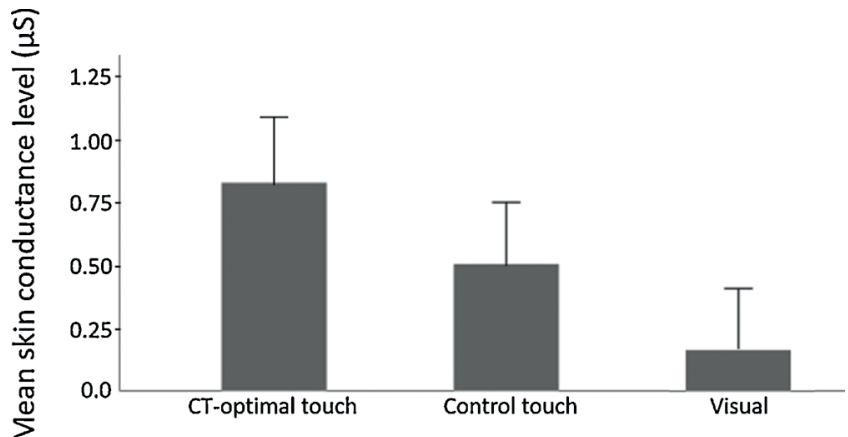

Fig. 6. Mean SCL with SEM measured over a period of two minutes during touch delivered at $3 \mathrm{~cm} / \mathrm{sec}$ (CT optimal touch), $0.3 \mathrm{~cm} / \mathrm{sec}$ (control touch) and visual stimulation.

ratings following active touch (slow versus fast). Thus, whereas pleasantness ratings appear to be consistently linked to the velocity of the stroke, the intensity ratings appear to be linked to other features of the strokes, possibly reflecting the level of indentation of the skin, or the perceived roughness of the stroke. Furthermore, an interesting novel finding from the present study is that CT optimal touch delivered for two minutes was considered just a fraction more pleasant and no more intense than merely watching a computer screen displaying colorful objects moving at different speeds. It is difficult to ascertain the implications of this, but it is conceivable that the pleasantness of CT targeted touch reported elsewhere has been given undue recognition, being driven perhaps more by the relative discomfort of the very slow touch $(0.3 \mathrm{~cm} / \mathrm{sec})$ or the seemingly non-social characteristics of the
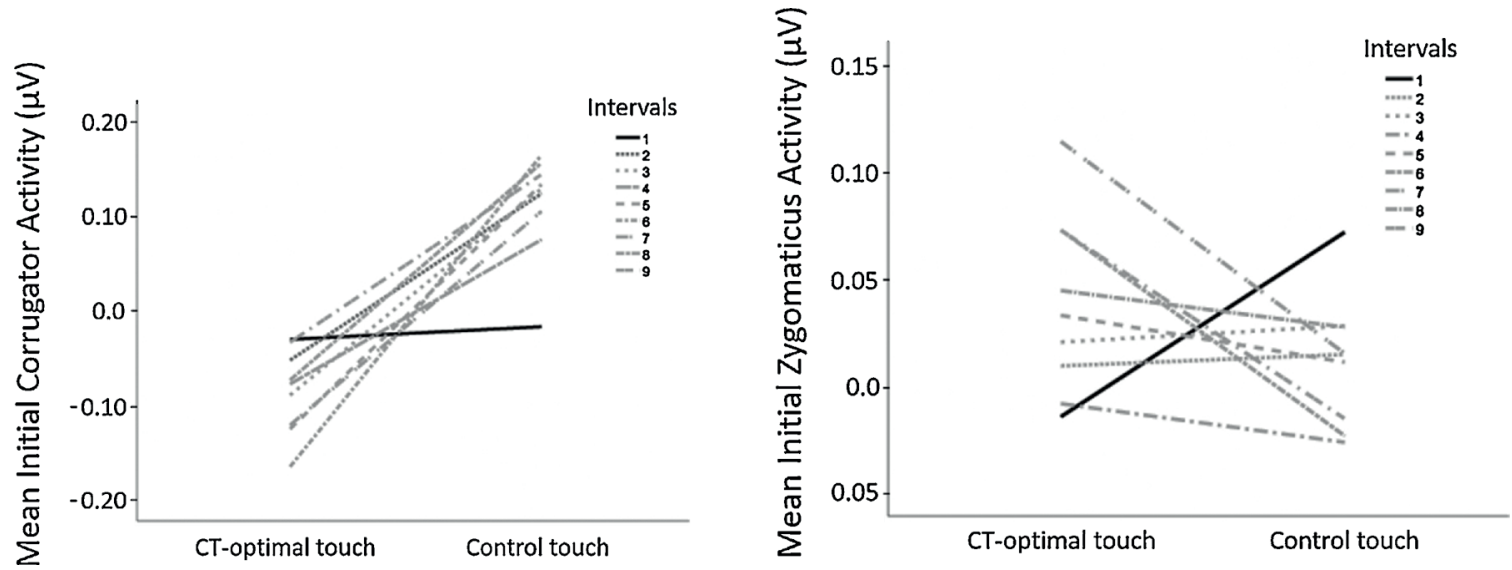

Fig. 5. Mean corrugator activity (left) showing a gradual decrease in corrugator activity in response to CT optimal touch evident after the initial 700 ms (interval 1 ). Right: Mean zygomaticus activity. There appears to be no difference in zygomaticus activity related to A $\beta$ and CT fiber input in response to CT optimal touch and control touch. 
very fast touch $(30 \mathrm{~cm} / \mathrm{sec})$.

The higher pleasantness ratings for CT optimal touch compared to control touch were paralleled by a significant difference in corrugator activity during the initial $6300 \mathrm{~ms}$ of stroking. Notably, CT optimal touch led to a reduction, and control touch to an increase in corrugator activity during this interval. The increase in corrugator reactivity in response to control touch is consistent with an increase in negative affect, while the reduction in corrugator activity elicited by CT optimal touch might suggest a reduction in negative affect. To our knowledge, this is the first study reporting a velocity-specific difference in corrugator activity that compares CT optimal touch $(3 \mathrm{~cm} / \mathrm{s})$ to very slow touch $(0.3 \mathrm{~cm} / \mathrm{s})$. Our study is consistent with a recent study who found increased corrugator activity in response to fast touch $(30 \mathrm{~cm} / \mathrm{s}) \mathrm{com}$ pared to CT targeted touch [3 cm/s] (Mayo et al., 2018). Thus, it appears as if the initial physiological responses of the corrugator muscle to CT optimal touch and control touch are more consistent with the subjective reports provided by the participants after the completion of the two minute trials, than the physiological responses measured across the entire two minute trials. Therefore, facial EMG is more suitable to capture the early responses to a tactile stimulus than an ongoing evaluative process. Facial EMG recordings of the corrugator in particular may complement our understanding of how a tactile stimulus is perceived. Judging by the results from the present study, facial EMG offers small "snapshots" of the participants' implicit responses to tactile stimuli.

Importantly, the corrugator did not respond differently to CT optimal touch or control touch during the initial $700 \mathrm{~ms}$ or the full twominute period of CT-optimal stroking. After the initial $700 \mathrm{~ms}$ and throughout the duration of the first CT optimal stroke across the skin, (see Fig. 4, right), corrugator activity decreased with CT optimal touch, but increased somewhat in the control touch condition. It is impossible to distinguish between afferent input derived exclusively from $A \beta$ fibers and that derived from CT fibers in healthy individuals. However, the conduction velocity of the CT fibers is much slower than A $\beta$ signaling (Watkins et al., 2017), consistent with a previously reported ultralate EEG potential in response to CT targeted touch (Ackerley et al., 2013), as well as with the temporal pattern of corrugator facial EMG activity reported here. We therefore tentatively propose that the facial EMG signal from CT touch is primarily driven by A $\beta$-fibers for the first $700 \mathrm{~ms}$, and that the decreased corrugator signal observed after this time interval may be due to gradually increasing activation of the CT fibers on the forearm. Alternatively, it may be that the higher pleasantness of the CT optimal touch gradually increased over the first few seconds of the 2-minute block, and that the pleasantness led to a reduction of the corrugator activity.

Contrary to previous results, we did not find that the positive affective response to CT targeted touch was reflected in activation of the zygomaticus muscle (Pawling, Cannon et al., 2017). The inconsistent results between the findings from the present study and that reported by Pawling, Cannon, et al. (2017) may be due to methodological differences. The present study used 2-minute stimulation blocks of CT targeted $(3 \mathrm{~cm} / \mathrm{sec})$ and very slow control touch $(0.3 \mathrm{~cm} / \mathrm{sec})$, whereas Pawling, Cannon, et al. (2017) compared CT targeted touch $(3 \mathrm{~cm} / \mathrm{sec})$ and fast control touch $(30 \mathrm{~cm} / \mathrm{sec})$. Alternatively, there appears to be a greater element of the participants being observed in the experimental set-up implemented by Pawling, Cannon, et al. (2017). This may have differentially affected the urge to smile as a means of communication in the two studies.

In the present study, communication between the researcher and the participants was kept to an absolute minimum and a custom-made hat was used to restrict the participants from viewing the researcher during the study. In contrast, the experimental set-up in the study by Pawling, Cannon et al. (2017) seemed to allow more interaction between the participants and the researchers. Previous research has shown that facial expressions (measured with EMG) to odors are enhanced when participants are observed by other persons (Jäncke \&
Kaufmann, 1994). This may also apply to the participants in the study by Pawling, Cannon et al. (2017). Their participants may have had a greater inclination to communicate signs of appreciation than the participants in the present study. This has some support by findings from Hertenstein, Holmes, McCullough, and Keltner, 2009; Hertenstein, Keltner, App, Bulleit, \& Jaskolka, 2006), who argue that touch has the ability to communicate both positive and negative emotions in a more differentiated manner than vocal and facial communication. Alternatively, Larsen et al. (2003) have previously reported that the corrugator and the zygomaticus muscles show different response patterns across a variety of positive and negative stimuli. Specifically, the corrugator demonstrates a linear response pattern across the affective spectrum, with negative affective stimuli showing increased corrugator activity and positive affective stimuli showing reduced corrugator activity. Zygomaticus responses on the other hand, appear to have a " $\mathrm{J}$ shaped" distribution pattern, in which positive affective stimuli elicit zygomaticus activation and negative affective stimuli elicit more activation than neutral stimuli (Larsen et al., 2003). Importantly, in the study by Larsen et al. (2003), only highly affective pictures led to an increase in zygomaticus activity. Thus, it may be that in the present study, the pleasantness of the touch may not have been sufficient to yield a distinct response in the zygomaticus muscle. Moreover, since all conditions were rated as pleasant, the lack of an unpleasant or neutral control condition may have diluted the differences between the stimuli. Future studies should investigate whether the pleasantness associated with CT targeted touch is a necessity of tactile research, or whether pleasantness is a by-product of the firing frequency unrelated to any subsequent social or affective effects.

There was no significant difference in SCL between CT optimal touch, control touch and visual stimulation. The findings from the present study are somewhat in contrast to a recent study by Etzi et al. (2017) who reported higher SCL in response to fast non-CT targeted and slow CT-targeted touch than to non-CT targeted tapping. Etzi et al. (2017) argue that the tactile conditions were more socially relevant than tapping and this may account for the higher SCL associated with the touch conditions. However, Etzi et al. (2017) also speculate as to whether the differences observed in their study were due to differences in stimulation time. In the present study in which all three conditions had equal stimulation time, there was a non-significant difference between the CT optimal touch and the presumably less social visual control condition. Moreover, there was no difference between the tactile conditions. It therefore appears that when tactile inputs are applied for the same amount of time, the differences in SCL are minimal. In comparison, Greco et al. (2015; Greco, Valenza, and Scilingo (2016) found a general reduction of SCL in response to various forms of touch, thought to reflect a general relaxation effect, independent of the valence of the touch. A recent study by Pawling, Trotter et al. (2017) found that fast touch $(30 \mathrm{~cm} / \mathrm{sec})$ was more arousing than CT targeted touch $(3 \mathrm{~cm} / \mathrm{sec})$, evident by higher SCRs in the fast touch group. Methodological differences may partly account for these inconsistent findings, however, it is clear that the autonomic responses to touch are as of now, not fully understood. Previous studies have shown that CT targeted touch also affects other autonomic measures, such as heart rate deceleration (Fairhurst et al., 2014; Pawling, Cannon et al., 2017; Pawling, Cannon et al., 2017; Triscoli, Croy, Olausson et al., 2017) and heart rate variability (Triscoli, Croy, Steudte-Schmiedgen et al., 2017). Therefore, future studies investigating autonomic responses to touch should preferably combine EDA and cardiac measures.

Some limitations apply to the present study. For one, we used a brush as opposed to direct human contact when delivering the touch. We acknowledge that this could possibly influence the ecological validity of the touch (Kress, Minati, Ferraro, \& Critchley, 2011). However, due the length of the stimulation period, we maintain that it was important to standardize the touch as much as possible, thereby limiting other factors, such as skin temperature and sweating to influence the results. Secondly, the study population was predominantly young and 
healthy students, and the results may not be generalized beyond this population. Thirdly, it is impossible to selectively stimulate CT fibers without also activating $A \beta$ fibers in healthy humans. Thus, it is entirely conceivable that the reduction in corrugator activity observed in response to CT optimal touch could in fact be due to the A $\beta$-input. However, we believe this to be unlikely for several reasons. Firstly, there is no difference in corrugator activity in response to control or CT optimal touch in the initial period of touch. This period is arguably free from CT-fiber input due to their reported slow conduction velocity. Therefore it is likely that a reduction of corrugator activity mediated by $\mathrm{A} \beta$ input would have been present in the initial part of the touch also. Moreover, $A \beta$ fibers continue to fire in the presence of repeated stimulation (Olausson et al., 2010), as opposed to the fatigue-prone CT fibers (Vallbo et al., 1999). In our study, the main difference between CT optimal and control touch is evident between $700 \mathrm{~ms}-5600 \mathrm{~ms}$ of touch onset. Between 5600 and $6300 \mathrm{~ms}$, the reduction of corrugator activity in response to CT optimal touch is still evident, however, the differences between CT optimal and control touch seem to diminish steadily [See Fig. 4, right]. It is tempting to speculate that this observation reflects CT-fiber fatigue. Nevertheless, as the control touch response is unchanged in this period, we argue that the reduced corrugator activity is not primarily mediated by $\mathrm{A} \beta$-input, but most likely the arrival of CT afferent input. Lastly, the SCL results need to be interpreted cautiously as they may be confounded by the use of sub-optimal gel and alcohol as a means of cleaning the hands. Alcohol may reduce the natural conductivity of the skin (Dawson, Schell, \& Filion, 2007). The soft gel utilized in the present study may interfere with the SCL due to leakage of gel into sweat ducts (Tronstad, Johnsen, Grimnes, \& Martinsen, 2010). Whilst we do not know the extent that our results may be influenced by the inappropriate gel, it is our understanding that the issue pertaining to soft gels is mostly relevant with long-term recordings and recordings from abdominal sites, due to the thinner skin corneum of the abdomen.

In conclusion, this study has demonstrated that CT optimal touch delivered to the forearm during 2-minute trials was rated as significantly more pleasant and intense than control touch, but not visual input. CT-optimal touch did not elicit significant changes in the activity of the corrugator or zygomaticus muscles, or electrodermal activity, during these stimulation periods. However, CT-optimal touch was associated with an early, transient reduction in corrugator activity, consistent with the notion that facial expressions may supplement verbal communication. Moreover, the temporal pattern through which the reduced corrugator activity is expressed, possibly reflecting the slow conduction velocity of CT fibers, suggests that firing from CT fibers may have led to the relaxation in frowning muscle activity.

\section{Declaration of interest}

None.

This research did not receive any specific grant from funding agencies in the public, commercial or not-for-profit sectors.

\section{Acknowledgements}

We thank Ralph Endemann for drawing Fig. 1.

\section{References}

Abraira, V. E., \& Ginty, D. D. (2013). The sensory neurons of touch. Neuron, 79(4), 618-639. https://doi.org/10.1016/j.neuron.2013.07.051.

Ackerley, R., Eriksson, E., \& Wessberg, J. (2013). Ultra-late EEG potential evoked by preferential activation of unmyelinated tactile afferents in human hairy skin. Neuroscience Letters, 535, 62-66. https://doi.org/10.1016/j.neulet.2013.01.004.

Ackerley, R., Carlsson, I., Wester, H., Olausson, H., \& Backlund Wasling, H. (2014). Touch perceptions across skin sites: Differences between sensitivity, direction discrimination and pleasantness. Frontiers in Behavioral Neuroscience, 8, 54. https://doi.org/10. 3389/fnbeh.2014.00054

Ackerley, R., Wasling, H. B., Liljencrantz, J., Olausson, H., Johnson, R. D., \& Wessberg, J.
(2014). Human C-tactile afferents are tuned to the temperature of a skin-stroking caress. The Journal of Neuroscience, 34(8), 2879-2883. https://doi.org/10.1523/ JNEUROSCI.2847-13.2014.

AcqKnowledge (4.4) (2018). Software Guide. Biopac Systems Inc. In.

Beck, A. T., Steer, R. A., \& Brown, G. K. (1996). Beck depression inventory-II. San Antonio, 78(2), 490-498.

Bensafi, M., Rouby, C., Farget, V., Bertrand, B., Vigouroux, M., \& Holley, A. (2002). Autonomic nervous system responses to odours: The role of pleasantness and arousal. Chemical Senses, 27(8), 703-709. https://doi.org/10.1093/chemse/27.8.703.

Bolker, B. M., Brooks, M. E., Clark, C. J., Geange, S. W., Poulsen, J. R., Stevens, M. H. H., ... White, J.-S. S. (2009). Generalized linear mixed models: A practical guide for ecology and evolution. Trends in Ecology \& Evolution, 24(3), 127-135. https://doi. org/10.1016/j.tree.2008.10.008.

Boucsein, W. (2012). Generalized psychophysiological states. In electrodermal activity. Springer Science \& Business Media347-370.

Boucsein, W., Fowles, D., Grings, W., Ben-Shakhar, G., Roth, W., \& Dawson, M. (2012). Society for psychophysical research Ad Hoc committee on electrodermal measures. (2012). Publication recommendations for electrodermal measurements. Psychophysiology, 49(8), 1017-1034. https://doi.org/10.1111/j.1469-8986.2012 01384.x.

Bradley, M., \& Lang, P. (2000). Affective reactions to acoustic stimuli. Psychophysiology, 37(2), 204-215.

Bradley, M., Codispoti, M., Cuthbert, B., \& Lang, P. (2001). Emotion and motivation I: Defensive and appetitive reactions in picture processing. Emotion, 1(3), 276.

Braithwaite, J. J., Watson, D. G., Jones, R., \& Rowe, M. (2013). A guide for analysing electrodermal activity (EDA) \& skin conductance responses (SCRs) for psychological experiments. Psychophysiology, 49, 1017-1034.

Cohen, N., Moyal, N., Lichtenstein-Vidne, L., \& Henik, A. (2016). Explicit vs. implicit emotional processing: The interaction between processing type and executive control. Cognition and Emotion, 30(2), 325-339. https://doi.org/10.1080/02699931.2014. 1000830.

Cowen, A. S., \& Keltner, D. (2017). Self-report captures 27 distinct categories of emotion bridged by continuous gradients. Proceedings of the National Academy of Sciences of the United States of America, 114(38), E7900-e7909. https://doi.org/10.1073/pnas. 1702247114

Croy, I., Angelo, S. D., \& Olausson, H. (2014). Reduced pleasant touch appraisal in the presence of a disgusting odor. PLoS One, 9(3), https://doi.org/10.1371/journal.pone. 0092975.

Crucianelli, L., Metcalf, N. K., Fotopoulou, A. K., \& Jenkinson, P. M. (2013). Bodily pleasure matters: Velocity of touch modulates body ownership during the rubber hand illusion. Frontiers in Psychology, 4. https://doi.org/10.3389/fpsyg.2013.00703.

Dawson, M. E., Schell, A. M., \& Filion, D. L. (2007). The electrodermal system. In J. T. Cacioppo, L. G. Tassinary, \& G. G. Berntson (Eds.). Handbook of psychophysiology (pp. 159-181). (3rd ed.). Cambridge: Cambridge University Press.

Dimberg, U. (1982). Facial reactions to facial expressions. Psychophysiology, 19(6), 643-647.

Edwards, L. J., Muller, K. E., Wolfinger, R. D., Qaqish, B. F., \& Schabenberger, O. (2008). An R2 statistic for fixed effects in the linear mixed model. Statistics in Medicine, 27(29), 6137-6157. https://doi.org/10.1002/sim.3429.

Essick, G. K., McGlone, F., Dancer, C., Fabricant, D., Ragin, Y., Phillips, N., ... Guest, S. (2010). Quantitative assessment of pleasant touch. Neuroscience \& Biobehavioral Reviews, 34(2), 192-203. https://doi.org/10.1016/j.neubiorev.2009.02.003.

Etzi, R., Carta, C., \& Gallace, A. (2017). Stroking and tapping the skin: Behavioral and electrodermal effects. Experimental Brain Research. https://doi.org/10.1007/s00221017-5143-9.

Fairhurst, M. T., Löken, L., \& Grossmann, T. (2014). Physiological and behavioral responses reveal 9-month-old infants' sensitivity to pleasant touch. Psychological Science, 25(5), 1124-1131. https://doi.org/10.1177/0956797614527114.

Fridlund, A. J., \& Cacioppo, J. T. (1986). Guidelines for human electromyographic research. Psychophysiology, 23(5), 567-589.

Gallace, A., \& Spence, C. (2010). The science of interpersonal touch: An overview. Neuroscience and Biobehavioral Reviews, 34(2), 246-259. https://doi.org/10.1016/j neubiorev.2008.10.004.

Greco, A., Valenza, G., Nardelli, M., Bianchi, M., Lanata, A., \& Scilingo, E. P. (2015). Electrodermal activity analysis during affective haptic elicitation. Paper Presented at the Engineering in Medicine and Biology Society (EMBC), 2015 37th Annual International Conference of the IEEE.

Greco, A., Valenza, G., \& Scilingo, E. P. (2016). Investigating mechanical properties of a fabric-based affective haptic display through electrodermal activity analysis. Paper Presented at the Engineering in Medicine and Biology Society (EMBC), 2016 IEEE 38th Annual International Conference of the.

Hartley, C., Goksan, S., Poorun, R., Brotherhood, K., Mellado, G. S., Moultrie, F., ... Slater, R. (2015). The relationship between nociceptive brain activity, spinal reflex withdrawal and behaviour in newborn infants. Scientific Reports, 5, 12519. https://doi. org/10.1038/srep12519.

Hertenstein, M. J., Holmes, R., McCullough, M., \& Keltner, D. (2009). The communication of emotion via touch. Emotion, 9(4), 566. https://doi.org/10.1037/a0016108.

Hertenstein, M. J., Keltner, D., App, B., Bulleit, B. A., \& Jaskolka, A. R. (2006). Touch communicates distinct emotions. Emotion, 6(3), 528. https://doi.org/10.1037/15283542.6.3.528

Horio, T. (2003). EMG activities of facial and chewing muscles of human adults in response to taste stimuli. Perceptual and Motor Skills, 97(1), 289-298. https://doi.org/ 10.2466/pms.2003.97.1.289.

Jäncke, L., \& Kaufmann, N. (1994). Facial EMG responses to odors in solitude and with an audience. Chemical Senses, 19(2), 99-111.

Johansson, R. S., Trulsson, M., Olsson, K., \& Westberg, K. G. (1988). Mechanoreceptor 
activity from the human face and oral mucosa. Experimental Brain Research, 72(1), 204-208.

Jonsson, E. H., Backlund Wasling, H., Wagnbeck, V., Dimitriadis, M., Georgiadis, J. R., Olausson, H., ... Croy, I. (2015). Unmyelinated tactile cutaneous nerves signal erotic sensations. The Journal of Sexual Medicine, 12(6), 1338-1345. https://doi.org/10. 1111/jsm.12905.

Joussain, P., Ferdenzi, C., Djordjevic, J., \& Bensafi, M. (2017). Relationship between psychophysiological responses to aversive odors and nutritional status during normal aging. Chemical Senses, 42(6), 465-472. https://doi.org/10.1093/chemse/bjx027.

Kress, I. U., Minati, L., Ferraro, S., \& Critchley, H. D. (2011). Direct skin-to-skin vs. indirect touch modulates neural responses to stroking vs. tapping. Neuroreport, 22(13), 646-651. https://doi.org/10.1097/WNR.0b013e328349d166.

Lang, P. J., Greenwald, M. K., Bradley, M. M., \& Hamm, A. O. (1993). Looking at pictures: Affective, facial, visceral, and behavioral reactions. Psychophysiology, 30(3), 261-273. https://doi.org/10.1111/j.1469-8986.1993.tb03352.x.

Larsen, J. T., Norris, C. J., \& Cacioppo, J. T. (2003). Effects of positive and negative affect on electromyographic activity over zygomaticus major and corrugator supercilii. Psychophysiology, 40(5), 776-785. https://doi.org/10.1111/1469-8986.00078.

Löken, L. S., Wessberg, J., McGlone, F., \& Olausson, H. (2009). Coding of pleasant touch by unmyelinated afferents in humans. Nature Neuroscience, 12(5), 547-548. https:// doi.org/10.1038/nn.2312.

Luong, A., Bendas, J., Etzi, R., Olausson, H., \& Croy, I. (2017). The individual preferred velocity of stroking touch as a stable measurement. Physiology \& Behavior, 177, 129-134. https://doi.org/10.1016/j.physbeh.2017.04.022.

Mayo, L. M., Linde, J., Olausson, H., Heilig, M., \& Morrison, I. (2018). Putting a good face on touch: Facial expression reflects the affective valence of caress-like touch across modalities. Biological Psychology, 137, 83-90. https://doi.org/10.1016/j.biopsycho. 2018.07.001.

McGlone, F., Olausson, H., Boyle, J., Jones-Gotman, M., Dancer, C., Guest, S., ... Essick, G. (2012). Touching and feeling: Differences in pleasant touch processing between glabrous and hairy skin in humans. European Journal of Neuroscience, 35(11), 1782-1788.

McGlone, F., Wessberg, J., \& Olausson, H. (2014). Discriminative and affective touch: Sensing and feeling. Neuron, 82(4), 737-755. https://doi.org/10.1016/j.neuron. 2014.05.001.

Nisbett, R. E., \& Wilson, T. D. (1977). Telling more than we can know: Verbal reports on mental processes. Psychological Review, 84(3), 231-259.

Öhman, A., \& Soares, J. J. (1998). Emotional conditioning to masked stimuli: Expectancies for aversive outcomes following nonrecognized fear-relevant stimuli. Journal of Experimental Psychology: General, 127(1), 69-82.

Olausson, H., Cole, J., Rylander, K., McGlone, F., Lamarre, Y., Wallin, B. G., ... Bushnell, M. C. (2008). Functional role of unmyelinated tactile afferents in human hairy skin: Sympathetic response and perceptual localization. Experimental Brain Research, 184(1), 135-140. https://doi.org/10.1007/s00221-007-1175-x.

Olausson, H., Wessberg, J., McGlone, F., \& Vallbo, ̊̊ (2010). The neurophysiology of unmyelinated tactile afferents. Neuroscience \& Biobehavioral Reviews, 34(2), 185-191. https://doi.org/10.1016/j.neubiorev.2008.09.011.

Page-Gould, E. (2016). Multilevel modeling. In C. J.T, L. G. Tassinary, \& B. G.G (Eds.). The handbook of psychophysiology (pp. 662-678). (4th ed.). Cambridge: Cambridge University Press.

Pawling, R., Cannon, P. R., McGlone, F. P., \& Walker, S. C. (2017). C-tactile afferent stimulating touch carries a positive affective value. PLoS One, 12(3), 1-15. https:// doi.org/10.1371/journal.pone.0173457.

Pawling, R., Trotter, P. D., McGlone, F. P., \& Walker, S. C. (2017). A positive touch: C- tactile afferent targeted skin stimulation carries an appetitive motivational value. Biological Psychology, 129, 186-194. https://doi.org/10.1016/j.biopsycho.2017.08. 057.

Quirin, M., Kazen, M., Rohrmann, S., \& Kuhl, J. (2009). Implicit but not explicit affectivity predicts circadian and reactive cortisol: Using the implicit positive and negative affect test. Journal of Personality, 77(2), 401-425. https://doi.org/10.1111/j.14676494.2008.00552.x.

Rosenberger, L. A., Ree, A., Eisenegger, C., \& Sailer, U. (2018). Slow touch targeting CTfibres does not increase prosocial behaviour in economic laboratory tasks. Scientific Reports, 8(1), 7700. https://doi.org/10.1038/s41598-018-25601-7.

Strack, F., \& Deutsch, R. (2004). Reflective and impulsive determinants of social behavior. Personality and Social Psychology Review, 8(3), 220-247. https://doi.org/10.1207/ s15327957pspr0803_1.

Tassinary, L. G., Cacioppo, J. T., \& Vanman, E. J. (2007). The somatic system. In J. T. Cacioppo, L. G. Tassinary, \& G. G. Berntson (Eds.). Handbook of psychophysiology (pp. 267-302). (3rd ed.). Cambridge: Cambridge University Press.

Tipper, S. P., Lloyd, D., Shorland, B., Dancer, C., Howard, L. A., \& McGlone, F. (1998). Vision influences tactile perception without proprioceptive orienting. Neuroreport, 9(8), 1741-1744.

Triscoli, C., Olausson, H., Sailer, U., Ignell, H., \& Croy, I. (2013). CT-optimized skin stroking delivered by hand or robot is comparable. Frontiers in Behavioral Neuroscience, 7, 208. https://doi.org/10.3389/fnbeh.2013.00208.

Triscoli, C., Croy, I., Olausson, H., \& Sailer, U. (2017). Touch between romantic partners: Being stroked is more pleasant than stroking and decelerates heart rate. Physiology \& Behavior, 177, 169-175. https://doi.org/10.1016/j.physbeh.2017.05.006.

Triscoli, C., Croy, I., Steudte-Schmiedgen, S., Olausson, H., \& Sailer, U. (2017). Heart rate variability is enhanced by long-lasting pleasant touch at CT-optimized velocity. Biological Psychology, 128, 71-81. https://doi.org/10.1016/j.biopsycho.2017.07.007.

Tronstad, C., Johnsen, G. K., Grimnes, S., \& Martinsen, O. G. (2010). A study on electrode gels for skin conductance measurements. Physiological Measurement, 31(10), 1395-1410. https://doi.org/10.1088/0967-3334/31/10/008.

Vallbo, Å., Olausson, H., \& Wessberg, J. (1999). Unmyelinated afferents constitute a second system coding tactile stimuli of the human hairy skin. Journal of Neurophysiology, 81(6), 2753-2763. https://doi.org/10.1152/jn.1999.81.6.2753.

Watkins, R. H., Wessberg, J., Wasling, H. B., Dunham, J. P., Olausson, H., Johnson, R. D., ... Ackerley, R. (2017). Optimal delineation of single C-tactile and C-nociceptive afferents in humans by latency slowing. Journal of Neurophysiology, 117(4), 1608-1614. https://doi.org/10.1152/jn.00939.2016.

Wessberg, J., Olausson, H., Fernstrom, K. W., \& Vallbo, A. B. (2003). Receptive field properties of unmyelinated tactile afferents in the human skin. Journal of Neurophysiology, 89(3), 1567-1575. https://doi.org/10.1152/jn.00256.2002.

West, B. T., Welch, K. B., \& Galecki, A. T. (2014). Linear mixed models: A practical guide using statistical software. Chapman and Hall/CRC.

Westfall, J. (2016). PANGEA: Power analysis for general anova designs. https://jakewestfall. shinyapps.io/pangea/.

Winkielman, P., \& Berridge, K. C. (2004). Unconscious emotion. Current Directions in Psychological Science, 13(3), 120-123. https://doi.org/10.1111/j.0963-7214.2004. 00288.x.

Zajonc, R. B. (2000). Feeling and thinking: Closing the debate over the independence of affect In: Feeling and thinking: The role of affect in social cognition. In. Cambridge University Press.

Zhou, P., Lock, B., \& Kuiken, T. A. (2007). Real time ECG artifact removal for myoelectric prosthesis control. Physiological Measurement, 28(4), 397-413. https://doi.org/10. 1088/0967-3334/28/4/006. 



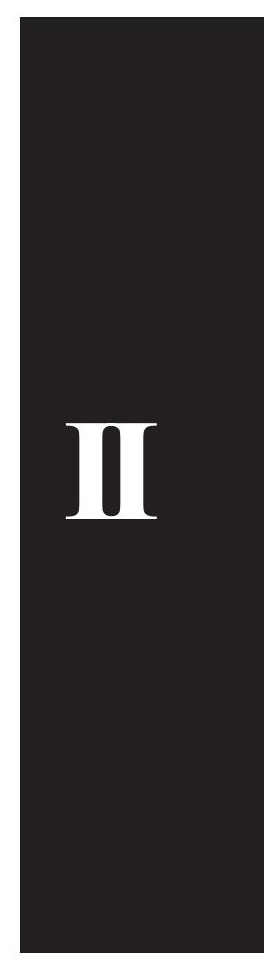



Received: 26 September 2017 Accepted: 24 April 2018 Published online: 16 May 2018

\section{Slow touch targeting CT-fibres does not increase prosocial behaviour in economic laboratory tasks}

\author{
Lisa Anna Rosenberger ${ }^{1}$, Anbjørn Ree ${ }^{2}$, Christoph Eisenegger ${ }^{1}$ \& Uta Sailer $\left(\mathbb{1}^{2}\right.$
}

Field studies have demonstrated that humans become more generous, helpful and compliant after having been touched by another person. Here, we explored whether these effects are larger for touch activating the $\mathrm{C}$-tactile (CT) fibres, as it is ascribed a particular role in establishing and maintaining bonds and affiliative interactions. The role of CT-targeted and non-targeted touch on prosocial behaviour was investigated in three different experiments using a trust game and a task measuring individual differences in social value orientations (the SVO task). Whereas participants in general acted prosocially, there was no influence of CT-targeted touch on prosocial behaviour, both in comparison to non-CT-targeted control touch and visual (non-tactile) stimulation. The null findings were further corroborated by Bayesian statistics. Thus, under the controlled laboratory conditions employed, CTtargeted touch did not play a particular role in prosocial behaviour. This indicates that touch does not increase prosocial behaviour in the absence of meaningful social and psychological connotations. Any touch related effects on prosocial behaviour likely depends on the ecological validity of the situation.

Touch plays an important role in initiating and maintaining social affiliation and attachment, as has been shown for primates ${ }^{1-3}$ rats $^{4}$, and humans $s^{5-7}$. Besides its role for establishing and upholding bonding, touch has also been found to increase helping behaviour and compliance with requests. As a now classic example, restaurant customers who were briefly touched by a waitress gave larger tips ${ }^{8,9}$, and supermarket shoppers were more willing to take part in alleged research interviews following touch ${ }^{10}$. Touch also increased compliance with the request to look after a "large and very excited" dog while the owner went to a shop where dogs were prohibited ${ }^{11}$. Many more field studies ${ }^{12-14}$ and one study using an economic game ${ }^{15}$ showed that touch recipients are more likely to be unselfish and generous (for reviews, $\operatorname{se}^{16,17}$ ).

These studies have in common that they only applied one type of touch and compared it to no use of touch. However, this is not sufficient to determine what kind of touch is most effective (for example, tapping versus stroking), and what the underlying mechanisms may be. Moreover, being touched may induce arousal and other psychological (e.g., assumed affection) and physiological (e.g., heart rate increase) effects which would not be present in a control condition of no touch. Therefore, in order to understand the specific effects of touch, experimental approaches are needed that disentangle these potential factors.

Since most of these existing studies were field studies, there was also a limit to how well the variable touch could be controlled. However, different characteristics of the touch applied may lead to different effects on prosocial behaviour. Humans have both a rapid touch system, where signals are transmitted via myelinated, fast conducting $A \beta$ afferent nerves, and a slow touch system consisting of unmyelinated $C$ fibres with a conduction velocity about 50 times lower. A particular type of $C$ fibres, the $\mathrm{C}$-tactile (CT) fibres, are present only in the hairy skin of humans ${ }^{18-20}$. They are believed to filter information relevant to hedonic or social aspects of gentle touch, before transmitting it to the brain where it is processed within affective brain networks (for a recent review, $\left.\mathrm{see}^{21}\right)$. CT-fibres are maximally activated to stimuli at skin temperature ${ }^{22}$ and by gently stroking the participant at a velocity similar to that of caressing ${ }^{23,24}$. Since they appear to respond to stimuli signalling interpersonal caress, they are thought to represent a peripheral mechanism to promote affiliative behaviour ${ }^{22,25}$. Indeed, the "social touch hypothesis" assumes a relationship between CT-targeted touch and bonding, attachment, and social

${ }^{1}$ Neuropsychopharmacology and Biopsychology Unit, Department of Basic Psychological Research and Research Methods, Faculty of Psychology, University of Vienna, Vienna, Austria. ${ }^{2}$ Faculty of Medicine, Institute of Basic Medical Sciences, Dept. of Behavioural Sciences in Medicine, University of Oslo, Oslo, Norway. Christoph Eisenegger is deceased. Correspondence and requests for materials should be addressed to L.A.R. (email: lisa.anna. rosenberger@univie.ac.at) 
perceptions ${ }^{21}$. Given these previous findings and theoretical assumptions, it seems plausible to hypothesise that the positive effect of touch on social behaviour is mediated via CT-fibres. The present study set out to test this hypothesis in an experimentally controlled laboratory setting, and to establish the specific role of CT-targeted tactile stimulation in prosocial behaviour. To this end, we conducted three experiments with two different economic tasks and different control conditions under controlled laboratory conditions. Based on the literature review above, we hypothesised that prosocial behaviour would be enhanced following CT-targeted touch.

To determine the influence of CT-targeted touch on prosocial behaviour, we employed a repeated trust game ${ }^{26}$ in two experiments, a classic two-player task of behavioural trust and reciprocity. The participants always played in the role of trustee, where they had to make decisions on how much of the entrusted money they wanted to send back to their interaction partner. Thus, the prosocial measure in experiments 1 and 2 was the back-transfer amount, or in other words the amount of reciprocity displayed to the interaction partner. The other player was either identical to the person providing touch (experiment 1), or not (experiment 2). In experiment 3 we employed a Social Value Orientation task $\left(\mathrm{SVO}^{27}\right)$ which measures prosocial behaviour in terms of concern for other people's pay-off. Here, the participant makes decisions on how to allocate a monetary amount between themselves and an anonymous other. In all three experiments, the monetary decision of the participant was measured after having either received CT-targeted touch $(3 \mathrm{~cm} / \mathrm{s})$ or control touch (tapping in experiments 1 and 2, and very slow touch in experiment 3), both executed with a soft brush. A brush was preferred to the more ecologically valid hand, because previous studies have shown reliable CT-fibre activation using a brush ${ }^{22,23}$. Moreover, a brush allows for more controlled tactile stimulation, since it is independent of skin temperature and humidity, and also because the force can be better monitored via the bending of the hairs.

In experiment 3 , an additional control condition with a moving visual stimulus was employed in order to investigate whether a potential increase in prosociality was specific to the tactile stimuli, or whether it is just the pleasantness of any sensory stimulus that leads to an effect. In order to provide evidence to support the null hypothesis of no differences between conditions, Bayesian analysis was performed. Instead of computing a p-value, Bayesian analysis computes the odds favoring the null hypothesis or a plausible alternative in light of the data $^{28}$. This allows us to determine the strength of the evidence for CT-targeted touch (not) having an effect on prosociality.

\section{Results}

Experiment 1. Pleasantness for CT-targeted touch was rated higher than for control touch $(\mathrm{F}(1,98)=6.907$, $\mathrm{p}<0.001)$. Intensity was not rated as being different for the two touch types $(\mathrm{F}(1,98)=0.053 ; \mathrm{p}=0.818)$.

The return ratio was larger with a multiplication factor of 6 , that is when the investment was multiplied with 6 , than with a multiplication factor of $3\left(\chi^{2}(1)=53.553, p<0.001\right)$, but it did not differ for touch types $\left(\chi^{2}\right.$ $(1)=0.098, p=0.754)$, or pleasantness $\left(\chi^{2}(1)=0.578, p=0.447\right)$. There was also no interaction between multiplication factor, touch type, or pleasantness (see Supplementary Material Results 1 for details on the results, and Table 1 for means and standard deviations of the ratings and return ratios).

Experiment 2. As in experiment 1, pleasantness for CT-targeted touch was rated higher than for control touch $(\mathrm{F}(1,156)=29.65 ; \mathrm{p}<0.0001)$. Intensity was not rated as being different for the two touch types $(\mathrm{F}(1$, $156)=0.022 ; \mathrm{p}=0.882$ ). As in experiment 1 , the return ratio was larger with a multiplication factor of 6 , than with a multiplication factor of $3\left(\chi^{2}(1)=131.020, p<0.001\right)$. Pleasantness was found to influence the return ratio $\left(\chi^{2}(1)=4.602, p<0.05\right)$ : higher pleasantness ratings were associated with higher return ratios. The return ratio was not different for the two touch types $\left(\chi^{2}(1)=0.441 ; p=0.506\right)$, and there was also no interaction between multiplication factor, touch type, or pleasantness (see Supplementary Material Results 1 for details on the results, and Table 1 for means and standard deviations of the ratings and return ratios).

Pooled data from experiment 1 and 2 . The data from experiments 1 and 2 were pooled in order to investigate potential differences between the experiments, and to additionally explore the effect of hypothesis guessing.

Pleasantness and intensity. CT-targeted touch was rated as more pleasant than control touch (see Fig. 1) (F(1, $250)=34.819, \mathrm{p}<0.0001$ ), with a Bayes factor $(\mathrm{BF})$ of 7.714 . This means that the data support a difference in pleasantness ratings between CT-targeted touch and control touch over no difference between the two by almost a factor of 8 . At the same time, both touch types were rated as equally intense $(F(1,250)=0.066, \mathrm{df}=1, \mathrm{p}=0.798)$, with a BF of 0.107 . There were no differences in pleasantness or intensity ratings between experiment 1 and 2 , nor was there an effect of hypothesis guessing on the ratings (all $\mathrm{F}<2.139$ ).

Return ratio. Return ratio following both types of touch was larger than 1 (see Fig. 2), indicating that participants on average returned more than the investor had invested. However, there was no general difference in the return ratio depending on the type of touch $\left(\chi^{2}(1)=0.173, p=0.678\right.$, see Supplementary Material Results 2 for a full model description). The Bayes factor analysis revealed a BF of 0.098 for touch type differences, thus, the data support the null hypothesis of no difference between the two touch types with a BF of 10.25. The BF for touch type differences with multiplication factors of 3 and 6 were both 0.136 . Again, the data support an absent difference between the two touch types with a BF of 7.34. Furthermore, the BF on the interaction between pleasantness and touch type (thus the probability that a return ratio difference between the touch types depends on pleasantness ratings, given the data) was 0.225 . Thus, in contrast to our hypothesis, both the mixed model analysis and the Bayes factor analysis indicate that there was no effect of touch type on return ratios.

As to hypothesis guessing, 6 participants in experiment 1 (12\%) and 14 participants (18\%) in experiment 2 correctly guessed the hypothesis of our study despite the cover story. Hypothesis guessing affected the return ratio, as shown by a significant interaction between multiplication factor and hypothesis guessing $\left(\chi^{2}(1)=15.789\right.$, 

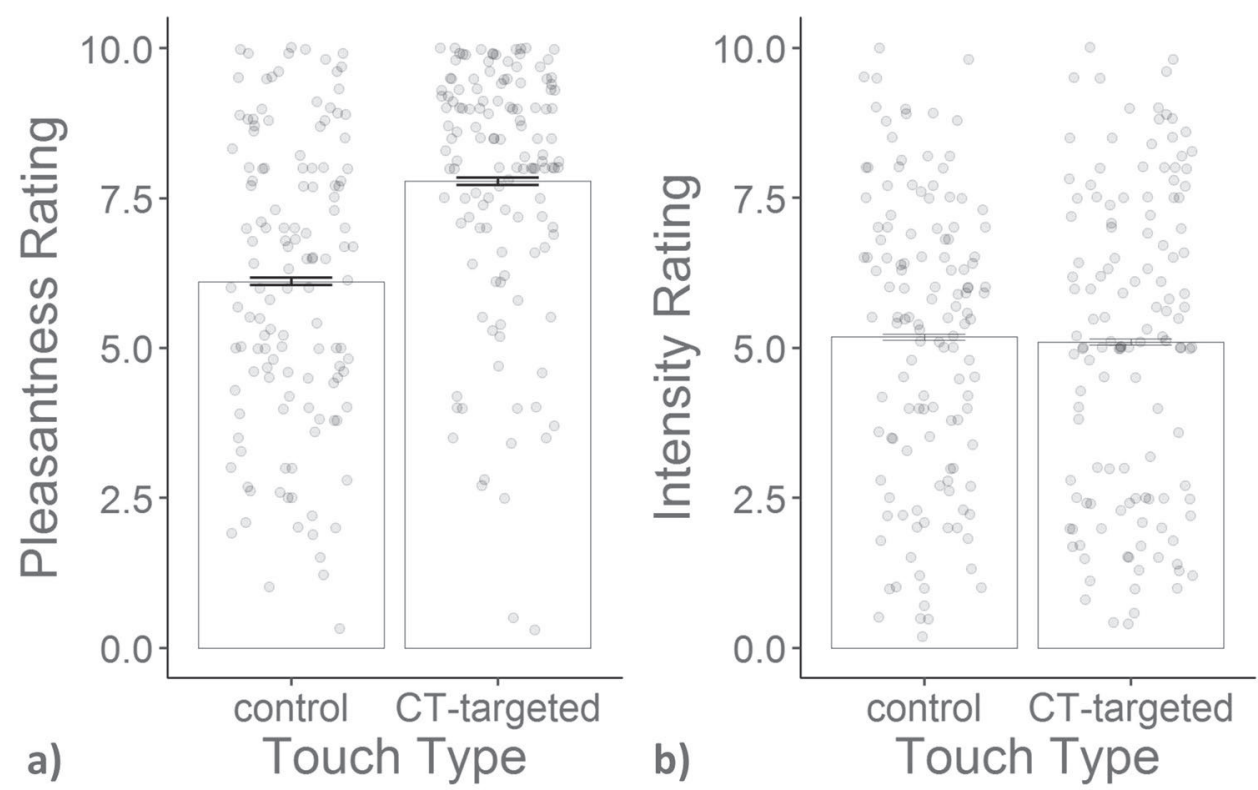

Figure 1. Mean pleasantness (panel a) and intensity (panel b) with within-subject standard error of the mean (SEM) and individual single-trial ratings of experiment 1 and 2 for CT-targeted and control touch.

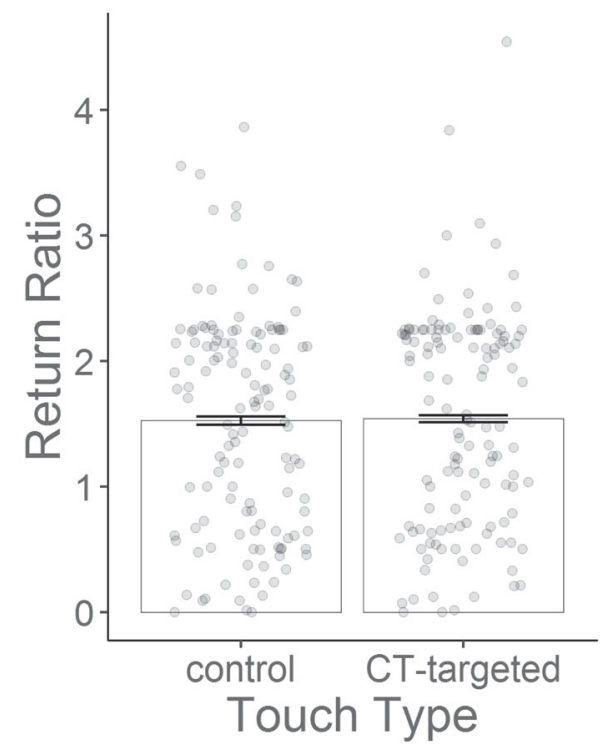

Figure 2. Mean return ratio with SEM and individual data points (averaged for each participant from experiment 1 and 2) for CT-targeted and control touch.

$\mathrm{p}<0.01$ ), as well as a significant interaction between multiplication factor, hypothesis guessing and pleasantness $\left(\chi^{2}(1)=7.226, p<0.01\right.$, see supplementary material Results 2$)$. To further explore this 3 -way interaction, an additional analysis was performed separately for participants who guessed and did not guess the hypothesis. For participants who guessed the hypothesis, there was a significant interaction between multiplication factor and pleasantness $\left(\chi^{2}(1)=3.999, p<0.05\right)$, see Fig. 3. In trials with higher multiplication factor, the return ratio increased with increasing pleasantness ratings.

For participants who did not guess the hypothesis, there was a significant interaction between multiplication factor, touch type, and pleasantness $\left(\chi^{2}(1)=4.912, \mathrm{p}<0.05\right)$. Calculating separate analyses for both touch types (see Supplementary Material Results 3 for full model description) showed that this interaction was due to an effect of control touch, where higher pleasantness ratings in trials with a high multiplication factor were associated with lower return ratios (interaction between multiplication factor and pleasantness; $\chi^{2}(1)=13.234, p<0.001$ ), see Fig. 4. 


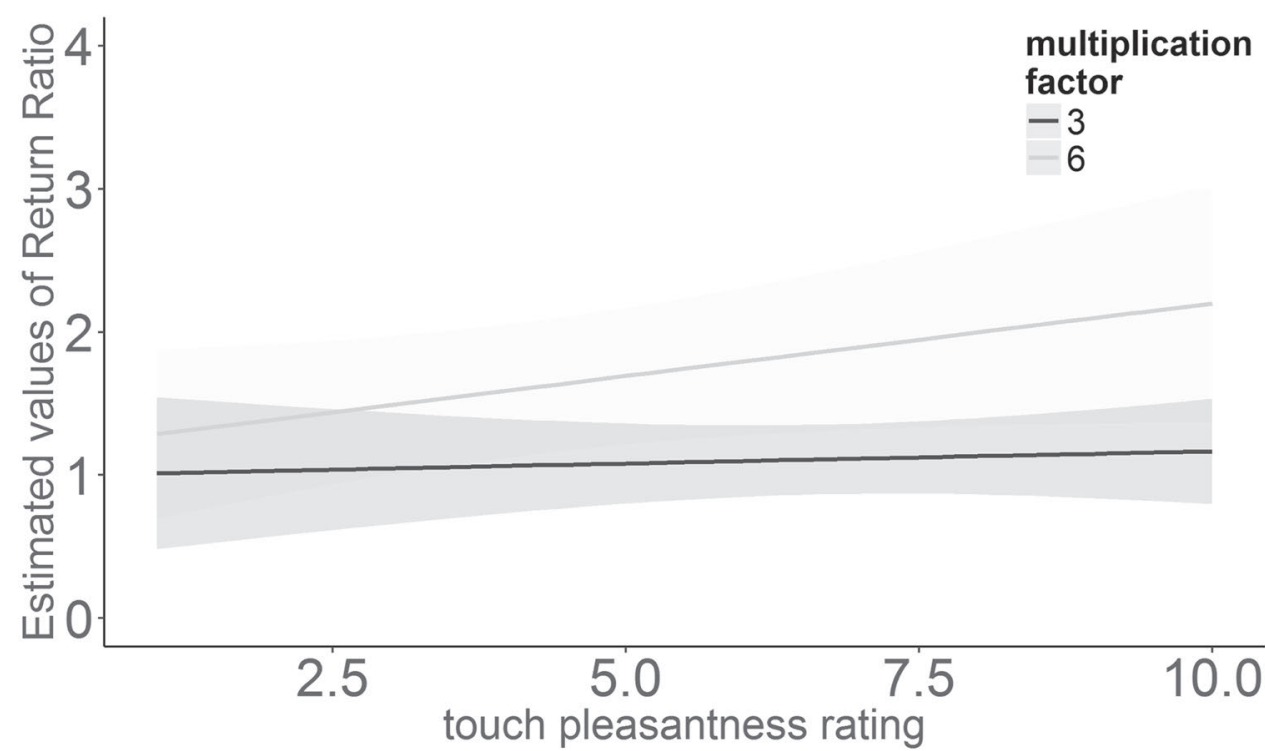

Figure 3. Regression line of estimated return ratios from linear mixed model analysis with $95 \%$ confidence intervals (shaded areas) for touch pleasantness ratings (both CT-targeted and control touch) of participants who guessed the study's hypothesis split by multiplication factor.

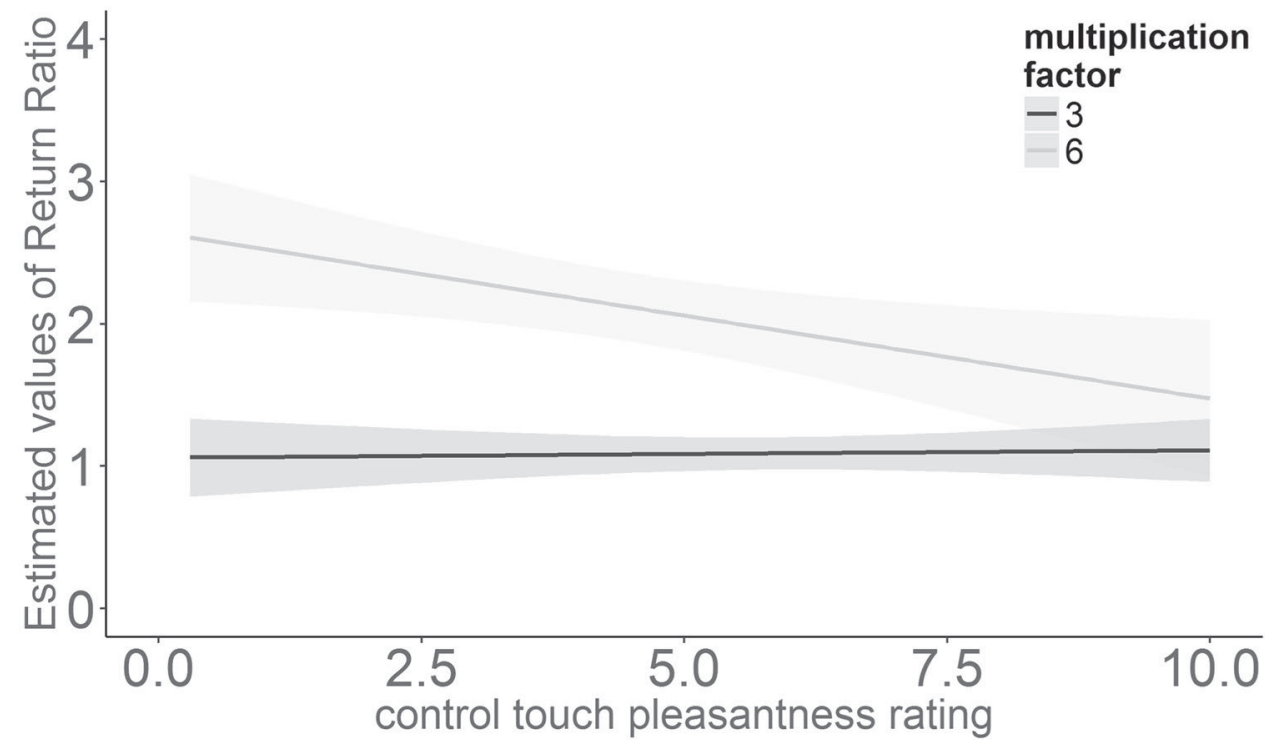

Figure 4. Regression line of estimated return ratios from linear mixed model analysis with $95 \%$ confidence intervals (shaded area) for different control touch pleasantness ratings of participants who did not guess the study's hypothesis split by multiplication factor.

Thus, whereas participants who correctly guessed the hypothesis returned more money the more pleasant they evaluated the touch, participants who did not guess the hypothesis returned less money the more pleasant they evaluated the touch. The latter did, however, only apply to control touch and with the higher multiplication factor.

Experiment 3. As in experiments 1 and 2, pleasantness was rated differently for the three types of stimulation (see Fig. 5, $\chi^{2}(2)=6.961, \mathrm{p}<0.05$ ), with CT-targeted touch being evaluated as more pleasant than control touch $(\mathrm{t}(86)=2.542, \mathrm{p}<0.05)$. Bayes factor analysis revealed that a difference between the two touch types is 2.135 more likely than no difference between the two ratings, given our data. However, CT-targeted touch was not rated as more pleasant than visual stimulation $(\mathrm{t}(86)=0.661, \mathrm{p}=0.787)$, which is supported by a $\mathrm{BF}$ of 0.257 . There was a trend for intensity to be rated differently for the three types of stimulation $\left(\chi^{2}(2)=5.639, p=0.060\right)$, which was driven by tendentially higher intensity ratings for CT-targeted touch than for control touch $(\mathrm{t}(86)=2.371$; $\mathrm{p}=0.052)$. However, Bayes factor analysis actually does not support the existence of a difference in intensity ratings between the three types of stimulation $(\mathrm{BF}=0.242)$. 

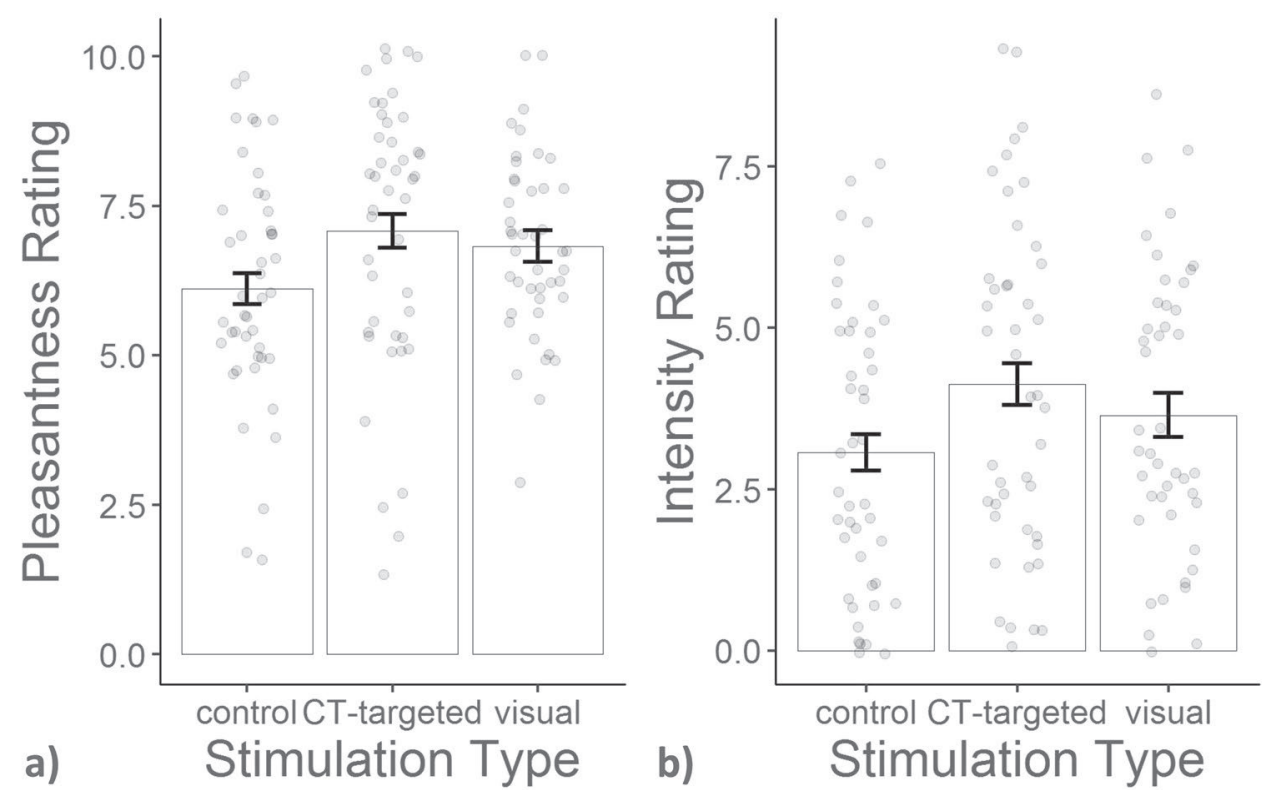

Figure 5. Mean pleasantness (panel a) and intensity (panel b) with within-subject SEM and individual ratings for different sensory stimulation.

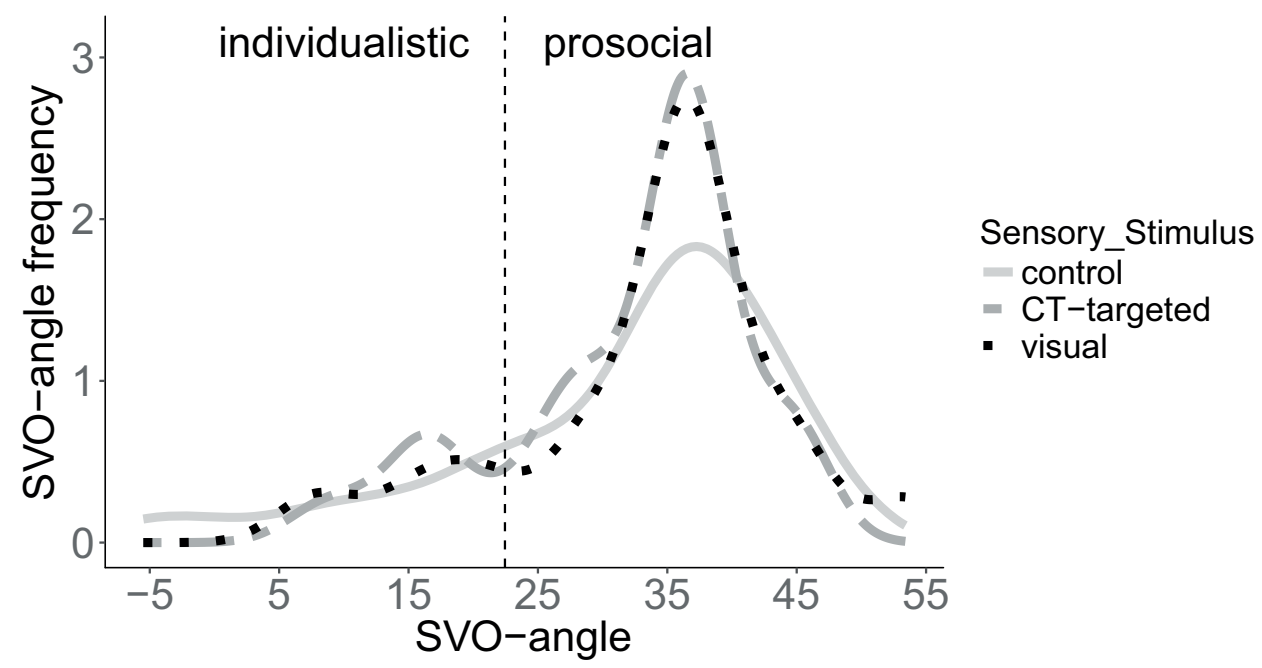

Figure 6. Distribution of SVO angles following different sensory stimulation. Behavioural categorization is based on the following ranges: "altruistic" (>57.15 deg), "individualistic" (between $-12.04-22.45 \mathrm{deg}$ ), "prosocial" (between 22.45-57.15 deg), or "competitive (<-12.04 deg)".

Following all three types of stimulation, all of the participants had an SVO angle that classified them as either individualistic or - the majority - as prosocial (see Fig. 6). None of them fell into the competitive or altruistic range. For three participants following control touch and for one participant following visual stimulation, an SVO angle could not be calculated because of inconsistent behaviour.

SVO angles did not change depending on type of stimulation, or its pleasantness. There was only a tendency for the SVO angle to differ between the three types of stimulation $\left(\chi^{2}(2)=5.756, p=0.056\right.$, see supplements Results 4). No other effects or interactions were significant. Post-hoc tests revealed that the SVO angle was higher following visual stimulation $(\mathrm{M}=33.519, \mathrm{SD}=10.470)$ than control touch $(\mathrm{M}=31.463, \mathrm{SD}=12.491$; $\mathrm{t}(78.52)=-2.662 ; \mathrm{p}<0.05)$. The SVO angle for CT-targeted touch $(\mathrm{M}=32.148 ; \mathrm{SD}=9.491)$ was in-between visual stimulation and control touch, and did not differ significantly from any of them (all ts $<1.53$ ). The BF for differences in the SVO angle between stimulation types was 0.104. Thus, our data support an absent difference between the stimulation types with a BF of 9.593. The BF for differences in SVO between stimulation types depending on pleasantness (thus the stimulation type $\mathrm{x}$ pleasantness interaction) was 0.146 , and therefore, gave more support for an absent effect. Thus, as in experiments 1 and 2, and against our hypothesis, CT-targeted touch did not increase prosocial behaviour. 


\section{Discussion}

The goal of the study was to test the hypothesis that slow brushing with an optimal velocity to activate CT-fibres increases prosocial behavior. To test the hypothesised prosociality-enhancing effect of touch, three experiments with two different behavioural economic laboratory tasks and different control conditions were performed. However, following CT-targeted touch (and compared to control touch or visual stimulation) neither reciprocity to the person who touched the participant, nor reciprocity to an unrelated person in the trust game were altered. Additionally, prosocial dispositions as measured with the SVO also did not shift.

In general, our data replicated some typical findings from both the Repeated Trust Game and the SVO. For example, it is well-established that participants are willing to return positive amounts ${ }^{29,30}$. It has also been shown previously that the same participants return a larger amount if the investment has been multiplied by a larger factor compared to a smaller factor ${ }^{31-33}$ (however, see ${ }^{29}$ for opposite results in between-subjects designs). We were also able to replicate the effects from the Repeated Trust Game during a second experiment, where the change in some experimental details did not affect the participants' behaviour. Importantly, experiment 2 showed that the absent effect of CT-targeted stimulation on trust game behaviour in experiment 1 was not due to playing with the experimenter, or to conducting the task in an Excel-sheet.

Based on their SVO-angle, the majority of participants were classified as prosocial, and the remainder as individualistic. That is, prosocial participants chose to allocate the money in a manner that evenly distributed the money between "self" and "other", as opposed to individualistic participants who opted to allocate a larger portion of the allocated money to themselves. This is in accordance with findings from the original study ${ }^{27}$, where $59 \%$ of participants were prosocial, $35 \%$ were individualist and the remainder competitive. Thus, our participants seem to behave similarly to other healthy participants in studies with the same tasks.

Although we were able to replicate basic findings of both tasks reported in literature, and from the Repeated Trust Game in two experiments with different samples, our data did not support our main hypothesis regarding CT-targeted touch. Many field studies in contexts as different as stores, restaurants, the street and the classroom demonstrated that casual touch leads to more favourable attitudes and behaviour towards the toucher, as well as to larger compliance and increased helping behaviour (for reviews, see ${ }^{16,17}$ ). Our data did not provide evidence for increased prosocial behaviour following CT-targeted touch, or following touch compared to visual stimulation. This was despite the fact that CT-targeted touch was consistently experienced as more pleasant than control touch. Such an absent influence of different touch types on behaviour, despite differences in their experienced pleasantness, is in line with findings that gentle touch in general, irrespective of CT-optimality, elicits affiliative emotions ${ }^{34}$.

CT-fibres are known to show depressed responses with repeated stimulation, a phenomenon called fatigue. However, human CT's continue to respond to repeated touch ${ }^{18,20}$ as opposed to non-human animals, whose responses quickly depress with repeated mechanical stimulation ${ }^{35}$. When stimulated every 3 seconds, CT responses in humans became shorter, but maintained the initial peak firing frequency ${ }^{18}$. This may suggest that the extended brushing period on the same area on the arm in experiment 1 and 2 led to decreased CT responding. However, in experiment 3 , stroking was alternated between 2 different areas on the arm, which did not lead to different pleasantness responses. Moreover, each brush stroke can be expected to activate a large number of CTs. Therefore, it appears unlikely that the absent effect of CT-targeted touch on prosocial behaviour is due to fatigue of CT-fibres. Nevertheless, as little is known about fatigue in CTs and its effect on subjective experience, further studies are warranted.

Regarding the comparison of tactile versus visual stimulation, prosocial behaviour was not different for visual stimulation either. Interestingly, participants showed opposing effects of touch on prosocial behaviour during the Repeated Trust Game, as measured with the return ratio, depending on whether they guessed the hypothesis correctly or not. This highlights the general importance of assessing the presence of hypothesis guessing when using the trust game. It needs to be taken into consideration, however, that the specific sample in experiment 1 and 3 may have increased the tendency and particularly the accuracy to guess the hypothesis, as it contained a number of psychology and medical students. Both can be expected to know about the use of deception in experiments and/or have some knowledge about the tactile system. However, in experiment 2 only a minority of the participants were students, but still the results were similar to the ones from experiment 1 .

Besides showing no advantage of CT-targeted touch compared to control touch in eliciting prosocial behaviour, the findings of experiment 3 also documented a lack of enhancement of prosocial behaviour following touch compared to a visual control condition. This was a rather surprising finding. One reason for this absent difference in prosocial behaviour might lie in the experienced pleasantness of the two stimulations which were rated as similarly pleasant. However, comprehensive analyses showed that pleasantness did not influence the SVO angle. It therefore seems that it was not the similarity in pleasantness for CT-targeted touch and visual stimulation that underlay the absent difference in prosocial behaviour. Similarly, arousal cannot serve to interpret the results, since different arousal following the different types of stimulation would be expected to alter intensity ratings, which was not the case. What could then be the reason for the failure to replicate the field findings of increased prosocial behaviour following touch in our study? It could be speculated that an individual receiving touch may, consciously or subconsciously, interpret the meaning of this behavior ${ }^{36}$. Accordingly, being touched by a waitress or a person asking for a favour in a natural context may be interpreted as a sign of affection ${ }^{37}$ or need ${ }^{38}$. Receiving touch may also indicate physical and emotional closeness to the toucher, social inclusion, and/or felt security ${ }^{36}$. This may in turn lead to positive feelings and beneficial physiological changes. It appears likely that the effect of touch on prosocial behaviour is dependent on one or several of these mediators that we were unable to replicate in a laboratory setting. Moreover, it is well-known that C-fibres are subject to modulation from higher-order brain regions via descending influences (e.g. $\left.{ }^{39}\right)$. Therefore, affective processing of CT-targeted touch is also influenced by top-down cognitive modulation (as reviewed in ${ }^{40}$ ). For example, the assumed sex of the touch provider ${ }^{41,42}$, concomitant visual ${ }^{43}$ and olfactor $y^{44}$ stimuli have all been found to influence the response to soft touch. Thus, early sensory processing will be altered by contextual mechanisms related to aspects such as expectations or the interpretation of touch. 
To our knowledge, previous studies investigating the effect of touch on prosocial behaviour in economic games are scarce ${ }^{15,45,46}$. One recent study compared the effect of vibratory touch, an auditory cue or silence on behaviour in the Ultimatum game ${ }^{45}$. In this game, one player offers a portion of an endowment to another player who can either accept the offer or reject it. If the second player accepts the offer, the money is divided according to the proposed division, otherwise, both players leave with nothing. The authors found higher acceptance rates of offers following vibratory touch than silence, but no difference in acceptance rates following touch compared to sound ${ }^{45}$. In a different study on emotional face processing ${ }^{47}$, the authors concluded that auditory and tactile primes rather seemed to affect stimulus evaluation in general by facilitating cognitive processing instead of having differential effects. Such a general facilitating effect may also exist for visual and tactile stimuli in the present study.

In a different study, massage increased reciprocity in a one-shot trust game ${ }^{15}$, with participants returning more than twice as much following massage than following rest. However, in that study the difference between the two conditions may have been maximized because of the length and high intensity of the massage on the one hand, and because of the low arousal and possibly boredom in the rest condition on the other hand. Nevertheless, in comparing touch to "nothing", the design of this study is similar to the many field studies on touch effects on prosociality, which may explain why similar results were found. The current control condition with visual stimulation necessitated task engagement, because participants were required to rate the videos and therefore, to attentively watch them. This raises the possibility that task engagement, or the lack thereof, may have an influence on prosociality. It has been shown previously that boredom can affect decision-making in terms of choosing a simpler strategy ${ }^{48}$. A potential effect of boredom on prosocial behaviour could be an interesting question to investigate in further studies.

To conclude, it has been suggested that CT-fibres constitute a specific pathway for signaling touch with social-affective meaning ${ }^{25,49}$. Our data suggest that touch that particularly activates this pathway does not influence social behaviour in the present laboratory context. We reason that in order to obtain such an effect, the social context may be crucial. Potentially, touch needs to be understood as expressing affection, not as a rather neutral stimulation as part of an experiment. Therefore, future studies on similar research questions should increase the potential affiliative meaning even in the laboratory context.

\section{Methods}

Participants. Only participants who had not previously participated in other touch or economics related experiments were eligible for the studies. This was assessed when appointments were booked. For experiment 1 , 50 healthy participants, 29 women and 21 men, were recruited via announcements on boards at the University of Gothenburg, Sweden. They were aged between 19 and 72 years, with a mean age of 30 years $(S D=12)$, and the majority of them were students. For experiment 2, 79 participants, 56 women and 23 men, were recruited via announcements on university boards and on social media. They were aged between 19 and 76 years, with a mean age of 41 years $(S D=19) .8$ of them were medical students and 2 were psychology students. Following experiments 1 and 2, participants were asked what they thought the aim of the study was. The response was registered and coded as hypothesis guessing yes/no to be used in later analyses. Subsequently, participants were fully debriefed about the real aim and all deceptive elements in the experiments. All participants received financial compensation for participation which included a show-up-fee of 200 SEK ( 20 EUR) and an additional amount that depended on their actual choices during the Repeated Trust Game (see detailed description below).

For experiment 3, 45 healthy participants were recruited by announcements in various academic institutions in Oslo, Norway. The theme of the announcements focused on how various forms of sensory stimuli could potentially affect decision making, empathy and perceptions of various phenomena. Most participants (approximately 75\%) were physiotherapy, osteopathy, psychology or medical students. One participant was subsequently excluded due to an acute bout of rheumatoid arthritic joint pain reported in the written consent form. Thus, a total of 27 women and 17 men, aged between $18-47(M=25$ years, $S D=6)$ completed the study. Participants were informed that both their own and a future participant's compensation for participating in the study could be affected by how they chose to allocate the money. However, during the debriefing, the participants were informed that the deception of "self" and "other" was included to ensure full commitment to the procedure of distributing money and all participants received a voucher with a value of $200 \mathrm{NOK}(\sim 20 \mathrm{EUR})$.

All participants provided informed consent before participating in the study. Experiments 1 and 2 were approved by the regional ethical board at the University of Gothenburg, Sweden (Dnr288-15), and experiment 3 by the regional committee for medical and health research ethics South East, Norway (2011/1337), and all were carried out according to the Declaration of Helsinki.

Procedure. Experiment 1. After having signed the informed consent, participants were asked to fill in a form about demographics, potential skin diseases and medication use. The task procedure was similar in experiment 1 and 2 and consisted of the following blocks: tactile stimulation 1, Repeated Trust Game 1, filler task, tactile stimulation 2, and Repeated Trust Game 2. The order of tactile stimulation type (CT-targeted touch and control touch) was counterbalanced between participants. Participants were told that the aim of the experiment was to investigate the effect of different sensory experiences, among which tactile stimulation and hunger, on gaming behaviour. To increase the credibility of the cover story, they were also told not to eat for at least 2 hours prior to the experiment, and later answered two items about their hunger feelings. During the experiment, participants were seated at a table with a PC where all the tasks were administered. The experimenter sat next to the participant at the same table during the tactile stimulations and the repeated trust games. At the end of the experiment, participants were asked what they thought the aim of the experiment was, and if they had noticed anything particular, and were subsequently debriefed and paid. 
Tactile stimulation. Participants were asked to put their left forearm on a vacuum pillow which lay on a table and was adjusted to their arm. A distance of $10 \mathrm{~cm}$ was marked with a pen in the middle of the dorsal surface on their forearm. They were asked to put on occluding glasses to block view of their arm, to look straight ahead and to concentrate on the upcoming tactile stimulation. Using a hand-held soft watercolour brush that was $75 \mathrm{~mm}$ wide, the experimenter then delivered one of two different tactile stimulations. In the experimental condition "CT-targeted touch", repeated brushing-strokes were performed in the proximal-distal direction for 3 minutes with a $0.5 \mathrm{~s}$ break in-between strokes, i.e. 32 stroking trials altogether. Brushing was performed with a velocity of $3 \mathrm{~cm} / \mathrm{sec}$ and an approximate force of $0.4 \mathrm{~N}$. Brushing with these parameters has previously been found to maximally activate CT-fibres ${ }^{22,23}$. The experimenter was trained in delivering this type of stimulation by performing the brush strokes on a scale and under the guidance of a bar on a computer monitor moving at $3 \mathrm{~cm} / \mathrm{s}$ to maintain constant pressure and velocity. During the experiment, the experimenter was also guided by the same bar shown on a monitor not visible to the participant.

In the control condition "control touch", the experimenter had the brush "jump" across the marked area in four equally large steps, i.e. giving the impression that the arm was being prodded at four different positions within a $10 \mathrm{~cm}$ distance. The four hopping steps took as much time as one brushing stroke and were performed with a similar force and in the same direction as the brushing, and on the same area of the arm. This stimulation was also performed for 3 minutes. This kind of stimulation was chosen because it was assumed to activate CT-fibres to a lesser extent than slow stroking, while at the same time providing an experience that qualitatively was considerably distinct from stroking in order to increase the probability of an effect. It has previously been shown that this kind of tactile stimulation is perceived as less pleasant than stroking with CT-targeted parameters ${ }^{50}$.

Whereas the majority of field studies on prosocial touch effects used short stimulation, a longer stimulation period of 3 minutes was chosen in order to increase the reliability of ratings, and because previous studies of our group showed that pleasantness and physiological effects of CT-targeted touch change very slowly with repeated stimulation $^{51-53} \cdot 3$ minutes is also an interval in-between the short tactile interventions in field studies and the 15 minute massage in a different laboratory study ${ }^{15}$.

Following each type of stimulation, participants were asked to grade the pleasantness and intensity of the stimulation on a visual analogue scale (VAS) on a paper. Above the VAS for pleasantness, the question "How did you experience the touch?" was written, and the endpoints were "unpleasant" (scored as -10$)$ and "pleasant" $(+10)$. Above the VAS for intensity, the question "How intensive did you experience the touch?" was written, and the endpoints were "weak" $(-10)$ and "strong" $(+10)$.

Repeated Trust Game. The trust game ${ }^{26}$ is a frequently used and replicated measure of behavioural trust and reciprocity involving the sequential exchange of a monetary endowment ${ }^{29}$. It is played by two players, an investor and a trustee. The investor, who is the first mover, receives an endowment and can transfer a variable amount from his/ her endowment to the trustee. This investment gets multiplied by a specific factor, called a multiplication factor, by the experimenter. For example if the multiplication factor is 2 , the investment gets doubled by the experimenter. The trustee receives this multiplied investment and can make a back-transfer to the investor based on the multiplied investment ${ }^{26}$. The amount passed by the investor is assumed to capture trust, and the amount returned by the trustee is assumed to reflect reciprocity ${ }^{26}$.

Participants played this game with the experimenter, i.e. the person touching them. Participants always played in the role of trustee, but were led to believe that this was assigned randomly with a lottery drawing. The endowment size was set to 100 SEK ( 11 EUR) and the multiplication factor was either 3 (round 1-5) or 6 (round 6-10). Participants played with the same investor for 10 rounds. Investments were fixed to $70,90,80,70$, and 80 SEK for rounds $1-5$, and were repeated in rounds 6-10. Participants were instructed that the investor would not see the size of the back-transfer in each round, but would only see the final result of all trials at the end of the experiment. This was done so that participants did not believe their choice would influence the investor's allocation in the next trial.

Participants were also informed that $10 \%$ of the amount they had decided to keep in two randomly selected rounds would be added to their show-up-fee. In fact, these two rounds were not randomly selected, but were the fifth round from block 1 and the last round from block 2 . They were also told that the investor would receive the amount transferred back by the trustee from these randomly selected rounds, so that the actual payoff for both players depended on the trustee's behaviour in the game.

The game was implemented in an Excel sheet (see Fig. 7). Prior to the actual experiment, participants played 2 practice rounds (analogous to the "real rounds" during the experiment) in order to get familiar with the procedure.

Filler task. Participants were asked to repeatedly estimate the length of a 1 second interval and were given a sweet or salty snack, depending on the participant's preferences, during 3 breaks. Subsequently, participants again answered a question on paper about how hungry they felt. The snack as well as this question was given in order to support the cover story. Another aim of this filler task was to distract the participants in order to avoid carry-over effects from the first stimulation. The break in between the two conditions was on average $31 \mathrm{~min}(\mathrm{SD}=6)$.

Experiment 2. Experiment 2 served to replicate the results from experiment 1 with a larger sample and revised procedure. To increase differences between the two stimulation types, a watercolour brush was used to deliver CT-targeted touch as in experiment 1, but the control touch was delivered using a cooled-down steel brush. This was done in order to minimise CT-fibre responding, since they are reported to respond preferentially to tactile stimuli at skin temperature ${ }^{22}$.

In experiment 2, participants sat on a hospital bed with a keyboard on their lap and a screen at the height of their eyes in front of them, see Fig. 8. The experimenter was sat to the left of the participants with a dividing curtain in-between, so that participants were unable to see the experimenter/ the other alleged player at all times. In addition, the participant wore occluding glasses that prevented peripheral vision. 


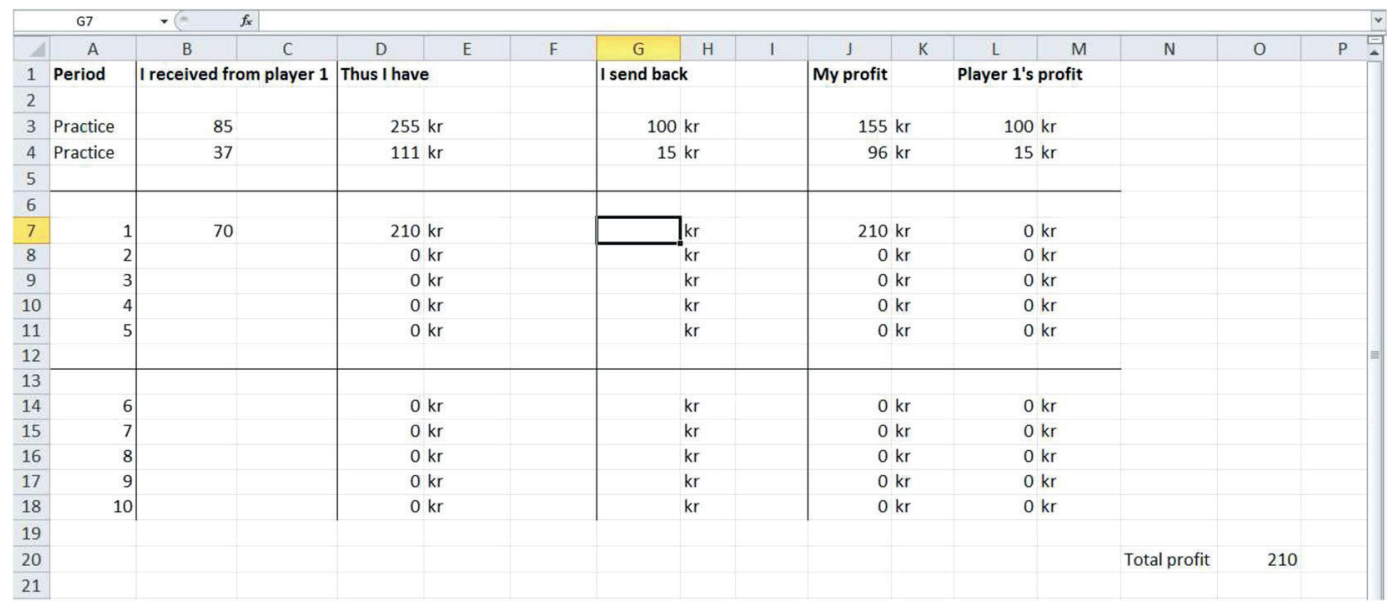

Figure 7. Implementation of the Repeated Trust Game in Experiment 1 (originally in Swedish). Participants always saw the complete Excel sheet. In a given round, the participant received a paper with the investment decision from the experimenter and filled this amount in the column "I received from player 1". The multiplied amount was automatically displayed in the "Thus I have" column. Then the participant filled in his back-transfer decision in the "I send back" column, which led to the automatic calculation and display of the players profits in the last two columns. The Excel sheet was only visible to the participant throughout the task.

In order to reduce a potential influence of the experimenter's impression on the participants' behaviour in the Repeated Trust Game, the participants were instructed that they would play the Repeated Trust Game with a colleague of the experimenter, a person they would neither see nor talk to during the experiment. The participants view of the experimenter and their own arm was obscured by a dividing curtain. Unbeknown to the participant, the experimenter played the investor. The experimenter opened and closed doors, walked and breathed distinctly in the role of the investor, to increase believability of the deception. Prior to post-experimental de-briefing, the participants were asked about their impression of the investor. None of them mentioned any suspicions about the investor being the same person as the experimenter.

The design of the repeated trust game was exactly the same as in experiment 1 , except that the task was now implemented in the software $\mathrm{z}$-tree ${ }^{54}$ instead of in an excel sheet (see Fig. 9). Instead of entering back-transfer decisions in an excel sheet, participants now clicked through an interactive task. We opted for a different task interface for the participants to ensure that the results of experiment 1 were not due to the rather bare, mathematical layout of the excel sheet, and also because a standardised and commonly used way of presentation was preferred (see f.e. ${ }^{55-57}$ ). Again, participants always played in the role of trustee, but were led to believe that this was assigned randomly by z-tree.

Experiment 3. Participants were informed that the main purpose of the experiment was to investigate if and how various forms of sensory stimuli influence our values and perceptions of different phenomena. They were further informed that they would be asked to rate the pleasantness and intensity of the sensory stimuli before performing a task that involved allocating money between themselves and a different player. Following signature of the written consent form, electrodes for facial EMG and skin conductance recordings were attached to the participant (results not reported here). Participants were then seated in front of a computer screen with the left arm placed on an inflatable cushion that was adjusted to their arm. A custom-made cap which limited lateral view was provided in order to ensure that the participants did not see their left arm or the experimenter during the experiment. The participants were also equipped with a set of headphones throughout the experiment (AKG, K $271 \mathrm{MkII}$ ). The task procedure for experiment 3 consisted of the following blocks: sensory stimulation 1, Social Value Orientation scale $1\left(\mathrm{SVO}^{27}\right)$, sensory stimulation 2 , SVO 2 , sensory stimulation 3 , SVO 3.

To further mask the main objective of the study, the participants were also exposed to auditory stimulation with 2 minutes of pink noise which was not followed by an economic task but by a questionnaire pertaining to ratings of facial attractiveness, questions of soft drink preferences and how one would spend an imaginary lottery win. The questionnaire served to further mask the main objective of the study and was therefore not analysed. The order of sensory stimulation types (CT-targeted, control touch, visual and auditory stimulation) was counterbalanced between participants. Visual stimulation was presented as an alternative to a passive "no touch" control condition. A moving, non-tactile control stimulus was chosen, that that was not expected to increase prosociality.

CT-targeted touch was performed as in experiments 1 and 2, however, to control for the possibility of CT-fibre fatigue, the stroking alternated between two equally large areas of the dorsal forearm. Additionally, control touch consisted here of slow brushing at $0.3 \mathrm{~cm} / \mathrm{s}$ to complement the findings from the previous two experiments which used $30 \mathrm{~cm} / \mathrm{sec}$ as control touch. The duration of CT-targeted and control touch was 2 minutes each to ensure equal contact time between the conditions. For visual stimulation, participants watched a two minute long film which was edited from six films (Shutterstock Inc; New York, USA) displaying colourful geometrical objects moving at various speeds. 


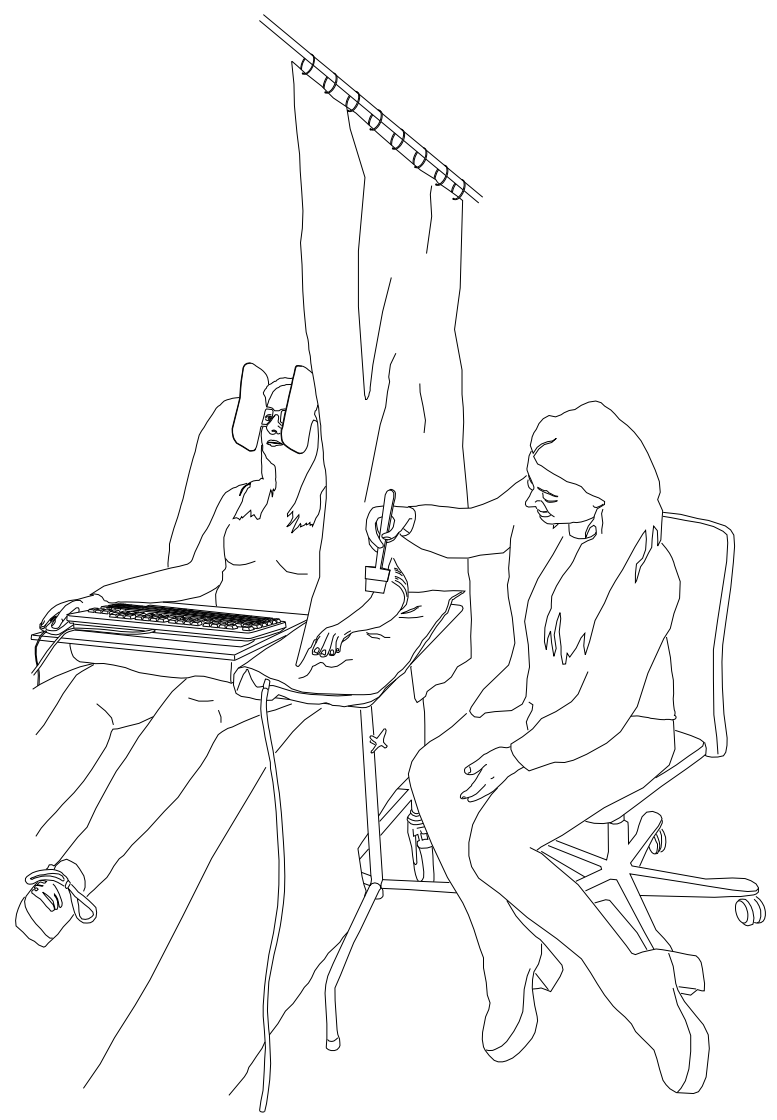

Figure 8. Setup of experiment 2. The participant faced a monitor. The experimenter was seated beside the participant and stroked the participant's left dorsal forearm with a paintbrush or tapped it with a steel brush.

Immediately after the tactile or visual stimulation, the participants rated the pleasantness and intensity of the sensory stimulus using two subsequently appearing visual analogue scales (VAS) as in experiments 1 and 2 on the screen in front of them.

Social Value Orientation Task. Participants performed the online version of the Social Value Orientation task $\left(\mathrm{SVO}^{27,58}\right)$. The SVO is designed to measure prosocial behaviour, i.e., the concern for other people's pay-off, with social value orientation corresponding "to the quantity of how much a decision maker is willing to sacrifice in order to make another decision maker better off (or perhaps worse off) ${ }^{27}$." (p.772). Participants are categorized into one of four different types, based on an angle score calculated from their decisions during the task. A larger SVO angle indicates that participants more often chose the option that maximised the allocation to the other person. On the other hand, a small SVO angle indicates that the participant opted for a larger portion of the allocated money themselves. The angle ranges for the four categories are as follows: "altruistic" ( $>57.15 \mathrm{deg})$, "individualistic" (between -12.04-22.45 deg), "prosocial" (between 22.45-57.15 deg), or "competitive (<-12.04 deg)".

In the present SVO-task, participants were instructed to allocate between NOK 100 and NOK 150 between themselves and a future random participant. They were told that there were no right or wrong answers, but that they had to carefully consider how they chose to allocate the money as the allocations could affect their own payment and that of the future randomized participant. The participants played the short version, whereby six slots of monetary allocations constitute one game (see Fig. 10). Angle calculations from the website were verified by manual computations by the experimenter. Participants practiced 2-4 rounds prior to the actual experiment.

Data analysis. All data were analysed with linear mixed models, which are ideally suited for repeated measures designs. There is no need for data aggregation, which increases power and makes it possible to model individual response styles, while at the same time controlling for within-subject dependences of observations ${ }^{59}$. We modelled participants as random intercept and the highest order within-subject interaction as random slope (as recommended by ${ }^{59}$ ) with the lme4 package ${ }^{60}$ in R. For the reported interactions we calculated Type 3 Sum of Squares and used orthogonal contrasts. Reported main effects are based on Type 2 Sum of Squares. P-values are based on Wald-Chi-square tests from the car package ${ }^{61}$. Post-hoc Tukey tests for factors were computed with the lsmeans package ${ }^{62}$. Results were supplemented with Bayes Factors, which were computed with the BayesFactor package ${ }^{63}$. Plots were created with the packages ggplot $2^{64}$ and sjPlot ${ }^{65}$ in R. 


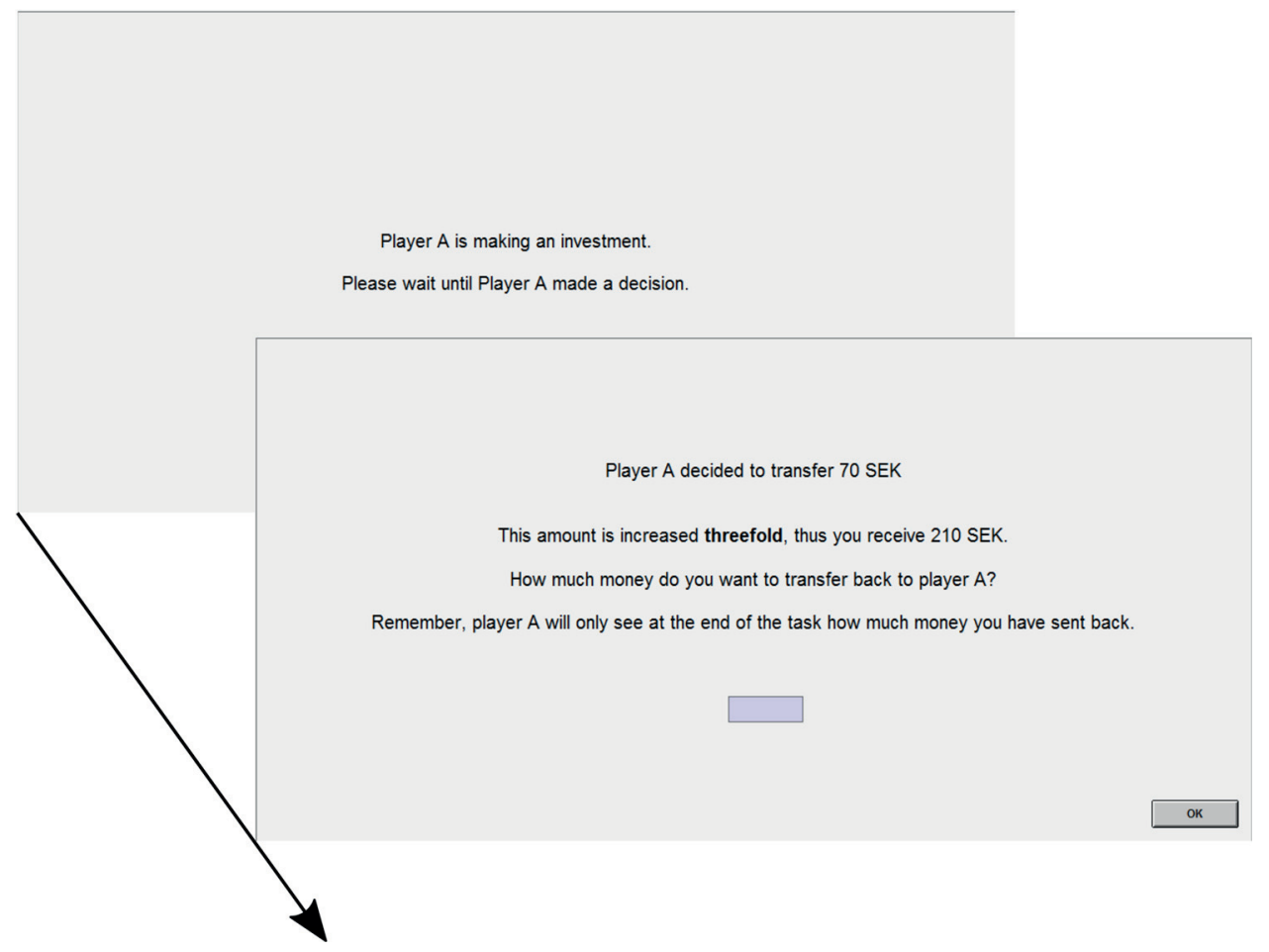

Figure 9. Layout of a trial of the trust game implemented in z-tree (originally in Swedish). The investment screen was displayed between 4-6 seconds. Participants had unlimited time for their back-transfer decision.
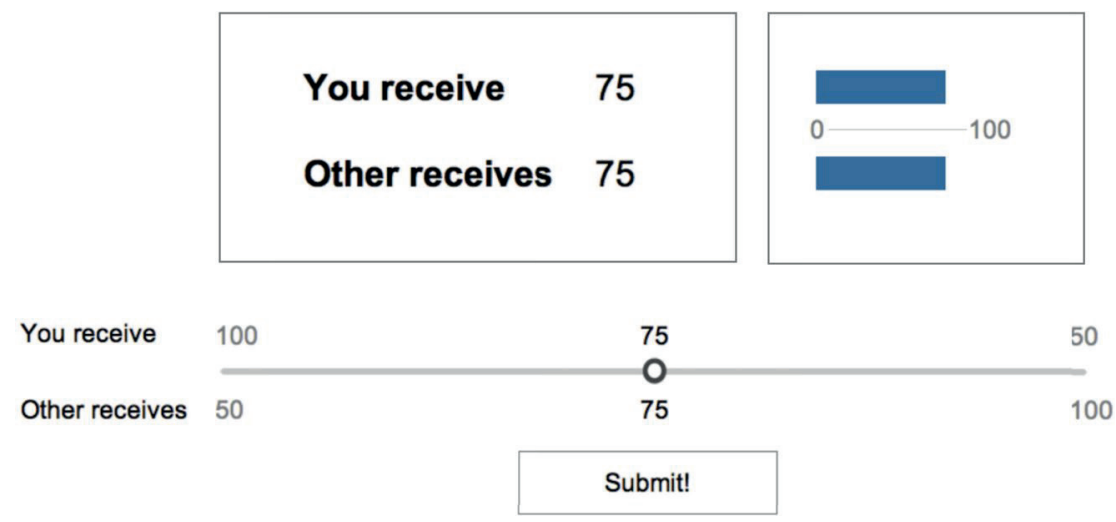

Figure 10. Example trial involving the distribution of NOK 150. The participants were instructed that "you receive" and "other receives" referred to their own and a future randomized participant's payment. Picture reproduced from ${ }^{27}$ under Creative Commons Attribution 3.0 License.

Dependent variables were pleasantness and intensity, and for the Repeated Trust Game the return ratio $\left(\frac{\text { back-transfer }}{\text { investment }}\right)$. The return ratio was preferred to the absolute amount returned as a measure of prosocial behaviour because the size of the return ratio is not dependent on the amount invested.

For experiment 1, pleasantness and intensity were compared for the two touch types (CT-targeted, control) in two separate analyses. The return ratio was analysed using a model with the predictors multiplication factor ( 3 , 6), touch type (CT-targeted, control), and pleasantness. An analogous analysis was done for experiment 2. Next, the data of both experiments were collapsed and analysed together. This was done, first, to evaluate whether there were any differences between the experiments, and second, to analyse the effect of hypothesis guessing in both experiments. Participants may correctly guess the intent of the study and consciously, or subconsciously, alter their behaviour. To investigate whether this was the case, hypothesis guessing was added as a predictor to this analysis. Pleasantness and intensity were separately analysed, and the return ratio was analysed with the predictors multiplication factor $(3,6)$, touch type (CT-targeted, control), experiment number $(1,2)$, hypothesis guessing (yes, no), and pleasantness. 
The central question of experiment 1 and 2 was to determine whether the return ratio is larger after CT-targeted than control touch (hypothesis H1). In contrast, the null-hypothesis (H0) would assume no difference between the two types of touch. Conventional frequentist inference statistics only allows testing H1-hypotheses by rejecting the null-hypothesis. However, if the null-hypothesis cannot be rejected, it does not automatically mean that it is true. Bayesian statistics ${ }^{66,67}$ allow to determine whether the data provide stronger evidence for $\mathrm{H} 1$ or the null-hypothesis. The Bayes factor B means that the data are B times more likely under the $\mathrm{H} 1$ than under the null-hypothesis. If the Bayes factor (BF) is larger than 1, support for the $\mathrm{H} 1$ is stronger, whereas a BF smaller than 1 means that support for the $\mathrm{H} 0$ is stronger, given the data. Conventionally, a $\mathrm{BF}>3$ can be interpreted as substantial evidence, whereas a BF $>10$ is considered strong evidence for the model under consideration $^{68}$. However, these thresholds should be used cautiously as rules of thumbs (se ${ }^{69,70}$ for an overview of $\mathrm{BF}$ interpretation), which is why we refrain from referring to these thresholds in the results section. BF were calculated for pleasantness and return ratio for the factor touch type, and for return ratio also on the interaction between pleasantness and touch type. BF were calculated for the pooled data only for variables where the mixed model found no difference between the experiments. We used the default prior setting of the BayesFactor package, which is described in detail in $^{71}$ for regression models and in $^{72}$ for ANOVA designs. The default settings specify priors for the variance, the intercept (in the regression models), and the mean of standardized effect sizes of the null and the alternative hypotheses. For the null hypothesis the prior for the mean is 0 , and the variance is a non-informative Jeffreys prior. For the alternative hypothesis the priors for the variance and the intercept are also non-informative Jeffreys priors, for the mean it is a multivariate Cauchy distribution with a scale value of 0.5 .

For experiment 3, the dependent variables were pleasantness, intensity, and the SVO angle. Pleasantness and intensity were separately analysed for the 3 stimulus types (CT-targeted, control, visual). The SVO angle was analysed using a model with the predictors stimulus type (CT-targeted, control, visual) and pleasantness. BF were calculated for SVO angle and pleasantness.

Data availability statement. Data and analyses scripts are available at the open science foundation website $^{73}$.

\section{References}

1. Silk, J. B. Using the 'F'-word in primatology. Behaviour 139, 421 (2002).

2. Dunbar, R. Grooming, gossip, and the evolution of language. (Harvard University Press, 1998).

3. Dunbar, R. I. Coevolution of neocortical size, group size and language in humans. Behav. Brain Sci. 16, 681-694 (1993).

4. Broad, K. D., Curley, J. P. \& Keverne, E. B. Mother-infant bonding and the evolution of mammalian social relationships. Philosophical Transactions of the Royal Society of London B: Biological Sciences 361, 2199-2214 (2006).

5. Debrot, A., Schoebi, D., Perrez, M. \& Horn, A. B. Touch as an interpersonal emotion regulation process in couples' daily lives: the mediating role of psychological intimacy. Personality and Social Psychology Bulletin 39, 1373-1385 (2013).

6. Gulledge, A. K., Gulledge, M. H. \& Stahmannn, R. F. Romantic physical affection types and relationship satisfaction. The American Journal of Family Therapy 31, 233-242 (2003).

7. Triscoli, C., Croy, I., Olausson, H. \& Sailer, U. Touch between romantic partners: being stroked is more pleasant than stroking and decelerates heart rate. Physiol. Behav. 177, 169-175 (2017).

8. Crusco, A. H. \& Wetzel, C. G. The Midas touch: The effects of interpersonal touch on restaurant tipping. Personality and Social Psychology Bulletin 10, 512-517 (1984).

9. Stephen, R. \& Zweigenhaft, R. L. The effect on tipping of a waitress touching male and female customers. The Journal of Social Psychology 126, 141-142 (1986).

10. Hornik, J. \& Ellis, S. Strategies to secure compliance for a mall intercept interview. Public Opin. Q. 52, 539-551 (1988).

11. Guéguen, N. \& Fischer-Lokou, J. An evaluation of touch on a large request: A field setting. Psychol. Rep. 90, 267-269 (2002).

12. Kleinke, C. L. Compliance to requests made by gazing and touching experimenters in field settings. J. Exp. Soc. Psychol. 13, 218-223 (1977).

13. Joule, R.-V. \& Guéguen, N. Touch, compliance, and awareness of tactile contact. Percept. Mot. Skills 104, 581-588 (2007).

14. Brockner, J., Pressman, B., Cabitt, J. \& Moran, P. Nonverbal intimacy, sex, and compliance: A field study. Journal of Nonverbal Behavior 6, 253-258 (1982).

15. Morhenn, V. B., Park, J. W., Piper, E. \& Zak, P. J. Monetary sacrifice among strangers is mediated by endogenous oxytocin release after physical contact. Evolution and Human Behavior 29, 375-383 (2008).

16. Schirmer, A., Wijaya, M. T. \& Liu, S. in Affective touch and the neurophysiology of CT afferents 283-299 (Springer, 2016).

17. Gallace, A. \& Spence, C. The science of interpersonal touch: an overview. Neurosci. Biobehav. Rev. 34, 246-259 (2010).

18. Vallbo, A., Olausson, H. \& Wessberg, J. Unmyelinated afferents constitute a second system coding tactile stimuli of the human hairy skin. J. Neurophysiol. 81, 2753-2763 (1999).

19. Wessberg, J., Olausson, H., Fernström, K. W. \& Vallbo, Å. B. Receptive field properties of unmyelinated tactile afferents in the human skin. J. Neurophysiol. 89, 1567-1575 (2003).

20. Nordin, M. Low-threshold mechanoreceptive and nociceptive units with unmyelinated (C) fibres in the human supraorbital nerve. The Journal of Physiology 426, 229-240 (1990).

21. McGlone, F., Wessberg, J. \& Olausson, H. Discriminative and affective touch: sensing and feeling. Neuron 82, 737-755 (2014).

22. Ackerley, R. et al. Human C-tactile afferents are tuned to the temperature of a skin-stroking caress. J. Neurosci. 34, 2879-2883 (2014).

23. Löken, L. S., Wessberg, J., McGlone, F. \& Olausson, H. Coding of pleasant touch by unmyelinated afferents in humans. Nat. Neurosci. 12, 547 (2009)

24. Croy, I. et al. Interpersonal stroking touch is targeted to C tactile afferent activation. Behavioural Brain Research 297, 37-40 (2016).

25. Morrison, I., Loken, L. S. \& Olausson, H. The skin as a social organ. Exp. Brain Res. 204, 305-314, https://doi.org/10.1007/s00221009-2007-y (2010).

26. Berg, J., Dickhaut, J. \& McCabe, K. Trust, reciprocity, and social history. GEB 10, 122-142 (1995).

27. Murphy, R. O., Ackermann, K. A. \& Handgraaf, M. J. Measuring Social Value Orientation. Judgment and Decision Making 6, 771-781 (2011).

28. Gallistel, C. The importance of proving the null. Psychol. Rev. 116, 439 (2009).

29. Johnson, N. D. \& Mislin, A. A. Trust games: A meta-analysis. Journal of Economic Psychology 32, 865-889, https://doi.org/10.1016/j. joep.2011.05.007 (2011).

30. Camerer, C. F. Behavioral game theory: Experiments in strategic interaction. (Princeton University Press, 2011). 
31. Ackert, L. F., Church, B. K. \& Davis, S. An experimental examination of the effect of potential revelation of identity on satisfying obligations. New Zealand Economic Papers 45, 69-80 (2011).

32. Mislin, A., Williams, L. V. \& Shaughnessy, B. A. Motivating trust: Can mood and incentives increase interpersonal trust? Journal of Behavioral and Experimental Economics 58, 11-19, https://doi.org/10.1016/j.socec.2015.06.001 (2015).

33. Güth, W., Mugera, H., Musau, A. \& Ploner, M. Intentions and consequences: An experimental investigation of trust and reciprocity determinants. (Jena Economic Research Papers, 2012).

34. Kirsch, L. P. et al. Reading the mind in the touch: Neurophysiological specificity in the communication of emotions by touch. Neuropsychologia (2017).

35. Iggo, A. \& Kornhuber, H. A quantitative study of C-mechanoreceptors in hairy skin of the cat. The Journal of physiology 271, 549-565 (1977).

36. Jakubiak, B. K. \& Feeney, B. C. Affectionate touch to promote relational, psychological, and physical well-being in adulthood: A theoretical model and review of the research. Personality and Social Psychology Review 21, 228-252 (2017).

37. Floyd, K. Communicating affection: Interpersonal behavior and social context. (Cambridge University Press, 2006).

38. Rose, S. A. The sense of touch. Touch: The Foundation of Experience. International Universities Press, Madison, WI, 299-324 (1990).

39. Melzack, R. \& Wall, P. D. Pain mechanisms: a new theory. Science 150, 971-979 (1965).

40. Ellingsen, D.-M., Leknes, S., Løseth, G., Wessberg, J. \& Olausson, H. The neurobiology shaping affective touch: expectation, motivation, and meaning in the multisensory context. Frontiers in psychology 6, 1986 (2016).

41. Gazzola, V. et al. Primary somatosensory cortex discriminates affective significance in social touch. Proceedings of the National Academy of Sciences 109, E1657-E1666 (2012).

42. Scheele, D. et al. An oxytocin-induced facilitation of neural and emotional responses to social touch correlates inversely with autism traits. Neuropsychopharmacology 39, 2078 (2014).

43. Ellingsen, D.-M. et al. In touch with your emotions: oxytocin and touch change social impressions while others' facial expressions can alter touch. Psychoneuroendocrinology 39, 11-20 (2014).

44. Croy, I., D’Angelo, S. \& Olausson, H. Reduced pleasant touch appraisal in the presence of a disgusting odor. PloS one 9 , e92975 (2014).

45. Spapé, M. M., Hoggan, E. E., Jacucci, G. \& Ravaja, N. The meaning of the virtual Midas touch: An ERP study in economic decision making. Psychophysiology 52, 378-387 (2015)

46. Koppel, L., Andersson, D., Morrison, I., Vastfjall, D. \& Tinghog, G. The (Null) Effect of Affective Touch on Betrayal Aversion, Altruism, and Risk Taking. Front Behav Neurosci 11, 251, https://doi.org/10.3389/fnbeh.2017.00251 (2017).

47. Spapé, M. M., Harjunen, V. \& Ravaja, N. Effects of touch on emotional face processing: a study of event-related potentials, facial EMG and cardiac activity. Biol. Psychol. 124, 1-10 (2017).

48. Slovic, P., Lichtenstein, S. \& Edwards, W. Boredom-induced changes in preferences among bets. The American journal of psychology 78, 208-217 (1965)

49. Olausson, H., Wessberg, J., McGlone, F. \& Vallbo, Å. The neurophysiology of unmyelinated tactile afferents. Neurosci. Biobehav. Rev. 34, 185-191 (2010).

50. Kress, I. U., Minati, L., Ferraro, S. \& Critchley, H. D. Direct skin-to-skin vs. indirect touch modulates neural responses to stroking vs. tapping. Neuroreport 22, 646 (2011).

51. Sailer, U. et al. Temporal dynamics of brain activation during 40 minutes of pleasant touch. NeuroImage 139, 360-367 (2016).

52. Triscoli, C., Ackerley, R. \& Sailer, U. Touch satiety: differential effects of stroking velocity on liking and wanting touch over repetitions. PloS one $\mathbf{9}$, e113425 (2014).

53. Triscoli, C., Croy, I., Steudte-Schmiedgen, S., Olausson, H. \& Sailer, U. Heart rate variability is enhanced by long-lasting pleasant touch at CT-optimized velocity. Biol. Psychol. 128, 71-81 (2017).

54. Fischbacher, U. z-Tree: Zurich toolbox for ready-made economic experiments. Experimental economics 10, 171-178 (2007).

55. Kosfeld, M., Heinrichs, M., Zak, P. J., Fischbacher, U. \& Fehr, E. Oxytocin increases trust in humans. Nature 435, 673-676, https:// doi.org/10.1038/nature03701 (2005).

56. Baran, N. M., Sapienza, P. \& Zingales, L. Can we infer social preferences from the lab? Evidence from the Trust Game. (National Bureau of Economic Research, 2010).

57. Fehr, E. \& Gachter, S. Cooperation and punishment in public goods experiments. Am. Econ. Rev. 90, 980-994 (2000)

58. Murphy, R. O. http://ryanomurphy.com/styled-2/index.html (Accessed between January 2016 and April 2016).

59. Barr, D. J., Levy, R., Scheepers, C. \& Tily, H. J. Random effects structure for confirmatory hypothesis testing: Keep it maximal. Journal of memory and language 68, 255-278 (2013).

60. Bates, D., Mächler, M., Bolker, B. \& Walker, S. Fitting linear mixed-effects models using lme4. Journal of Statistical Software 67, 1-48 (2015).

61. Fox, J. \& Weisberg, S. An R companion to applied regression. (Sage Publications, 2011).

62. Lenth, R. V. Least-squares means: the R package lsmeans. Journal of statistical software 69, 1-33 (2016).

63. Morey, R. D., Rouder, J. N. \& Jamil, T. BayesFactor: Computation of Bayes factors for common designs. R package version 0.9 9, 2014 (2015).

64. Wickham, H. ggplot2: Elegant Graphics for Data Analysis. (Springer, 2009).

65. Ludecke, D. \& Schwemmer, C. sjPlot: Data Visualization for Statistics in Social Science. R package version 2.3.1, https://CRAN.Rproject.org/package $=$ sjPlot. (accessed 8 august 2017) (2017).

66. Dienes, Z. Using Bayes to get the most out of non-significant results. Frontiers in psychology 5, 781 (2014).

67. Rouder, J. N., Speckman, P. L., Sun, D., Morey, R. D. \& Iverson, G. Bayesian t tests for accepting and rejecting the null hypothesis. Psychonomic bulletin \& review 16, 225-237, https://doi.org/10.3758/PBR.16.2.225 (2009).

68. Jeffreys, H. The theory of probability. 3 edn, (Oxford University Press, 1961).

69. Rouder, J. N., Haaf, J. M. \& Aust, F. From theories to models to predictions: A Bayesian model comparison approach. Communication Monographs 85, 41-56, https://doi.org/10.1080/03637751.2017.1394581 (2017).

70. Lee, M. D. \& Wagenmakers, E.-J. Bayesian cognitive modeling: A practical course. (Cambridge University Press, 2014).

71. Rouder, J. N. \& Morey, R. D. Default Bayes Factors for Model Selection in Regression. Multivariate Behav Res 47, 877-903, https:// doi.org/10.1080/00273171.2012.734737 (2012).

72. Rouder, J. N., Morey, R. D., Speckman, P. L. \& Province, J. M. Default Bayes factors for ANOVA designs. J. Math. Psychol. 56, 356-374, https://doi.org/10.1016/j.jmp.2012.08.001 (2012).

73. Rosenberger, L. A., Ree, A. \& Sailer, U. Trust game and Social Value orientation following different types of sensory stimulation. Retrieved from https://osf.io/fpqnz (2017, August 9).

\section{Acknowledgements}

This study was supported by the Swedish Research Council (grant number 2011-1529), and the Vienna Science and Technology Fund (WWTF VRG13-007). We thank Patrik Andersson and in particular Petra Valej for refinement of the procedure and for collecting the data for experiments 1 and 2. Thanks also to Claus Lamm for helpful comments on a previous version of the manuscript, to Rochelle Ackerley for useful information regarding CT fatigue, and to Ralph Endemann for drawing Fig. 8. Open access funding provided by University of Vienna. 


\section{Author Contributions}

The studies were designed collaboratively by U.S., L.A.R., C.E., and A.R. (exp. 3). L.A.R. analysed the data, made the graphs, wrote large parts of the results and prepared the supplementary materials. A.R. collected data (exp. 3), and helped drafting the manuscript. C.E. contributed critically to data interpretation of exp. 1 and 2. U.S developed the study ideas and coordinated the experiments, wrote the main text with contributions from L.A.R. and A.R. The authors L.A.R., A.R., U.S. gave final approval for publication.

\section{Additional Information}

Supplementary information accompanies this paper at https://doi.org/10.1038/s41598-018-25601-7.

Competing Interests: The authors declare no competing interests.

Publisher's note: Springer Nature remains neutral with regard to jurisdictional claims in published maps and institutional affiliations.

(c) (i) Open Access This article is licensed under a Creative Commons Attribution 4.0 International License, which permits use, sharing, adaptation, distribution and reproduction in any medium or format, as long as you give appropriate credit to the original author(s) and the source, provide a link to the Creative Commons license, and indicate if changes were made. The images or other third party material in this article are included in the article's Creative Commons license, unless indicated otherwise in a credit line to the material. If material is not included in the article's Creative Commons license and your intended use is not permitted by statutory regulation or exceeds the permitted use, you will need to obtain permission directly from the copyright holder. To view a copy of this license, visit http://creativecommons.org/licenses/by/4.0/.

(C) The Author(s) 2018 


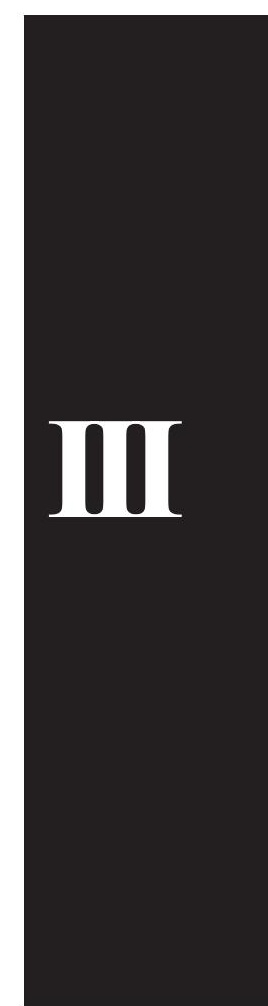





\title{
Right between the eyes: Corrugator muscle activity tracks the changing pleasantness of repeated slow stroking touch
}

\author{
Anbjørn Ree ${ }^{\mathrm{a}, 1, *}$, Johanna Bendas ${ }^{\mathrm{b}, 1}$, Luise Pabel ${ }^{\mathrm{b}}$, Ilona Croy ${ }^{\mathrm{b}}$, Uta Sailer ${ }^{\mathrm{a}}$ \\ ${ }^{a}$ Department of Behavioural Medicine, Institute of Basic Medical Sciences, Faculty of Medicine, University of Oslo, Norway \\ ${ }^{\mathrm{b}}$ Department of Psychotherapy and Psychosomatic Medicine, Faculty of Medicine, Technische Universität Dresden, Germany
}

\section{A R T I C L E I N F O}

\section{Keywords:}

facial EMG

explicit implicit responses

Heart rate variability

Pleasant Touch

corrugator muscle

RMSSD

\begin{abstract}
A B S T R A C T
Subjective reports and physiological responses provide different appraisals of sensory input. The coherence between subjective and physiological responses to repeated pleasant stimuli remains largely unexplored, and is particularly important in situations where subjective responses are prone to cognitive or contextual bias. Here, we investigate how subjective and physiological responses to repeated gentle touch correspond at two separate sessions and compare these to responses obtained when smelling an odorant. Forty-eight participants underwent 60 trials of skin-to-skin slow stroking touch directed to the forearm. We collected subjective pleasantness reports, recorded facial electromyography (EMG) of the corrugator and zygomaticus muscles and heart-rate variability (HRV). With increasing touch repetitions, mean ratings of pleasantness decreased and corrugator muscle activity increased during session 1 , whereas zygomaticus activity remained largely unchanged during both sessions. HRV was significantly higher during the first session, but did not increase from baseline during either sessions. Touch was rated as more pleasant than odor, and demonstrated greater resilience to satiety than the odor responses. Facial EMG recordings of the corrugator muscle appear to be a relevant measure for capturing satiety effects in skin-to-skin touch. Zygomaticus and HRV responses were independent of the subjective appraisal of the gentle touch. Rather than being blueprints of the subjective reports, physiological responses appear to reflect different parts of the subjective experience. As such, an improved understanding of the subjective and physiological responses to pleasant stimuli may improve our understanding of the dynamic interactions that take place in shaping complex emotional phenomena, such as aversion and pleasantness.
\end{abstract}

\section{Introduction}

We express our emotions in many different ways: A subdued sigh of delight from sensing the sunrays on our skin, or a loud roar when scoring a goal in the decisive moment of a football match, are both pleasurable expressions, yet their physiological manifestations are vastly different. These multitudes of subjective expressions and physiological manifestations of emotional states offer considerable possibilities for understanding emotional responses [38]. However, subjective explicit reports are constructed appraisals based on multiple processes, such as autonomic responses and memory and thus represent only selected fragments in a series of processes that ultimately shape an experience [11]. Moreover, not all individuals may be capable of or willing to report their emotional state [35]. In contrast, implicit physiological responses are largely unedited by the conscious mind [38]. Thus, a combination of subjective and physiological measures is required to further our understanding of complex emotional phenomena [65].

Physiological responses to sensory stimuli can be measured by changes in electrocardiogram (ECG) and electromyography (EMG) activity. These physiological responses are frequently employed as autonomic indicators of emotional arousal [7]. Heart rate variability (HRV) is derived from an ECG and indicates the variation of heartbeats within a given timeframe [51]. HRV is considered highly related to the activation of the autonomic nervous system (ANS). Broadly speaking, a high HRV is associated with improved resilience to stress and emotion regulation $[2,53,22]$. In contrast, facial EMG responses are believed to reflect instantaneous responses to emotionally charged stimuli, due to the high temporal resolution of the EMG signal [52]. Commonly, the corrugator muscle is believed to indicate negative affect, by forming a furrow of the brow ("frowning"). The zygomaticus muscle is believed to indicate positive affect ("smiling") [13]. The rapid detection of EMG

\footnotetext{
* Corresponding author.

E-mail address: anbjorn.ree@medisin.uio.no (A. Ree).

${ }^{1}$ Both authors contributed equally
} 
signals allows for analysis of responses that are willingly or unwillingly suppressed by the participants' expressive behavior. For instance, in a study of prejudices, white students verbally reported a preference for working with black students, but displayed greater negative affect (increased corrugator and reduced zygomaticus activity) towards black students than towards white students [59]. The authors argued that the facial EMG activity reflected uncontrolled, automatic responses that were not accessible from self-reports.

Some diversion between subjective and physiological responses can be found for virtually every measure intended to capture implicit responses to emotional stimuli [35]. For example, in a recent study on the effect of music on emotion and HRV, the self-reported emotional response to music and the HRV response were not related to each other [32]. Specifically, while self-selected music led to higher ratings of perceived joy and engagement than classical music, it also led to a lower HRV than classical music [32]. This suggests a complex interactive process between subjective and physiological mechanisms that are not always compatible.

With our background in affective touch, we set out to study the coherence between subjective and physiological responses to skin-toskin touch. Such touch has the ability to elicit distinct and very powerful subjective emotional responses $[19,25]$, but the latter do not always seem to be reflected in concomitant changes of physiological responses. Pawling, Cannon, McGlone, and Walker [41] reported a distinct zygomaticus EMG response to touch that was not discernible from the subjective reports alone. However, recent findings by Mayo, Linde, Olausson, Heilig, and Morrison [36] and our group [42] differ somewhat to those results as pleasant touch led to a relaxation of the corrugator muscle, but did not affect the zygomaticus activity. Controversial results are also observed for the correspondence between subjective ratings and HRV in response to touch. Participants rated stroking touch applied for approximately $40 \mathrm{~min}$ as less pleasant towards the end than at the start of the experiment $[44,55]$, but the HRV was reported to increase during stroking in another similar study [58]. In a clinical study of patients scheduled for aortic surgery, however, the patients who received therapeutic massage reported a greater reduction in anxiety levels than the control group, but the HRV did not differ between the two groups [31].

We aimed to investigate comprehensively the subjective and physiological responses to repeated gentle touch. This served as "Part 1" of the experiment. To this end, subjective ratings of pleasantness, facial EMG and ECG data were collected in response to the repeated administration of a gentle, stroking touch. To verify these responses, the same participants attended a second session with identical set-up. Moreover, we aimed to compare the touch responses to those elicited by smelling an odorant, previously reported as mildly pleasant [61]. This served as "Part 2" of the experiment and was included to control for modality specific effects and effects related to the mere passage of time. Our hypotheses may thus be summarized as follows: Firstly, in line with previous studies on longer-lasting repeated touch [44,55,57], we expected that the subjective pleasantness ratings would drop with increasing repetitions. Secondly, we expected the subjective drop in pleasantness ratings to be accompanied by distinct physiological responses: Specifically, we expected a gradual increase in corrugator activity (indicating increased negative affect towards the touch) and a gradual reduction in zygomaticus activity (indicating decreased positive affect towards the pleasant touch). In line with Triscoli et al. [57], we also expected the HRV to increase with repetitions. All these measures were expected to be similar in session 1 and 2 .

\section{Methods}

\subsection{Participants}

The sample size was estimated using the online program "Power ANalysis for GEneral Anova designs" (PANGEA) [62,63]. Using a fully crossed within-subject design with an estimated medium effect size of 0.45 , forty-five participants were deemed necessary for a power of 0.9. In order to account for potential dropouts, forty-eight people were recruited via flyers and information distributed at TU Dresden and the University Hospital website. The participants reported to be healthy men $(N=25)$ and women $(N=23)$ (mean age $27 \pm 4 \mathrm{SD}$, range 21-38), with no subjectively reported sensory impairments of tactile function. Forty-seven participants took part in two sessions. One participant canceled the second session because of illness, therefore the data for this participant was included for session 1 only.

The study was part of a larger project and included a brief investigation of olfactory responses. Olfactory function was tested using the Sniffin' Sticks Test [23]. Impairments of olfactory function in addition to insufficient comprehension of the German language served as exclusion criteria. Three participants were pregnant at the time of testing. Participants were compensated with 20 Euros for taking part in both sessions. The study was approved by the ethics committee of the Medical Faculty of TU Dresden.

\subsection{Study design}

The experiment consisted of two sessions (Fig 1). In both sessions, each participant received and rated 60 trials of gentle stroking touch to the left forearm. This constituted "Part 1" of the experiment. Afterwards, in one of the sessions, each participant received and rated 30 trials of an odorant. This constituted "Part 2" of the experiment. Importantly, "Part 2" of the experiment was always performed after the completion of one of the touch sessions and was only repeated once for each participant.

Each session lasted approximately $60 \mathrm{~min}$, including the time for preparation. All participants completed a set of questionnaires on personality and social life in-between session 1 and 2 (data reported elsewhere). Questionnaires were filled in at home and online. Between session 1 and session 2 , a mean of $10.7 \pm 4.4$ SD days passed (range 6-20 days).

\subsection{Setup}

During the experiment, the participants sat comfortably in a chair in front of a computer screen. Three people served as the main data collectors (two women), of which one was always present during the data collection and was in charge of the facial EMG and HRV preparations. There were always two experimenters present, and the participants were unable to see the actual touch or who was providing the stimulation. This was done as previous studies have shown that participants' responses may be facilitated by observing the actual touch itself [54], by interpersonal dynamics $[46,15,9,21,57,64]$, by being observed or not [24] or by the gender of the experimenter $[20,43]$. The participant's left arm was positioned on a pillow and shielded from the participant's view by a curtain. A distance of $10 \mathrm{~cm}$ was marked on the dorsal forearm to indicate the skin area to be touched. Electrodes for the facial EMG and electrocardiogram (ECG) were applied and connected to the receivers. The experimenter checked the impedance of EMG-electrodes and, if necessary, readjusted the electrodes (see Fig 2 for experimental set-up).

The appearance of an " $\mathrm{X}$ " on the screen announced a pending stimulus for the participants. Immediately after the touch, the participants were instructed to rate its perceived pleasantness on a visual analogue scale (VAS) by using a mouse. The VAS was anchored by the words "unpleasant" and "pleasant" (coded as -10 and +10 ). No time constraint was imposed for rating. The next trial started $30 \mathrm{~s}$ after the participant's response. Prior to the experiment, participants completed two practice trials to familiarize themselves with the use of the VAS. The VAS and sounds for timing of the touch were presented via E-Prime 2.0 (Psychology Software Tools, Pittsburgh, PA). 


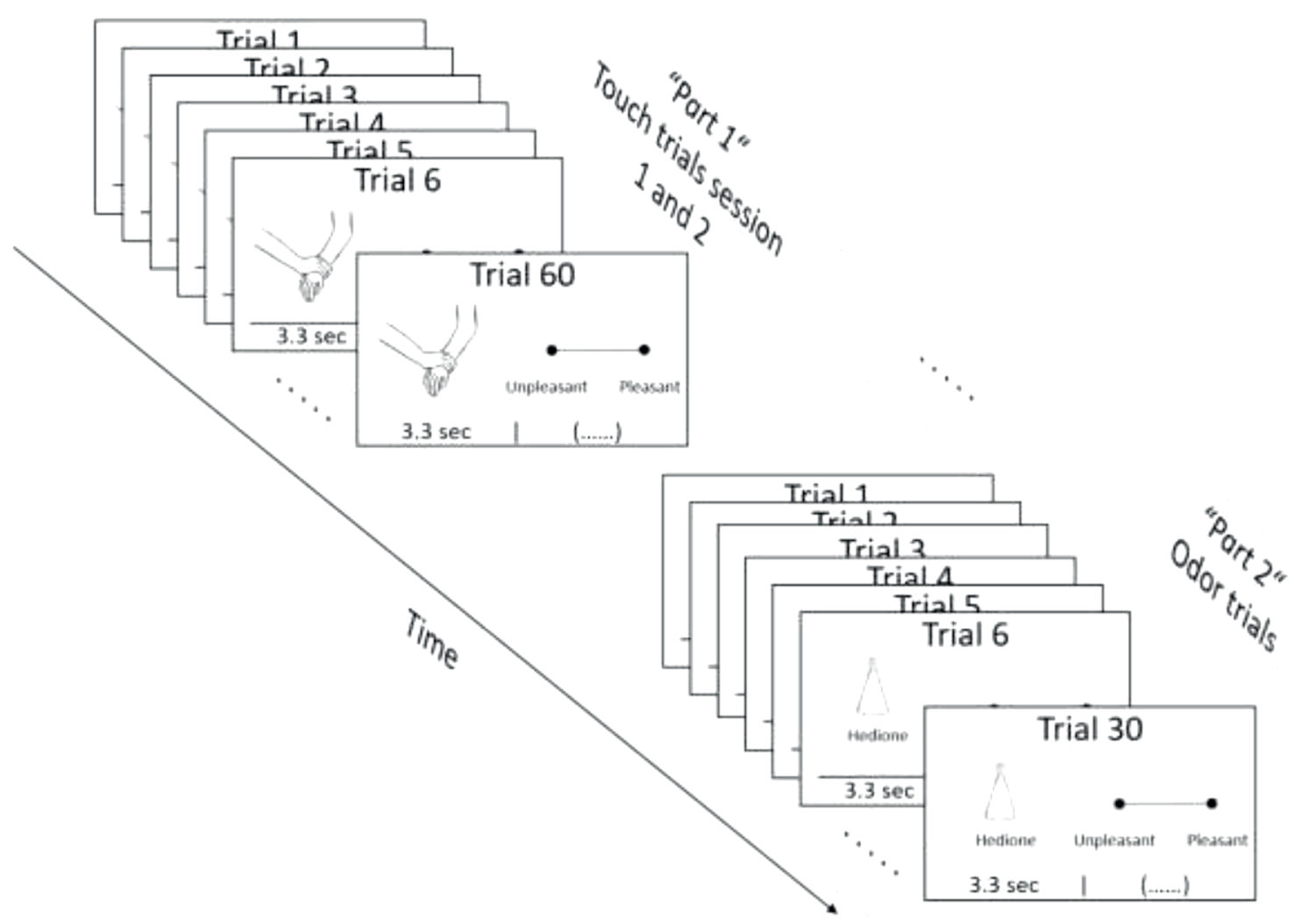

Fig. 1. In part 1 of the study, the participants underwent 60 trials of gentle stroking touch applied to the dorsal forearm in two separate sessions. After each trial, the participants rated the pleasantness of the touch on a visual analogue scale. In part 2 of the study, a subset of 36 participants rated a mildly pleasant odorant following the touch trials in one of the sessions. The odorant was presented 30 times. Facial EMG responses and the electrocardiogram were recorded during both modalities.

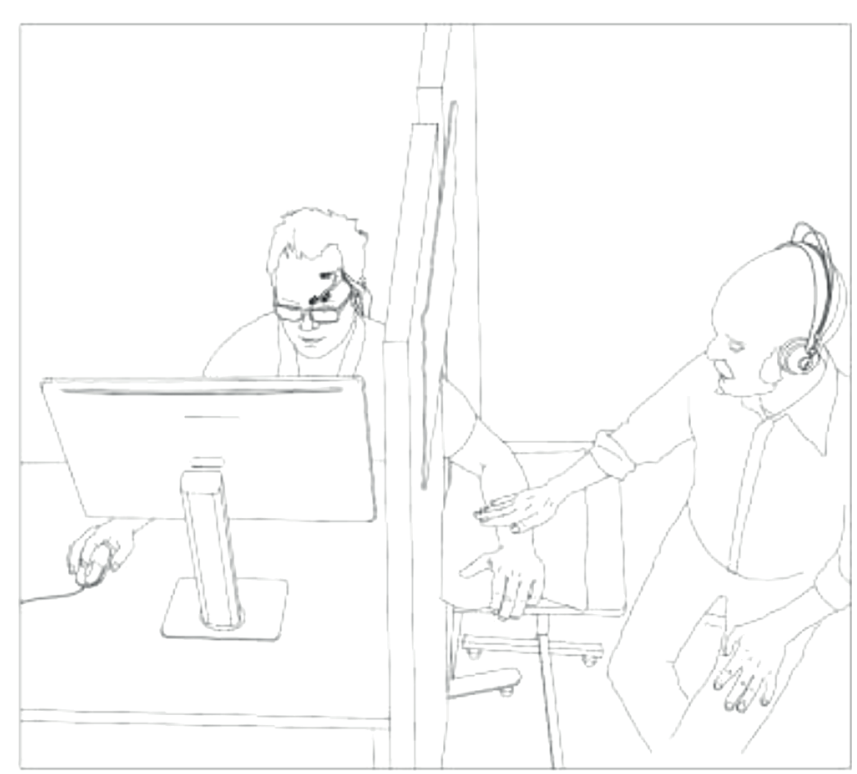

Fig. 2. Overview of the experimental set-up.

\subsubsection{Touch stimulation}

The touch was performed manually using the palmar surface of digits 2-4. The experimenter was guided by auditory cues delivered through a pair of headsets to ensure accurate timing and velocity of the strokes. A distance of $10 \mathrm{~cm}$ was stroked with a velocity of $3 \mathrm{~cm} / \mathrm{sec}$ in a proximal-distal direction on the participant's dorsal left forearm. This velocity has been shown to activate a group of afferent tactile fibers, referred to as C-tactile fibers when applied to hairy skin [33] and has been consistently found to be the most pleasant velocity [16,37]. Skin- to-skin stimulation was used because of its greater ecological validity [26] and because healthy participants' responses are similar when touched by hand and brush [49]. The experimenter was trained to perform the touch with constant pressure and velocity using a scale and visual feedback on a screen. Out of consideration for participants with a potential touch aversion, a stop criterion was implemented. Whenever a participant rated five consecutive strokes as "unpleasant" (ratings between -10 to -8 ), the experiment was prematurely terminated. This criterion was applied to one participant after the 49th touch-trial of session 1.

\subsubsection{Odor stimulation}

The odorant "Hedione" (Firmenich, Meyrin, Switzerland) was presented through a gap in the curtains for $3.3 \mathrm{~s}$. The odorant was contained within an unlabeled opaque glass bottle with a screw lid and an inner diameter of $3 \mathrm{~cm}$. Prior to the inhalation phase of the trial, the lid was removed and the bottle was placed just in front of the participant' lips before the participant was requested to inhale. After approximately $3.3 \mathrm{~s}$, the odorant was removed and the lid was closed.

\subsection{Apparatus}

Facial EMG and ECG data were collected using the BioPac MP150 Nomadix wireless system (BioPac Systems Inc, Santa Barbara, CA, USA). Data was recorded using AcqKnowledge software ([1] version 4.4, BioPac Systems Inc, Ca, USA) and sampled at $1000 \mathrm{kHz}$.

\subsection{Electromyography}

$4 \mathrm{~mm} \mathrm{Ag} / \mathrm{AgCl}$ surface click electrodes with disposable adhesive caps (BioPac Inc, Add204) were filled with electrode gel (BioPac SignaGel 100) and positioned over the corrugator supercilii and 
zygomaticus major muscles of the left side of the face, as described by Fridlund and Cacioppo [18] and Tassinary et al., [52]. The reference electrode was placed on the participant's forehead. The impedance was checked using the "EL-CHECK" (BioPac Inc, Ca, USA) and was kept below $20 \mathrm{k} \Omega$. The facial EMG data were amplified 5000x, filtered online with $10-500 \mathrm{~Hz}$ band pass filter, a $50 \mathrm{~Hz}$ comb band stop filter to remove power line interference and a $50 \mathrm{~Hz}$ FIR high pass filter to remove electrocardiogram artifacts [36,67]. The data were then averaged and integrated over 20 samples for each participant. The $1 \mathrm{~s}$ immediately preceding the onset of each stimulus was designated as baseline.

\subsection{Electrocardiogram}

ECG data were collected using a three-lead set-up with $\mathrm{Ag} / \mathrm{AgCl}$ surface click electrodes (BioPac Inc, EL 503) placed inferior to the right and left clavicle and left 8th rib, as described by BioPac (AcqKnowledge, 4.4). A separate 3-minute baseline was collected prior to the start of part 1 of the experiment and prior to the start of part 2 of the experiment. The data were processed offline and the peak-to-peak $\mathrm{R}-\mathrm{R}$ intervals were identified using the BioPac event-related analysis routine. The data were then visually inspected on a participant-byparticipant basis to correct for missing heartbeats or multiple peak identifications. Artifacts and multiple peaks were cross-referenced to the raw ECG file and deleted as appropriate. In the rare case of missing peaks, the $\mathrm{R}$ peak was manually inserted into the correct position, as described by the [51]. The R-R intervals were saved as a tachogram and exported to Kubios Standard 3.1.0 [Kubios Oy, Kuopio, Finland [50]] for further data analysis. The primary measure of interest was the root mean square of successive R-R interval differences (RMSSD) analyzed in the time-domain [47].

\subsection{Data analysis}

The RMSSD is recommended for investigations of short time-periods [47]. The RMSSD reflects the beat-to-beat variance in heart rate and is used to estimate vagally-induced changes in HRV. The RMSSD was analyzed in bins of $3 \mathrm{~min}$, to assess how the HRV changed during the session.

\subsubsection{Data pre-processing}

One trial was defined as containing a stimulus presentation (3.3 s) and the subsequent rating by the participant. The facial EMG data were baseline-corrected by subtracting the $1 \mathrm{~s}$ immediately preceding the start of a trial from the raw EMG during the touch. Visual inspection showed violations of normal distribution of the facial EMG data. Therefore, the facial EMG residuals were categorized into standard deviation units (i.e. distributed around a mean of 0 with a standard deviation of 1 ). Thereafter, values outside the \pm 2.58 standard deviations were defined as outliers and excluded from the analysis, as described by Field, [17]. In total, $\sim 5 \%$ of the group facial EMG trials were removed.

Each participant's ECG tachogram was analyzed in Kubios HRV Standard 3.1.0 [Kubios Oy, Kuopio, Finland] [50] and visually inspected to verify that they were normally distributed. To calculate the RMSSD, the tachogram was split into time bins of three minutes (see below). Four tachograms from the first session and two tachograms from the second session were artifactual and could not be analyzed in Kubios. These datasets were removed from the statistical analyses. The data of the three pregnant participants were scrutinized because pregnancy has been reported to affect several cardiac measures, including HRV [e.g. Stein et al. [48]]. One of these subjects had RMSSD values that were outside of the mean $\pm 2 \mathrm{x}$ SD in both sessions. Consequently, the participant's RMSSD data were not analyzed any further.

For the touch investigations (part 1), data from 43 participants were used for the ECG analysis for session 1, and from 44 participants for session 2 (one participant canceled the second session due to illness).
The pleasantness and facial EMG analyses were based on responses from 48 participants for session 1 , and from 47 participants for session 2. For the comparisons between the touch and odor responses (part 2), the pleasantness ratings, facial EMG responses and ECG responses from 36 participants were included.

\subsubsection{Statistical analysis}

In order to investigate how pleasantness ratings, facial EMG and HRV responses changed during the course of the experiments, linear mixed models were performed. In part 1 , pleasantness ratings, corrugator and zygomaticus activity and RMSSD served as dependent variables. Separate analyses were run for each dependent variable. In the analysis of pleasantness, corrugator and zygomaticus activity, "Session" with 2 levels (session 1, session 2) and "Trial" as a continuous covariate were included in the model as fixed factors. To investigate whether the slope of the regression line ("Trial") differed between session 1 and session 2, an interaction term between "Session" and "Trial" was added to the model. Significant interactions involving the factor "Session" were followed up by separately interpreting and reporting the slopes for session 1 and 2 across trials.

In the analyses of RMSSD, "Session" and "Bins" (11 levels: [baseline +10 three-minute bins] as a continuous covariate) served as fixed factors. Similarly, the interaction term was included to test for differences in "Session" over "Bins".

In part 2, the responses to 30 trials of tactile stimulation were compared to the responses to 30 trials of odorant stimulation from the same participant and the same session. In the analysis of ratings, corrugator activity and zygomaticus activity, "Modality" (2 levels: [touch and odor]), and "Trial" as a continuous covariate together with their interaction term were included as fixed factors in the model. In the analyses of RMSSD, "Bins" (6 levels: [baseline +5 three-minute bins]) and "Modality" ( 2 levels: [touch and odor]) and their interaction effect served as fixed factors. In all the mixed models, "Subjects" was included as random intercept and "Trial" as random slope to take into account the dependency in the data. Further, the statistical model for the analyses was built according to the principles described by Bolker et al. [4]. Specifically, residuals were plotted and inspected and found to display a normal distribution. Then, Bayesian Information Criteria (BIC) was used to choose the covariance structure, evident by a reduction in BIC value of minimum 2. In the analyses of pleasantness and facial EMG an unstructured covariance type was used, while in the RMSSD analyses, scaled identity was used as covariance type to ensure convergence of the model.

Effect sizes were calculated according to Edwards, Muller, Wolfinger, Qaqish, and Schabenberger [14]. Specifically, the "semi-

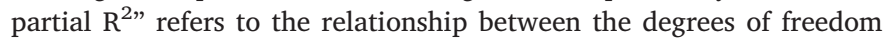
numerator, degrees of freedom denominator and the F-value. The effect sizes are thus expressed and interpreted as a semi-partial $R^{2}$ of 0.02 indicating a small effect, a semi-partial $\mathrm{R}^{2}$ of 0.13 indicating a medium effect, and a semi-partial $\mathrm{R}^{2}$ of 0.26 indicating a large effect [40]. The data were analyzed using SPSS version 25.0 (IBM Corp., NY, USA).

\section{Results}

\section{Part 1: Touch responses}

\subsection{Pleasantness ratings}

The perceived pleasantness of the tactile stimulation dropped significantly across trials in both sessions (Fig. 3, top left), as shown by a main effect of "Trial" $\left(\mathrm{F}(1,47)=11.523, p=0.001\right.$ [semi-partial $\mathrm{R}^{2}=$ 0.1969). Pleasantness ratings in session 1 and session 2 were similar at the start of the session, as the main effect of "Session" was not significant $(\mathrm{F}(1,5596)=2.335, p=0.127)$ [semi-partial $\left.\mathrm{R}^{2}=0.0004\right)$. The pleasantness ratings changed differently across the subsequent trials during the two sessions. This was evident from a significant 

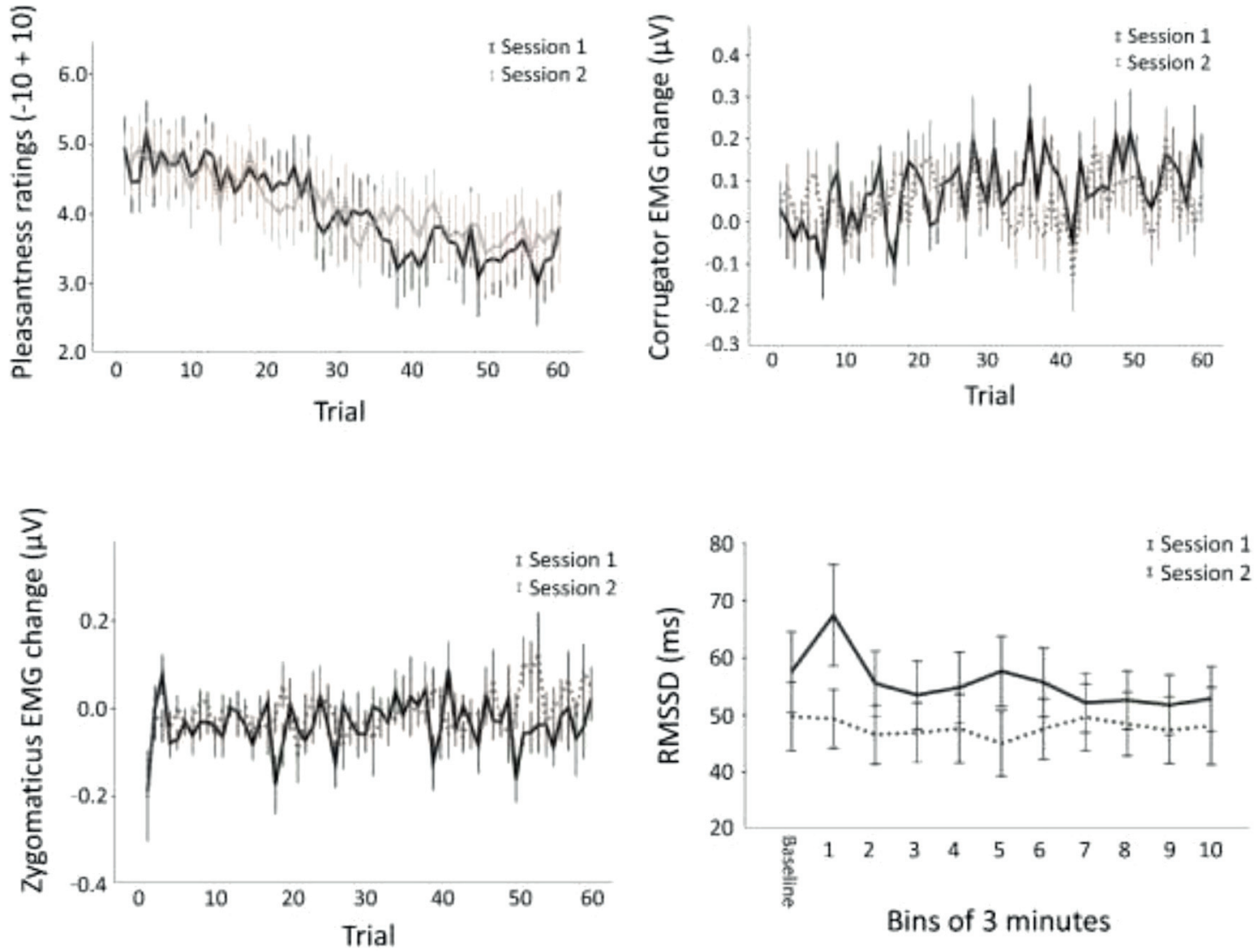

Fig. 3. Top left: Mean pleasantness ratings with SEM. Pleasantness ratings in response to pleasant touch dropped gradually as the sessions progressed and were not significantly different in session 1 and 2. Top right: Mean corrugator activity with SEM. The corrugator activity in response to pleasant touch increased during the first session (full line). Bottom left: Mean zygomaticus activity with SEM. The zygomaticus remained largely unchanged in response to pleasant touch. Bottom right: RMSSD with SEM. The RMSSD remained higher during session 1 than during session 2 . However, the RMSSD did not increase significantly from baseline in either session.

\section{Table 1}

Interaction effects from linear mixed model with pleasantness ratings, corrugator and zygomaticus activity as dependent variables. Legends: VAS; visual analogue scale $(-10+10)$, SE, standard error of the mean, dfd; degrees of freedom denominator, X; interaction between "Session" and "Trial". Trials Session 1: effect of trials in session 1, Trials Session 2: effect of trials in session 2.

\begin{tabular}{|c|c|c|c|c|c|c|}
\hline & & Coefficient & SE & Dfd & $\mathrm{T}$ & $\mathrm{P}$ \\
\hline a & Session X Trial & 0.009 & 0.003 & 5598 & -2.66 & 0.008 \\
\hline \multirow[t]{2}{*}{ Pleasantness ratings (VAS) } & Trials Session 1 & -0.031 & 0.01 & 51 & -3.86 & 0.001 \\
\hline & Trials Session 2 & -0.022 & 0.008 & 51 & -2.79 & 0.007 \\
\hline b & Session X Trial & 0.0023 & 0.001 & 5601 & 3.21 & 0.001 \\
\hline \multirow[t]{2}{*}{ Corrugator activity $(\mu \mathrm{V})$} & Trials Session 1 & 0.0024 & 0.001 & 107 & 3.99 & 0.001 \\
\hline & Trials Session 2 & 0.0001 & 0.001 & 107 & 0.23 & 0.817 \\
\hline c & Session $X$ Trial & 0.0009 & 0.0005 & 5546 & 1.759 & 0.079 \\
\hline \multirow[t]{2}{*}{ Zygomaticus activity $(\mu \mathrm{V})$} & Trials Session 1 & 0.0004 & 0.0001 & 71 & 0.734 & 0.466 \\
\hline & Trials Session 2 & 0.0013 & 0.0005 & 72 & 2.309 & 0.024 \\
\hline
\end{tabular}

interaction between "Session" and "Trial" $(\mathrm{F}(1,5598)=7.071$, $p=0.008$ [semi-partial $\mathrm{R}^{2}$ 0.0013], for statistical overview, see Table 1a. The drop in pleasantness ratings was slightly steeper during session 1 than during session 2. For every trial, the pleasantness ratings dropped on a VAS by 0.031 units during session $1(p=0.001)$ and by 0.022 units during session $2(p=0.007)$.

\subsubsection{Facial EMG; corrugator}

The corrugator activity increased slightly during both sessions, but the main change occurred during session 1 (see Fig. 3, top right). There was a significant main effect of "Trial" $(\mathrm{F}(1,47)=6.718, p=0.013)$, [semi-partial $\mathrm{R}^{2}=0.13$ ]), no significant main effect of "Session" ( $F(1$, $5596)=3.214, p=0.073$ ), [semi-partial $\mathrm{R}^{2}=0.0006$ ]), and a significant interaction between "Session" and "Trial" (F (1,
5601) $=10.287, p=0.001$ ) [semi-partial $\mathrm{R}^{2}=0.018$ ], for statistical overview, see Table 1b). Thus, corrugator activity was similar at the start of the sessions, but developed differently across trials in session 1 and 2. In particular, the corrugator activity only increased significantly during session 1, but not during session 2 . Specifically, for every trial, the corrugator increased by $0.0024 \mu \mathrm{V}$ during session $1(p=0.001)$ and $0.0001 \mu \mathrm{V}$ during session $2(p=0.817)$, which indicates that the main effect of "Trial" was driven by session 1 .

\subsubsection{Facial EMG; zygomaticus}

In contrast to the corrugator, the zygomaticus activity remained largely unchanged throughout both sessions (Fig. 3, bottom left). There was no significant main effect of "Trial" $(\mathrm{F}(1,46)=2.909, p=0.095$ [semi-partial $\left.\mathrm{R}^{2}=0.0595\right]$ ), nor a main effect of "Session" ( $F(1$, 

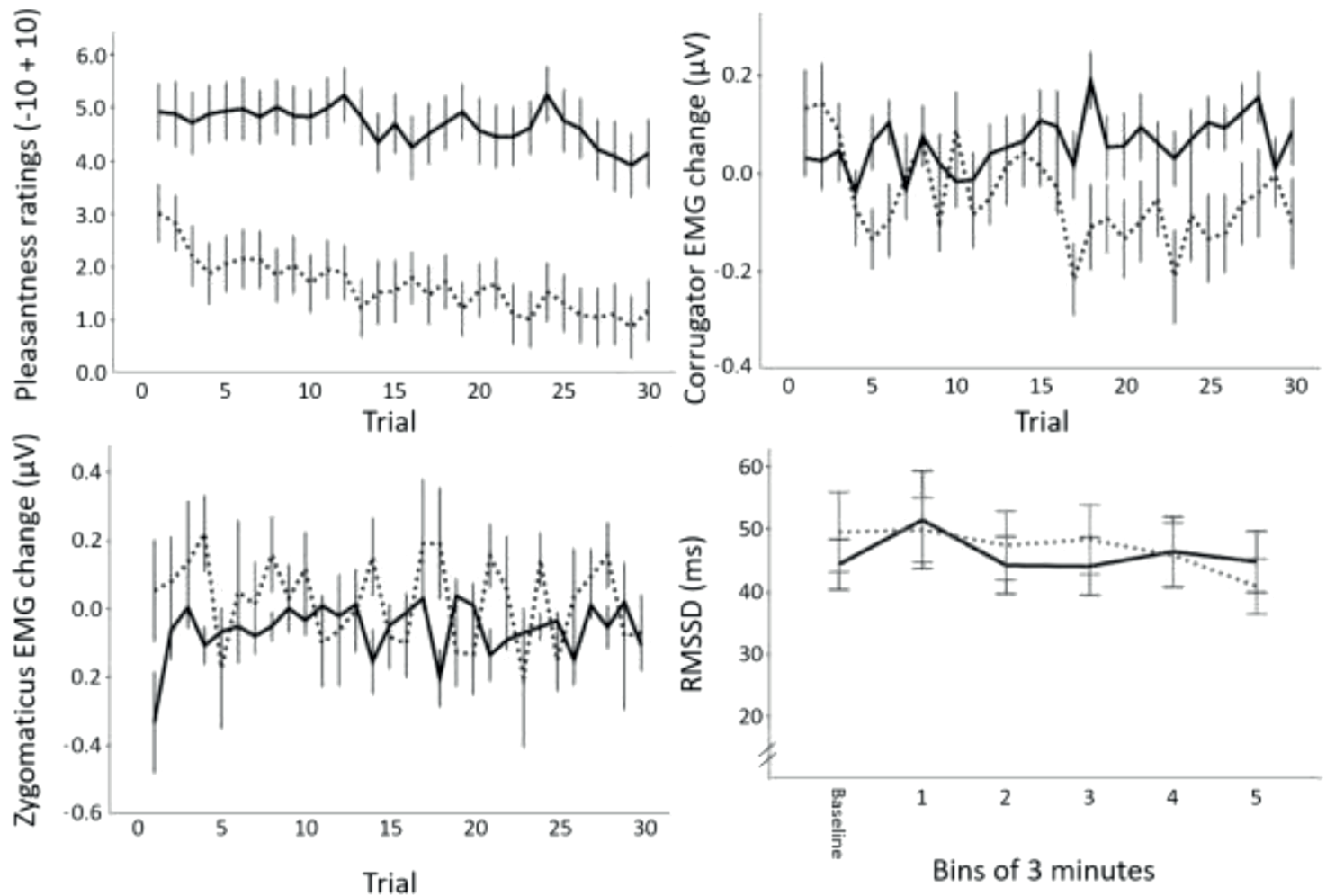

Fig. 4. Top left: Mean pleasantness ratings with SEM. Touch was rated as significantly more pleasant than odor and the ratings decreased less as the session progressed. Top right: Mean corrugator activity with SEM. The corrugator responses decreased for odor, but remained unchanged for touch. Bottom left: Mean zygomaticus activity with SEM. The zygomaticus responses to tactile input was significantly lower than to odor input. Bottom right: RMSSD with SEM. The RMSSD did not increase significantly from baseline in either modality. (Full line, touch condition, dotted line, odor condition).

$5546)=0.006, p=0.938)\left[\right.$ semi-partial $\left.\mathrm{R}^{2}=0.0001\right)$, nor any interaction between "Session" and "Trial" (F $(1,5546)=3.095$, $p=0.079$ ) [semi-partial $\left.\mathrm{R}^{2}=0.0006\right]$ ), for statistical overview, see Table 1c.

\subsection{Heart rate variability}

The RMSSD was overall significantly higher during session 1 than during session $2(\mathrm{~F}(1,679)=43.036, p=0.001)$, [semi-partial $\mathrm{R}^{2}=$ 0.0596]. However, there was no significant main effect of "Bins" on $\operatorname{RMSSD}(\mathrm{F}(10,753)=0.694, p=0.731)$ [semi-partial $\mathrm{R}^{2}=0.0091$ ], indicating that the RMSSD did not increase during the sessions compared to baseline. There was no interaction between "Session" and "Bins" $(\mathrm{F}(10,686)=1.093, p=0.365)$ [semi-partial $\left.\mathrm{R}^{2}=0.0157\right]$, see Fig. 3, bottom right.

Part 2: Comparison of touch and odor responses in $\mathbf{3 0}$ trials

The main effect of "Trial" shows that the pleasantness ratings decreased significantly $(\mathrm{F}(1,35)=6.367, p=0.016)$ [semi-partial $\left.\mathrm{R}^{2}=0.1539\right]$, see Fig 4). Touch pleasantness ratings were significantly higher than odor ratings at the start of the session, evident by a significant main effect of "Modality", $(\mathrm{F}(1,2068)=124.100, p=0.001)$ [semi-partial $\mathrm{R}^{2}=0.0566$ ]. In addition, the ratings changed differently for the two modalities as the trials progressed. This was evident from a significant interaction between "Modality" and "Trial" (F (1, 2071) $=4.660, p=0.031$ ) [semi-partial $\mathrm{R}^{2}=0.0023$ ], for statistical overview, see Table 2a. Whereas odor ratings dropped significantly by 0.053 units for every trial $(p=0.003)$, touch pleasantness ratings dropped by 0.024 units, but non-significantly, for every trial $(p=0.149)$.

Regarding the comparison of the facial EMG responses, the main effect of "Trial" shows that the corrugator increased by $0.0029 \mu \mathrm{V}$ per trial $(\mathrm{F}(1,35)=0.951, p=0.336)$ [semi-partial $\mathrm{R}^{2}=0.0265$ ], see Fig 4. At the start of the session, the corrugator activity was similar during touch and odor presentation, evident by a non-significant main effect of "Modality" $(\mathrm{F}(1,1999)=0.285, p=0.593)$ [semi-partial $\left.\mathrm{R}^{2}=0.0001\right]$. However, corrugator activity changed differently for the two modalities during the subsequent trials. This was evident by a significant interaction between "Modality" and "Trial" (F (1, 2006) $=18.882, p=0.001$ ) [semi-partial $\mathrm{R}^{2}=0.0093$ ], for statistical overview, see Fig 4 and Table 2b. Specifically, during odor presentation corrugator activity decreased significantly by $-0.0055 \mu \mathrm{V}$ per trial $(p=0.001)$. During touch, corrugator activity increased slightly, but not significantly across trials (increased by $0.0029 \mu \mathrm{V}$ per trial; $p=0.086)$

The zygomaticus activity did not change during the touch and odor presentation as there was no significant effect of "Trial" (F (1, $35)=0.097, p=0.757$ ) [semi-partial $\mathrm{R}^{2}=0.0028$, see Fig 4 . However, the zygomaticus activity was significantly lower during the touch than during odor presentation during all trials, as there was a significant main effect of "Modality" $(\mathrm{F}(1,2045)=7.171, p=0.007)$ [semi-partial $\mathrm{R}^{2}=0.0035$ ]. There was no significant interaction between "Modality" and "Trial" $(\mathrm{F}(1,2052)=1.370, p=0.242)$ [semipartial $\left.\mathrm{R}^{2}=0.0007\right]$, for statistical overview, see Fig 4 and Table 2c.

Lastly, the RMSSD responses were not different between odor and touch, as there was no main effect of "Modality" $(\mathrm{F}(1,239)=1.309$, $p=0.254$ ) [semi-partial $\mathrm{R}^{2}=0.0055$ ], see Fig 4, bottom right. There was no significant main effect of "Bins" $(\mathrm{F}(5,264)=0.580, p=0.715)$ [semi-partial $\mathrm{R}^{2}=0.0108$ ], nor any significant interaction between "Modality" and "Bins" $(\mathrm{F}(5,238)=0.901, p=0.481)$ [semi-partial $\left.\mathrm{R}^{2}=0.0186\right]$.

\section{Discussion}

We aimed to investigate the correspondence between subjective and physiological responses to repeated gentle stroking touch by using subjective ratings, facial EMG and heart rate variability responses. In 
Table 2

Interaction effects from linear mixed model with pleasantness ratings, corrugator and zygomaticus activity as dependent variables. VAS; visual analogue scale $(-10+10)$, SE; standard error of the mean, dfd; degrees of freedom denominator, X; interaction between "Modality" and "Trial", Trials Touch; effect of trials for touch, Trials Odor; effect of trials for odor.

\begin{tabular}{|c|c|c|c|c|c|c|}
\hline & & Coefficient & SE & Dfd & $\mathrm{T}$ & $\mathrm{p}$ \\
\hline a & Modality X Trial & -0.029 & 0.013 & 2071 & -2.16 & 0.031 \\
\hline \multirow[t]{2}{*}{ Pleasantness ratings (VAS) } & Trials Touch & -0.024 & 0.017 & 48 & -1.47 & 0.149 \\
\hline & Trials Odor & -0.053 & 0.017 & 49 & -3.17 & 0.003 \\
\hline b & Modality X Trial & 0.0083 & 0.002 & 2006 & 4.338 & 0.001 \\
\hline \multirow[t]{2}{*}{ Corrugator activity $(\mu \mathrm{V})$} & Trials Touch & 0.0029 & 0.002 & 78 & 1.736 & 0.086 \\
\hline & Trials Odor & -0.0055 & 0.002 & 79 & -3.300 & 0.001 \\
\hline c & Modality X Trial & 0.0035 & 0.0030 & 2052 & 1.171 & 0.242 \\
\hline \multirow[t]{2}{*}{ Zygomaticus activity $(\mu \mathrm{V})$} & Trials Touch & 0.0011 & 0.0027 & 72 & 0.394 & 0.695 \\
\hline & Trials Odor & -0.0024 & 0.0027 & 73 & 0.909 & 0.366 \\
\hline
\end{tabular}

line with previous studies, subjective pleasantness ratings decreased steadily and significantly with repeated exposure to gentle touch. The reduction of the subjective pleasantness ratings across trials was accompanied by a concomitant increase in the corrugator activity. However, the change in perceived pleasantness of the gentle touch was not reciprocated by changes in the zygomaticus muscle or in the heart rate variability. When comparing the touch responses to those elicited by smelling a pleasant odorant, touch was consistently rated as more pleasant than the odorant, but the zygomaticus activity was lower during the touch trials than during the odor trials. However, the drop in pleasantness ratings was more pronounced for the odor responses and was also accompanied by a gradual reduction in corrugator activity. Moreover, we sought to identify consistent response patterns by examining the participants at a second session with an identical set-up. We found that the subjective pleasantness ratings to repeated touch were similar during both sessions, but dropped quicker during session 1. The corrugator activity, however, only increased during the first session, and not during the second session. Whilst the zygomaticus remained largely unchanged during both sessions, the heart rate variability was significantly higher during the first session, but did not change from baseline.

\subsection{Pleasantness ratings}

Our hypothesis that subjective pleasantness ratings drop with prolonged stimulation was confirmed. The drop is commonly interpreted as a slow "touch satiety" [55]. In contrast to that study, where repeated brush-stroking was applied by a robot [55], pleasantness ratings in the present study remained at a rather high level even towards the end of the session. This may indicate that skin-to-skin touch is more robust to habituation than brush-stroking and could reflect a greater ecological validity of skin-to-skin touch, as suggested by Kress et al. [26]. However, comparisons across the two studies should be interpreted cautiously due to differences in methodology.

\subsection{Facial EMG}

We believe there is partial support for our second hypothesis: Specifically, we predicted that a drop in subjective ratings would be accompanied by physiological adjustments that indicate changes in positive and negative affect towards the gentle touch. During the first session, the reduction in pleasantness ratings coincided with increased activity in the corrugator muscle, indicating a physiological response that reciprocated the subjective response. Specifically, at the start of the session, the touch was reported to be most pleasant and evoked lowest corrugator activity, and at the end, the touch was reported to be less pleasant and evoked highest overall corrugator activity. In line with our findings, Larsen, Norris, and Cacioppo [29] proposed that the corrugator responds in a linear manner across the affective spectrum. Specifically, when participants were exposed to pictures, sounds and words, negative affective stimuli led to increased activity and positive affective stimuli led to reduced activity in the corrugator muscle. In the present study, the corrugator activity increased as the pleasantness ratings dropped during the first session only. The difference in corrugator activity during session 1 and 2 might reflect subtle differences in attention, which has been reported to affect corrugator activity [10]. Attention can be assumed to be lower in session 2 when participants are familiar with the task and setting.

We were unable to demonstrate a change of zygomaticus activity with repeated touch, and consequently, a correspondence between zygomaticus activity with the ratings. Despite that the zygomaticus has been shown to respond to pleasant auditory [6] and visual input [28], at present, two other studies have failed to identify touch-related responses in the zygomaticus muscle [36, 42], As such, these findings contradict the findings of Pawling and colleagues (2017) who reported increased activity in the zygomaticus to slow stroking touch. Three alternative explanations may help to interpret these contradictory results. First, Larsen et al. [29] proposed that the zygomaticus responds in a "J"-shaped manner. That is, stimuli that are either highly pleasant or aversive will activate the zygomaticus, whereas neutral stimuli will not. In the present study, it may be that the slow stroking touch was not sufficiently pleasant or aversive to yield a response in the zygomaticus muscle. Second, in the present study, the participants were shielded from the experimenters, whereas in the study by Pawling et al. [41] the participant was flanked on either side by two experimenters that observed the participant as the VAS rating was provided. Being observed by the experimenter may affect facial EMG responses, as demonstrated in a study where facial EMG responses to pleasant odors were different when the participants were observed by the experimenter compared to when they were alone [24]. Third, in the present study the participants were only evaluating one type of touch, as opposed to the participants in the study by Pawling et al. [41]. Thus, the differences between the present findings and those reported by Pawling et al. [41] might also reflect the inability to make comparative affective responses between different types of stimuli, which has previously been found to affect touch ratings [55].

\section{3. $H R V$}

We were unable to identify a coherent response between the HRV and the subjective responses to gentle touch. HRV did not change from baseline during the tactile stimulation period. This was contrary to our hypothesis. An increase in HRV is typically accredited to emotional well-being and an increased resilience to stress responses [22, 34]. One explanation could be that although the participants reported the repeated touch to be pleasant, it was not sufficiently pleasant to instigate an increase in the HRV. A previous study reported an increase in HRV to pleasant touch [57], however, that particular study used a different HRV measure, the standard deviation of $\mathrm{N}-\mathrm{N}$ intervals (SDNN). The SDNN is commonly recommended for 24 hours' measurements [51]. 
For shorter time intervals, the RMSSD is advocated [47]. Thus, the differences in how HRV changes with repeated touch may be due to the measures used. Alternatively, it may be that the contextual settings were affecting the HRV more than the actual stimulus did, as we observed a higher HRV in session 1 than session 2 although the stimulus was the same. Future studies should investigate the clinical relevance of these findings by comparing the effects of pleasant touch on HRV measures to other interventions that have been reported to increase the HRV, such as meditation [27] or exercise [45].

\subsection{Touch and odor comparison}

Our findings that pertain to the comparison of the touch and odor responses may be interpreted in several different ways: Firstly, the results suggest that the ratings and corrugator activity are specific for the type of stimulation used. Specifically, the greater reduction in pleasantness observed in the odor ratings was accompanied by a decrease in corrugator activity whereas the reduction in touch pleasantness ratings was accompanied by an increase in corrugator activity. Thus, "satiety" appears to develop differently for stimuli of different modalities and their physiological characteristics are different. Previous findings on odorant processing and corrugator activation report that the corrugator decreased as a function of pleasantness when smelling 12 different food-related odors [3]. However, in the present study, the participants were limited to smelling one single odorant that was also not related to food, making the results of these studies not directly comparable. The development of olfactory satiety may depend on the type of odor $[12,56,8]$. Secondly, these findings demonstrate that the change in responses is not simply due to the passage of time. If it were, we would expect to see a greater activation of the corrugator during the odor trials, which was always undertaken after the touch trials.

\subsection{General discussion}

The results from the present study demonstrate a coherence between the subjective pleasantness ratings and the corrugator activity responses to gentle touch during the first session. However, the subjective ratings, zygomaticus activity and HRV responses were non-coherent. Physiological and subjective measures may be incoherent because they reflect different aspects of the experience. For instance, the subjective ratings reflect the conscious evaluation of the gentle touch and the cognitive appraisal of the contextual setlings. While participants try to achieve consistency in their ratings [60], they cannot deliberately influence their facial muscle activity or HRV in the same way. Therefore, we speculate that the facial EMG responses in particular reflect a "coarser" physiological evaluation of repeatedly being exposed to a gentle touch that is more prone to change from one session to another than the subjective ratings. Another putative reason for the lack of coherence between the subjective and physiological measures may be explained by the "mere-exposure effect" [66]. The "mere-exposure effect" describes that ratings of stimuli that are repeated typically increase first (i.e., become more positive), before they drop with the number of repetitions. This response pattern can be explained by two opposed processes: habituation and boredom [30 5,39]. It may be speculated that physiological responses and subjective ratings each reflect boredom and habituation to a different extent, therefore they develop differently over time. In general, facial EMG and HRV respond on different time scales. Whereas facial EMG reflects instantaneous emotions, HRV may rather reflect long-term processes such as emotion regulation $[53,22]$. Altogether, our findings indicate that physiological responses are not blueprint read-outs of the subjective responses, and that cognitive and contextual factors might affect the relationship between the subjective and physiological responses.

\section{Limitations}

Several limitations apply to the current study. This study collected subjective and physiological responses to repeated pleasant touch and odor. Naturally, due to the lengthy nature of the experiment, the participants' responses are prone to change due to several cognitive factors, such as boredom and attention. Such ratings were not collected as we did not want the participants' perception of mood and boredom to interfere with the evaluation of the gentle touch. However, the ratings from session 1 and 2 were similar and we would expect a larger drop in ratings in session 2 if the change was primarily due to boredom or lack of novelty. Nevertheless, we cannot ascertain the extent to which the detected responses represent a genuine effect of the applied sensory stimulus or a general effect, representing novelty and saliency of potentially any pleasant stimulus. Future studies could circumvent this problem by comparing several types of pleasant stimuli applied for fewer trials.

\section{Conclusion}

This study presents a comprehensive analysis of the dynamics of subjective and physiological responses to repeated gentle touch examined at two separate sessions. Our findings demonstrate that the drop in perceived pleasantness of repeated gentle touch may be reciprocated by a gradually increasing activity of the corrugator muscle. However, although the corrugator muscle appears to be a promising measure of physiological responses to touch satiety, we were unable to demonstrate coherent subjective and physiological responses during both sessions. The zygomaticus muscle activity and the HRV responses did not change in accordance with the subjective ratings and are likely to reflect other processes that occur irrespective of the subjective appraisal of the gentle touch.

\section{Declaration of Competing Interest}

None.

\section{Acknowledgments}

The study was supported by the Research Council of Norway, project number: 267446/F10, and the German Academic Exchange Service (DAAD), project number: 094_5159. We thank Ralph Endemann for drawing Fig 1, and Ragnhild Sørum Falk for statistical advice.

\section{References}

[1] AcqKnowledge. (4.4). Software Guide, Biopac Systems Inc. https://www.biopac. $\mathrm{com} /$ wp-content/uploads/acqknowledge-4-software-guide.pdf. Date last accessed 19.03.2020.

[2] B.M. Appelhans, L.J. Luecken, Heart rate variability as an index of regulated emotional responding, Rev. General Psychol. 10 (3) (2006) 229-240, https://doi. org $/ 10.1037 / 1089-2680.10 .3 .229$

[3] M. Bensafi, C. Rouby, V. Farget, B. Bertrand, M. Vigouroux, A. Holley, Psychophysiological correlates of affects in human olfaction, Neurophysiol. Clin 32 (5) (2002) 326-332, https://doi.org/10.1016/s0987-7053(02)00339-8.

[4] B.M. Bolker, M.E. Brooks, C.J. Clark, S.W. Geange, J.R. Poulsen, M.H. Stevens, J.S. White, Generalized linear mixed models: a practical guide for ecology and evolution, Trend. Ecol. Evolut. 24 (3) (2009) 127-135, https://doi.org/10.1016/j. tree.2008.10.008

[5] R.F. Bornstein, P.R. D'Agostino, Stimulus recognition and the mere exposure effect, J. Pers. Soc. Psychol. 63 (4) (1992) 545-552, https://doi.org/10.1037//0022-3514. 63.4.545.

[6] M.M. Bradley, P.J. Lang, Affective reactions to acoustic stimuli, Psychophysiology 37 (2) (2000) 204-215, https://doi.org/10.1111/1469-8986.3720204.

[7] J.T. Cacioppo, G.G. Berntson, J.T. Larsen, K.M. Poehlmann, T.A. Ito, The psychophysiology of emotion, in: J.M. Haviland-Jones, M. Lewis (Eds.), Handbook of Emotions, Guilford Press, New York, 2000, pp. 173-191 2nd ed.

[8] W.S. Cain, F. Johnson, Lability of odor pleasantness: influence of mere exposure, Perception 7 (4) (1978) 459-465, https://doi.org/10.1068/p070459.

[9] N. Caruana, G. McArthur, A. Woolgar, J. Brock, Simulating social interactions for the experimental investigation of joint attention, Neurosci. Biobehav. Rev. 74 (Pt A) (2017) 115-125, https://doi.org/10.1016/j.neubiorev.2016.12.022. 
[10] B.H. Cohen, R.J. Davidson, J.A. Senulis, C.D. Saron, D.R. Weisman, Muscle tension patterns during auditory attention, Biol. Psychol. 33 (2-3) (1992) 133-156, https:// doi.org/10.1016/0301-0511(92)90028-s.

[11] A.S. Cowen, D. Keltner, Self-report captures 27 distinct categories of emotion bridged by continuous gradients, Proceed. Natl. Acad. Sci. USA 114 (38) (2017) E7900-e7909, https://doi.org/10.1073/pnas.1702247114.

[12] S. Delplanque, G. Coppin, L. Bloesch, I. Cayeux, D. Sander, The mere exposure effect depends on an odor's initial pleasantness, Front. Psychol. 6 (2015) 911, https://doi. org/10.3389/fpsyg.2015.00920.

[13] U. Dimberg, Facial reactions to facial expressions, Psychophysiology 19 (6) (1982) 643-647, https://doi.org/10.1111/j.1469-8986.1982.tb02516.x.

[14] L.J. Edwards, K.E. Muller, R.D. Wolfinger, B.F. Qaqish, O. Schabenberger, An R2 statistic for fixed effects in the linear mixed model, Stat. Med. 27 (29) (2008) 6137-6157, https://doi.org/10.1002/sim.3429.

[15] D.M. Ellingsen, J. Wessberg, O. Chelnokova, H. Olausson, B. Laeng, S. Leknes, In touch with your emotions: oxytocin and touch change social impressions while others' facial expressions can alter touch, Psychoneuroendocrinology 39 (2014) 11-20, https://doi.org/10.1016/j.psyneuen.2013.09.017.

[16] G.K. Essick, F. McGlone, C. Dancer, D. Fabricant, Y. Ragin, N. Phillips, S Guest, Quantitative assessment of pleasant touch, Neurosci. Biobehav. Rev. 34 (2) (2010) 192-203, https://doi.org/10.1016/j.neubiorev.2009.02.003.

17] A. Field, Discovering Statistics Using IBM SPSS Statistics (4th Ed), Sage, 2013.

[18] A.J. Fridlund, J.T. Cacioppo, Guidelines for human electromyographic research, Psychophysiology 23 (5) (1986) 567-589.

[19] A. Gallace, C. Spence, The science of interpersonal touch: an overview, Neurosci. Biobehav. Rev. 34 (2) (2010) 246-259, https://doi.org/10.1016/j.neubiorev.2008. 10.004.

[20] V. Gazzola, M.L. Spezio, J.A. Etzel, F. Castelli, R. Adolphs, C. Keysers, Primary somatosensory cortex discriminates affective significance in social touch, Proceed. Natl. Acad. Sci. USA 109 (25) (2012) E1657-E1666, https://doi.org/10.1073/pnas. 1113211109.

[21] V.J. Harjunen, M. Spapé, I. Ahmed, G. Jacucci, N. Ravaja, Individual differences in affective touch: behavioral inhibition and gender define how an interpersonal touch is perceived, Pers. Individ. Dif. 107 (2017) 88-95, https://doi.org/10.1016/j.paid. 2016.11.047.

[22] J.B. Holzman, D.J. Bridgett, Heart rate variability indices as bio-markers of topdown self-regulatory mechanisms: a meta-analytic review, Neurosci. Biobehav. Rev. 74 (2017) 233-255, https://doi.org/10.1016/j.neubiorev.2016.12.032.

[23] T. Hummel, B. Sekinger, S.R. Wolf, E. Pauli, G. Kobal, 'Sniffin'sticks': olfactory performance assessed by the combined testing of odor identification, odor discrimination and olfactory threshold, Chem. Senses 22 (1) (1997) 39-52.

[24] L. Jäncke, N. Kaufmann, Facial EMG responses to odors in solitude and with an audience, Chem. Senses 19 (2) (1994) 99-111.

[25] L.P. Kirsch, C. Krahe, N. Blom, L. Crucianelli, V. Moro, P.M. Jenkinson, A. Fotopoulou, Reading the mind in the touch: neurophysiological specificity in the communication of emotions by touch, Neuropsychologia 116 (Pt A) (2018) 136-149, https://doi.org/10.1016/j.neuropsychologia.2017.05.024.

[26] I.U. Kress, L. Minati, S. Ferraro, H.D. Critchley, Direct skin-to-skin vs. indirect touch modulates neural responses to stroking vs. tapping, Neuroreport 22 (13) (2011) 646, https://doi.org/10.1097/WNR.0b013e328349d166.

[27] J.R. Krygier, J.A. Heathers, S. Shahrestani, M. Abbott, J.J. Gross, A.H. Kemp, Mindfulness meditation, well-being, and heart rate variability: a preliminary in vestigation into the impact of intensive Vipassana meditation, Int. J. Psychophysiol. 89 (3) (2013) 305-313, https://doi.org/10.1016/j.ijpsycho.2013.06.017.

[28] P.J. Lang, M.K. Greenwald, M.M. Bradley, A.O. Hamm, Looking at pictures: affective, facial, visceral, and behavioral reactions, Psychophysiology 30 (3) (1993) 261-273, https://doi.org/10.1111/j.1469-8986.1993.tb03352.x.

[29] J.T. Larsen, C.J. Norris, J.T. Cacioppo, Effects of positive and negative affect on electromyographic activity over zygomaticus major and corrugator supercilii, Psychophysiology 40 (5) (2003) 776-785, https://doi.org/10.1111/1469-8986. 00078.

[30] A.M. Leventhal, R.L. Martin, R.W. Seals, E. Tapia, L.P. Rehm, Investigating the dynamics of affect: psychological mechanisms of affective habituation to pleasurable stimuli, Motiv. Emot. 31 (2) (2007) 145-157, https://doi.org/10.1007/ s11031-007-9059-8.

[31] L. Lindgren, S. Lehtipalo, O. Winso, M. Karlsson, U. Wiklund, C. Brulin, Touch massage: a pilot study of a complex intervention, Nurs. Crit. Care 18 (6) (2013) 269-277, https://doi.org/10.1111/nicc.12017.

[32] E. Lynar, E. Cvejic, E Schubert, U. Vollmer-Conna, The joy of heartfelt music: an examination of emotional and physiological responses, Int. J. Psychophysiol. 120 (2017) 118-125, https://doi.org/10.1016/j.ijpsycho.2017.07.012.

[33] L.S. Löken, J. Wessberg, I. Morrison, F. McGlone, H. Olausson, Coding of pleasant touch by unmyelinated afferents in humans, Nat. Neurosci. 12 (5) (2009) 547-548, https://doi.org/10.1038/nn.2312

[34] M. Mather, J. Thayer, How heart rate variability affects emotion regulation brain networks, Curr. Opin. Behav. Sci. 19 (2018) 98-104, https://doi.org/10.1016/j. cobeha.2017.12.017.

[35] I.B. Mauss, M.D. Robinson, Measures of emotion: a review, Cognit. Emot. 23 (2) (2009) 209-237, https://doi.org/10.1080/02699930802204677.

[36] L.M. Mayo, J. Linde, H. Olausson, M. Heilig, I. Morrison, Putting a good face on touch: facial expression reflects the affective valence of caress-like touch across modalities, Biol. Psychol. 137 (2018) 83-90, https://doi.org/10.1016/j.biopsycho. 2018.07.001.

[37] F. McGlone, H. Olausson, J. Boyle, M. Jones-Gotman, C. Dancer, S. Guest, G. Essick, Touching and feeling: differences in pleasant touch processing between glabrous and hairy skin in humans, Eur. J. Ncurosci. 35 (11) (2012) 1782-1788,

[38] W. Mendes, Emotion and the Autonomic Nervous System, in: L.F. Barrett, M. Lewis, J.M Haviland-Jones (Eds.), Handbook of Emotions, Guilford Publications, 2016, pp. 166-181 4th ed..
[39] R.M. Montoya, R.S. Horton, J.L. Vevea, M. Citkowicz, E.A. Lauber, A re-examination of the mere exposure effect: the influence of repeated exposure on recognition, familiarity, and liking, Psychol. Bull. 143 (5) (2017) 459-498, https://doi.org/10. 1037/bul0000085.

[40] E. Page-Gould, Multilevel modeling, in: J.T. Cacioppo, L.G. Tassinary, G.G. Berntson (Eds.), The Handbook of Psychophysiology, Cambridge University Press, Cambridge, 2016, pp. 662-678 4th ed.

[41] R. Pawling, P.R. Cannon, F.P. McGlone, S.C. Walker, C-tactile afferent stimulating touch carries a positive affective value, PLoS ONE 12 (3) (2017) e0173457, , https://doi.org/10.1371/journal.pone.0173457.

[42] A. Ree, L.M. Mayo, S. Leknes, U. Sailer, Touch targeting C-tactile afferent fibers has a unique physiological pattern: a combined electrodermal and facial electromyography study, Biol. Psychol.. (2019), https://doi.org/10.1016/j.biopsycho. 2018.11.006.

[43] V. Russo, C. Ottaviani, G.F. Spitoni, Affective touch: a meta-analysis on sex differences, Neurosci. Biobehav. Rev 108 (2019) 445-452, https://doi.org/10.1016/j. neubiorev.2019.09.037.

[44] U. Sailer, C. Triscoli, G. Häggblad, P. Hamilton, H. Olausson, I. Croy, Temporal dynamics of brain activation during $40 \mathrm{~min}$ of pleasant touch, Neuroimage 139 (2016) 360-367, https://doi.org/10.1016/j.neuroimage.2016.06.031.

[45] G.R. Sandercock, P.D. Bromley, D.A. Brodie, Effects of exercise on heart rate variability: inferences from meta-analysis, Med. Sci. Sport. Exerc. 37 (3) (2005) 433-439, https://doi.org/10.1249/01.MSS.0000155388.39002.9D.

[46] L. Schilbach, B. Timmermans, V. Reddy, A. Costall, G. Bente, T. Schlicht, K. Vogeley, Toward a second-person neuroscience, Behav. Brain Sci. 36 (4) (2013) 393-414, https://doi.org/10.1017/s0140525x12000660.

[47] F. Shaffer, J.P. Ginsberg, An Overview of Heart Rate Variability Metrics and Norms, Front. Public Health 5 (2017) 258, https://doi.org/10.3389/fpubh.2017.00258.

[48] P.K. Stein, M.T. Hagley, P.L. Cole, P.P. Domitrovich, R.E. Kleiger, J.N. Rottman, Changes in 24-hour heart rate variability during normal pregnancy, Am. J. Obstet. Gynecol. 180 (4) (1999) 978-985 0.1016/S0002-9378(99)70670-8.

[49] T. Strauss, R. Kampe, J.P. Hamilton, H. Olausson, F. Rottstadt, C. Raue, I. Croy, Deactivation of default mode network during touch, Sci. Rep. 9 (1) (2019) 1293 https://doi.org/10.1038/s41598-018-37597-1.

[50] M.P. Tarvainen, J.P. Niskanen, J.A. Lipponen, P.O. Ranta-Aho, P.A. Karjalainen, Kubios HRV-heart rate variability analysis software, Comput. Method. Program. Biomed. 113 (1) (2014) 210-220, https://doi.org/10.1016/j.cmpb.2013.07.024.

[51] Task Force of the European Society of Cardiology and the North American Society of Pacing and Electrophysiology, Standards of measurement, physiological interpretation, and clinical use, Circulation 93 (5) (1996) 1043-1065.

52] L.G Tassinary, J.T. Cacioppo, E. Vanman, The Somatic System, in: J.T. Cacioppo, L.G. Tassinary, G.G. Berntson (Eds.), The Handbook of Psychophysiology, Cambridge University Press, Cambridge, 2016, pp. 151-182 4th ed.

[53] 3rd, J.F. Thayer, F. Ahs, M. Fredrikson, J.J. Sollers, T.D. Wager, A meta-analysis of heart rate variability and neuroimaging studies: implications for heart rate variability as a marker of stress and health, Neurosci. Biobehav. Rev. 36 (2) (2012) 747-756, https://doi.org/10.1016/j.neubiorev.2011.11.009.

[54] S.P. Tipper, D. Lloyd, B. Shorland, C. Dancer, L.A. Howard, F. McGlone, Vision influences tactile perception without proprioceptive orienting, Neuroreport 9 (8) (1998) 1741-1744, https://doi.org/10.1097/00001756-199806010-00013.

[55] C. Triscoli, R. Ackerley, U. Sailer, Touch satiety: differential effects of stroking velocity on liking and wanting touch over repetitions, PLoS ONE 9 (11) (2014) e113425, , https://doi.org/10.1371/journal.pone.0113425.

[56] C. Triscoli, I. Croy, H. Olausson, U. Sailer, Liking and wanting pleasant odors: different effects of repetitive exposure in men and women, Front. Psychol. 5 (2014) 526, https://doi.org/10.3389/fpsyg.2014.00526.

[57] C. Triscoli, I. Croy, H. Olausson, U. Sailer, Touch between romantic partners: being stroked is more pleasant than stroking and decelerates heart rate, Physiol. Behav. 177 (2017) 169-175, https://doi.org/10.1016/j.physbeh.2017.05.006.

[58] C. Triscoli, I. Croy, S. Steudte-Schmiedgen, H. Olausson, U. Sailer, Heart rate variability is enhanced by long-lasting pleasant touch at CT-optimized velocity, Biol. Psychol. 128 (2017) 71-81, https://doi.org/10.1016/j.biopsycho.2017.07. 007.

[59] E.J. Vanman, B.Y. Paul, T.A. Ito, N. Miller, The modern face of prejudice and structural features that moderate the effect of cooperation on affect, J. Pers. Soc. Psychol. 73 (5) (1997) 941-959.

[60] R.B. Wallace, F.J. Kohout, P.L. Colsher, Observations on interviews surveys of the oldest old, in: R.M. Suzman, D.P. Willis, K.G. Manton (Eds.), The Oldest Old, Oxford, New York, 1992, pp. 123-135 UP, 1992. Print.

[61] I. Wallrabenstein, J. Gerber, S. Rasche, I. Croy, S. Kurtenbach, T. Hummel, H. Hatt, The smelling of Hedione results in sex-differentiated human brain activity, Neuroimage 113 (2015) 365-373, https://doi.org/10.1016/j.neuroimage.2015.03. 029 .

[62] Westfall, J. (2016). PANGEA: power analysis for general anova designs. https:// jakewestfall.shinyapps.10/pangea/. Date last accessed 19.03.2020.

[63] J. Westfall, D.A. Kenny, C.M. Judd, Statistical power and optimal design in experiments in which samples of participants respond to samples of stimuli, J. Exper. Psychol. Gen. 143 (5) (2014) 2020-2045, https://doi.org/10.1037/xge0000014.

[64] M. Wijaya, D. Lau, S. Horrocks, F. McGlone, H. Ling, A. Schirmer, The human "feel" of touch contributes to its perceived pleasantness, J. Exp. Psychol. Hum. Percept. Perform. 46 (2) (2020) 155-171, https://doi.org/10.1037/xhp0000705.

[65] P. Winkielman, K.C. Berridge, Unconscious emotion, Curr. Dir. Psychol. Sci. 13 (3) (2004) 120-123, https://doi.org/10.1111/j.0963-7214.2004.00288.x.

[66] R.B. Zajonc, Attitudinal effects of mere exposure, J. Pers. Soc. Psychol. 9 (2, Pt.2) (1968) 1-27, https://doi.org/10.1037/h0025848.

[67] P. Zhou, B. Lock, T. $\Lambda$. Kuiken, Real time ECG artifact removal for myoclectric prosthesis control, Physiol. Meas. 28 (4) (2007) 397-413, https://doi.org/10.1088/ 0967-3334/28/4/006. 


\title{
Video Article \\ Using Facial Electromyography to Assess Facial Muscle Reactions to Experienced and Observed Affective Touch in Humans
}

\author{
Anbjørn Ree ${ }^{1}$, India Morrison ${ }^{2}$, Håkan Olausson ${ }^{2}$, Uta Sailer ${ }^{1}$, Markus Heilig ${ }^{2}$, Leah M. Mayo ${ }^{2}$ \\ ${ }^{1}$ Department of Behavioral Sciences in Medicine, Institute of Basic Medical Sciences, Faculty of Medicine, University of Oslo \\ ${ }^{2}$ Center for Social and Affective Neuroscience, Department of Clinical and Experimental Medicine, Linköping University
}

Correspondence to: Leah M. Mayo at leah.mayo@liu.se

URL: https://www.jove.com/video/59228

DOI: doi:10.3791/59228

Keywords: Behavior, Issue 145, facial electromyography, C-tactile afferents, affective touch, affect, emotion, corrugator

Date Published: 3/15/2019

Citation: Ree, A., Morrison, I., Olausson, H., Sailer, U., Heilig, M., Mayo, L.M. Using Facial Electromyography to Assess Facial Muscle Reactions to Experienced and Observed Affective Touch in Humans. J. Vis. Exp. (145), e59228, doi:10.3791/59228 (2019).

\section{Abstract}

"Affective" touch is believed to be processed in a manner distinct from discriminatory touch and to involve activation of C-tactile (CT) afferent fibers. Touch that optimally activates CT fibers is consistently rated as hedonically pleasant. Patient groups with impaired social-emotional functioning also show disordered affective touch ratings. However, relying on self-reported ratings of touch has many limitations, including recall bias and communication barriers. Here, we describe a methodological approach to study affective responses to touch via facial electromyography (EMG) that circumvents the reliance on self-report ratings. Facial EMG is an objective, quantitative, and non-invasive method to measure facial muscle activity indicative of affective responses. Responses can be assessed across healthy and patient populations without the need for verbal communication. Here, we provide two separate datasets demonstrating that CT-optimal and non-optimal touch elicit distinct facial muscle reactions. Moreover, facial EMG responses are consistent across stimulus modalities, e.g. tactile (experienced touch) and visual (observed touch). Finally, the temporal resolution of facial EMG can detect responses on timescales that supersede that of verbal reporting. Together, our data suggest that facial EMG is a suitable methodology for use in affective tactile research that can be used to supplement, or in some cases, supplant, existing measures.

\section{Video Link}

The video component of this article can be found at https://www.jove.com/video/59228/

Introduction

C-tactile (CT) afferents are proposed to convey the affective component of touch, which can be distinguished from the discriminative aspects of touch processed via $A \beta$ fibers ${ }^{1,2}$. CT-mediated affective touch is believed to play an integral role in social affiliative behaviors ${ }^{3}$, leading to the "skin as a social organ" hypothesis ${ }^{4}$. Physical ${ }^{5,6}$, developmental ${ }^{7}$, and psychiatric ${ }^{8,9}$ factors can influence CT-mediated touch processing. Thus, establishing an objective measure to quantify affective reactions to CT-relevant touch is critical to allow for comparisons across populations.

In recent years, much insight has been gained regarding the characteristics of CT afferents. These unmyelinated afferents demonstrate an inverted U-shaped firing frequency, with velocities of 1-10 $\mathrm{cm} / \mathrm{s}$ ("CT-optimal") eliciting the greatest frequency and both greater ("fast nonoptimal") or lesser ("slow non-optimal") velocities eliciting reduced firing ${ }^{10}$. CT firing frequency correlates with self-reported ratings of touch "pleasantness", producing a similar inverted U-shaped curve in pleasantness ratings ${ }^{10}$. Moreover, CT-afferents also respond most robustly to stimuli close to skin temperature ${ }^{11}$. These fibers also show distinct conduction speeds. The unmyelinated CT afferents are slower ${ }^{2}$ and thus the volley of afferent input to the cortex shows a temporal lag when compared to the speed of the faster, myelinated $A \beta$ fibers ${ }^{1,12}$. Affective and discriminative touch can also be distinguished on a neural level. While both types of touch activate overlapping somatosensory areas, affective touch is more likely to activate the posterior insula, while discriminative touch activates sensorimotor areas ${ }^{13,14,15,16}$. This activation pattern is consistent whether the touch is directly experienced or merely observed ${ }^{17}$, suggesting that affective touch is not just a "bottom-up" process driven by physical activation of CT afferents, but also involves "top-down" integration of multimodal sensory processing.

Situations in which CT processing is deficient or otherwise atypical has also provided insight into the functional significance of these afferents. In a unique patient group with a heritable mutation affecting the nerve growth factor $\beta$ gene, there is a reduction in the density of thin and unmyelinated nerve fibers, including CT afferents. Compared to healthy controls, these patients report touch at CT-optimal velocities as less pleasant ${ }^{5}$. The converse scenario is also true; patients who lack myelinated $A \beta$ fibers are able to retain a faint sensation of pleasant touch carried by the still intact CT afferents ${ }^{6}$. Abnormal affective touch processing is not just confined to instances of physical changes in CT-afferents. Across patient and healthy populations, those higher on the spectrum of autistic traits reported reduced pleasantness ratings of touch ${ }^{8}$. Psychiatric patients also demonstrate reduced hedonic ratings of affective touch, with a history of childhood maltreatment as one of the most consistent predictors of dysregulated affective touch awareness ${ }^{8}$. Dysregulation in the CT-based affective touch system in anorexia nervosa has also been reported ${ }^{9}$. Thus, both physical and psychological factors can influence affective touch processing, and as such, it is imperative to establish methodologies that can be applied to all individuals in an equitable and comparable manner. 
Insights into normo-typical and dysregulated affective processing have the opportunity to provide a more nuanced picture of many patient groups. However, one potential limitation of affective touch research is the necessity of self-reported ratings. At times, self-report can be unreliable ${ }^{18}$ and subject to recall bias ${ }^{19}$. Inquiries of self-report can psychologically remove a participant from the current setting, limiting the ecological validity of the responses and removing them temporally from the experience ${ }^{20}$. Moreover, self-report relies on a firm understanding of language and semantics, making cross-cultural and developmentally diverse (e.g. infant and toddler-aged individuals) comparisons challenging. For instance, individuals with an autism spectrum diagnosis frequently show distinct behavioral responses to touch ${ }^{21}$, but can also have difficulties in communicating verbally ${ }^{22}$. Thus, finding non-invasive methods to measure responses to touch that circumvent a reliance on selfreport may translate, at least, to a better understanding of the mechanisms of affective touch, and at most, novel insights into dysregulation of social processing in patient populations.

Facial electromyography (EMG) is a suitable candidate to objectively assess affective responses to touch. It has been used to measure valencespecific reactions to visual ${ }^{23}$, audio-visual ${ }^{24}$, olfactory ${ }^{25}$, and gustatory ${ }^{26}$ stimuli. Facial EMG is a safe and non-invasive method consisting of surface electrodes that adhere to the face ${ }^{27}$. These surface electrodes record facial muscle activity continuously in real-time with time scale sensitivity in the tens of milliseconds. Of particular interest is the corrugator supercilii ("corrugator"), which is activated when furrowing the brow and relaxes during a smile. As a result, corrugator activity has a linear relationship with affective valence, with increased response to negative stimuli and decreased activity in response to positive stimuli ${ }^{28}$. In addition, the zygomaticus major ("zygomatic") is the muscle activated as the corners of the mouth pull up into a smile. The zygomatic displays a "J-shaped" activation pattern with positive stimuli eliciting the greatest response, and the most negative stimuli eliciting a greater response than neutral stimuli ${ }^{28}$. Facial EMG recordings of these muscles can even be observed when stimuli are presented outside conscious awareness or when individuals are explicitly trying to suppress their reactions ${ }^{29,30}$. Importantly, facial EMG can be used alone or in combination with self-report ratings or other physiological recordings. Thus, it is an ideal methodology to assess affective reactions to tactile stimulation ${ }^{31,32}$.

In sum, facial EMG can be combined with self-report ratings to determine how CT-optimal tactile stimulation influences facial muscle activity as a potential indicator of affective response. One can take advantage of the velocity-dependent firing frequency of CTs to apply touch at CToptimal and non-optimal velocities, and touch can be applied both to the CT-rich arm and the putatively CT-lacking palm. Comparisons can be made across modalities to determine whether affective responses to touch require direct stimulation or can be elicited via mere observation, suggestive of shared processing across sensory modalities. Finally, upon establishing facial EMG as a suitable methodology to study affective reactions to affective touch, researchers can then explore how affective touch processing may be influenced by various interventions (e.g., drug administration; stress exposure), how it changes throughout development ${ }^{7}$, how it is influenced by the relationship of the interactants ${ }^{33}$, and whether it is dysregulated in clinical populations ${ }^{8}$.

\section{Protocol}

This protocol is based on Mayo et al. ${ }^{31}$ (Experiment 1 ) and Ree et al. ${ }^{32}$ (Experiment 2). Ethical approval was granted by the Regional Ethical Review Board, Linköping, Sweden (Experiment 1) and the local ethical committee at the Department of Psychology, University of Oslo, Norway (Experiment 2).

\section{Participant Screening and Preparation}

1. Recruit participants who lack tactile or uncorrected visual disturbances and are free of any neurological or psychiatric disorder, unless a specific patient population is being recruited.

2. Ensure that participants are fully able to understand task instructions (e.g., fluent in the language that tasks are administered).

3. If including more than one task (e.g. Experienced, Observed), ensure that task order is counterbalanced across participants, stratifying for gender, age, or other distinguishing factors.

\section{Stimuli and Task Construction}

NOTE: See Table 1 for experimental design.

1. Experienced touch task (Experiments 1 and 2)

1. Create trials such that they consist of a baseline period, touch administration, and self-report ratings, all separated by jittered ITIs.

1. Baseline periods consist of a blank screen, fixation cross, or other neutral scene prior to tactile stimulation.

2. Tactile stimulation is followed by a short (e.g. 1-2 s) ITI, then self-report ratings are obtained.

3. A jittered inter-trial interval (ITI; e.g. 6-7 s) follows self-report ratings to allow muscle activity to return to baseline levels before the next trial begins.

2. Use either audio (Experiment $1^{31}$ ) or visual (Experiment $2^{32}$ ) cues to ensure that touch is delivered at the appropriate velocity.

1. To use audio cues, have cues delivered to headphones worn by the experimenter to track the pace of the stimulation using a metronome. Distinguish velocities using tones of differing pitches (or other distinguishing audio cue, e.g., a cue saying "10 cm/s") that precede the stimulation cues.

2. To use visual cues, display cues on a tablet only in view of the experimenter. Use a moving bar to track velocity of touch administration.

3. Prior to the start of the study, practice to ensure that touch is delivered at the appropriate velocity and a consistent pressure. To do so, apply brushstrokes to the scale in a similar manner as to the participant. The scale readout is used to determine if the pressure changes throughout touch administration. For instance, a pressure of $0.4 \mathrm{~N}$ would read as $40 \mathrm{~g}$ on the scale.

2. Observed touch task (Experiment 1)

1. Ensure that videos of touch administration are of similar length, regardless of velocity. 
1. Include both CT-optimal $(1-10 \mathrm{~cm} / \mathrm{s})$ and non-optimal (less than $1 \mathrm{~cm} / \mathrm{s}$ or more than $10 \mathrm{~cm} / \mathrm{s}$ ) velocities.

2. Start trials with a fixation cross or other neutral condition followed by video.

NOTE: Videos contain touch delivered to CT-rich hairy skin (arm), CT-lacking glabrous skin (palm), and a non-social condition in which touch is delivered to a fake wooden arm (Fig. 2; see supplemental videos).

1. After a 1-2 s ITI, obtain self-report ratings.

2. Allow another 6-7 ITI following ratings to precede the next trial to allow EMG activity to return to baseline.

\section{Facial Electromyography}

1. Data acquisition and filtering guidelines (based on previous protocols ${ }^{27,34}$ )

1. Use software to apply filtering steps either in real-time or offline. Typical filtering steps include a comb band stop filter to filter out potential noise from AC power $(50 / 60 \mathrm{~Hz})$, followed by smoothing and rectification.

NOTE: Initial basic filtering steps may be set on EMG amplifiers (e.g., a high pass filter of $10 \mathrm{~Hz}$ and a low pass filter of $500 \mathrm{~Hz}$ or $1,000 \mathrm{~Hz})$.

2. Electrode application (based on previous protocols ${ }^{27,34}$ )

1. Briefly describe the application process to the participant. Use neutral words ("sensor") instead of potentially anxiety-evoking words ("electrode") ${ }^{34}$.

1. Decide what information to tell the participants regarding the purpose of the sensors.

NOTE: In the current studies, participants were told sensors would measure muscle and sweat activity during the session.

2. Clean the participants' skin prior to electrode application.

1. Use water to wipe clean the areas in which sensors will be applied.

2. Use an exfoliant scrub to lightly abrade the same areas. Use caution to prevent major skin irritation, though minor irritation is likely to occur.

3. Use electrode pairs consisting of two $4 \mathrm{~mm}$ shielded bipolar recording electrodes plus one monopolar reference electrode.

1. Apply adhesive collars to the electrodes such that they adhere to the skin.

2. Once collars adhere to the outer rim of the electrodes, fill sensors with a conductive electrode gel, taking care to prevent the formation of air bubbles.

4. Place electrode pairs parallel to the muscle(s) of interest and perpendicular to potential sources of noise, such as other muscles ${ }^{34}$.

1. Corrugator: Affix one electrode directly above the eyebrow along an imaginary vertical line that traverses the inner corner of the eye. Place the second electrode $1 \mathrm{~cm}$ lateral and slightly superior to the first, along the border of the eyebrow.

2. Zygomatic: Place the first sensor midway along an imaginary line that connects the upper ear (where the ear meets the skull) and the corner of the mouth. Place the second electrode $1 \mathrm{~cm}$ medial (towards the mouth). Take care to avoid the masseter muscle.

3. Use an $8 \mathrm{~mm}$ unshielded, monopolar recording electrode as a reference electrode. Place the electrode in the middle of the forehead, equidistant (above) the inner brows and (below) the hairline.

4. Ensure that electrode wires are placed such that they do not impede vision. Use medical tape to ensure long-term adherence of the electrodes to skin and reduce noise/artifacts due to cord movement.

5. Determine the quality of electrode application with an impedance monitor. Acceptable impedance levels are below $20 \mathrm{k} \Omega$. If electrodes need to be reapplied to reach appropriate impedance levels, use a clean pair of electrodes.

\section{Task Procedure}

1. General order

1. Following sensor application, complete task(s). If using more than one task, counterbalance order across participants.

2. Ensure that participants are seated comfortably to minimize extraneous movement that may introduce movement artifacts ${ }^{34}$

2. Experienced touch task

1. Seat participants in front of computer with the to-be-touched arm extended laterally, resting comfortably (e.g., on a cushion). NOTE: It is recommended to apply touch to the arm that is not being used for self-reported ratings in order to minimize potential movement artifacts in the EMG signal.

2. Occlude view of the arm from the participant either using a curtain separator ${ }^{31}$ or goggles that occlude lateral vision (Figure $\left.1^{32}\right)^{35}$.

3. Instruct the participant to focus on how the touch makes them feel.

4. Vary touch location to avoid CT fatigue ${ }^{36}$.

5. Administer touch using a $75 \mathrm{~mm}$ goat hair brush applied to designated section(s) marked on the arm (and palm). Alternatively, apply touch using a force-controlled robot ${ }^{37}$.

6. Use consistent touch administration direction, e.g., back-and-forth (distal-to-proximal, then proximal to distal) or single direction (proximal-to-distal only)

3. Observed touch task

1. Seat participant in front of the computer that will display the videos.

2. Instruct the participant that they will have to rate how the video made them feel. 
3. Ensure that the participant is out of view of the experimenter ${ }^{34}$.

\section{Data Cleaning and Analysis}

1. To assess the mean EMG activation to a specific touch stimulus type, compare the response to the touch stimulus to the preceding baseline, i.e. [mean activation during $6 \mathrm{~s}$ touch stimulation] - [mean activation during $1 \mathrm{~s}$ prestimulus "baseline"], as suggested by Fridlund and Cacioppo ${ }^{34}$.

1. Average responses for each touch stimulus type (CT-optimal, non-optimal and, if appropriate, each location (arm/palm)

2. Do this for each muscle (corrugator, zygomatic) and self-report rating (pleasantness, intensity) individually.

2. To obtain a more sensitive time course, compute mean EMG activation during smaller time intervals (e.g., 700 ms; see Figure $5^{32}$ ). Subtract the same $1 \mathrm{~s}$ baseline from all intervals to remove baseline EMG activity.

NOTE: Prior to analysis, it is recommended to have data manually checked by raters blinded to touch conditions to eliminate trials with artifactual activations ${ }^{34}$.

\section{Representative Results}

\section{CT-optimal touch elicits distinct EMG responses compared to fast non-optimal touch across modalities}

The first experiment addressed whether differential EMG reactivity could be detected in response to CT-optimal $(3 \mathrm{~cm} / \mathrm{s})$ and fast non-optimal $(30$ $\mathrm{cm} / \mathrm{s}$ ) tactile stimulation that was directly experienced (Figure 3) or merely observed (Figure 2 and Figure 3$)^{31}$.

Experienced CT-optimal touch was rated as more pleasant than non-optimal touch $(F(1,28)=32.2 ; p<0.001$; Figure 3A) regardless of touch location ( $p=0.063$; velocity $\times$ location: $p=0.32$ ). Similarly, observed CT-optimal touch was rated as more pleasant that non-optimal touch (touch velocity: $F(1,28)=47.5 ; p<0.001$; touch type: $F(2,56)=6.09, p=0.004$; type $\times$ velocity interaction $F(2,56)=5.87, p=0.005)$. CT-optimal touch to the arm was rated as more pleasant than touch to the palm $(p=0.024)$ and non-social touch (e.g., touch to the wooden arm; $p=0.001)$. Fast non-optimal touch was always rated as more intense (Figure 3B), regardless of whether the touch was experienced (touch velocity: $F(1,28)=$ $34.3, p<0.001$; touch location: $p=0.28$; velocity $\mathrm{x}$ location interaction: $p=0.64$ ) or observed (touch velocity: $F(1,28)=35.1, p<0.001 ;$ touch type: $p=0.40$; velocity $\times$ type interaction: $p=0.39$ ).

Experienced fast, non-optimal touch elicited robust corrugator reactivity that was mitigated by recruitment of CT-afferents during CT-optimal touch (effect of touch velocity: $F(1,28)=4.84, p=0.036$; effect of touch location: $p=0.93$; touch velocity $\mathrm{x}$ location interaction: $p=0.42$; Figure 3C). Corrugator response significantly differed between CT-optimal and non-optimal touch for touch to the arm $(p=0.050)$ but only trend level effects were seen for touch to the palm $(p=0.092)$. There was no main effect of touch velocity $(p=0.11)$ or type $(p=0.79)$ on corrugator reactivity to observed touch, but there was a touch velocity $\mathrm{x}$ type interaction $(F(2,56)=3.80, p=0.028)$. Post hoc tests revealed that fast nonoptimal touch elicited greater corrugator reactivity than CT-optimal touch particularly for videos of touch to the arm $(p=0.007)$, but not touch to the palm $(p=0.13)$ or non-social touch $(p=0.25)$. Zygomatic activity was not significantly affected by experienced touch (effect of touch velocity: $p=0.15$; effect of touch type: $p=0.73$; touch velocity $\times$ type interaction: $p=0.63$; Figure 3D), nor observed touch (main effect of touch velocity: $p$ $=0.37$; main effect of touch type: $p=0.84$; touch velocity $\mathrm{x}$ type interaction: $p=0.23$ ).

\section{CT-optimal touch elicits EMG responses distinct from slow non-optimal touch}

Experiment 2 assessed whether slow non-optimal $(0.3 \mathrm{~cm} / \mathrm{s})$ would elicit similar responses as fast non-optimal $(30 \mathrm{~cm} / \mathrm{s})^{32}$. We found that slow non-optimal touch was rated as less pleasant (Figure 4A) and less intense (Figure 4B) than CT-optimal touch. Similar to fast non-optimal touch, slow non-optimal touch elicited robust corrugator activitythat was attenuated by CT-optimal touch (effect of touch velocity: $F(1,83)=9.723, p=$ 0.002 ; Figure $4 \mathrm{C})$. There was no effect of touch on zygomatic activity ( $p=0.35$; Figure 4D).

We next assessed the time course of EMG responses. During the first $700 \mathrm{~ms}$, a window putatively free of CT input, there was no difference in corrugator reactivity $\left(-0.031 \pm 0.06 \mu \mathrm{V}\right.$ and $-0.017 \pm 0.49 \mu \mathrm{V}, p_{B o n}=0.98$; Figure $\left.5 \mathrm{~A}\right)$. However, over the next $5.6 \mathrm{~s}$, corrugator reactivity in response to CT optimal touch decreased gradually, whereas it gradually increased in response to slow non-optimal touch: during interval 2 , the corrugator reactivity was marginally lower for $C T$ optimal touch than non-optimal touch $\left(p_{B o n}=0.071\right)$. During intervals $3,5,6,7$ and 8 , the corrugator reactivity was significantly lower during CT optimal touch than during non-optimal touch $\left(p_{B o n}<0.034\right.$; Figure $\left.5 \mathrm{~A}\right)$. This pattern was absent in analysis of zygomatic reactivity $(p=0.83$; Figure 5 B) 


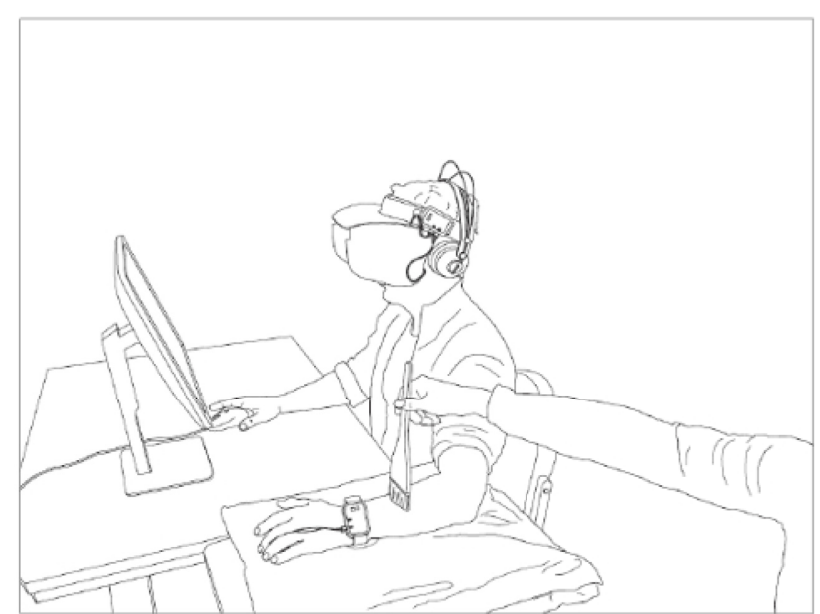

Figure 1: Example of experimental setup for the Experienced Touch task. Seat the participant in front of the computer with their arm extended laterally, comfortably resting on a cushion. If obtaining self-report ratings, it is recommended to apply touch to the arm that is not used to provide ratings to avoid potential movement artifacts from contaminating the EMG signal. The arm should be occluded from view of the participant ${ }^{35,39}$, either with customized glasses, as above, or using a curtain separator. This figure is adapted from Ree et al. ${ }^{32}$ Please click here to view a larger version of this figure.
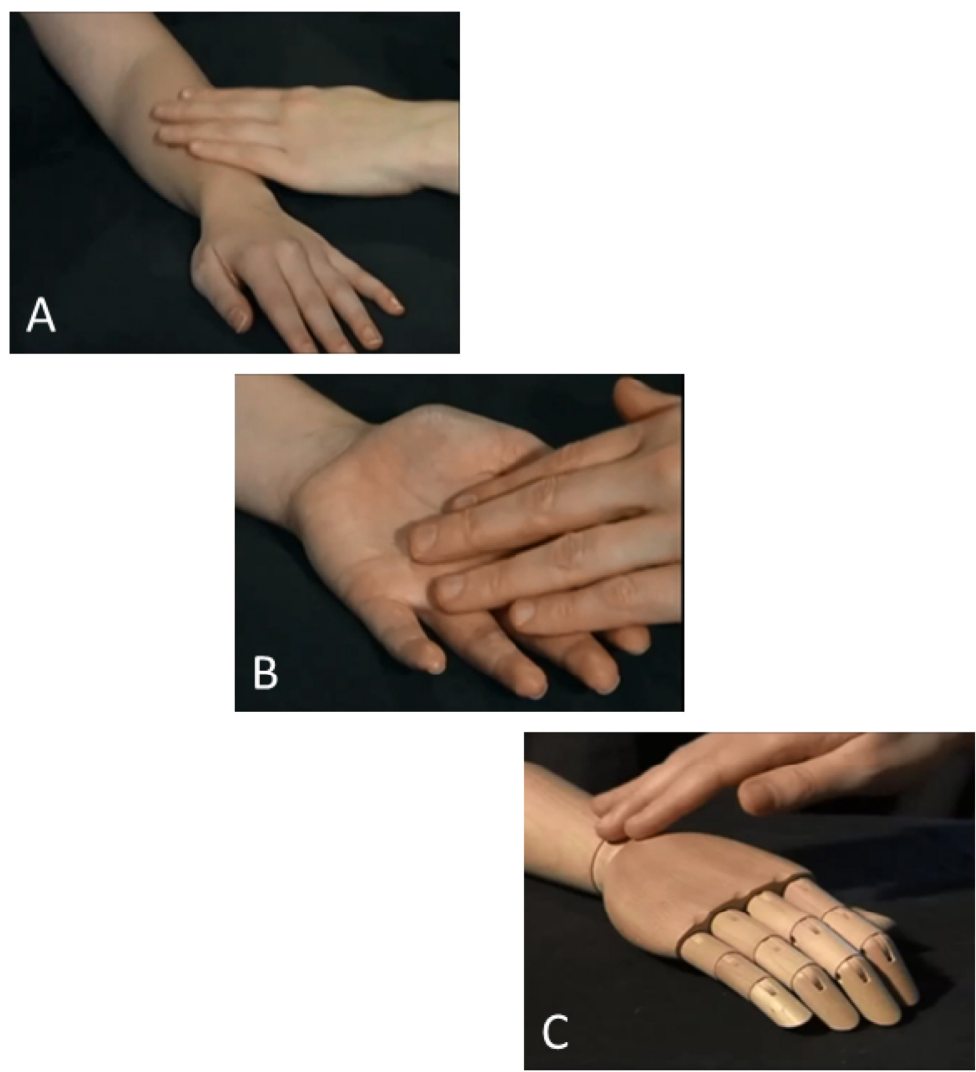

Figure 2: Example of touch stimuli used in the Observed Touch task. The observed touch task included $6 \mathrm{~s}$ videos of touch to the (A) CTrich arm, (B) CT-lacking palm, and (C) non-social touch to a wooden arm. Please click here to view a larger version of this figure. 

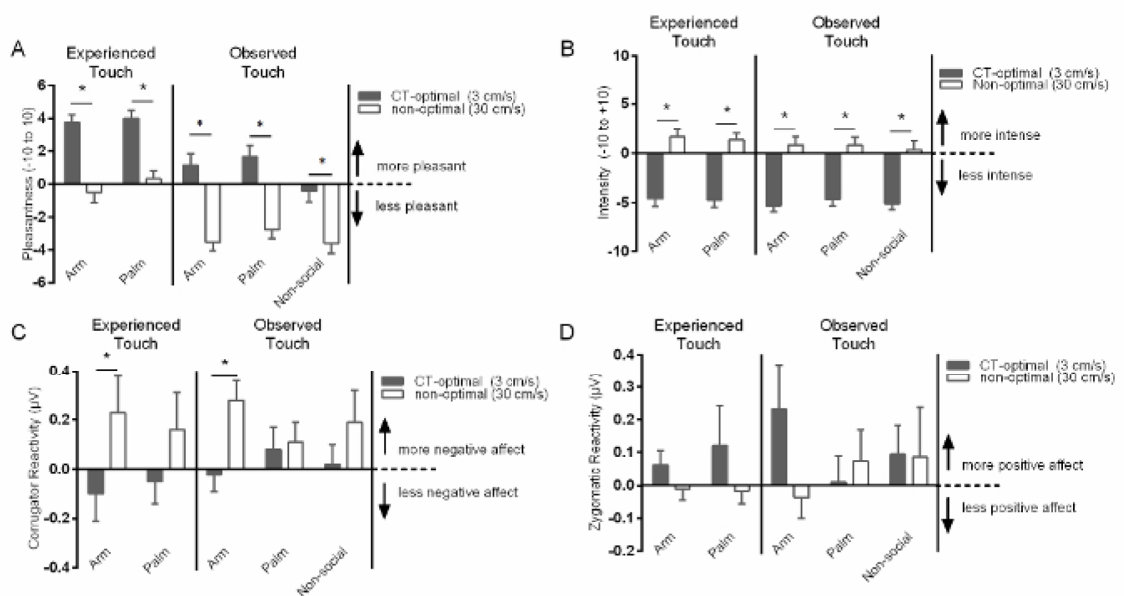

Figure 3: CT-optimal touch elicits distinct responses compared to fast non-optimal touch across modalities. (A) CT-optimal touch (3 cm/ s) is consistently rated as more pleasant than fast non-optimal touch $(30 \mathrm{~cm} / \mathrm{s})$ across both tasks. Experienced touch is rated as most pleasant, followed by social (arm, palm) observed touch, then non-social touch (e.g. touch to a wooden arm). (B) CT-optimal touch is $(3 \mathrm{~cm} / \mathrm{s})$ rated as less intense across modalities, regardless of modality or social content. (C) Fast non-optimal touch $(30 \mathrm{~cm} / \mathrm{s})$ elicits more corrugator reactivity than CT-optimal touch $(3 \mathrm{~cm} / \mathrm{s})$. This difference is most robust for touch to the CT-rich arm. (D) CT-optimal touch $(3 \mathrm{~cm} / \mathrm{s}) \mathrm{marginally}$ increases zygomatic reactivity, though this does not reach significance for any modality or location. Bars and errors bars represent mean and standard error of the mean; ${ }^{*} p<0.05$ effect of velocity. This figure is adapted from Mayo et al. ${ }^{31}$ Please click here to view a larger version of this figure.
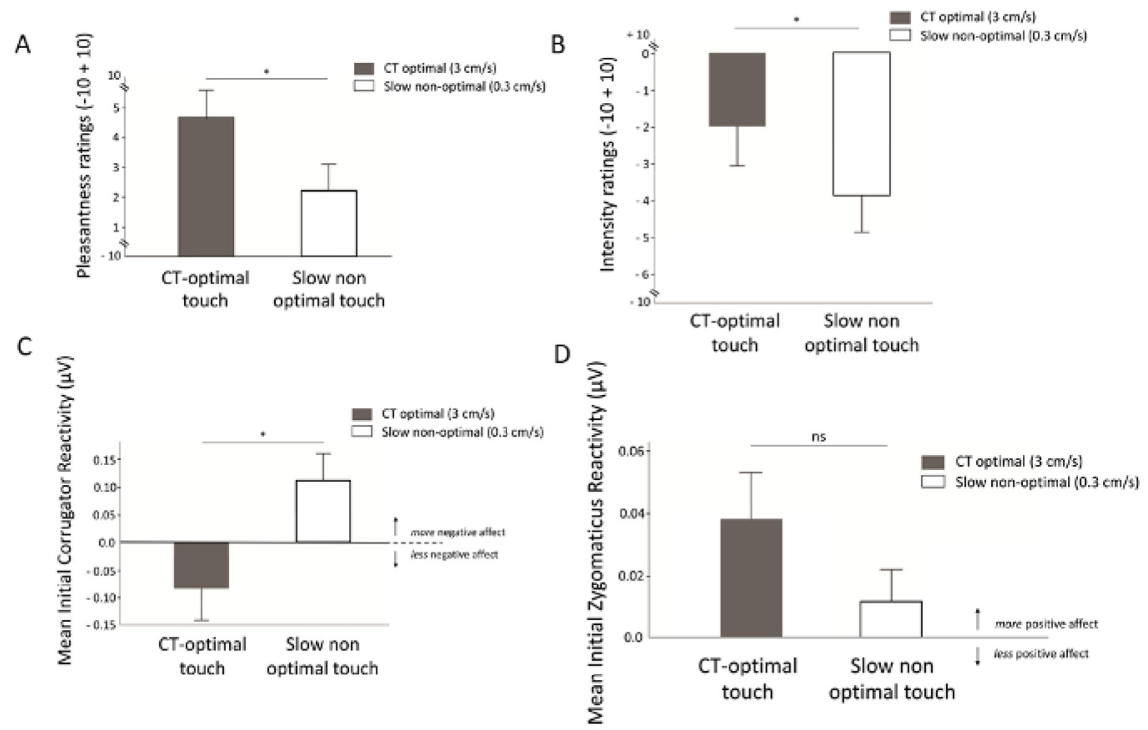

Figure 4: CT-optimal touch $(3 \mathrm{~cm} / \mathrm{s})$ elicits distinct responses as compared to slow non-optimal touch (0.3 cm/s). (A) CT-optimal touch (3 $\mathrm{cm} / \mathrm{s})$ is rated as more pleasant than slow non-optimal touch $(0.3 \mathrm{~cm} / \mathrm{s})$. (B) CT-optimal touch $(3 \mathrm{~cm} / \mathrm{s})$ is rated as more intense than slow nonoptimal touch $(0.3 \mathrm{~cm} / \mathrm{s})$. (C) Mean corrugator reactivity in response to CT-optimal $(3 \mathrm{~cm} / \mathrm{s})$ is reduced compared to slow non-optimal $(0.3 \mathrm{~cm} / \mathrm{s})$. (D) Touch does not significantly influence zygomatic reactivity. Bars and error bars represent means and standard error of the mean; ${ }^{*} p<0.05$. This figure is adapted from Ree et al. ${ }^{32}$ Please click here to view a larger version of this figure. 

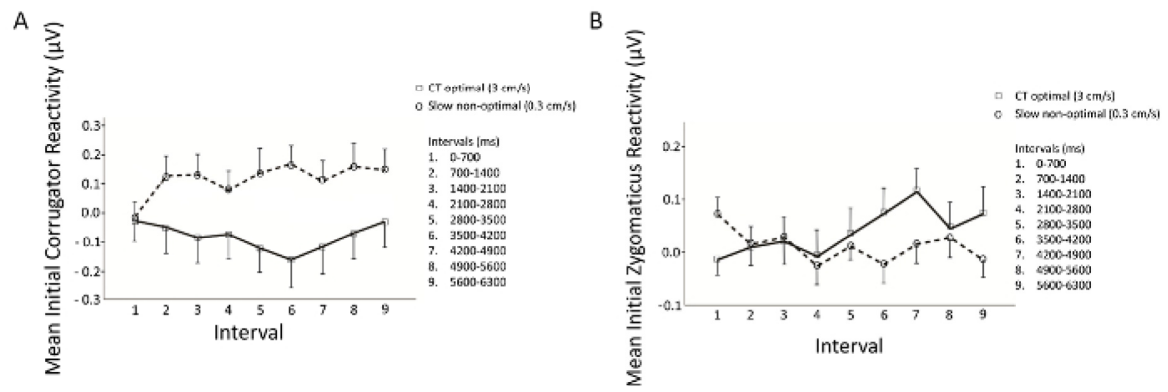

Figure 5: Corrugator responses to CT-optimal touch are temporally specific. (A) When binned in intervals of $700 \mathrm{ms,} \mathrm{CT-optimal} \mathrm{touch}$ elicits significantly less corrugator reactivity. The exception is in the first $700 \mathrm{~ms}$, which is putatively free of CT input due to the slower conduction velocity of these unmyelinated afferents. (B) Zygomatic reactivity is not significantly different in response to optimal or slow non-optimal touch at any of the time points. Dots represent means and bars represent standard errors of the mean. This figure is adapted from Ree et al. ${ }^{32}$ Please click here to view a larger version of this figure.

\begin{tabular}{|c|c|c|c|c|c|c|}
\hline \multirow[b]{3}{*}{ Experiment 1} & \multirow{2}{*}{$\begin{array}{l}\text { Study N } \\
(M / F)\end{array}$} & \multicolumn{2}{|c|}{ Velocity } & \multirow{2}{*}{$\begin{array}{c}\text { Touch } \\
\text { Location/Type }\end{array}$} & \multirow{2}{*}{$\begin{array}{c}\text { Touch } \\
\text { Duration }\end{array}$} & \multirow{2}{*}{$\begin{array}{l}\text { Number of } \\
\text { repetitions }\end{array}$} \\
\hline & & Cr-optimal & $\begin{array}{c}\text { Non- } \\
\text { optimal }\end{array}$ & & & \\
\hline & & & & & & \\
\hline Experienced Touch & $30(17 / 13)$ & $3 \mathrm{~cm} / \mathrm{s}$ & $30 \mathrm{~cm} / \mathrm{s}$ & Arm, palm & $6 \mathrm{sec}$ & $\begin{array}{c}8 \times \text { velocity, location } \\
\text { (32 total) }\end{array}$ \\
\hline Observed Touch & $30(17 / 13)$ & $3 \mathrm{~cm} / \mathrm{s}$ & $30 \mathrm{~cm} / \mathrm{s}$ & $\begin{array}{l}\text { Arm, palm, non- } \\
\text { social }\end{array}$ & $6 \mathrm{sec}$ & $\begin{array}{c}4 \times \text { location, type } \\
\text { total) }\end{array}$ \\
\hline Experiment 2 & & & & & & \\
\hline Experienced Touch & $\begin{array}{c}44 \\
(17 / 27)\end{array}$ & $3 \mathrm{~cm} / \mathrm{s}$ & $0.3 \mathrm{~cm} / \mathrm{s}$ & Arm & $\begin{array}{l}6.3 \mathrm{sec} \\
\text { (of } 2 \mathrm{~min} \text { ) }\end{array}$ & $\begin{array}{c}2 \times \text { velocity } \\
\text { total) }\end{array}$ \\
\hline
\end{tabular}

Table 1: Summary of Experimental Designs. In the Experienced Touch task of Experiment 1, touch was delivered at CT-optimal ( $3 \mathrm{~cm} / \mathrm{s})$ or fast non-optimal $(30 \mathrm{~cm} / \mathrm{s})$ velocities to hairy $(\mathrm{arm})$ and glabrous (palm) skin. The Observed Touch instead included videos of touch delivered to the arm, palm, or to a wooden arm (e.g., non-social) at the same touch velocities. The "non-social" condition was included to control for potential responses elicited by low-level periodicity information encoded in the movement ${ }^{17}$, and determine the relevance of social content ${ }^{38}$ on ratings and EMG responses. Results were analyzed using repeated measures analysis of variance (ANOVA) with touch velocity and touch type as within-subjects factors. A post-hoc power analysis based on Experiment 1 suggests at least 22 individuals should be included to achieve similar effects. In Experiment 2, touch was delivered to the arm at CT-optimal $(3 \mathrm{~cm} / \mathrm{s})$ or slow non-optimal $(0.3 \mathrm{~cm} / \mathrm{s})$ velocities. Touch was delivered for a total of $2 \mathrm{~min}$, but here we only report on the first $6.3 \mathrm{~s}$ in order to compare results to Experiment 1 . Each velocity was repeated twice. In all experiments, self-reported ratings of the affective quality (e.g., pleasantness) and discriminative aspects (e.g., intensity) were assessed ${ }^{10}$.

\section{Discussion}

Here, we report on the use of facial electromyography (EMG) as a method to study affective responses to observed and experienced touch Previously, many studies have focused on the use of self-report ratings to characterize the affective quality of touch. Touch that optimally activates CT afferents (e.g., $1-10 \mathrm{~cm} / \mathrm{s}$ ) is consistently rated as more pleasant than either faster or slower touch velocities ${ }^{10}$. In contrast, ratings of intensity seem to track with velocity, with faster touch velocities rated as more intense, likely mediated via $A \beta$ fibers ${ }^{37}$. Using two separate datasets, we show that both fast and slow non-optimal touch elicit robust corrugator reactivity that is attenuated during CT-optimal touch. Thus, we find that touch that is rated as less pleasant (e.g., non-optimal touch) also increases corrugator activity, suggestive of enhanced negative affect. In addition, we find that responses are similar across modalities. That is, both observed and experienced touch elicit similar facial muscle activity. In both modalities, these effects were only significant for touch to the arm, and not the palm or a wooden arm. Thus, while self-reported ratings of experienced and observed affective touch are similar regardless of location (arm, palm), facial EMG only significantly differentiates between touch velocities applied to the CT-rich arm, and not the CT-fiber-lacking palm.

The results further show that the temporal sensitivity of facial EMG yields insight into emotional processing that cannot be obtained solely by selfreport. Namely, we found that corrugator reactivity to CT-optimal touch becomes evident at a timescale that coincides with known conduction velocities of CT afferents ${ }^{1,12}$. Thus, in the initial $700 \mathrm{~ms}$ of touch, which are believed to be dominated by A $\beta$ activation, there is no difference in EMG activation between the two touch velocities. However, the distinction between CT-optimal and non-optimal touch becomes evident following the first $700 \mathrm{~ms}$, consistent with the previously reported temporal time lag of CT-afferents ${ }^{2,12}$. Hence, facial EMG is able to detect changes in affective responses to touch that occur with a temporal specificity that is likely inaccessible via verbal reporting

Across both studies, we find that CT-optimal and non-optimal touch can be distinguished via corrugator activity. However, we did not find an effect of touch on zygomatic reactivity, which is in contrast to previous reports ${ }^{40}$. One potential reason for the discrepancies between the current data and previous findings include methodological differences such as inclusion of a post-touch period in the analysis. Thus, we stress the importance of methodological considerations such as the length of the touch stimulation and inter-trial intervals when designing these experiments.

There are several factors that should be considered when assessing affective reactions to touch. One potential area of concern is the gender of the experimenter (and thus, toucher) to that of the participant, as well as the relationship, if any, between the two ${ }^{41}$. Moreover, one should ensure that participants are precluded from viewing the experimenter and touch application, as visual processing of touch can influence the perception of touch ${ }^{35,39}$. There are also concerns to weigh during task design. For instance, it is important to consider the potential for order effects, both in 
regards to touch stimuli presentation (e.g. discussed in ${ }^{42}$ ) or touch location ${ }^{43}$. If several touch repetitions are used, one may want to vary touch location to avoid CT fatigue ${ }^{36}$. Here, we used a brush to apply touch to compare to previous studies ${ }^{17}$, though it is possible that EMG responses may be different using more ecologically valid methods (e.g., touch by hand).

While we believe the use of facial EMG will be of a great benefit to the field of affective touch, there are limitations to this methodology that warrant consideration. Training is required to learn how to apply the electrodes correctly, producing an increased burden on the experimenter on the outset of experimental planning. Excessive movement, talking, or other environmental factors present during the experiment may cause artifacts in the EMG signal, thus constraining some experimental design features. Moreover, the application of electrodes to the face may elicit an attempt to discern the purpose of the study. As such, one must consider what information to tell the participant regarding not only the purpose of the experiment, but also the use of the electrodes during the experiment. In the current experiments, the participants were told that the purpose of the study was the investigate decision-making and perceptions of various sensations ${ }^{32}$ or reactions to social interactions ${ }^{31}$. In both cases, participants were told that the electrodes would measure sweat and muscle activity and were fully debriefed following the conclusion of the experiment. These concerns and others are addressed thoroughly in Fridlund and Cacioppo $1986^{34}$.

In sum, we demonstrate that facial EMG is a reliable, robust, and informative method to assess the affective valence of tactile stimulation. This method provides a means to implicitly assess responses to tactile stimulation independent of verbal reports, paving the way for studies in infants and young children, cross-cultural comparisons, investigations of clinical conditions, and other situations in which semantics and language may otherwise preclude scientific exploration.

\section{Disclosures}

The authors have nothing to disclose

\section{Acknowledgments}

The authors are grateful to Dr. Margaret Wardle for her exceptional training and technical assistance. This work was funded in part by Swedish Research Council grant FYF-2013-687 (IM).

\section{References}

1. Abraira, V. E., Ginty, D. D. The sensory neurons of touch. Neuron. 79 (4), 618-639 (2013).

2. Olausson, H., Wessberg, J., Morrison, I., McGlone, F., Vallbo, A. The neurophysiology of unmyelinated tactile afferents. Neuroscience and Biobehavioral Reviews. 34 (2), 185-191 (2010).

3. Gallace, A., Spence, C. The science of interpersonal touch: an overview. Neuroscience and BiobehavioralReviews. 34 (2), $246-259$ (2010).

4. Morrison, I., Loken, L. S., Olausson, H. The skin as a social organ. Experimental Brain Research. 204 (3), $305-314$ (2010).

5. Morrison, l. et al. Reduced C-afferent fibre density affects perceived pleasantness and empathy for touch. Brain: A Journal of Neurology. 134 (Pt 4), 1116-1126 (2011).

6. Olausson, H. et al. Unmyelinated tactile afferents signal touch and project to insular cortex. NatureNeuroscience. 5 (9), $900-904$ (2002).

7. Croy, I., Sehlstedt, I., Wasling, H. B., Ackerley, R., Olausson, H. Gentle touch perception: From early childhood to adolescence. Developmental Cognitive Neuroscience. (2017).

8. Croy, I., Geide, H., Paulus, M., Weidner, K., Olausson, H. Affective touch awareness in mental health and disease relates to autistic traits - An explorative neurophysiological investigation. Psychiatry Research. 245, 491-496 (2016).

9. Crucianelli, L., Cardi, V., Treasure, J., Jenkinson, P. M., Fotopoulou, A. The perception of affective touch in anorexia nervosa. Psychiatry Research. 239, 72-78 (2016).

10. Loken, L. S., Wessberg, J., Morrison, I., McGlone, F., Olausson, H. Coding of pleasant touch by unmyelinated afferents in humans. Nature Neuroscience. 12 (5), 547-548 (2009).

11. Ackerley, R. et al. Human C-Tactile Afferents Are Tuned to the Temperature of a Skin-Stroking Caress. The Journal of Neuroscience. 34 (8), 2879-2883 (2014).

12. Ackerley, R., Eriksson, E., Wessberg, J. Ultra-late EEG potential evoked by preferential activation of unmyelinated tactile afferents in human hairy skin. Neuroscience Letters. 535, 62-66 (2013).

13. Morrison, I. ALE meta-analysis reveals dissociable networks for affective and discriminative aspects of touch. Human Brain Mapping. 37 (4), 1308-1320 (2016).

14. Case, L. K. et al. Encoding of Touch Intensity But Not Pleasantness in Human Primary Somatosensory Cortex. The Journal of Neuroscience. 36 (21), 5850-5860 (2016).

15. Case, L. K. et al. Touch Perception Altered by Chronic Pain and by Opioid Blockade. eNeuro. 3 (1) (2016).

16. Davidovic, M., Starck, G., Olausson, H. Processing of affective and emotionally neutral tactile stimuli in the insular cortex. Developmental Cognitive Neuroscience. (2017).

17. Morrison, I., Bjornsdotter, M., Olausson, H. Vicarious responses to social touch in posterior insular cortex are tuned to pleasant caressing speeds. The Journal of Neuroscience. 31 (26), 9554-9562 (2011).

18. Nisbett, R. E., Wilson, T. D. Telling more than we can know: Verbal reports on mental processes. Psychological Review. 84 (3), $231-259$ (1977).

19. Sato, H., Kawahara, J. Selective bias in retrospective self-reports of negative mood states. Anxiety, Stress, and Coping. 24 (4), $359-367$ (2011).

20. Robinson, M. D., Clore, G. L. Belief and feeling: evidence for an accessibility model of emotional self-report. Psychological Bulletin. 128 (6), 934-960 (2002).

21. Cascio, C. J. et al. Perceptual and neural response to affective tactile texture stimulation in adults with autism spectrum disorders. Autism Research. 5 (4), 231-244 (2012). 
22. Tager-Flusberg, H., Paul, R., Lord, C. Language and communication in autism. Handbook of Autism and Pervasive Developmental Disorders. 1, 335-364 (2005).

23. Lang, P. J., Greenwald, M. K., Bradley, M. M., Hamm, A. O. Looking at pictures: affective, facial, visceral, and behavioral reactions. Psychophysiology. 30 (3), 261-273 (1993).

24. Rozga, A., King, T. Z., Vuduc, R. W., Robins, D. L. Undifferentiated facial electromyography responses to dynamic, audio-visual emotion displays in individuals with autism spectrum disorders. DevelopmentalScience. 16 (4), 499-514 (2013).

25. Joussain, P., Ferdenzi, C., Djordjevic, J., Bensafi, M. Relationship Between Psychophysiological Responses to Aversive Odors and Nutritional Status During Normal Aging. ChemicalSenses. 42 (6), 465-472 (2017).

26. Horio, T. EMG activities of facial and chewing muscles of human adults in response to taste stimuli. Perceptual and Motor Skills. 97 (1), 289-298 (2003).

27. Tassinary, L. G., Cacioppo, J. T., Vanman, E. J. in Handbook of Psychophysiology., eds. Gary Berntson, John T. Cacioppo, Louis G. Tassinary. 267-300. Cambridge University Press, Cambridge, UK (2007).

28. Larsen, J. T., Norris, C. J., Cacioppo, J. T. Effects of positive and negative affect on electromyographic activity over zygomaticus major and corrugator supercilii. Psychophysiology. 40 (5), 776-785 (2003).

29. Dimberg, U., Thunberg, M., Grunedal, S. Facial reactions to emotional stimuli: Automatically controlled emotional responses. Cognition and Emotion. 16 (4), 449-471 (2002).

30. Dimberg, U., Thunberg, M., Elmehed, K. Unconscious facial reactions to emotional facial expressions. Psychological Science. 11 (1), $86-89$ (2000).

31. Mayo, L. M., Lindé, J., Olausson, H., Heilig, M., Morrison, I. Putting a good face on touch: Facial expression reflects the affective valence of caress-like touch across modalities. Biological Psychology. (2018).

32. Ree, A., Mayo, L. M., Leknes, S., Sailer, U. Touch targeting C-tactile afferent fibers has a unique physiological pattern: a combined electrodermal and facial electromyography study. Biological Psychology. (2018).

33. Kreuder, A. K. et al. How the brain codes intimacy: The neurobiological substrates of romantic touch. Human Brain Mapping. 38 (9), 4525-4534 (2017).

34. Fridlund, A. J., Cacioppo, J. T. Guidelines for human electromyographic research. Psychophysiology. 23 (5), 567-589 (1986).

35. Tipper, S. P. et al. Vision influences tactile perception without proprioceptive orienting. Neuroreport. 9 (8), 1741-1744 (1998).

36. Vallbo, A. B., Olausson, H., Wessberg, J. Unmyelinated Afferents Constitute a Second System Coding Tactile Stimuli of the Human Hairy Skin. Journal of Neurophysiology. 81 (6), 2753-2763 (1999).

37. Triscoli, C., Olausson, H., Sailer, U., Ignell, H., Croy, I. CT-optimized skin stroking delivered by hand or robot is comparable. Frontiers in Behavioral Neuroscience. 7, 208 (2013).

38. Croy, I. et al. Interpersonal stroking touch is targeted to C tactile afferent activation. Behavioural Brain Research. 297, 37-40 (2016).

39. Keizer, A., de Jong, J. R., Bartlema, L., Dijkerman, C. Visual perception of the arm manipulates the experienced pleasantness of touch. Developmental Cognitive Neuroscience. (2017).

40. Pawling, R., Cannon, P. R., McGlone, F. P., Walker, S. C. C-tactile afferent stimulating touch carries a positive affective value. PloS One. 12 (3), e0173457 (2017).

41. Scheele, D. et al. An oxytocin-induced facilitation of neural and emotional responses to social touch correlates inversely with autism traits. Neuropsychopharmacology. 39 (9), 2078-2085 (2014).

42. Ackerley, R., Saar, K., McGlone, F., Backlund Wasling, H. Quantifying the sensory and emotional perception of touch: differences between glabrous and hairy skin. Frontiers in Behavioral Neuroscience. 8 (34) (2014).

43. Loken, L. S., Evert, M., Wessberg, J. Pleasantness of touch in human glabrous and hairy skin: order effects on affective ratings. Brain Research. 1417, 9-15 (2011). 